UNIVERSIDADE DE SÃO PAULO

FACULDADE DE FILOSOFIA, LETRAS E CIÊNCIAS HUMANAS

DEPARTAMENTO DE GEOGRAFIA

PROGRAMA DE PÓS-GRADUAÇÃO EM GEOGRAFIA FÍSICA

Maria Carolina Villaça Gomes

\title{
ANÁLISE DA INFLUÊNCIA DA CONDUTIVIDADE HIDRÁULICA SATURADA DOS SOLOS NOS ESCORREGAMENTOS RASOS NA BACIA DO RIO GUAXINDUBA (SP)
}

São Paulo

2012 
UNIVERSIDADE DE SÃO PAULO

FACULDADE DE FILOSOFIA, LETRAS E CIÊNCIAS HUMANAS

DEPARTAMENTO DE GEOGRAFIA

PROGRAMA DE PÓS-GRADUAÇÃO EM GEOGRAFIA FÍSICA

Maria Carolina Villaça Gomes

\section{ANÁLISE DA INFLUÊNCIA DA CONDUTIVIDADE HIDRÁULICA SATURADA DOS SOLOS NOS ESCORREGAMENTOS RASOS NA BACIA DO RIO GUAXINDUBA (SP)}

Dissertação apresentada ao Programa de PósGraduação em Geografia Física da Faculdade de Filosofia, Letras e Ciências Humanas da Universidade de São Paulo para obtenção do título de Mestre.

Orientadora: $\operatorname{Prof}^{\mathrm{a}}$ Dr $^{\mathrm{a}}$ Bianca Carvalho Vieira Área de Concentração: Geografia Física

Linha de Pesquisa: Estudos interdisciplinares em pedologia e geomorfologia

Agência Financiadora: $\mathrm{CNPq}$

São Paulo 


\title{
FICHA CATALOGRÁFICA
}

\author{
Catalogação na Publicação
}

Serviço de Biblioteca e Documentação

Faculdade de Filosofia, Letras e Ciências Humanas da Universidade de São Paulo.

Gomes, Maria Carolina Villaça

Análise da influência da condutividade hidráulica saturada dos solos nos escorregamentos rasos na bacia do rio Guaxinduba (SP) / Maria Carolina Villaça Gomes; orientadora: Bianca Carvalho Vieira - São Paulo, 2012.

138 f.; il.

Dissertação (Mestrado) - Faculdade de Filosofia, Letras e Ciências Humanas da Universidade de São Paulo. Departamento de Geografia. Área de concentração: Geografia Física.

1. Geomorfologia. 2. Escorregamentos translacionais rasos. 3. Levantamentos in situ. 4. Condutividade hidráulica saturada.

I. Vieira, Bianca Carvalho. II. Universidade de São Paulo Programa de Pós-Graduação em Geografia Física. III. Título de Mestre. 
Maria Carolina Villaça Gomes

\section{Análise da influência da condutividade hidráulica saturada dos solos nos escorregamentos rasos na bacia do rio Guaxinduba (SP)}

Dissertação apresentada ao Programa de PósGraduação em Geografia Física da Faculdade de Filosofia, Letras e Ciências Humanas da Universidade de São Paulo para obtenção do título de Mestre.

Banca Examinadora

Prof $^{a}$ Dr $^{a}$ Bianca Carvalho Vieira (Orientadora)

Departamento de Geografia - Universidade de São Paulo

Prof $^{a}$ Dra. Maria Cristina Perusi

Universidade Estadual Paulista - Campus Experimental de Ourinhos

Prof. Dr. Nelson Ferreira Fernandes

Departamento de Geografia - Universidade Federal do Rio de Janeiro

São Paulo 


\section{RESUMO}

A previsão de áreas suscetíveis a escorregamentos translacionais rasos tem como fundamental etapa a investigação dos fatores condicionantes e dos mecanismos de ruptura. Algumas destas propriedades, como os parâmetros físicos e hidrológicos dos solos, são determinantes para a instabilização de encostas que estão sujeitas a eventos pluviométricos intensos. Uma destas propriedades é a condutividade hidráulica saturada, cujo comportamento pode influenciar no desenvolvimento de poro-pressão positiva ou levar à perda de sucção dos solos, ocasionando rupturas. Desta forma, o objetivo principal desta pesquisa foi analisar a distribuição lateral e vertical da condutividade hidráulica saturada $\left(\mathrm{K}_{\mathrm{sat}}\right)$ dos solos e sua influência nos escorregamentos translacionais rasos na Serra do Mar (SP). Para tanto, foi selecionada uma bacia representativa da Serra do Mar e nela foram escolhidas três cicatrizes acessíveis e com limites bem preservados para a realização dos ensaios in situ. As profundidades onde foram realizados os ensaios foram definidas a partir da caracterização morfológica dos mantos de alteração nas trincheiras abertas no topo, no centro e na lateral das cicatrizes $(0.25,0.50,1.00,1.50,2.00$ e $2.50 \mathrm{~m})$. Finamente, foram realizados os ensaios in situ utilizando-se o Permeâmetro de Guelph, utilizando-se duas cargas hidráulicas H para a que fosse possível calcular a $\mathrm{K}_{\text {sat }}$ empregando-se as equações de Richards, Laplace e a análise de Elricket al. (1989), embora tenha sido utilizada esta última para a análise da variação dos valores. A partir dos valores de $\mathrm{K}_{\text {sat }}$, das propriedades físicas dos materiais (distribuição granulométrica, micro e macroporosidade, porosidade total. Além disso, foi analisada a tendência de variação entre $10^{-4}$ e $10^{-7} \mathrm{~m} / \mathrm{s}$, predominando da $\mathrm{K}_{\mathrm{sat}}$ com a profundidade. Foram obtidos 41 valores de $\mathrm{K}_{\mathrm{sat}}$, os quais variaram entre as ordens de grandeza $10^{-5}$ e $10^{-6} \mathrm{~m} / \mathrm{s}$ (82,5\% dos valores), que mostraram a pequena variabilidade da $\mathrm{K}_{\text {sat }}$ nos perfis de alteração investigados, se comparada às diferenças observadas nas propriedades dos solos e corroboram com os trabalhos desenvolvidos na Serra do Mar. Quando confrontado com as propriedades físicas dos materiais (por exemplo, granulometria e porosidade total), observou-se, principalmente, a correlação positiva com a fração areia. De forma geral, foi possível identificar uma tendência de aumento da $\mathrm{K}_{\text {sat }}$ com a profundidade, assim como a existência de algumas descontinuidades hidráulicas significativas, tanto de redução quanto de aumento brusco da $\mathrm{K}_{\mathrm{sat}}$ em uma pequena profundidade.

Palavras-chave: Escorregamentos translacionais rasos, ensaios in situ, condutividade hidráulica saturada, Serra do Mar. 


\begin{abstract}
The prediction of landslides-prone areas has as fundamental step researching controlling factors and failure mechanisms. Some of these properties, such as the physical and hydrological soil properties are crucial to the instability of slopes subject to intense rainfall events. One of these properties is the saturated hydraulic conductivity, whose behavior can influence and lead to the development of positive pore-pressure or the loss of soil suction, causing failures. The main objective of this research was to analyze the lateral and vertical hydraulic conductivity $\left(\mathrm{K}_{\mathrm{sat}}\right)$ of soils and their influence on shallow landslides in the Serra do Mar (SP). Therefore, we selected a representative basin in the Serra do Mar and there three accessible scars, well preserved, were chosen for in situ measurements. Was also performed the topographical characterization of the scars (slope angle, curvature and orientation and contributing area). The depths where the measurements were performed were defined from the morphological characterization of soil profiles in opened trenches at the top, at the lateral and inside the scars $(0.25,0.50$, $1.00,1.50,2.00$ and $2.50 \mathrm{~m}$ ). At last, were performed the in situ measurements using the Guelph Permeameter, using two heads $\mathrm{H}$ for calculating $\mathrm{K}_{\text {sat }}$ using Richards equations, Laplace equations and Elrick et al. (1989) analysis, although the latter has been used to analyze the range of values. From the $\mathrm{K}_{\mathrm{sat}}$ values and physical soil properties (e. g. grain size distribution, micro and macroporosity, total porosity) we discussed the role played by them in $\mathrm{K}_{\mathrm{sat}}$ values. Moreover was analyzed the trend of $\mathrm{K}_{\mathrm{sat}}$ variation with depth. We obtained $41 \mathrm{~K}_{\text {sat }}$ values, which varied between $10^{-4}$ e $10^{-7} \mathrm{~m} / \mathrm{s}$, mostly among the orders of magnitude $10^{-5}$ e $10^{-6} \mathrm{~m} / \mathrm{s}(82.5 \%$ values $)$, that showed the small variability of $\mathrm{K}_{\mathrm{sat}}$ in the soil profiles if compared to the observed differences in soil properties, and corroborate with studies developed in the Serra do Mar. When confronted with the physical properties of materials (eg, grain size and total porosity), we observed mainly the positive correlation with the sand content. In general, we observed a tendency of increase of $\mathrm{K}_{\mathrm{sat}}$ with depth, as well as the existence of some significant hydraulic discontinuities, both the sudden decrease as the increase in $\mathrm{K}_{\text {sat }}$ in a small depth.
\end{abstract}

Keywords: Shallow landslides, in situ measurements, saturated hydraulic conductivity, Serra do Mar Escarpment. 


\section{LISTA DE FIGURAS}

Figura 1.1.Escorregamentos translacionais rasos ocorridos em março de 1967 na Serra do Mar, Caraguatatuba (SP). O material mobilizado alcançou a rede de drenagem, formando corridas de detritos que destruíram parcialmente o município. (Fonte: http://www.caraguatatuba.sp.gov.br, acesso em 24.04. 2011)

Figura 2.1. Número de mortes associadas a eventos de movimentos de massa registrados nos Estados do Rio de Janeiro, São Paulo e Santa Catarina, a partir de 1988. Fonte: banco de dados do Instituto de Pesquisas Tecnológicas do Estado de São Paulo.

Figura 2.2. Efeitos hidrológicos (a) e mecânicos (b) da vegetação na estabilidade das encostas Fonte: modificado de Kuriakose (2006) adaptado de Van Beek (2005).

Figura 2.3. Umidade do solo em relação às chuvas no período de 23/09/05 a $31 / 12 / 06$. As curvas coloridas representam a profundidade das mensurações realizadas (Magenta $(0,5 \mathrm{~m})$, vermelha $(0,98 \mathrm{~m})$, azul $(1,96 \mathrm{~m})$, roxa $(2,88 \mathrm{~m})$ e verde $(4,0 \mathrm{~m})$ ). Notar a variação do comportamento em cada profundidade, o que evidencia a existência de descontinuidades no solo. Fonte: modificada de Tu et al. (2009).

Figura 2.4. Esquema que ilustra o mecanismo de ruptura associado à geração de pressões neutras e formação de fluxos paralelos, em decorrência da brusca redução da permeabilidade do material. Fonte: Wolle e Carvalho (1994).

Figura 2.5. Esboço do desenvolvimento de fluxos verticais decorrentes do avanço da frente de saturação. Este movimento descendente da água reduz bruscamente a coesão aparente do solo, aumentando a instabilidade na encosta. Fonte: Wolle e Carvalho (1994).

Figura 2.6. Relação entre a variação da poro-pressão, o deslocamento por cisalhamento com o tempo. Observa-se que o aumento de poro-pressões ocorre após o ponto de ruptura Fonte: modificado de Wang e Sassa (2003).

Figura 2.7. Estimativa da condutividade hidráulica e permeabilidade de acordo com diferentesmateriais. Observa-se que os diferentes valores são expressos em ordem de grandeza, uma vez que é nesta escala que a variação da condutividade hidráulica influi estabilidade de encostas. Fonte: modificada de Freeze e Cherry (1979).

Figura 2.8. Desenho esquemático do Permeâmetro de Guelph (PG), com seus principais componentes. Fonte: modificado de Vieira (2001).

Figura 2.9. Permeâmetro de Guelph Modificado (PGM). Observa-se sua estrutura simples, como um único reservatório de água e apenas 4 conexões entre a ponteira e o reservatório de água e o tubo de saída de ar. O tripé maior e estendível é outra vantagem em relação ao PG Original.

Figura 2.10. Permeâmetro de Guelph Modificado (a). Na figura (b) destaca-se o tripé e a ponteira a partir de onde é aplicada a carga hidráulica $\mathrm{H}$, enquanto a figura (c) mostra o recipiente armazenador de água.

Figura 2.11. Variação do parâmetro $\mathrm{C}$ em relação à razão entre a carga aplicada $(\mathrm{H})$ e o raio do furo (a) e as curvas de diferentes texturas de solos. Destaca-se que os 
valores de $\mathrm{C}$ se encontram na área demarcada como área de trabalho. Fonte: modificada de Reynolds e Elrick (1985).

Figura 2.12. Variação da permeabilidade saturada $\left(\mathrm{K}_{\mathrm{fs}}\right)$ e não saturada $(\alpha)$ com a profundidade. Nota-se que ambas apresentam comportamento semelhante- a brusca descontinuidade entre 1.0 e $2.0 \mathrm{~m}$. Este ensaio ratifica a utilização do PG para mensuração dos referidos parâmetros, em profundidade e pequeno intervalo de tempo. Fonte: Campos et al., (1992a).

Figura 2.13. Variação da $K_{\text {sat }}$ em profundidade. A macroporosidade (Ma) apresenta a mesma tendência da $K_{\text {sat }}$ entre as profundidades de 60 e $90 \mathrm{~cm}$. No entanto, entre os 90 e $120 \mathrm{~cm}$, não há uma correlação positiva entre a $\mathrm{K}_{\text {sat }}$ ea macroporosidade. Fonte: modificada de Vieira e Fernandes (2004).

Figura 3.1. Esquema hipotético do perfil de uma das encostas que foram atingidas por escorregamentos translacionais rasos na Serra do Mar (SP). Fonte: Wolle e Carvalho (1989).

Figura 3.2. Gráfico do evento chuvoso de 23 de janeiro de 1985, em Cubatão-SP, relacionando acumulada pluviométrica e intensidade horária. Fonte: Tatizanaet al. (1987).

Figura 3.3. Encostas florestadas com vegetação densa, de grande porte.

Figura 3.4. Recuo da Serra do Mar e planície sedimentar em Caraguatatuba-SP.

Figura 3.5. Vista da Rodovia dos Tamoios para a enseada de Caraguatatuba, de onde se observavam as cicatrizes dos escorregamentos ocorridos no ano de 1967. Fonte: O. Cruz e Prof. Nogamiapud Gramani (2001).

Figura 3.6. Os pontos pretos na figura representam os escorregamentos identificados em Caraguatatuba. Fonte: modificado de Fúlfaroet al., (1976) apud Gramani (2001).

Figura 3.7. Fotografia aérea do ano de 1973, em que as cicatrizes dos escorregamentos generalizados e o material proveniente das encostas que atingiu a planície sedimentar aparecem em tons de cinza claro e branco (escala original 1:25.000). Foto: Secretaria de Agricultura do Estado de São Paulo (1973).

Figura 3.8. Cicatrizes dos escorregamentos de 1967. Sua colonização pioneira pela espécie de pteridófitaGleycheniamanteve as cicatrizes preservadas por mais de 40 anos (Agosto/2010).

Figura 3.9. Baixo vale do rio Mantegueira, afluente do rio Santo Antônio, com os detritos provindos das vertentes. Fonte: Cruz (1974).

Figura 3.10. Chuvas mensais acumuladas (mm/mês) para o período entre $1966 \mathrm{e}$ 1967, a partir de dados do DAEE. Vale ressaltar que o mês de março de 1967, para os três postos, possuem informações apenas até o dia 18. Fonte: Ramos (2012).

Figura 3.11. Chuvas diárias acumuladas $(\mathrm{mm} / \mathrm{dia})$ para o mês de março de 1967, a partir de dados do DAEE. Vale ressaltar que neste o mês, para os três postos, existem informações apenas até o dia 18. Fonte: Ramos (2012).

Figura 3.12. Localização da bacia do rio Guaxinduba. Fonte: Ramos (2012). 
Figura 3.13. Perfis realizados sobre a bacia do Rio Guaxinduba e suas localizações. Fonte: modificado de Ramos (2012).

Figura 4.1. Fluxogramas das etapas metodológicas e dos materiais da pesquisa.

Figura 4.2. Imagem compreendendo a Baixada Santista e o litoral norte do estado de São Paulo. Em amarelo, alguns pontos registrados pelo GPS e visitados em campo. (Foto: GOOGLE EARTH, acesso em 07.08.2010).

Figura 4.3. Cicatriz (em vermelho) recolonizada por espécie pioneira de pteridófita.

Figura 4.4.Bacia do Guaxinduba. Nota-se, no centro da figura, uma cicatriz recoberta pela samambaia Gleychenia, adequado para a realização de levantamentos in situ.

Figura 4.5. Localização das três cicatrizes $(\mathrm{C} 1, \mathrm{C} 2$ e C3) na bacia do Guaxinduba.

Figura 4.6. Caracterização espacial da topografia (ângulo, curvatura e orientação da encosta e área de contribuição) das três cicatrizes.

Figura 4.7. Vista do centro da Cicatriz 1 em direção a sua lateral. Observa-se a samambaia Gleychenia em toda extensão.

Figura 4.8. Vista da lateral da Cicatriz 2, onde também se observa a Gleycheniae uma cobertura vegetal bem preservada no seu entorno.

Figura 4.9. Vista do ponto do centro da Cicatriz 3, na qual indivíduos de árvores isoladas estão em meio à Gleychenia.

Figura 4.10. Exemplo dalocalização dos perfis abertos em uma cicatriz de escorregamento.

Figura 4.11. Procedimentos de montagem do PGM. Limpeza das roscas (A), utilização de veda-rosca nos tubos de ar e de água e na ponteira (B e C) e acoplamento das mangueiras nos tubos de ar e água (D).

Figura 4.12. PGM com seu reservatório de água já abastecido (A); abertura do furo para posicionamento da ponteira no seu interior (B); e ajuste do tripé para o posicionamento do PGM para se realizar a leitura adequadamente (C).

Figura 4.13. Ponteira posicionada no furo (A); detalhe do posicionamento no furo (B); aplicação da carga H (C); e marcação da carga $\mathrm{H}$ estabelecida (D).

Figura 4.14. Leitura da queda d'água no PGM para se obter o valor Da vazão Q.

Figura 4.15. Ficha utilizada em campo para registro dos ensaios. Em vermelho estão as leituras realizadas quando o fluxo d'água já estava constante (steadystate).

Figura 5.1.Figura 5.1. Variação da condutividade hidráulica saturada (A) em relação à granulometria do material (B) no perfil do topo da Cicatriz 1 (C1P1). Podese observar a correlação entre a $\mathrm{K}_{\text {sat }}$ e as oscilações dos teores de areia e argila. Destaca-se a matriz franco-arenosa mais próxima à superfície, na qual estão os blocos centimétricos $(\mathrm{C})$, enquanto em profundidade (aproximadamente 2,00 m) está o regolito com aproximadamente $70 \%$ de areia. Dados de granulometria: Ferreira (no prelo). 
Figura 5.2. Variação da $K_{\text {sat }}(A)$ no ponto $C 1 P 2$. Neste ponto apenas dois ensaios foram realizados, apontando uma tendência de aumento da $\mathrm{K}_{\text {sat. }} \mathrm{Na}$ figura $\mathrm{B}$ observase a homogeneidade das frações argila, silte e areia com a profundidade, destacandose a grande porcentagem de areia (aproximadamente 83\%). A figura $\mathrm{C}$ mostra o saprolito que compõe este setor da encosta até os 2,70 m de profundidade,em que se observam em diversos pontos minerais primários (em destaque).Fonte dos dados de granulometria: Ferreira (no prelo).

Figura 5.3. Variação da $\mathrm{K}_{\text {sat }}$ no ponto $\mathrm{C} 2 \mathrm{P} 1$ (A). É observada a tendência de aumento da $\mathrm{K}_{\text {sat }}$ ao longo do perfil, que parece corresponder ao aumento do teor de areia e redução do silte (B). A figura $\mathrm{C}$ ilustra o perfil de solo observado neste ponto, com características de solo residual maduro, com raízes pequenas até $0,70 \mathrm{~m}$ de profundidade.Fonte dos dados de granulometria: Ferreira (no prelo).

Figura 5.4.Variação da $\mathrm{K}_{\text {sat }}$ no ponto $\mathrm{C} 2 \mathrm{P} 2$ (A), que, aparentemente, não apresenta uma correlação com a granulometria do material (B). Na figura $\mathrm{C}$ nota-se o material coluvial sobre o saprolito. Dados de granulometria: Ferreira (no prelo).

Figura 5.5. Feições relíquias da rocha no saprolito, com mergulho na direção do ângulo da encosta.

Figura 5.6.Variação da $\mathrm{K}_{\text {sat }}$ no ponto $\mathrm{C} 2 \mathrm{P} 3$ (A). Observa-se que a diminuição da $\mathrm{K}_{\text {sat }}$ está associada à redução dos teores de areia e aumento da argila (B), enquanto a granulometria não explica o aumento entre 2,00 e 2,50 m de profundidade.Perfil do ponto C2P3. Destaca-se a camada orgânica mais espessa neste ponto, além de raízes de diversos tamanhos e pipes $(\mathrm{C})$. Fonte dos dados de granulometria: Ferreira (no prelo).

Figura 5.7. Variação no ponto $C 3 P 1$ da $K_{\text {sat }}$. Nota-se uma redução da $K_{\text {sat }}$ de 10 vezes entre 0,50 e $1,00 \mathrm{~m}$ e um aumento até os $2,00 \mathrm{~m}$. A partir daí, há a diminuição novamente da $\mathrm{K}_{\text {sat }}$, que não pôde ser explicada pela distribuição granulométrica. Dados de granulometria: Ferreira (no prelo).

Figura 5.8. Variação da $\mathrm{K}_{\text {sat }}$ no ponto $\mathrm{C} 3 \mathrm{P} 2$ (5.8A). Observam-se descontinuidades hidráulicas ao longo do perfil, associadas ao aumento da microporosidade (entre 1,00 e $1,50 \mathrm{~m}$ ) e da fração areia (entre 2,00 e $2,50 \mathrm{~m})(5.8 \mathrm{~B})$. O perfil do ponto (5.8C) mostra três camadas com granulometria distintas, delimitadas pelas linhas amarelas. A primeira camada, com matriz fina e areia grossa, ocorre sobre um material arenosiltoso, que também ocorre na terceira camada, com microporosidade sensivelmente maior. Dados de granulometria: Ferreira (no prelo).

Figura 5.9. Ponto do centro da Cicatriz 3 (C3P2) com veio de quartzo intemperizado à profundidade de $1,50 \mathrm{~m}$.

Figura 5.10. Variação da $K_{\text {sat }}$ ao longo do perfil C3P3 (5.10A). Observa-se a redução entre as profundidades 1,00 e $1,50 \mathrm{~m}$, que pôde ser explicada pelo aumento no teor de argila entre 0,41 e 1,27 m, enquanto houve a redução de aproximadamente $10 \%$ na fração areia. $\mathrm{O}$ perfil do ponto $\mathrm{C} 3 \mathrm{P} 3$ mostra a profundidade a partir de onde a quantidade de raízes é significativamente menor. Dados de granulometria: Ferreira (no prelo).

Figura 5.11. Chão da trincheira a $1,00 \mathrm{~m}$ de profundidade. Observam-se dutos e raízes, possivelmente responsáveis pelo aumento da macroporosidade nesta 
profundidade.

Figura 5.12. Diagrama dos perfis formados a partir da sobreposição dos perfis do topo e do cento das cicatrizes, mostrando o presumível plano de ruptura.

Figura 5.13. Gráficos de variação da $\mathrm{K}_{\mathrm{sat}}$ (eixox) com a profundidade (eixo y) nas cicatrizes $\mathrm{C} 1, \mathrm{C} 2$ e $\mathrm{C} 3$ nos pontos do topo (P1), do centro (P2) e da lateral (P3).

Figura 5.14. Sobreposição dos perfis do topo (C1P1) e centro (C1P2) da Cicatriz 1 Observa-se uma importante descontinuidade hidráulica entre os 2,50 e 3,00 m, onde há uma diminuição brusca da $\mathrm{K}_{\mathrm{sat}}$. Dados de granulometria: Ferreira (no prelo).

Figura 5.15.Sobreposição dos perfis do topo $(\mathrm{C} 2 \mathrm{P} 1)$ e centro $(\mathrm{C} 2 \mathrm{P} 2)$ da Cicatriz 2. É observado neste ponto uma menor permeabilidade no topo do perfil, que aumenta entre 0,5 e $1,5 \mathrm{~m}$, se mantém até $2,5 \mathrm{~m}$ e volta a diminuir a partir desta profundidade. Dados de granulometria: Ferreira (no prelo).

Figura 5.16. Sobreposição dos perfis do topo (C3P1) e centro (C3P2) da Cicatriz 3 . Neste perfil ocorrem algumas descontinuidades hidráulicas de, pelo menos, uma ordem de grandeza. Dados de granulometria: Ferreira (no prelo).

Figura 5.17. Variação da $\mathrm{K}_{\mathrm{sat}}$ em profundidade encontradas por Campos et al. (1992a) Vieira e Fernandes (2004) e Gomes (2012). Observa-se a diminuição da $\mathrm{K}_{\text {sat }}$ entre 1,0C e 2,00 m, seguida por um aumento progressivo com a profundidade. 


\section{LISTA DE TABELAS}

Tabela 2.1. Valores de $\alpha$ de acordo com as características dos solos ensaiados. Fonte: modificada de Reynolds et al.(1992).

Tabela 3.1. Resultados provenientes de avaliações de cicatrizes de escorregamentos.

Tabela 5.1. Valores de $\mathrm{K}_{\text {sat }}$ obtidos com as equações de Laplace $\left(\mathrm{K}_{\mathrm{sat}}-\mathrm{L}\right)$, Richards $\left(\mathrm{K}_{\mathrm{sat}}-\mathrm{R}\right)$ e Elricket al. (1989) $\left(\mathrm{K}_{\mathrm{sat}}-\mathrm{U}\right)$.

Tabela 5.2. Valores de $\mathrm{K}_{\text {sat }}$ mensurados por diversos autores na Serra do Mar.

Tabela 5.3.Valores de macroporosidade, microporosidade e porosidade total dos pontos onde foram realizados os ensaios de $\mathrm{K}_{\text {sat }}$ Dados retirados de Ferreira (no prelo).

\section{LISTA DE QUADROS}

Quadro 2.1. Vantagens e desvantagens de alguns métodos freqüentemente utilizados para estimar a condutividade hidráulica saturada $\left(\mathrm{K}_{\text {sat }}\right)$ e não saturada $\left(\mathrm{K}_{\text {ñsat }}\right)$. Todos os métodos estimam a $\mathrm{K}$ in situ, com exceção dos Permeâmetros de carga constante $\mathrm{e}$ variável. 


\section{Sumário}

1 INTRODUÇÃO, OBJETIVOS E JUSTIFICATIVA.

\section{ESCORREGAMENTOS RASOS E A HIDROLOGIA DAS ENCOSTAS DA} SERRA DO MAR

2.1 Fatores condicionantes dos escorregamentos translacionais rasos na Serra do Mar......... 7

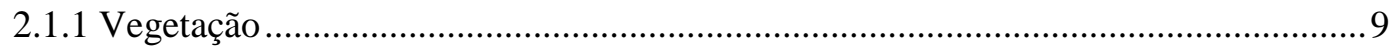

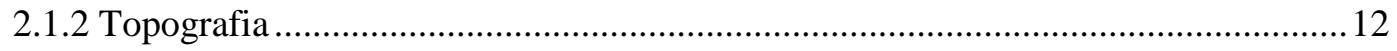

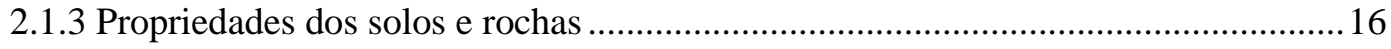

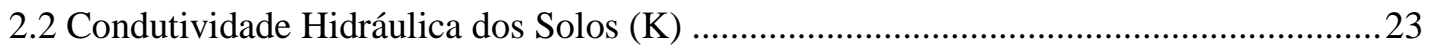

2.3 Método do Permeâmetro de Guelph............................................................................... 32

2.3.1 O Permeâmetro: estrutura, funcionamento e potencialidades ....................................32

2.3.2 Permeâmetro de Guelph Modificado (PGM) ...........................................................36

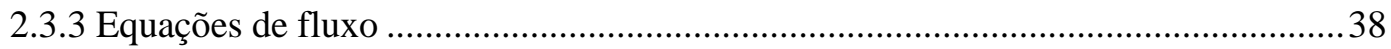

2.4 Propriedades físicas e hidrológicas dos solos e os escorregamentos rasos ......................44

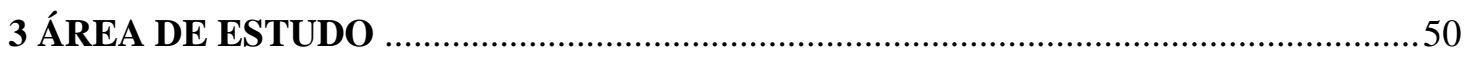

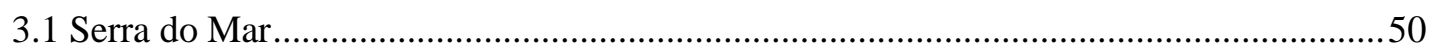

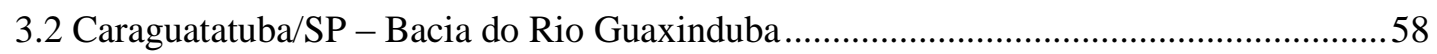

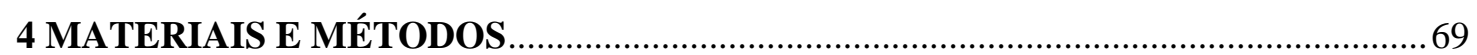

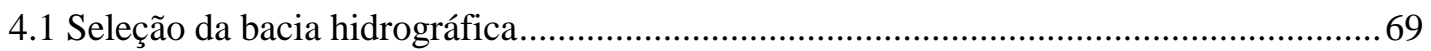

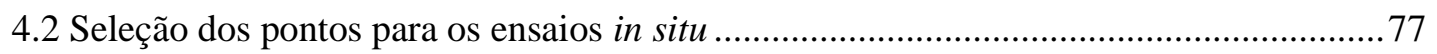

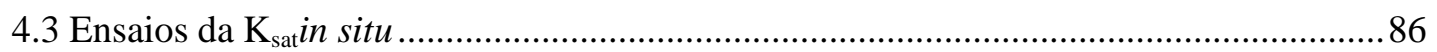

4.4 Análise das propriedades físicas dos solos na variabilidade espacial da $\mathrm{K}_{\text {sat }} \ldots \ldots \ldots \ldots \ldots \ldots . . . . .93$

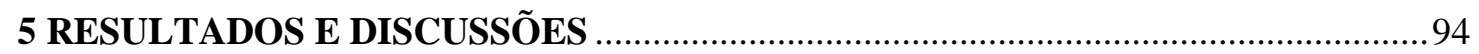

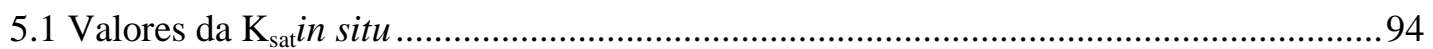

5.2 Variação espacial da $\mathrm{K}_{\mathrm{sat}} \mathrm{e}$ as propriedades físicas dos solos .........................................99

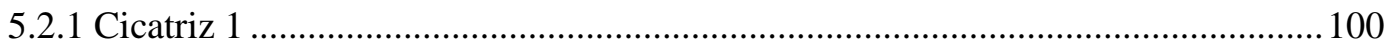

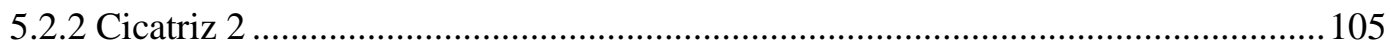

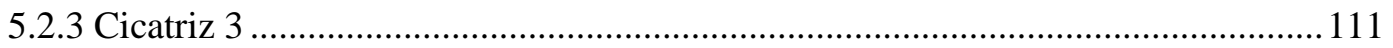

5.3 Padrões de variação da $\mathrm{K}_{\text {sat }}$ com a profundidade........................................................ 118

5.4 Variação espacial da $\mathrm{K}_{\mathrm{sat}}$ e os escorregamentos rasos ocorridos em 1967 na bacia

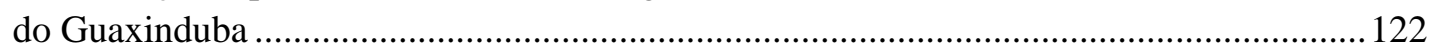

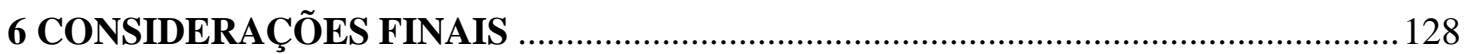

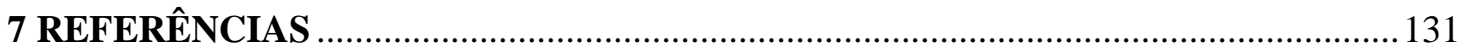




\section{INTRODUÇÃO, OBJETIVOS E JUSTIFICATIVA}

A previsão de áreas suscetíveis a escorregamentos translacionais rasos tem como fundamental etapa a investigação dos fatores condicionantes e dos mecanismos de ruptura. Em um primeiro momento, esse conhecimento pode subsidiar a escolha do método a ser utilizado, e, posteriormente, para que sua aplicação alcance resultados satisfatórios, é necessário que os dados utilizados sejam representativos da paisagem.

Dentre os parâmetros considerados pelos diversos métodos, alguns são de aquisição mais simples, como os parâmetros morfométricos (ex. ângulo da encosta e área de contribuição), que podem ser obtidos por meio de modelos digitais de terreno (MDTs), enquanto outros, para que sejam confiáveis, exigem investigações de campo.

Alguns desses parâmetros, como as propriedades dos solos, especialmente quando se trata de mensurações in situ, são, muitas vezes, de difícil execução e onerosos, além da sua variabilidade no espaço e no tempo. Contudo, espera-se dos ensaios in situ resultados mais próximos do real, uma vez que as condições em que são realizados representam a dinâmica natural, mesmo considerando as pequenas perturbações provocadas pelos experimentos.

A condutividade hidráulica saturada dos solos $\left(\mathrm{K}_{\mathrm{sat}}\right)$ é um parâmetro hidrológico do meio que se enquadra nessa situação, cuja mensuração é muito importante para a compreensão do comportamento hidrológico dos solos em relação às estabilidade das encostas. Trata-se da propriedade que reflete a habilidade com que um fluido é transportado em um meio poroso (FREEZE e CHERRY,1979; BRADY, 1989; PINTO, 2002; LIBARDI,2005; entre outros), sendo que o seu comportamento reflete as características físicas dos solos, como a textura e a estrutura. 
Considerando que os solos são de natureza anisotrópica e heterogênea, ou seja, não apresentam continuidade espacial em todas as direções(GUEDES et al., 2008),a $\mathrm{K}_{\text {sat }}$ é uma propriedade hidrológica sujeita a variações ao longo do perfil de solo, podendo gerar descontinuidades hidráulicas.A existência dessas descontinuidades atua significantemente nos modelos hipotéticos de mecanismos de ruptura, visto que seu aumento ou diminuição ao longo do perfil determina o tipo de mecanismo, como, por exemplo, rupturas atribuídas à elevação da poro-pressão positiva ou condicionadas pela redução da coesão aparente devido à perda de sucção (WOLLE e CARVALHO, 1989). Desta forma, pressupõe-se que as descontinuidades hidráulicas, verificadas, por exemplo,por meio da mensuração da $\mathrm{K}_{\text {sat }}$ em diferentes profundidades do solo (KLAR, 1984), realizadas em laboratório ou in situ, podem contribuir diretamente para a identificação do mecanismo de ruptura que predomina no manto de alteração.

Trabalhos como este comprovam a necessidade de investigações da $\mathrm{K}_{\mathrm{sat}}$ com o intuito dese compreender melhor sua influência na ocorrência dos escorregamentos rasos.

Para a mensuração da Kin situ inúmeros métodos foram desenvolvidos, como por exemplo, o permeâmetro de carga constante/variável, utilizados por Reynolds eElrick (1985), PaigeeHillel (1993) e Stephens (1996); o método do infiltrômetro de anel duplo fechado, utilizado por Daniel (1989), Little et al. (1995) e Stephens (1996); e o Permeâmetro de Guelph, desenvolvido por Reynolds et al. (1983).

O Permeâmetro de Guelph (PG), método com recorrente utilização nas investigações do movimento da água no solo, quando comparado aos demais, se destaca por permitir a mensuração de outros parâmetros hidráulicos do solo (ex. sorvidade). É possível também realizar ensaios em maiores profundidades, utilizando pouca água e causando mínima perturbação no solo (REYNOLDS e ELRICK, 1983). 
Tendo em vista que o procedimento baseado na utilização do PG é capaz de fornecer informações que permitem analisar a variação espacial da $K_{\text {sat, }}$ com a possibilidade de realizar os ensaios em maiores profundidades e a facilidade de transporte e manuseio, seu emprego contribui significativamente para pesquisas que tem por objetivo entender os mecanismos de instabilização em encostas, haja vista a importância da presença das descontinuidades hidráulicas para a deflagração dos escorregamentos translacionais rasos.

Essa tipologia de movimento de massa, com grande freqüência em modelados marcados por altas declividades, solos pouco espessos, clima tropical úmido, como a Serra do Mar, tem destaque dentre os processos geomorfológicos responsáveis pela evolução do relevo. Este compartimento geológico-geomorfológico, situado à costa leste do Brasil, é palco de abundantes escorregamentos rasos, que ocorrem de forma pontual com uma maior freqüência, ou generalizada, associadas a eventos pluviométricos de menor recorrência, porém de maior magnitude (Figura 1.1). No primeiro caso, são processos que merecem atenção em virtude dos danos sociais e prejuízos econômicos que podem causar. Quando generalizados, o material movimentado pode se acumular nas porções côncavas da paisagem, locais onde preferencialmente há concentração de fluxos superficiais e subsuperficiais de água (ANDERSON e BURT, 1978; LACERDA e SANDRONI,1985;RENEAU et al., 1986; RENEAU e DIETRICH, 1987; COATES, 1990; e FERNANDES et al.,1994), criando condições para a geração de corridas de detritos ou de lama (debrisflows). 


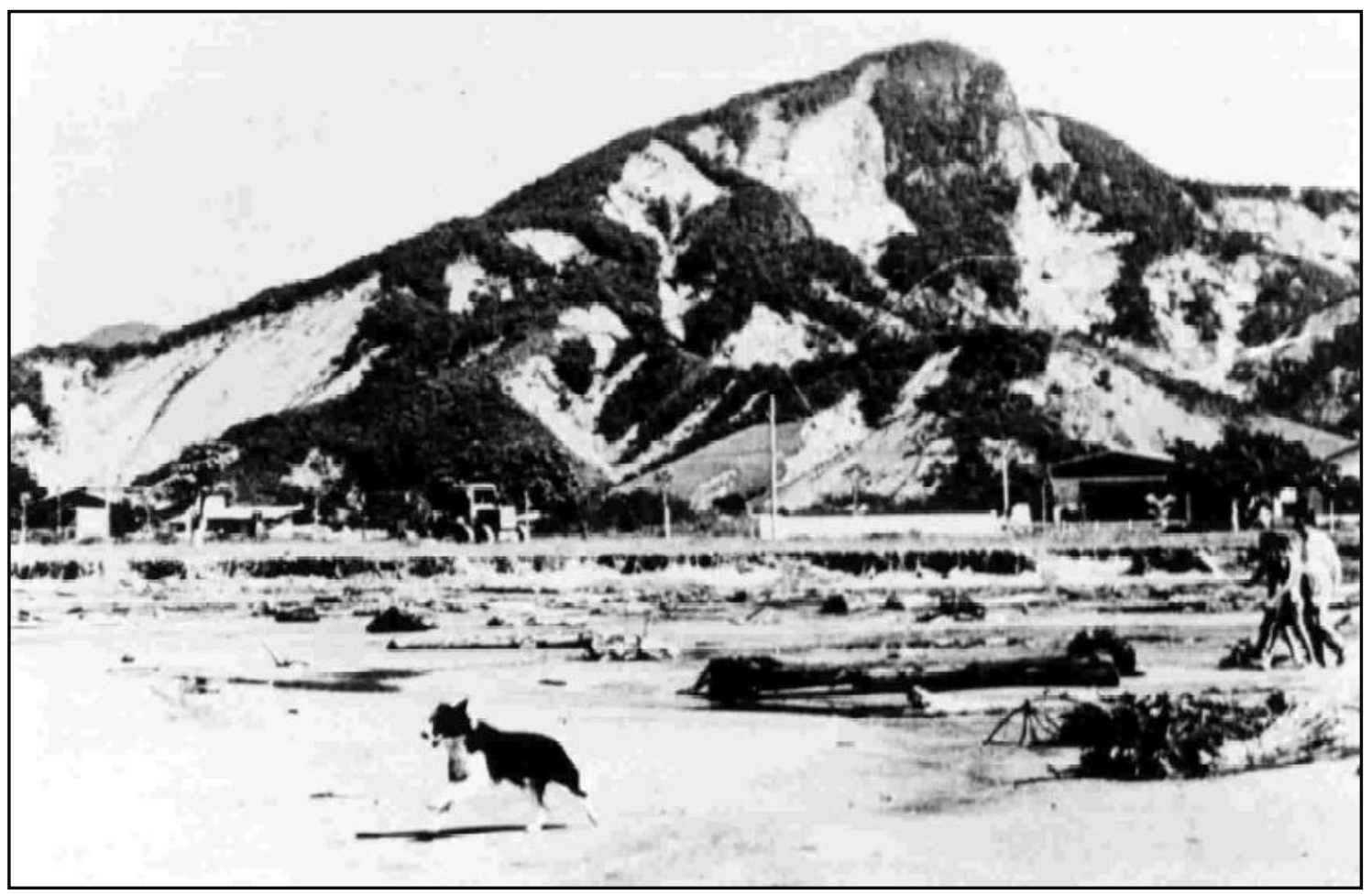

Figura 1.1.Escorregamentos translacionais rasos ocorridos em março de 1967 na Serra do Mar, Caraguatatuba (SP). O material mobilizado alcançou a rede de drenagem, formando corridas de detritos que destruíram parcialmente o município. (Fonte: http://www.caraguatatuba.sp.gov.br, acesso em 24.04. 2011)

Considerando o panorama sobre o papel da dinâmica hidrológica na deflagração dos movimentos de massa, bem como sua importância para a previsão de áreas suscetíveis, a presente pesquisa tem como objetivo principal analisar a distribuição lateral e vertical da condutividade hidráulica saturada $\left(\mathrm{K}_{\text {sat }}\right)$ dos solos e sua influência nos escorregamentos translacionais rasos na Serra do Mar (SP). Para tanto, serão necessários os seguintes objetivos específicos:

a) Selecionar uma bacia de drenagem representativa do meio físico da Serra do Mar, especialmente quanto à cobertura pedológica e às características topográficas, com registros de escorregamentos rasos e acesso para os levantamentos in situ; 
b) Analisar os condicionantes topográficos (ângulo, curvatura, orientação das encostas e área de contribuição) dos escorregamentos rasos ocorridos em 1967,como subsídio para a seleção dos pontos a serem ensaiados;

c) Determinar a condutividade hidráulica saturada dos solos $\left(\mathrm{K}_{\mathrm{sat}}\right)$ in situ; e

d) Avaliar a influência da $\mathrm{K}_{\text {sat }}$, das propriedades físicas dos solos (textura, microporosidade, macroporosidade e porosidade total, coesão e ângulo de atrito)na ocorrência dos escorregamentos rasos.

A compreensão da dinâmica hidrológica e sua influência na deflagração dos escorregamentos rasos têm as seguintes justificativas:

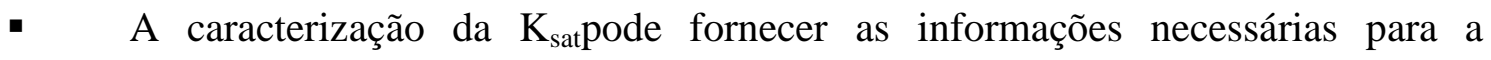
identificação de descontinuidades hidráulicas no perfil de alteração, que podem ser importantes condicionantes dos escorregamentos rasos;

- Os modelos hipotéticos dos mecanismos de ruptura estão diretamente associados à distribuição da $\mathrm{K}_{\text {sat }}$, e, para a Serra do Mar (SP), estudos detalhados em escala de bacia de drenagem, que forneçam informações sobre a dinâmica hidrológica das encostas, são extremamente escassos; e

- Para a previsão de áreas suscetíveis aos escorregamentos rasos por meio de modelos em bases físicas são requeridos dados confiáveis para alimentá-los, de forma que o produto final represente com maior acurácia a realidade. 


\section{ESCORREGAMENTOS RASOS E A HIDROLOGIA DAS ENCOSTAS DA SERRA DO MAR}

A evolução de paisagens em relevos acidentados tem como processos geomorfológicos predominantes os movimentos de massa, sejam aqueles associados exclusivamente às encostas, como os escorregamentos translacionais rasos, assim como aqueles que também ocorrem em ambiente fluvial em escala de bacia hidrográfica, como as corridas de lama e de detritos. Sua ocorrência está condicionada à razão entre as forças que promovem a resistência do material ao deslocamento e as forças solicitantes (SELBY, 1993).

Os fatores que levam ao aumento da tensão cisalhante nas encostas podem atuar de forma isolada ou em conjunto, tornando a sua investigação uma etapa imprescindível para a compreensão dos mecanismos de instabilização. A condutividade hidráulica saturada dos solos é uma propriedade hidrológica que, além de expressar o comportamento da água no solo, pode refletir a influência de outros fatores condicionantes.

Este capítulo tratará dos principais fatores condicionantes dos escorregamentos translacionais rasos na Serra do Mar (2.1), da condutividade hidráulica saturada dos solos $\left(\mathrm{K}_{\mathrm{sat}}\right)$ e da dinâmica hidrológica das encostas (2.2), da sua mensuração por meio do Permeâmetro de Guelph (2.3) e, por fim, do papel das propriedades físicas e hidrológicas dos solos na ocorrência de escorregamentos translacionais rasos. 


\subsection{Fatores condicionantes dos escorregamentos translacionais rasos na Serra do Mar}

A evolução natural da Serra do Mar tem nos movimentos coletivos de massa um dos seus principais processos, especialmente os escorregamentos translacionais, tipologia que, segundo Van Aschet al. (1999), é a mais comum e freqüente em todas as zonas climáticas. O número de mortes em decorrência dos movimentos de massa na área comprova é responsável pelo número expressivo de mortes no Brasil, ocorrendo principalmente nos eventos catastróficos (Figura 2.1).

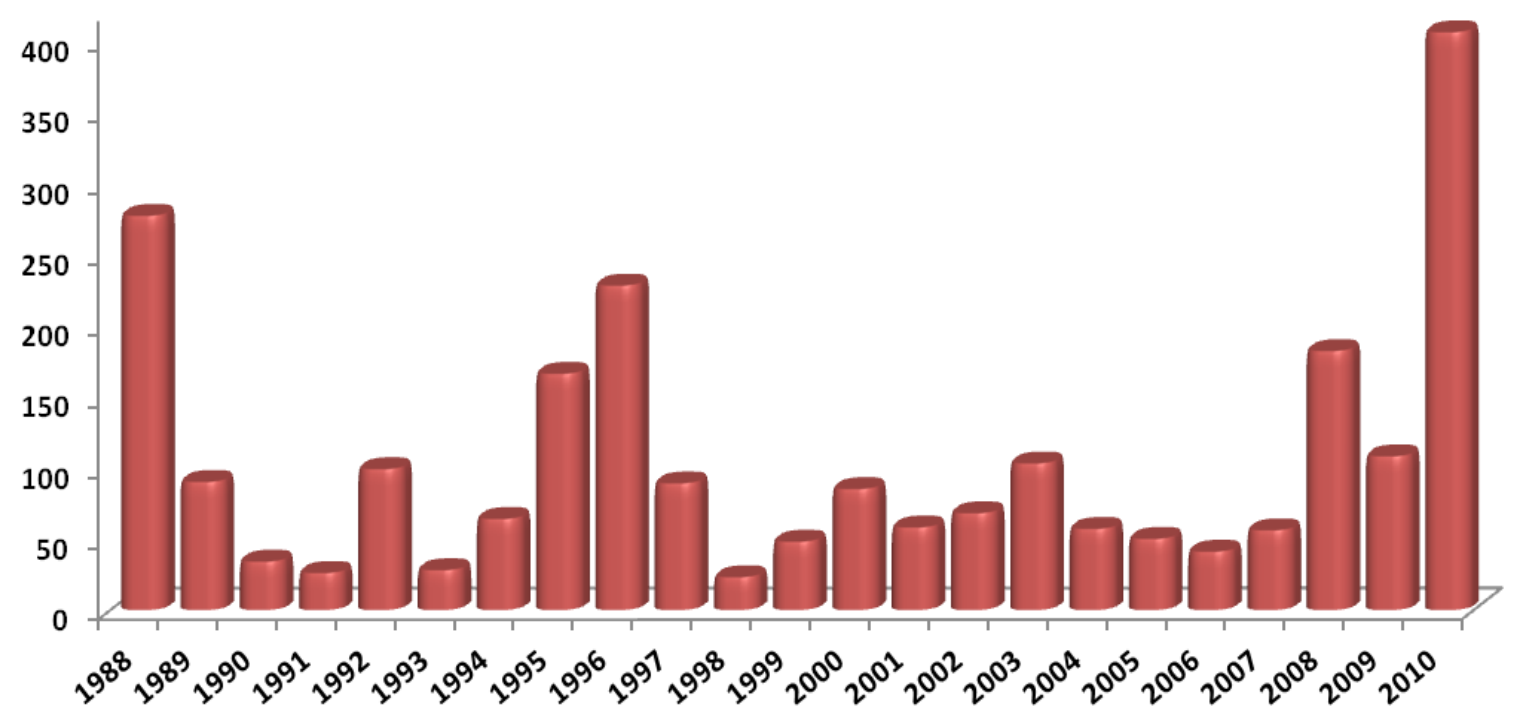

Figura 2.1: Número de mortes associadas a eventos de movimentos de massa registrados nos Estados do Rio de Janeiro, São Paulo e Santa Catarina, a partir de 1988. Fonte: banco de dados do Instituto de Pesquisas Tecnológicas do Estado de São Paulo. 
Os casos constatados nesse período na Serra do Mar paulista foram a maioria dos eventos que ocorreram no Brasil. Episódios como os ocorridos na Baixada Santista, em março 1956, na Serra de Caraguatatuba, em março de 1967, e em Cubatão, em janeiro de 1985, mobilizaram centenas de metros cúbicos de solos e rochas, originando corridas de detritos com alto poder destrutivo.

Os escorregamentos ocorridos na Baixada Santista, na Serra de Caraguatatuba e em Cubatão foram eventos generalizados, todos deflagrados a partir de intensos episódios de chuvas, tendo sido registrado na Serra de Caraguatatuba e em Cubatão, respectivamente, um total de $535 \mathrm{~mm}$ e $380 \mathrm{~mm}$ em apenas 48 horas.

Como observou Wolle (1988), a existência de encostas com alta declividade (ângulos maiores que $35^{\circ}$ ) na Serra do Mar, associadas às chuvas intensas e concentradas, características de ambiente tropical úmido, é uma circunstância na qual podem ser desencadeados processos nas encostas desta região, ainda que existam outros fatores condicionantes.

A literatura brasileira apresenta inúmeros fatores que atuam no desencadeamento destes processos, dentre os quais podem ser destacados o papel da vegetação, os fatores topográficos, como declividade e forma das encostas, propriedades dos solos e das rochas e a dinâmica da água dentro dos materiais (GUIDICINI e NIEBLE, 1983; AUGUSTO FILHO e VIRGILI, 1998; entre outros). 


\subsubsection{Vegetação}

A vegetação é um fator que pode influenciar na estabilidade das encostas por meio de vários mecanismos hidrológicos e outros mecânicos. Os fatores mecânicos aparecem como interações físicas, sejam da folhagem ou do sistema radicular da planta com a encosta, como por exemplo, o reforço do sistema radicular no solo, sobrecarga e a ação dos ventos (Figura 2.2). Os mecanismos hidrológicos são aquelas complexidades que ocorrem no ciclo hidrológico quando há cobertura vegetal, como o aumento da evapotranspiração e da infiltração (GREENWAY, 1987). Como se observa na Figura 2.1, entre seus efeitos tem-se o retardo da precipitação, em virtude da interceptação do dossel, e a remoção da umidade do solo pela evapotranspiração (PRANDINI et al. 1976; GREENWAY, 1987; entre outros).

Além da classificação em mecanismos mecânicos e hidrológicos, Greenway (1987) estabeleceu uma divisão entre ações estabilizadoras (benéficas) e instabilizadoras (adversas). Segundo o autor, são considerados benéficos, a atuação do dossel na interceptação da chuva, a absorção da água pelas raízes, o reforço do solo pelo sistema radicular, o ancoramento, a sobrecarga (aumento da tensão normal na encosta) e o travamento das partículas do solo pelas raízes. Quanto aos adversos, alguns deles são: a capacidade das raízes em aumentar a aspereza da superfície e a permeabilidade do solo, a mitigação da umidade/ressecamento do solo, sobrecarga (aumento na força paralela à encosta), exposição da vegetação ao vento. 


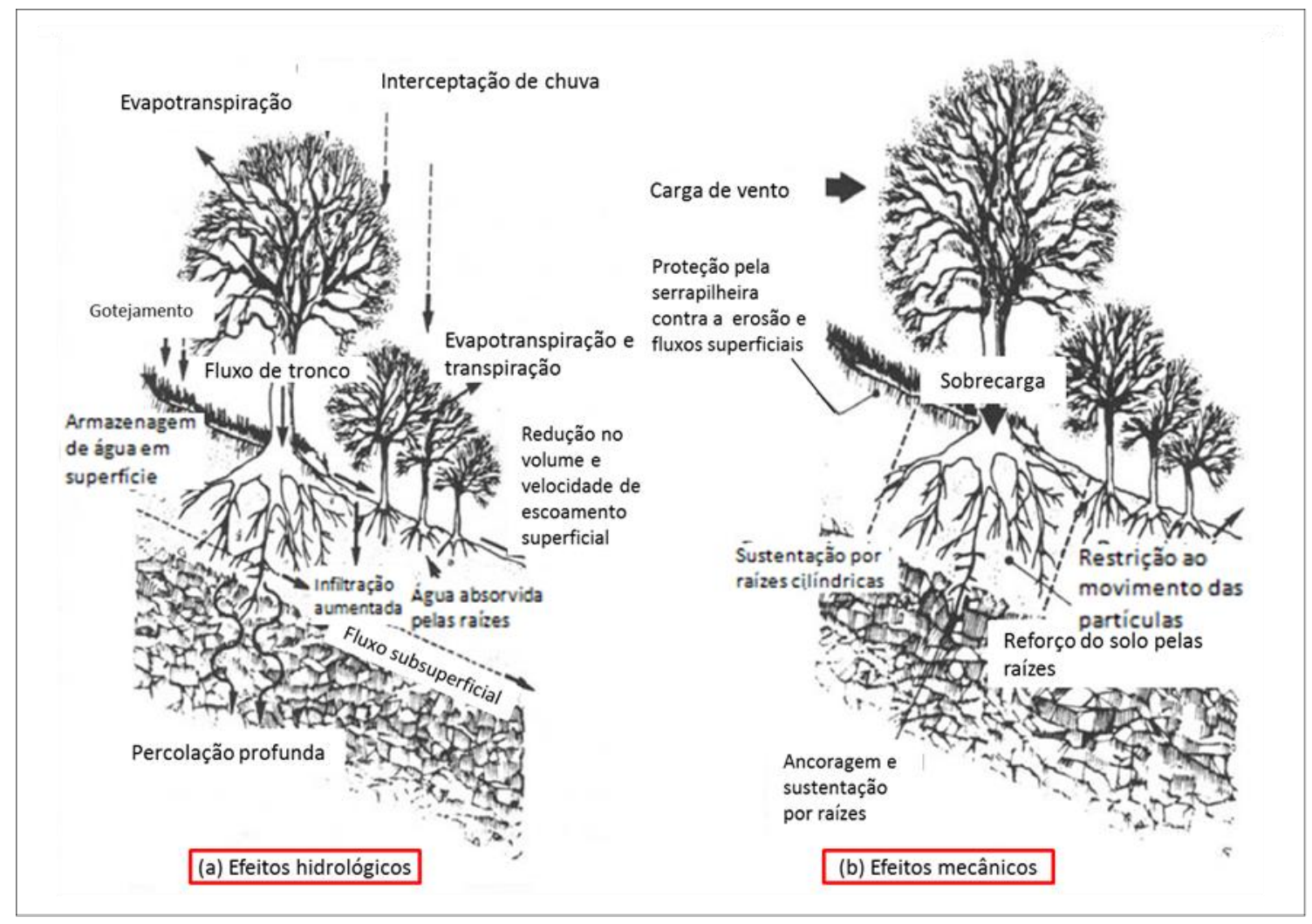

Figura 2.2. Efeitos hidrológicos (a) e mecânicos (b) da vegetação na estabilidade das encostas Fonte: modificado de Kuriakose (2006) adaptado de VanBeek(2005).

Keim e Skaugset (2003), na tentativa de apresentar dados de campo do efeito suavizador do dossel na intensidade da chuva na superfície em duas localidades no Pacífico noroeste, Estados Unidos, coletaram dados sobre a intensidade das chuvas em duas coberturas vegetais (diferentes estágios sucessivos), tendo sido realizado levantamentos sob o dossel e externo a eles. Após calcularem o fator de segurança (FS) com os dados obtidos sob o dossel e diretamente da chuva, observaram que, em ambas as localidades, o FS nas áreas sob o dossel eram maiores do que naquelas externas ao dossel, em clareiras. Portanto, o efeito da interceptação na intensidade e na duração das 
chuvas, em virtude da diminuição da infiltração, é capaz de retardar o aumento das poro-pressões, o que colabora com a estabilidade da encosta.

Buscando avaliar os efeitos hidrológicos e mecânicos da vegetação na susceptibilidade a escorregamentos rasos no alto curso da bacia do Tikovil (Kerala, Índia),Kuriakoseet al. (2009), utilizando um modelo hidrológico associado a um modelo de estabilidade de encosta, elaboraram mapas de estabilidade de encostas, um considerando a coesão das raízes e a sobrecarga da vegetação e outro, desconsiderandoas, incluindo o mapeamento de 11 escorregamentos. No cenário que não considerava a coesão das raízes e a sobrecarga, $42 \%$ da bacia foi prevista como instável, estando todos os locais de escorregamentos nessas áreas. Quanto ao cenário que inclui os efeitos da vegetação, a área da bacia prevista como instável diminuiu para 14\%, estando 8 dos 11 escorregamentos (aproximadamente 72\%) nas áreas instáveis. Houve uma diminuição sensível nas áreas previstas como instáveis, mantendo uma alta precisão na localização dos escorregamentos. Além disso, na análise de sensitividade, destacou-se o parâmetro coesão das raízes em detrimento da profundidade do solo, declividade e ângulo de atrito interno. 


\subsubsection{Topografia}

No que diz respeito aos parâmetros topográficos, estes são uns dos parâmetros mais investigados como condicionantes dos escorregamentos rasos, haja vista a possibilidade de levantamento de dados morfométricos em áreas que seriam de difícil acesso (FERNANDESet al., 2001).

Os parâmetros topográficos tratam das relações entre a forma e a hidrologia (superficial e sub-superficial) da encosta, englobando o ângulo, a forma da encosta (tanto em perfil quanto em planta), a área de contribuição, a orientação das encostas (aspecto), o comprimento da encosta, a (as)simetria dos vales e elevação (FERNANDES e AMARAL, 1996).

O ângulo da encosta representa a inclinação do terreno do topo à sua base, influenciando na velocidade de deslocamento do material, assim como na capacidade de transporte (LOPES, 2006). Este parâmetro, embora seja amplamente reconhecida sua influência nos escorregamentos translacionais, assim como a importância dos demais parâmetros topográficos, ainda hoje vem sendo utilizado como o principal, quando não o único parâmetro de caráter topográfico incorporado às investigações e à previsão de escorregamentos rasos (sobretudo em trabalhos geotécnicos). A negligência às demais variáveis implica na simplificação da topografia, tão importante para a compreensão dos fluxos de água em superfície e subsuperfície.

Com o objetivo de analisar a influência das variáveis geomorfológicas e geológicas nos escorregamentos rasos generalizados de 19 de junho de 1996, no noroeste da Toscana, Itália, D’Amato Avanziet al. (2004), encontraram gradientes entre $36^{\circ}$ e $40^{\circ}$ para $35,6 \%$ das cicatrizes, sendo que $84,5 \%$ ocorreram em encostas com ângulos entre $31^{\circ}$ e $45^{\circ}$. Para ângulos acima destas classes, poucas cicatrizes foram observadas, possivelmente por esses setores das encostas serem constituídas de rochas 
expostas.

Resultados semelhantes foram obtidos por Fernandes et al. (2004) nas encostas do maciço da Tijuca, no município do Rio de Janeiro, tanto da concentração dos escorregamentos nas classes entre $30^{\circ}$ e $55^{\circ}$ quanto da não ocorrência em encostas com ângulos superiores, por conta da rocha exposta, susceptível a outros movimentos, como quedas de blocos.

Outro parâmetro de maior importância é a curvatura da encosta, querepresenta a forma do terreno, determinante para a concentração e percolação de água sobre o terreno, bem como, a instabilização das encostas e os processos correlatos. As formas podem ser retilíneas, côncavas ou convexas, influindo diretamente na movimentação da água superficial e subsuperficial, assim como na coluna d'água dentro do solo.

Embora seja reconhecida a importância da curvatura no controle topográfico dos escorregamentos, essa variável freqüentemente não é incorporada em análises de estabilidade e em mapas de risco (FERNANDES et al., 2004).

IPT (1986), buscando elencar as características e as dinâmicas do meio físico úteis à recomposição vegetal da Serra do Mar, afirma que as encostas retilíneas associam-se quase sempre a ângulos muito altos até verticais, ocorrendo nesse tipo de encosta materiais com maior grau de predisposição a escorregamentos. Anderson e Burt (1978) e Reneauet al. (1986) afirmam que as porções côncavas do relevo (hollows) se apresentam como locais preferenciais para a origem de deslizamentos, pois, se apresentam como zonas convergentes de fluxos superficiais e subsuperficiais e de material transportado, originando depósitos coluvionares.Se esses depósitos se formarem sobre a rocha sã, ou mesmo solos residuais, há uma grande probabilidade de geração de descontinuidades mecânicas e hidrológicas. De acordo com Fernandes e 
Amaral (1996) e D’Amato Avanziet al. (2004), a brusca diminuição da condutividade hidráulica nesse contato favorece a geração de fluxos laterais, onde condições críticas de poro-pressão positiva podem ser alcançadas durante eventos pluviométricos de alta intensidade.

A orientação das encostas (aspecto) refere-se à posição das faces do terreno, frente à distribuição da radiação solar, bem como dos sistemas atmosféricos. Esse parâmetro pode influenciar,segundo Tabalipa e Fiori (2008), no teor de umidade sobre o terreno, bem como interferir nos processos biofísicos (tipo de vegetação e espessura do solo). Havenithet al. (2005), ao analisarem a suscetibilidade a escorregamentos no vale de Suusamyr, no Kirguistão, confrontam os resultados obtidos entre as várias combinações de fatores morfológicos, demonstrando que o aspecto é o segundo fator mais importante, depois do ângulo da encosta.

Quanto à área de contribuição, Fernandes et al. (2004) a definem como segmentos na paisagem nos quais há convergência de água, estando associados à concentração de fluxos superficiais e subsuperficiais, relacionados com a saturação dos solos. Os referidos autores, investigando as relações espaciais entre escorregamentos e seus fatores condicionantes no Rio de Janeiro, especialmente os parâmetros topográficos, comprovaram que áreas de contribuição maiores, ainda que com baixa freqüência nas bacias dos rios Quitite e Papagaio, apresentaram os maiores valores de índice potencial de escorregamentos.

As feições estruturais e litológicas, sistemas de falhas e fraturas, características da foliação e/ou bandamento, exercem um papel fundamental na estabilidade das encostas, uma vez que representam planos de fraqueza na rocha, preservados no solo saprolítico (WOLLE, 1988), importantes descontinuidades mecânicas e hidráulicas (FERNANDESe AMARAL, 1996). 
Um caso de ruptura significativa condicionada por estruturas no maciço é relatada em Wolle (1980), em que um escorregamento ocorreu no emboque do túnel TA-6 da Rodovia dos Imigrantes (SP). Esse escorregamento foi explicado como tendo sido causado pela existência de juntas de alívio no maciço rochoso, que, preenchidas por água, levaram ao colapso uma massa de solo e rocha, instabilizada pelo corte realizado para emboque do túnel. Além das juntas de alívio, neste maciço também havia uma falha geológica, o que o tornava potencialmente instável.

Meis e Xavier da Silva (1968), com o objetivo de tecer algumas considerações geomorfológicas sobre os movimentos de massa ocorridos na cidade do Rio de Janeiro entre 1966 e 1967, apresentaram algumas características geológicas estruturais que predominaram na deflagração de tais movimentos. Neste trabalho, observou-se a ocorrência de movimentos de massa (geralmente escorregamentos translacionais rasos) em locais onde uma seqüência de diáclases curvas tem direção oblíqua à encosta, penetrando para o interior da mesma, cuja configuração representa o plano de deslizamento. 


\subsubsection{Propriedades dos solos e rochas}

No que se refere às descontinuidades mecânicas nos solos, é notável seu controle na existência de descontinuidades hidráulicas, sobretudo pela anisotropia e heterogeneidade de solos tropicais. Tu et al. (2009), por meio do monitoramento em campo do comportamento da água das chuvas em uma encosta constituída de loess, observaram que a umidade, em diferentes profundidades variou sensivelmente, como mostra a Figura 2.3. É possível notar que a chuva diminui e cessa, mas a umidade volumétrica, no caso dos ensaios realizados na profundidade de 4,0m, não acompanha esse decréscimo, demonstrando que essas parcelas do perfil são constituídas por materiais que retêm água. Esse comportamento pode ser explicado pela granulometria do material, como as argilas, principalmente aquelas com maiores superfícies específicas e/ou porosidade total pequena, seja ela natural ou em virtude da profundidade da camada, que pode ter sido compactada pelo material sobrejacente. 


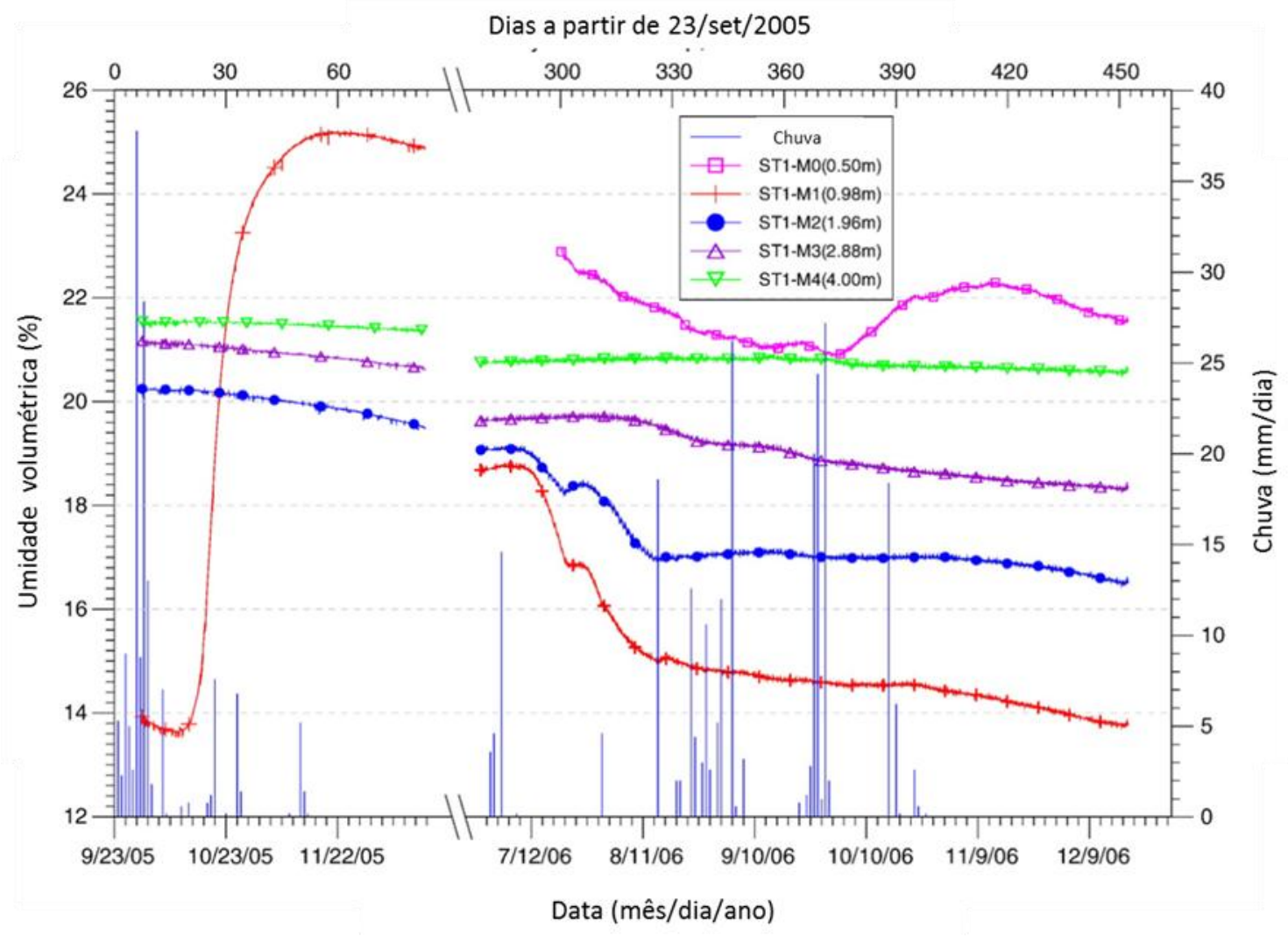

Figura 2.3.Umidade do solo em relação às chuvas no período de 23/09/05 a $31 / 12 / 06$. As curvas coloridas representam a profundidade das mensurações realizadas (Magenta $(0,5 \mathrm{~m})$, vermelha $(0,98 \mathrm{~m})$, azul $(1,96 \mathrm{~m})$, roxa $(2,88 \mathrm{~m})$ e verde $(4,0 \mathrm{~m}))$. Notar a variação do comportamento em cada profundidade, o que evidencia a existência de descontinuidades no solo. Fonte:modificada de Tuet al.(2009). 


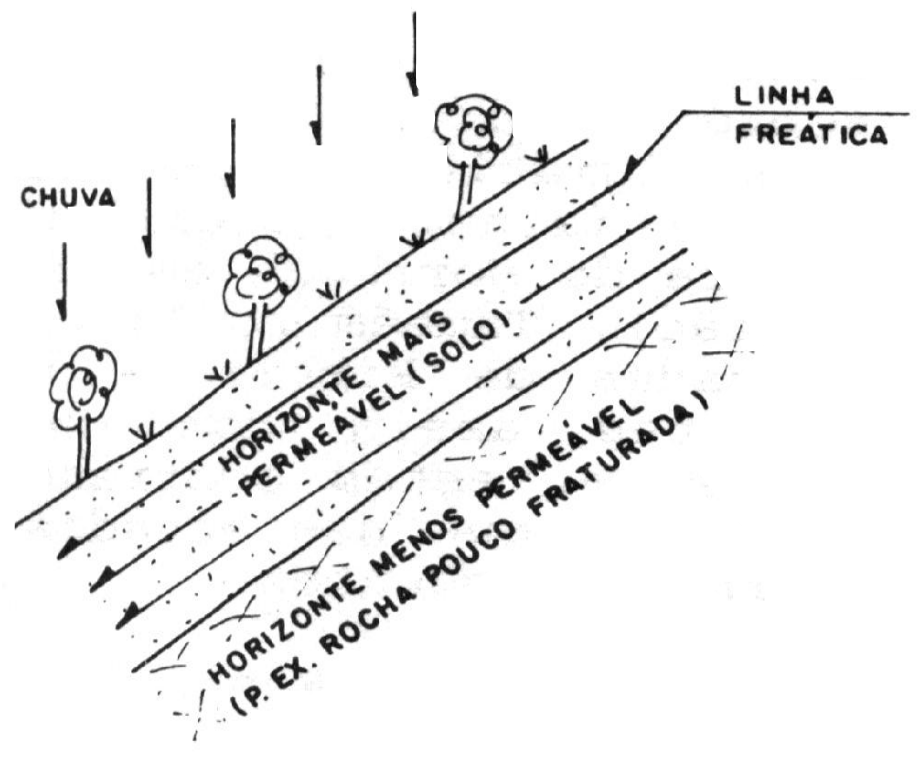

Figura 2.4. Esquema que ilustra o mecanismo de ruptura associado à geração de pressões neutras e formação de fluxos paralelos, em decorrência da brusca redução da permeabilidade do material. Fonte: Wolle e Carvalho (1994).

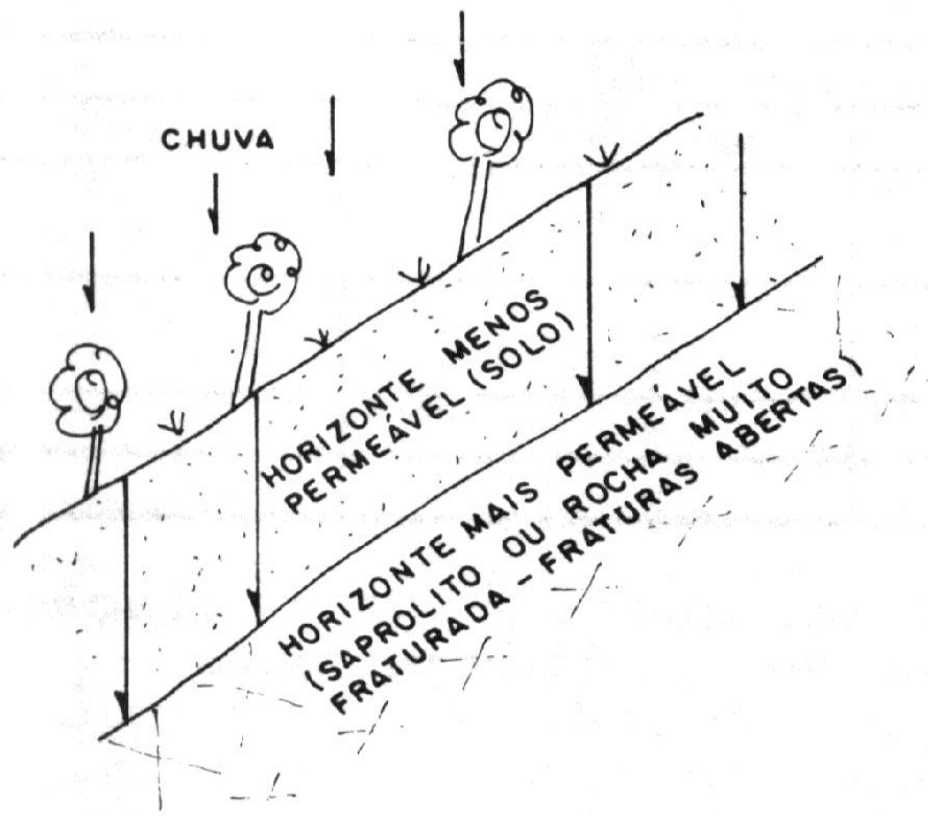

Figura 2.5. Esboço do desenvolvimento de fluxos verticais decorrentes do avanço da frente de saturação. Este movimento descendente da água reduz bruscamente a coesão aparente do solo, aumentando a instabilidade na encosta. Fonte: Wolle e Carvalho(1994). 
A presença de descontinuidades hidráulicas ao longo dos perfis de solos, atribuída às variações da condutividade hidráulica dos solos, são informações fundamentais para o reconhecimento do mecanismo de instabilização.Dentre os principais modelos hipotéticos de mecanismos de ruptura, destacam-se dois: aqueles associados ao aumento da poro-pressão dentro dos solos (Figura 2.4) e à perda de sucção dos solos parcialmente saturados (SELBY, 1993) (Figura 2.5).

No primeiro caso, a ruptura ocorre em virtude do fluxo d'água que se desenvolve paralelo à encosta devido à existência de um horizonte menos permeável abaixo de uma camada passível de estabilização, provocando, portanto, um aumento brusco das poro-pressões positivas. Ou seja, quanto mais próximo da superfície estiver a linha do lençol freático, poro-pressões positivas serão desenvolvidas mais rapidamente, atingindo uma condição limite para a instabilização da encosta (WOLLE, 1988).

Segundo Selby (1993), quando há geração de poro-pressão positiva, ocorre a transferência de carga do solo para a água, gerando um efeito de flutuabilidade. Atribuise a esse comportamento a redução do efeito do atrito entre os grãos do solo e quando há este aumento nas poro-pressões, ocorre uma redução na tensão normal efetiva no material (HARP et al., 1990). Para Campos et al. (1992b), o desenvolvimento de poropressões positivas nas encostas não-saturadas, pode levar a um processo de instabilização do solo que independe da perda de resistência do material não-saturado, devido à perda de sucção.

Quando há uma redução no fator de segurança como resultado da diminuição da resistência,devido ao aumento nas poro-pressões, pode-se afirmar que, nesse caso, os deflagradores de uma possível movimentação são de cunho hidrológico (TERLIEN, 1997). 
Quanto ao segundo modelo de ruptura das encostas, trata-se da instabilização a partir da perda de sucção, decorrente do processo de infiltração nas encostas e ao avanço da frente de saturação que, alcançando profundidades abaixo da zona de enraizamento, podem provocar a perda de coesão aparente, levando à ruptura (WOLLE eCARVALHO, 1989). Além da redução da coesão aparente que, em alguns casos, é o parâmetro que fornece maior resistência à ruptura (TERZAGHI, 1952), deve-se considerar a diminuição na coesão efetiva quando o elemento aglutinante das partículas do solo é removido por solução, perdendo a coesão (TERZAGHI, 1967).Neste processo de instabilização não há saturação do perfil, pois uma das principais características do solo à rocha alterada,é a presença de fratura e fendas, abertas e intercomunicantes, que conferem grande capacidade de drenagem a estes horizontes. Desta forma, é generalizada nas encostas uma condição de condutividade hidráulica $(\mathrm{K})$ crescente com a profundidade (WOLLE e CARVALHO, 1989; VAN ASCH et al., 1999).

Com o objetivo de caracterizar os principais mecanismos de instabilização atuantes nas encostas da Serra do Mar, IPT (1987), após a análise de algumas encostas de Cubatão (SP), chegou à conclusão que a ocorrência de instabilizações devido ao aumento de poro-pressões é um mecanismo inviável de ocorrer na região estudada, a não ser em locais restritos onde há anomalias geológicas que favoreçam a ocorrência de horizontes rochosos impermeáveis.

Para Wolle e Carvalho (1989), o fato de não terem localizado o nível d'água a menos de $20 \mathrm{~m}$ de profundidade, nem observado o desenvolvimento de poro-pressões positivas são suficientes para corroborar o modelo hipotético de perda de sucção por meio da diminuição da coesão aparente. 
Ainda que seja reconhecido quão fundamental é o desenvolvimento de poropressões positivas nas instabilizações nas encostas, poucos são os trabalhos que mostram o comportamento das poro-pressões durante a ruptura. Nesse sentido, Harpet al. (1990) e Wang eSassa (2003) desenvolveram pesquisas buscando compreender a relação entre poro-pressão e ruptura do solo.

Harpet al. (1990) investigaram o comportamento das poro-pressões durante rupturas nos solos em campo, em três locais, em Utah e na California (EUA). Foram utilizados piezômetros eletrônicos e medidores de deslocamento para registrar, respectivamente, as poro-pressões e os movimentos antes e durante a ruptura da encosta. Os dados obtidos demonstram que as respostas, nos três locais, foram bem próximas, em que o aumento ocorre anterior à ruptura, apresentando uma tendência consistente do comportamento predecessor da ruptura da encosta.

O trabalho de Wang e Sassa (2003) buscou, além disso, entender os efeitos da granulometria no desenvolvimento de poro-pressões positivas, especialmente as partículas finas. Os ensaios foram realizados em laboratório, a partir de um modelo experimental que simulava as condições naturais de uma encosta. No que se refere ao comportamento da poro-pressão em relação à ruptura, os materiais ensaiados (areias de diferentes granulometrias e Loess com matriz areno-siltosa de diferentes pesos específicos) apresentaram o mesmo padrão na geração/manutenção da poro-pressão, aqui representado pelo gráfico da amostra de areia sílica fina (Figura 2.6). Observa-se na figura, que representa a relação entre as poro-pressões e a ruptura ao longo do ensaio, que o aumento das poro-pressões ocorreram após a ruptura do solo. 


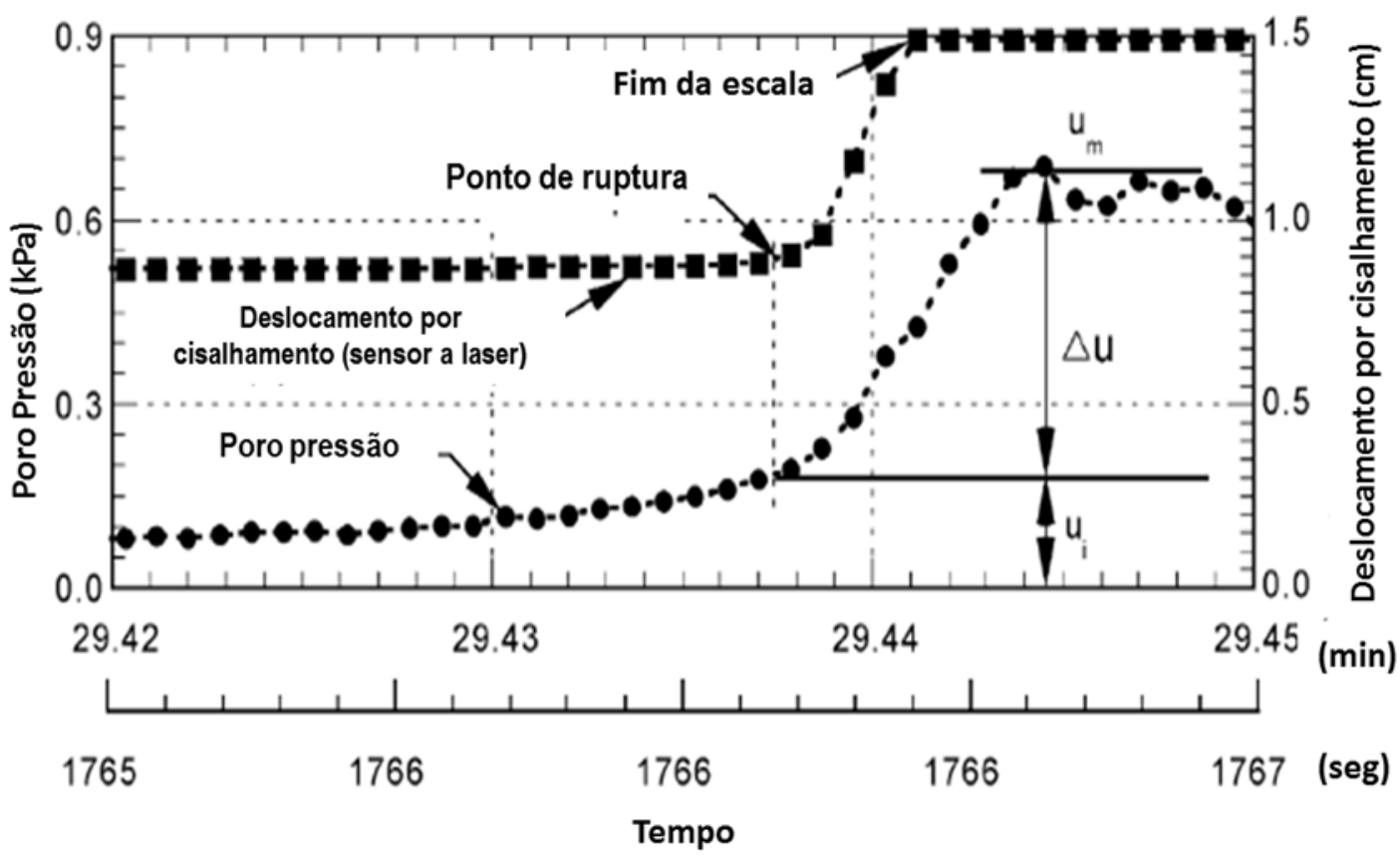

Figura 2.6. Relação entre a variação da poro-pressão, o deslocamento por cisalhamento com o tempo. Observa-se que o aumento de poro-pressões ocorre após o ponto de ruptura Fonte:modificado de Wang eSassa(2003).

É notável a participação de algumas propriedades físicas do solo no desenvolvimento de condições críticas de estabilidade. Isso ocorre por conta da influência direta dessas propriedades (textura, estrutura, porosidade, massa específica, entre outras) na dinâmica da água no solo. Assim, é possível inferir que os escorregamentos serão deflagrados dependendodo comportamento hidrológico dos materiais, havendo então a necessidade de conhecimento das propriedades dos solos que influenciam nesta dinâmica, sendo uma delas a condutividade hidráulica. Essa propriedade hidrológica dos solos, sujeita a variações espaciais e temporais, exerce influência significativa na dinâmica hidrológica das encostas e como consequiência, na sua estabilidade. 


\subsection{Condutividade Hidráulica dos Solos (K)}

O movimento do fluxo através de meios porosos saturados ou não-saturados ocorre em função da diferença de carga hidráulica, como resultado do decréscimo da carga, do maior potencial total para o menor potencial total (GERSCOVICH et al., 1992).

A condutividade hidráulica dos solos (K) é uma propriedade que representa a habilidade com que um fluido é transportado em um meio poroso, dependendo tanto das propriedades do meio como das propriedades do fluido (FREEZE e CHERRY, 1979; BRADY, 1989;LIBARDI, 2005; entre outros). Esta é uma variável que depende diretamente das dimensões, da geometria e da configuração dos poros do solo (BRADY, 1989).

O cálculo da condutividade hidráulica dos solos é realizado a partir da equação baseada na Lei de Darcy (Equação 1), a partir do experimento no qual uma amostra de material arenoso homogêneo, colocado em um cilindro de comprimento (L) e área transversal (A), foi submetido a uma carga constante (h). Após certo tempo de ensaio, a amostra saturava e o valor do fluxo de saída (Q) não mais variava com o tempo, chegando a uma situação de equilíbrio. Assim, pôde-se concluir que a velocidade do fluxo varia de acordo com a condutividade hidráulica.

$$
\mathrm{K}=\frac{Q L}{A h}(1)
$$

onde,
$\mathrm{K}$ - Condutividade hidráulica [L/T]
A - Seção transversal [ $\left.\mathrm{L}^{2}\right]$
$\mathrm{Q}$ - Fluxo constante medido no campo $\left[\mathrm{L}^{3 / T}\right]$
$\mathrm{h}-$ Carga constante $[\mathrm{L}]$
$\mathrm{L}$ - Comprimento de coluna de solo [L] 
Embora este experimento tenha sido pioneiro na mensuração K, sabe-se, hoje, que ensaios em laboratório apresentam uma restrição: a pequena representatividade espacial, devido ao tamanho da amostra, que poderá não englobar algumas estruturas do solo, como macroporos, raízes, fendas e feições reliquiares.

Levando-se em consideração as diferenças texturais eestruturais, a variação da $\mathrm{K}$ está condicionada às mudanças na granulometria ao longo de um perfil de solo. A Figura 2.7 apresenta os valores da $\mathrm{K}$ em materiais de diferentes granulometrias, podendo ser extremamente permeável $\left(10^{2} \mathrm{~cm} / \mathrm{s}\right.$ a $\left.10^{-1} \mathrm{~cm} / \mathrm{s}\right)$, como os cascalhos; de baixa permeabilidade $\left(10^{-2} \mathrm{~cm} / \mathrm{s}\right.$ a $\left.10^{-5} \mathrm{~cm} / \mathrm{s}\right)$, representados pelos materiais argiloarenosos e materiais praticamente impermeáveis, como as argilas homogêneas $\left(10^{-7}\right.$ $\left.\mathrm{cm} / \mathrm{s} \mathrm{a} 10^{-9} \mathrm{~cm} / \mathrm{s}\right)($ FREEZE e CHERRY,1979). 


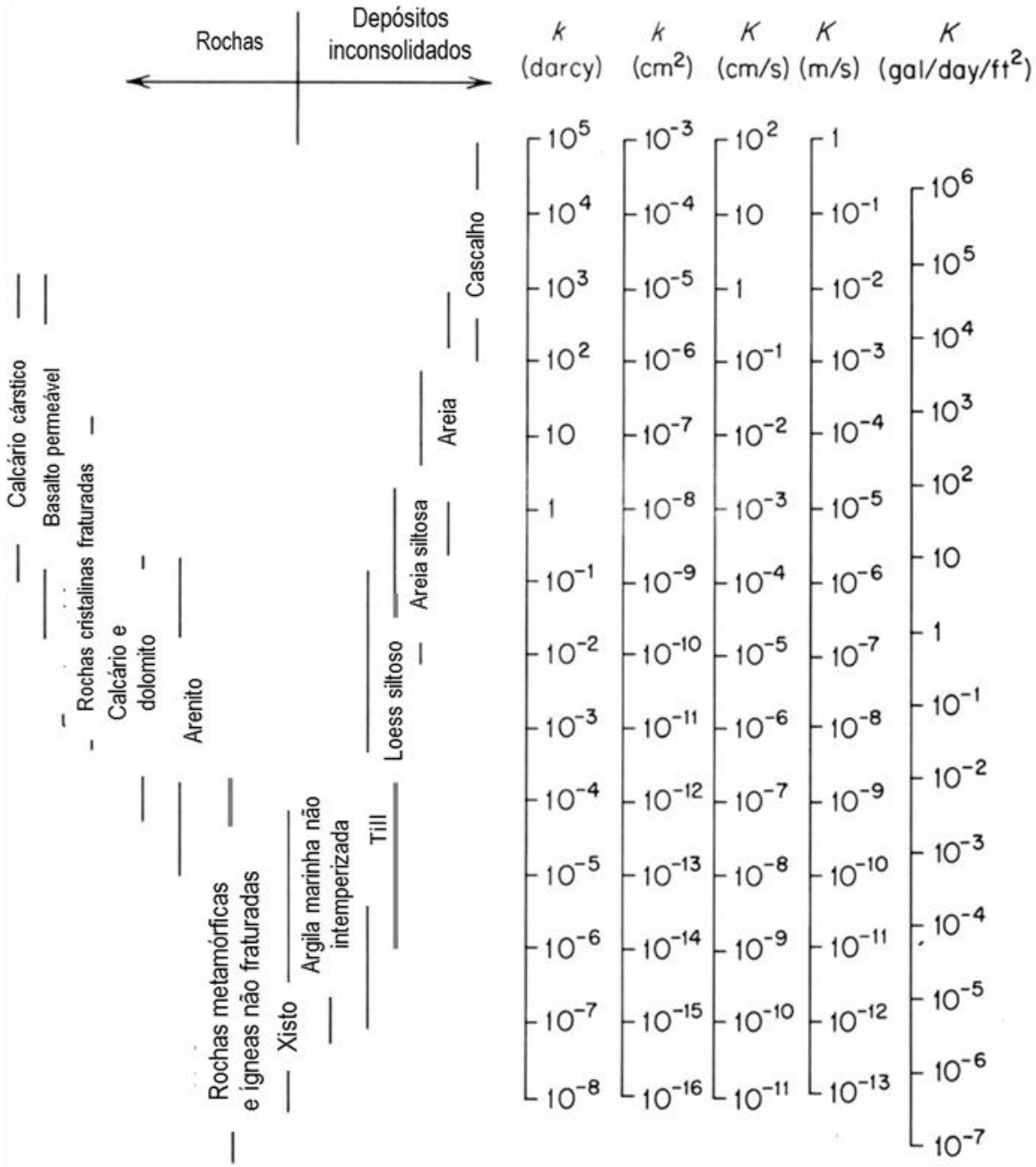

Figura 2.7. Estimativa da condutividade hidráulica e da permeabilidade de acordo com diferentesmateriais. Observa-se que os diferentes valores são expressos em ordem de grandeza, uma vez que é nesta escala que a variação da condutividade hidráulica influi estabilidade de encostas. Fonte: modificada de Freeze e Cherry(1979). 
Segundo Freeze e Cherry (1979) e Brady (1989), a K pode ser saturada (K sat $)$ ou não saturada $\left(\mathrm{K}_{\tilde{n} \text { sat- }-\theta}\right)$. A $\mathrm{K}_{\text {sat }}$ ocorre quando todos os poros do solo estão preenchidos com água, correspondendo a um valor constante, máximo para a $\mathrm{K}$ naquele solo.Já a $\mathrm{K}_{\text {ñsat }-\theta}$ corresponde ao fluxo que ocorre quando os poros do solo estão parcialmente cheios de água, e é função da umidade volumétrica disponível no solo.Contudo, sabe-se que, ao realizar um ensaio em campo, há uma pequena parcela do ar presente nos poros do soloque não consegue escapar, ficando aprisionado, o que leva a um fluxo saturado com valor abaixo do esperado se houvesse a saturação total. A esta "subsaturação" (REYNOLDS e ELRICK, 1987) dá-se o nome de Condutividade Hidráulica Saturada de Campo - Field-SaturatedHydraulicConductivity- $\left(K_{f s}\right)$, portanto, o que se denomina neste trabalho por $\mathrm{K}_{\text {sat }}$, na verdade, é a $\mathrm{K}_{f s}$. De acordo com Reynolds et al. (1983), este valor pode ser considerado como o mais representativo, pois são poucos os processos de infiltração natural ou mesmo antrópicos que produzem a completa saturação no campo.

A variabilidade espacial da $\mathrm{K}$ do solo é uma característica inerente aos mesmos, que surge desde o momento que este começa a ser formado até que alcance uma condição de equilíbrio dinâmico. Mesmo atingindo este estado, a variabilidade espacial persiste, embora seja mais acentuada nos solos mais jovens (MENEZES et al., 2006a). Segundo o referido autor, análises estatísticas sobre a variabilidade dos atributos do solo, apresentadas na literatura, mostram que alguns, como aqueles relacionados à dinâmica da água no solo, variam sensivelmente, alcançando $200 \%$. A K dos solos se destaca como um atributo de alta variabilidade, podendo até não apresentar uma estrutura de dependência espacial definida (MENEZES et al., 2006a).

A porosidade (total), propriedade que interfere na aeração, transmissão e retenção de água, capacidade de penetração e ramificação das raízes (que, por sua vez, 
também influenciam na porosidade do solo), ainda que de reconhecida importância, fornece informações restritas, sendo mais importante avaliar a distribuição dos poros e o comportamento da K (VIEIRA e FERNANDES, 2004; MENEZES et al., 2006b). Enquanto os microporos são responsáveis pela retenção de água no solo, os macroporos possibilitam o movimento livre do ar e da água de percolação (BRADY, 1989), sendo resultante, principalmente, da decomposição das raízes, bioturbação animal ou de mecanismos de erosão em subsuperfície (DUNNE et al., 1991).

Menezes et al. (2006b), com o objetivo de verificar o diâmetro de poros que mais interfere no valor da condutividade hidráulica saturada $\left(\mathrm{K}_{\mathrm{sat}}\right)$, realizaram ensaios de granulometria, porcentagem de argila dispersa em água e distribuição de vazios do solo, sendo este último por meio do método da dessorção de água, em amostras deformadas. Já a $\mathrm{K}_{\mathrm{sat}}$ foi determinada a partir de amostras indeformadas, utilizando-se um permeâmetro de carga constante. Os autores observaram que solos com porosidades totais semelhantes apresentaram distribuição de vazios, bem distinta, sendo que os valores encontrados para os poros com diâmetros maiores que $0,15 \mathrm{~mm}$ tendem a ser proporcionais aos valores encontrados para a $\mathrm{K}_{\text {sat }}$.

Procurando investigar a relação entre alguns parâmetros físicos e a condutividade hidráulica (K), Menezes et al. (2006a) realizaram alguns ensaios em laboratório e in situ, em vinte amostras de solos de uma mesma baciano município de Lavras (MG). Foram correlacionados os valores obtidos de $\mathrm{K}$ aos atributos físicos (umidade natural do solo, massa específica dos solos, limites de consistência, macro e microporosidade, porosidade e granulometria), sendo que o atributo que apresentou melhor coeficiente de correlação foi a macroporosidade.

Com o objetivo de investigar a variabilidade espacial da condutividade hidráulica saturada $\left(\mathrm{K}_{\mathrm{sat}}\right)$ em uma toposseqüênciarecoberta por floresta tropical e 
constituída por Latossolo Vermelho (terços superior e médio da encosta) e Latossolo Amarelo (terço inferior) no estado de Rondônia, Sobierajet al. (2002) realizaram ensaios de $\mathrm{K}_{\mathrm{sat}}$ em laboratório (permeâmetro de carga constante) em amostras retiradas nas profundidades de 20,30, 50 e $90 \mathrm{~cm}$, em cada terço da encosta. As análises estatísticas demonstraram que não houve correlação entre $\mathrm{K}_{\text {sat }}$ e a posição na topografia, possivelmente por conta da macroporosidade oriunda da bioturbação homogênea ao longo de toda a encosta.

Espinha Marques et al. (2009), motivados pela qualidade dos recursos hídricos subterrâneos e pela sua manutenção, caracterizaram a zona não saturada do solo de uma bacia localizada no Parque Nacional da Serra da Estrela, Centro-Norte de Portugal. Foram realizados levantamentos geológicos, pedológicos e mineralógicos em campo e em laboratório, destacando-se o emprego do Permeâmetro de Guelph para o levantamento da $\mathrm{K}_{\mathrm{sat}}$. Os ensaios demonstraram a alta permeabilidade dos solos $\left(10^{-4}\right.$ $\mathrm{m} / \mathrm{s}$ ) e sua alta correlação com o teor de fração areia do material, o que demonstra que a velocidade de recarga do aquífero é relativamente alta e que também desperta a atenção no que diz respeito à ocupação contaminação se houver uso inadequado do solo na área.

Outro trabalho que utilizou o instrumento de campo do Permeâmetro de Guelph foi desenvolvido por Aguiar (2001), em que o autor estudou a viabilidade e eficiência do referido instrumento na mensuração da permeabilidade de coberturas de aterros relacionados a resíduos sólidos. Os ensaios mostraram resultados satisfatórios, visto que mesmo tendo sido testadas diferentes soluções percolantes, que apresentam diferentes interações com as partículas dos solos, os valores foram todos na mesma ordem de grandeza.

Os trabalhos supracitados apresentam algumas das possíveis aplicações damensuração da $\mathrm{K}_{\mathrm{sat}}$, cujos procedimentos adotados demonstraram sua viabilidade em 
relação ao tema proposto. Executados em laboratório ou em campo, tais procedimentos apresentam vantagens e desvantagens, que devem ser consideradas quando da escolha do método a ser utilizado. Vieira (2001) apresenta uma síntese das vantagens e desvantagens de alguns métodos com utilização recorrente para a estimativa da condutividade hidráulica saturada $\left(\mathrm{K}_{\mathrm{sat}}\right)$ e não saturada $\left(\mathrm{K}_{\text {ñsat }}\right)($ Quadro 2.1).

Conforme apontado no quadro e pelos trabalhos de Espinha Marques et al. (2009) e Aguiar (2001), o Permeâmetro de Guelph é um dos instrumentos de campo que apresenta potencialidades que podem ser imprescindíveis para a realização de ensaios em ambientes onde os demais instrumentos apresentariam restrições. 
Quadro 2.1.Vantagens e desvantagens de alguns métodos freqüentemente utilizados para estimar a condutividade hidráulica saturada $\left(\mathrm{K}_{\text {sat }}\right)$ e não saturada ( $\mathrm{K}_{\text {ñsat }}$ ). Todos os métodos estimam a K in situ, com exceção dos Permeâmetros de carga constante e variável.

\begin{tabular}{|c|c|c|c|}
\hline MÉTODO & VANTAGENS & DESVANTAGENS & FONTE* \\
\hline $\begin{array}{l}\text { Permeâmetro de } \\
\text { carga constante/ } \\
\text { variável }\end{array}$ & $\begin{array}{l}\text { - simples e rápido; } \\
\text { - outras medições podem ser } \\
\text { feitas na mesma amostra } \\
\text { (ex. porosidade) } \\
\text { - facilita a aplicação de } \\
\text { análises computacionais } \\
\text { devido à simplicidade das } \\
\text { condições de limite. }\end{array}$ & $\begin{array}{l}\text { - perturbações na amostra podem alterar o valor de K; } \\
\text { - dificuldade de se verificar estruturas no solo de grandes dimensões (ex. } \\
\text { raízes e feições relíquias); } \\
\text { - os valores da K podem ser superestimados ou subestimados } \\
\text { dependendo da escala de mensuração (ex. efeito dos macroporos); } \\
\text { - muito lento e cuidados específicos devem ser tomados com as amostras } \\
\text { (ex. água esterilizada para evitar bactérias). }\end{array}$ & $\begin{array}{c}\text { Stephens (1996) } \\
\text { Paige e Hillel (1993) } \\
\text { Salverda e Dane (1993) } \\
\text { Reynolds e Elrick (1985b) }\end{array}$ \\
\hline Poço & - rápido & $\begin{array}{l}\text { - dificuldade no transporte e na montagem de equipamentos e } \\
\text { - necessidade mínima de } 1000 \text { litros de água. }\end{array}$ & Oliveira e Corrêa Filho (1996) \\
\hline Hvorlesv & - rápido e utiliza pouca água. & - necessidade da instalação de piezômetros (tubos abertos). & $\begin{array}{c}\text { Freeze e Cherry (1979) } \\
\text { Caputo (1973) Fetter (1994) }\end{array}$ \\
\hline $\begin{array}{l}\text { Infiltrômetro de } \\
\text { anel duplo fechado }\end{array}$ & $\begin{array}{l}\text { - custo moderado; } \\
\text { - grande volume de solo é } \\
\text { ensaiado; } \\
\text { - medição da permeabilidade } \\
\text { vertical e } \\
\text { - mede permeabilidades menores } \\
\text { que } 10^{-8} \mathrm{~cm} / \mathrm{s}\end{array}$ & $\begin{array}{l}\text { - dificuldade no transporte e na montagem de equipamentos; } \\
\text { - a frente de saturação tem que ser estimada; } \\
\text { - requer muito tempo, podendo durar algumas semanas ou meses. }\end{array}$ & $\begin{array}{l}\text { Stephens (1996) } \\
\text { Little et al. (1995) } \\
\text { Daniel (1989) }\end{array}$ \\
\hline $\begin{array}{l}\text { Infiltrômetro de } \\
\text { anel simples } \\
\text { fechado }\end{array}$ & $\begin{array}{l}\text { - baixo custo; } \\
\text { - medição da permeabilidade } \\
\text { vertical e } \\
\text { - mede permeabilidades menores } \\
\text { que } 10^{-8} \mathrm{~cm} / \mathrm{s}\end{array}$ & $\begin{array}{l}\text { - pequeno volume de solo é ensaiado; } \\
\text { - requer muito tempo, podendo durar algumas semanas ou meses; } \\
\text { - a frente de saturação tem que ser estimada e } \\
\text { - dificuldade no transporte e na montagem de equipamentos. }\end{array}$ & $\begin{array}{c}\text { Daniel (1989) } \\
\text { Sephens (1996) }\end{array}$ \\
\hline
\end{tabular}


(continuação do Quadro 2.1)

\begin{tabular}{|c|c|c|c|}
\hline MÉTODO & VANTAGENS & DESVANTAGENS & FONTE* \\
\hline $\begin{array}{l}\text { Infiltrômetro de } \\
\text { anel simples } \\
\text { aberto }\end{array}$ & $\begin{array}{l}\text { - mede a permeabilidade vertical; } \\
\text { - de fácil manuseio e } \\
\text { - grande volume de solo é ensaiado. }\end{array}$ & $\begin{array}{l}\text { - problemas com evaporação e } \\
\text { - requer muito tempo, podendo durar algumas semanas ou } \\
\text { meses. }\end{array}$ & $\begin{array}{l}\text { Daniel (1989) } \\
\text { Stephens (1996) } \\
\text { Guerra (1995) }\end{array}$ \\
\hline Air Entry & $\begin{array}{l}\text { - custo moderado; } \\
\text { - medição da permeabilidade vertical } \\
\text { - mede permeabilidades menores que } \\
{ }^{8} \mathrm{~cm} / \mathrm{s} \text {. }\end{array}$ & $\begin{array}{l}\text { - dificuldade no transporte e na montagem de equipamentos e } \\
\text { - hipóteses complexas devem ser consideradas. }\end{array}$ & $\begin{array}{c}\text { Daniel (1989) } \\
\text { Stephens (1996) } \\
\text { Reynolds e Elrick (1985b) }\end{array}$ \\
\hline $\begin{array}{l}\text { Permeâmetro de } \\
\text { Guelph }\end{array}$ & $\begin{array}{l}\text { - mede simultaneamente outros parâmetros } \\
\text { hidráulicos do solo (ex. sorptividade); } \\
\text { - permite medidas em grandes profundidades; } \\
\text { - baixo custo, portátil e utiliza pouca água; } \\
\text { - pode ser operado por uma única pessoa; } \\
\text { - requer pouco tempo para medição; } \\
\text { - causa perturbações mínimas no solo; } \\
\text { - permite várias opções de análise e } \\
\text { - mede permeabilidades entre } 10^{-2} \text { e } 10^{-8} \mathrm{~cm} / \mathrm{s}\end{array}$ & $\begin{array}{l}\text { - em um meio poroso muito heterogêneo pode-se encontrar, } \\
\text { através da análise de Richards, valores irreais; } \\
\text { - medidas pontuais e } \\
\text { - pode subestimar os valores de K de acordo com a textura do } \\
\text { solo e a umidade antecedente devido à "impermeabilização" } \\
\text { do furo durante a tradagem. }\end{array}$ & $\begin{array}{l}\text { Reynolds e Elrick (1985a) } \\
\text { Reynolds } \text { et al. }(1985) \\
\text { Reynolds e Elrick (1985b) } \\
\text { Reynolds e Zebchuk (1996) } \\
\text { Salverda e Dane (1996) } \\
\text { Reynolds } \text { et al. (1983) }\end{array}$ \\
\hline Perfil Instantâneo & $\begin{array}{l}\text { - aplicado em perfis heterogêneos e } \\
\text { - bastante efetivo para medir diretamente as } \\
\text { propriedades hidráulicas que variam no campo. }\end{array}$ & $\begin{array}{l}\text { - lento e restrito a profundidades rasas e a solos bastante } \\
\text { permeáveis e } \\
\text { - por mensurar o fluxo em uma única direção, uma pequena e } \\
\text { rápida subida do nível de água e uma abrupta mudança da } \\
\text { textura do material ensaiado podem alterar os resultados. }\end{array}$ & $\begin{array}{c}\text { Stephens (1996) } \\
\text { Libardi (1995) } \\
\text { Paige e Hillel (1993) }\end{array}$ \\
\hline
\end{tabular}

* Trabalhos que utilizam os métodos e citam suas vantagens e desvantagens.

Fonte: Vieira (2001). 


\subsection{Método do Permeâmetro de Guelph}

Este método(instrumento/equações de fluxo), com recorrente utilização na investigação do comportamento do fluxo de água nos solos em campo, foi desenvolvido por Reynolds eElrick (1983) na University of Guelph, no Canadá, visto que os permeâmetros de carga constante utilizados em campo apresentavam muitos problemas (VIEIRA, 2001). Assim, desenvolveram um permeâmetro de furo e de carga constante que determina a condutividade hidráulica saturada de campo $\left(\mathrm{K}_{\mathrm{sat}}\right)$ acima do nível freático (REYNOLDS e ELRICK, 1985).

\subsubsection{O Permeâmetro: estrutura, funcionamento e potencialidades}

Sua estrutura é responsável por grande parte das vantagens apresentadas na literatura: é leve,é operável por uma pessoa e, causa mínimas perturbações no solo e,em relação aos outros métodos,utiliza pouca água, tem baixo custoe leva muito menos tempo para a obtenção dos resultados (REYNOLDS e ELRICK, 1985). Além disso, segundo Sotoet al. (2009),embora apresente algumas limitações teóricas e experimentais possui a mais aceita fundamentação teórica para inclusão da capilaridade na determinação de $\mathrm{K}_{\mathrm{sat}}$, que será apresentada adiante.

Além da $\mathrm{K}_{\text {sat }}$, o PG também permite que sejam mensurados simultaneamente outros parâmetros hidráulicos do solo, como a sorvidade (S), parâmetro que representa a capacidade de um meio para absorver água por capilaridade, a condutividade hidráulica não-saturada $\left(\mathrm{K}_{\text {ñsat }}\right)$, o fluxo de potencial matricial $\left(\phi_{\mathrm{m}}\right)$ e o parâmetro $\alpha$, uma constante que depende das demais propriedades do solo (REYNOLDS e ELRICK, 1985). 
As limitações teóricas e experimentais do PG podem ser explicadas por suas hipóteses: (i) a existência de um fluxo constante, (ii)a homogeneidade, isotropia e rigidez do meio poroso; (iii)a existência de um fluxo semi-infinito; e (iv) a não ocorrência de perturbações no padrão do fluxo (REYNOLDS et al., 1983).

O PG consiste em um tubo de Mariotte (Figura 2.8), que se divide em três partes: um tubo central que conecta o furo ensaiado à atmosfera; um tubo que conecta o reservatório ao furo ensaiado; e um terceiro reservatório, que possui duas partes: um interno, graduado, utilizado em ensaios com solos de baixa permeabilidade e um externo, que, ao ser conectado ao interno, é utilizado em ensaios em solos com alta permeabilidade. A saída de água do aparelho é feita a partir de uma seção perfurada, a qual pode ser preenchida com areia, para reduzir a turbulência causada pela saída do fluxo.

O aparelho é instalado após a abertura de um furo de diâmetro conhecido no solo (Figura 2.9). É necessário que toda a extremidade inferior do Guelph toque o fundo do furo. Deixa-se fluir a água dentro da perfuração, mantendo-se uma carga hidráulica constante e conhecida. A $\mathrm{K}_{\text {sat }}$ ocorre quando a absorção se equilibra quando a velocidade de percolação da água torna-se igual à velocidade de saída da água do aparelho. 


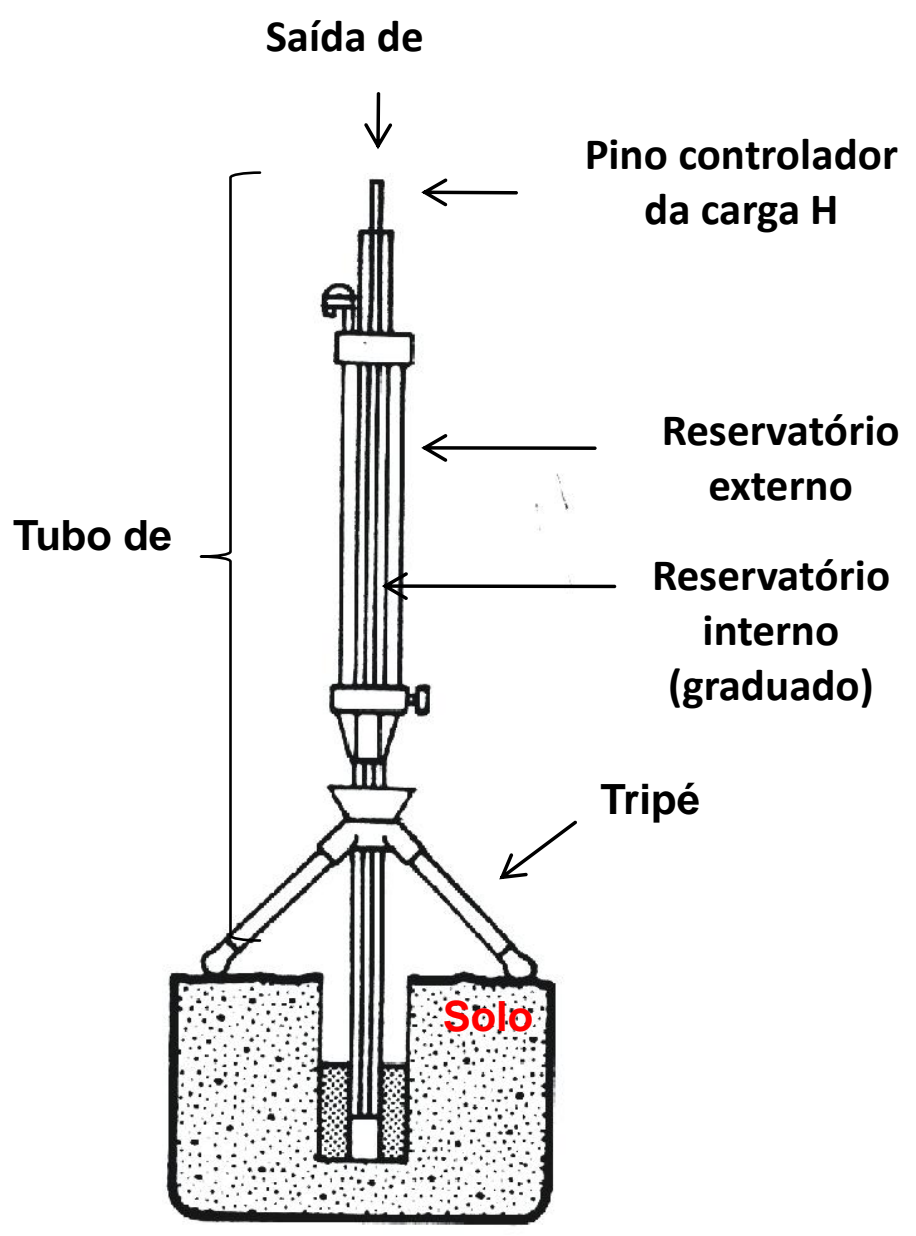

Figura 2.8. Desenho esquemático do Permeâmetro de Guelph (PG), com seus principais componentes. Fonte: modificado de Vieira (2001). 

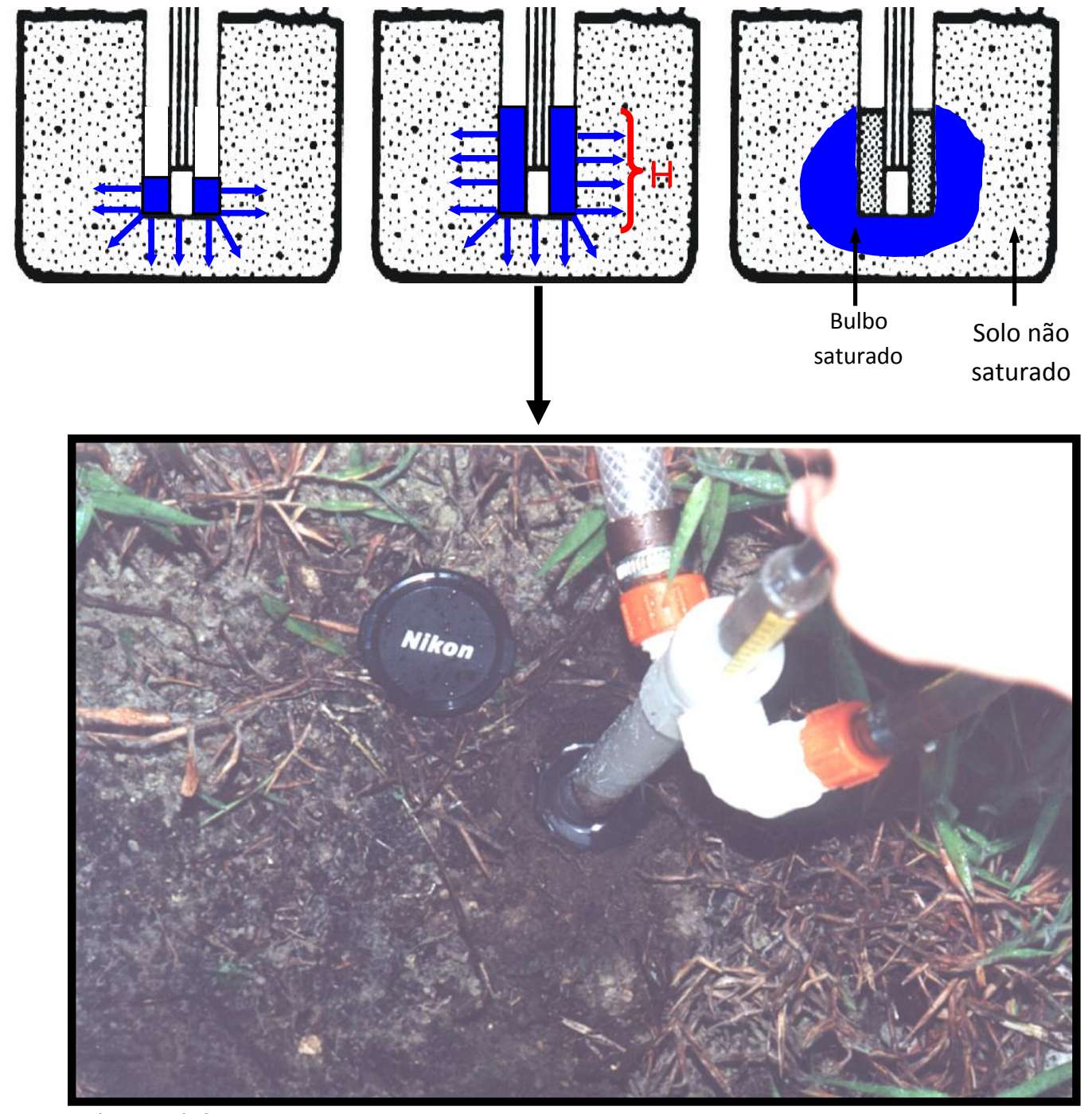

Figura 2.9.PG em uso para o levantamento da $K_{\text {sat }}$. Momento em que a água sai do equipamento para saturar o solo. Fonte:Vieira(2001). 


\subsubsection{Permeâmetro de Guelph Modificado (PGM)}

O Permeâmetro de Guelph (Figura 2.10)utilizado neste trabalho é uma versão adaptada do original, desenvolvido pelo Dr. Sidney Rosa Vieira, pesquisador do Instituto Agronômico de Campinas - IAC/SP. As modificações foram feitas no aparelho, pois,para o cálculo da condutividade hidráulica saturada dos solos, assim como das demais propriedades que podem ser medidas simultaneamente, são utilizadas as mesmas equações de fluxo desenvolvidas para o PG Original.

Considerando que poucos trabalhos no Brasil utilizaram ambas as versões, Vieira (2001),ao utilizá-las, apresentou as vantagens do PGM em relação ao PG, destacando-se: (i) o tripé do PGM foi modificado para conseguir sustentar o equipamento, evitando a compactação da base do furo; (ii) o PGM possui menos acessórios de montagem, facilitando seu transporte e utilização no campo; e (iii) é um corpo único, não necessitando de muitas conexões, o que o torna mais seguro, pois minimiza a possibilidade de entrada de ar no sistema.Além disso, o tripé estendível permite que sejam realizados ensaios em declividades muito acentuadas, assim como o fato do PGM ser um corpo único facilita a montagem do aparelho, otimizando o tempo. 


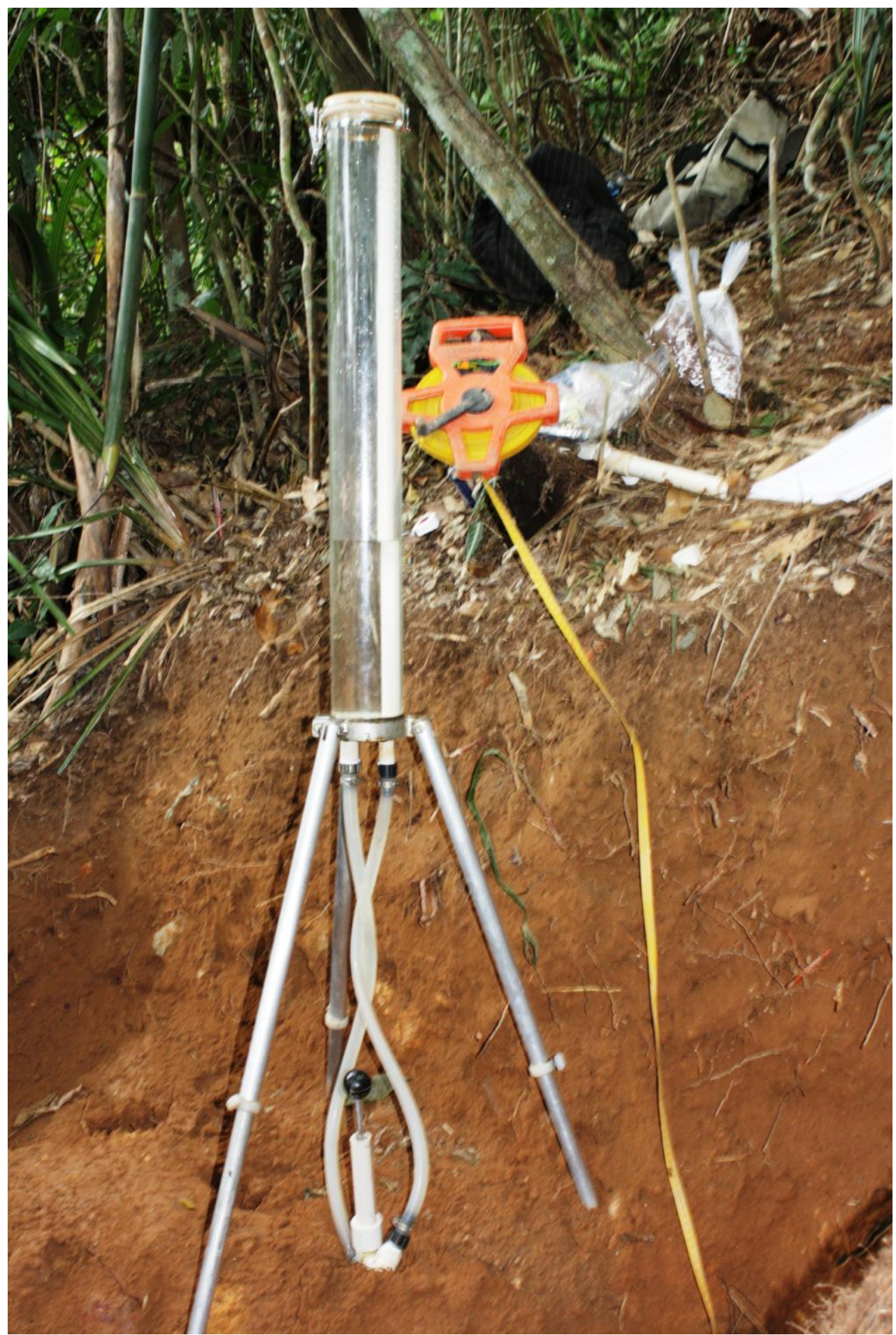

Figura 2.10. Permeâmetro de Guelph Modificado (PGM). Observa-se sua estrutura simples, como um único reservatório de água e apenas 4 conexões entre a ponteira e o reservatório de água e o tubo de saída de ar. O tripé maior e estendível é outra vantagem em relação ao PG Original. 


\subsubsection{Equações de fluxo}

De acordo com Reynolds e Elrick (1987), a recarga de um pequeno furo (no qual uma profundidade constante de água é colocada) em um solo não saturado é um processo de infiltração tridimensional, que deveria alcançar o estado constante rapidamente em uma região finita de umedecimento. As três direções preferenciais do fluxo são: umna parede do furo e os outros dois no fundo do furo, um deles o fluxo vertical de pressão e o outro o fluxo de gravidade (REYNOLDS et al., 1983).

Os referidos autoresaprimorarama equação já aplicada para a mensuração no campo por meio do método do permeâmetro de furo (Well Permeameter Method), a partir dos 3 fluxos na parede e base do furo, a Lei de Darcy e os parâmetros geométricos do furo (Equação 2). O desenvolvimento destas equaçõessão apresentadas em Reynolds et al. (1983).

$$
\mathrm{K}_{\mathrm{sat}}=\frac{\mathrm{CQ}}{2 \pi \mathrm{H}^{2}\left[1+\frac{\mathrm{C}}{2}\left(\frac{\mathrm{a}}{\mathrm{H}}\right)^{2}\right]}
$$

onde,

$\mathrm{K}_{\text {sat }}-$ condutividade saturada [L/T]

$\mathrm{C}$ - constante de proporcionalidade adimensional

Q- fluxo constante medido no campo $(\mathrm{Q}=\mathrm{R} \times \mathrm{A})\left[\mathrm{L}^{3} / \mathrm{T}\right]$

$\mathrm{H}$ - carga constante aplicada [L]

$\mathrm{a}$ - raio do furo [L] 
O parâmetro C é uma variável que descreve a distribuição do gradiente de pressão em torno do furo, que está diretamente associado à carga aplicada no furo (H), ao raio do furo (a) e com uma dependência secundária das características dos solos(Figura 2.11).A obtenção deste parâmetro pode se dar por meio de soluções analíticas ou numéricasReynolds et al. (1983), sendo que a última se mostra apropriada e prática, visto que os dados necessários são obtidos no campo e definem melhor as condições de contorno (VIEIRA, 2001).

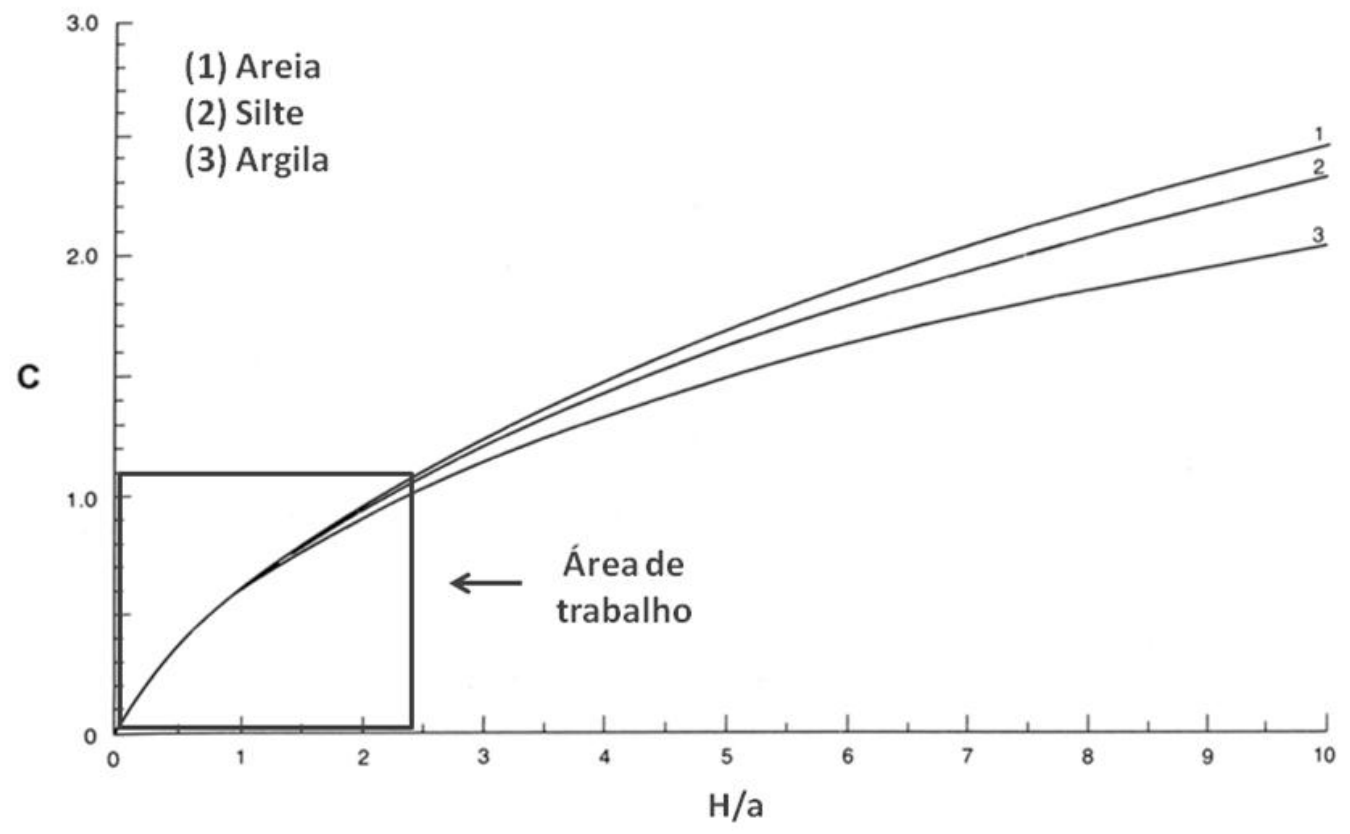

Figura 2.11. Variação do parâmetro $\mathrm{C}$ em relação à razão entre a carga aplicada $(\mathrm{H})$ e o raio do furo (a) e as curvas de diferentes texturas de solos. Destaca-se que os valores de $\mathrm{C}$ se encontram na área demarcada como área de trabalho. Fonte: modificada de Reynolds e Elrick(1985). 
Embora a Equação 2tenha sido adaptada para seu emprego quando o fluxo Q é obtido com o Permeâmetro de Guelph, as condições de campo ainda precisavam ser melhor interpretadas matematicamente. Desta forma, alguns métodos interpretativos foram desenvolvidos para que os valores de $\mathrm{K}_{\text {sat }}$ fossem mais representativos da realidade.

Reynolds eElrick (1985) apresentaram uma solução da Equação 2 baseada em Laplace $\left(\mathrm{K}_{\mathrm{sat}}-\mathrm{L}\right)$. A solução apresentada utiliza apenas uma carga de pressão He não considera os efeitos da capilaridade no entorno do bulbo de saturação criado durante o ensaio (Equação 3).

$$
\mathrm{K}_{\mathrm{sat}}=\frac{\mathrm{CQ}}{\left(2 \pi \mathrm{H}^{2}+\mathrm{C} \pi \mathrm{a}^{2}\right)}
$$

Considerando que a principal desvantagem apontada na análise baseada em Laplace advém do fato de serem ignoradas as propriedades capilares, Reynolds $e t$ al. (1985) reelaboraram a Equação 2, desta vez incluindo o efeito da capilaridade, o que foi possível a partir da análise da equação de Richards $\left(\mathrm{K}_{\mathrm{sat}}-\mathrm{R}\right)$ para fluxos permanentes tridimensionais em solos não saturados.A nova equação só foi possível a partir da inserção de outra variável, que representa o potencial matricial do solo $\left(\phi_{\mathrm{m}}\right)($ Equações 4,5 e 6), sendo que na Equação 4 a vazão Q é composta por duas parcelas - a primeira corresponde ao fluxo saturado e a segunda ao fluxo não saturado (Equação 7).

$$
\mathrm{Q}=\mathrm{AK}_{\mathrm{fs}}+\mathrm{B} \Phi_{\mathrm{Gm}}(4)
$$




$$
\begin{aligned}
& \mathrm{A}=\left(2 \pi \mathrm{H}^{2}\right) / \mathrm{C}+\pi \mathrm{a}^{2}(5) \\
& \mathrm{B}=(2 \pi \mathrm{H}) / \mathrm{C}(6) \\
& \mathrm{Q}=\left[\left(\frac{2 \pi \mathrm{H}^{2}}{\mathrm{C}}\right)+\pi \mathrm{a}^{2}\right] \mathrm{K}_{\mathrm{sat}}+\left(\frac{2 \pi \mathrm{H}}{\mathrm{C}}\right) \phi_{\mathrm{m}}(7)
\end{aligned}
$$

Conforme mencionado, a incorporação de uma variável que representa o potencial matricial resulta em uma equação com duas variáveis $-\mathrm{K}_{\mathrm{sat}} \mathrm{e} \phi_{\mathrm{m}}$., o que inviabiliza a mensuração de ambas diretamente. Assim, Reynolds et al. (1985) propõem a resolução da Equação7 por meio da utilização de duas equações (Equação 8 e 9) simultâneas, isto é, aplicando-se duas cargas constantes $\left(\mathrm{H}_{1}\right.$ e $\left.\mathrm{H}_{2}\right)$ no mesmo furo, o que forneceria dois valores de fluxo $\left(\mathrm{Q}_{1}\right.$ e $\left.\mathrm{Q}_{2}\right)$, respectivamente.

$$
\begin{aligned}
& \mathrm{Q}_{1}=\left[\left(\frac{2 \pi \mathrm{H}_{1}^{2}}{\mathrm{C}_{1}}\right)+\pi \mathrm{a}^{2}\right] \mathrm{K}_{\mathrm{sat}}+\left(\frac{2 \pi \mathrm{H}_{1}}{\mathrm{C}_{1}}\right) \phi_{\mathrm{m}}(8) \\
& \mathrm{Q}_{2}=\left[\left(\frac{2 \pi \mathrm{H}_{2}^{2}}{\mathrm{C}_{2}}\right)+\pi \mathrm{a}^{2}\right] \mathrm{K}_{\mathrm{sat}}+\left(\frac{2 \pi \mathrm{H}_{2}}{\mathrm{C}_{2}}\right) \phi_{\mathrm{m}}(9)
\end{aligned}
$$


A solução das Equações 8 e 9 para o cálculo da $K_{\text {sat }}$ é expresso pela Equação 10, que utiliza os parâmetros G1 e G2, calculados a partir das Equações 11 e 12.

$$
\begin{gathered}
\mathrm{K}_{\text {sat }}=\mathrm{G}_{2} \mathrm{Q}_{2}-\mathrm{G}_{1} \mathrm{Q}_{1} \\
\mathrm{G}_{1}=\frac{\mathrm{H}_{2} \mathrm{C}_{1}}{\pi \mathrm{H}_{1} \mathrm{H}_{2} \mathrm{H}_{2}-\mathrm{H}_{1}+\mathrm{a}^{2} \mathrm{H}_{1} \mathrm{C}_{2}-\mathrm{H}_{2} \mathrm{C}_{1}=} \\
\mathrm{G}_{2}=\frac{\mathrm{H}_{1} \mathrm{C}_{2}}{\pi \mathrm{H}_{1} \mathrm{H}_{2} \mathrm{H}_{2}-\mathrm{H}_{1} \mathrm{a}^{2} \mathrm{H}_{1} \mathrm{C}_{2}-\mathrm{H}_{2} \mathrm{C}_{1}^{-}=}
\end{gathered}
$$

A incorporação do potencial matricial do solo no cálculo da $\mathrm{K}_{\mathrm{sat}}$ representouum grande avanço para os trabalhos que se interessam por este parâmetro hidrológico dos solos na condição de saturação natural. A importância da capilaridade na vazão Q aumenta quanto mais fino for o solo (REYNOLDS e ELRICK, 1985), demonstrado no referido trabalho por meio de comparação entre mensuração da $\mathrm{K}_{\text {sat }}$ em campo com o PG (análises de Laplace e Richards) e em laboratório em amostras de solo franco. Quando são avaliados os valores da $\mathrm{K}_{\text {sat }}$ vertical e horizontal (em laboratório) e $\mathrm{K}_{\mathrm{sat}}-\mathrm{L}$ e $\mathrm{K}_{\mathrm{sat}}-\mathrm{R}$, observa-se que as amostras com maiores permeabilidades (análise de Laplace) apresentaram valores entre os mensurados nas amostras verticais e horizontais, enquanto as de menores 
permeabilidades (análise de Laplace) tiveram seus valores muito próximos aos das amostras verticais, denotando a importância da capilaridade. Quando são analisados os resultados da análise de Richards esta tendência não é observada entre os resultados de campo e de laboratório.No entanto, as hipóteses do método, em muitos casos, não concordam com ascondições observadas no campo, sobretudo a heterogeneidade e anisotropia do meio poroso, o que leva a aplicação desta análise a fornecer valores irreais da $\mathrm{K}_{\mathrm{sat}}$, como a alta porcentagem de resultados negativos. De acordo com Amoozegar (1989), qualquer diferença significativa entre os valores de $\mathrm{K}_{\text {sat }}$ para as duas cargas implica em heterogeneidades no bulbo saturado.Uma das soluções propostas por Reynolds et al. (1985) foi a utilização de três ou mais cargas $\left(\mathrm{H}_{1}, \mathrm{H}_{2}, \ldots \mathrm{H}_{\mathrm{i}}\right)$ a partir da Equação 7 , forma encontrada por Richards (1987, citado por Elricket al.,1989) para obter $98 \%$ de valores positivos em solo arenoso uniforme, neste caso, usando quatro níveis de carga $\mathrm{H}$.

Outra solução proposta parao cálculofoi elaborada por Elricket al.(1989), na qual foi inserido o parâmetro $\alpha\left[\mathrm{L}^{-1}\right]$ na Equação 3. Este parâmetro representa as características de textura e estrutura do solo, sobretudo a segunda (REYNOLDS e ELRICK, 1985). Seu valorselecionado em uma tabela elaborada a partir dos valores obtidos para $\alpha$ nos trabalhos desenvolvidos atéo momento da organização desta tabela(Tabela 2.1).Esta análise $\left(\mathrm{K}_{\mathrm{sat}}-\mathrm{U}\right)$ encontra-se descrita na Equação 13 e seu desenvolvimento pode ser consultado em Elricket al. (1989).

$$
\mathrm{K}_{\mathrm{sat}}=\frac{\mathrm{CQ}}{\left[2 \pi \mathrm{H}^{2}+\mathrm{C}^{2} \mathrm{a}^{2}+\left(\frac{2 \pi}{\alpha}\right)\right]^{(13)}}
$$


Tabela 2.1. Valores de $\alpha$ de acordo com as características dos solos ensaiados. Fonte: modificada de Reynolds et al.(1992).

\begin{tabular}{c|c}
\hline Características do meio poroso & $\begin{array}{c}\text { Valor do parâmetro } \alpha \\
\text { correspondente }\left[\mathbf{c m}^{-1}\right]\end{array}$ \\
\hline $\begin{array}{c}\text { Material argiloso compacto e estrutura como } \\
\text { sedimentosmarinhos }\end{array}$ & 0,01 \\
\hline $\begin{array}{c}\text { Solos com textura fina (argiloso) e sem estrutura } \\
\text { Solos estruturados argilosos e siltosos e também areias } \\
\text { finas e solos razoavelmente estruturados }\end{array}$ & 0,04 \\
\hline $\begin{array}{c}\text { Areias grossas e cascalhos. Podem ser incluídos solos } \\
\text { altamente estruturados com grandes fraturas e macroporos }\end{array}$ & 0,36 \\
\hline
\end{tabular}

\subsection{Propriedades físicas e hidrológicas dos solos e os escorregamentos rasos}

Os escorregamentos rasos, assim como outras tipologias de movimentos de massa e os processos erosivos, são, em muitos casos, controlados pelo comportamento da água no solo. A condutividade hidráulica dos solos (K)fornece informações fundamentais sobre este comportamento, principalmente quando estes dados são espacializados, tanto lateral quanto verticalmente.

Alguns trabalhos obtiveram resultados satisfatórios quandoempregaramo PG para mensurar a $\mathrm{K}_{\mathrm{sat}} \mathrm{e}$ utilizaram os valores obtidos para avaliar o seu comportamento em relação aos escorregamentos nas encostas.Campos et al. (1992a), procurando entender $\mathrm{o}$ processo de infiltração em solos não-saturados, desenvolveram um trabalho cujo objetivo foi determinar os parâmetros permeabilidade saturada $\left(\mathrm{K}_{\mathrm{fs}}\right)$ e não-saturada $(\alpha)$, que são utilizados na representação do comportamento da condutividade hidráulica em solos não saturados. Os ensaios foram realizados em uma encosta no Maciço da Tijuca, Rio de Janeiro, constituída 
por um horizonte superficial de solo maduro, com espessura média de 1,0m, sobrejacente a uma camada espessa de solo residual gnáissico de matriz arenosa. Os ensaios foram realizados até a profundidade de $3,0 \mathrm{~m}$, tendo sido elaborados dois perfis de permeabilidade, cada um com seis profundidades diferentes.

Os resultados obtidos (Figura 2.12) mostram que tanto a permeabilidade saturada quanto a nãosaturada apresentaram a mesma tendência de variação com a profundidade, ou seja, uma diminuição significativa entre 1,0 e 2,0 m. Em ambos, uma zona mais permeável ocorre aparentemente nas proximidades do contato solo maduro-solo saprolítico. Segundo os autores, esta tendência de diminuição pode ser decorrente das características granulométricas do contato solo maduro mais argiloso e solo saprolítico mais arenoso, além da lixiviação de ácidos no solo maduro e efeitos de raízes na superfície do terreno.Os autores ainda destacam a praticidade do PG em relação à pequena quantidade de água utilizada no ensaio, bem como a rapidez em sua execução (CAMPOS et al., 1992a). 

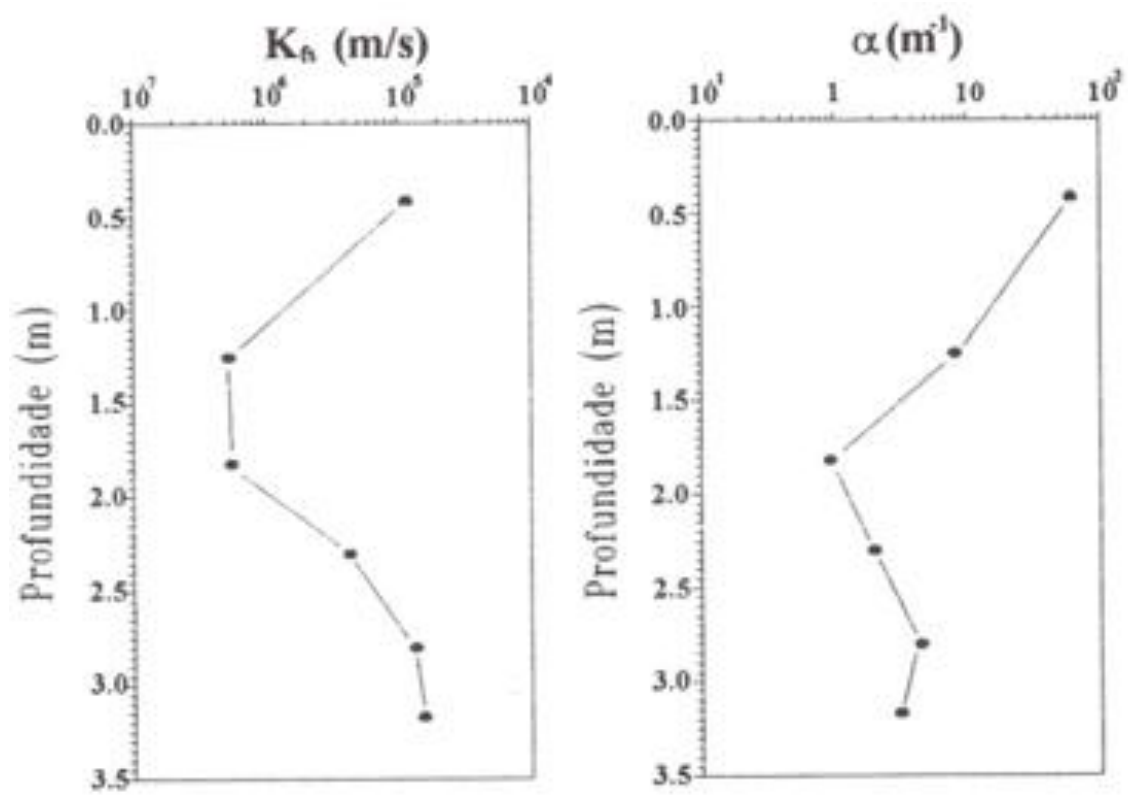

Figura 2.12. Variação da permeabilidade saturada $\left(K_{\mathrm{fs}}\right)$ e nãosaturada $(\alpha)$ com a profundidade. Nota-se que ambas apresentam comportamento semelhante- a brusca descontinuidade entre $1.0 \mathrm{e}$ $2.0 \mathrm{~m}$. Este ensaio ratifica a utilização do PG para mensuração dos referidos parâmetros, em profundidade e pequeno intervalo de tempo.Fonte: Camposet al., (1992a).

$\mathrm{Na}$ tentativa de identificar o papel desempenhado pelas descontinuidades hidráulicas na deflagração dos escorregamentos ocorridos em 1996, na bacia do rio Papagaio, Rio de Janeiro, Vieira eFernandes (2004) caracterizaram a variabilidade espacial na $\mathrm{K}_{\mathrm{sat}}$ dos solos em quatro cicatrizes, nas profundidades de 0,3 m, 0,6m, 0,9m, 1,2m, 1,5m, 2,0m, 2,5m e 3,0m, utilizando o PG. Para complementar a caracterização, foram coletadas amostras para a análise das propriedades físicas dos solos nas mesmas profundidades. Os valores obtidos nos ensaios variaram, em sua maioria, entre duas ordens de grandeza $\left(1,0 \times 10^{-5} \mathrm{a} 1,0 \times 10^{-6} \mathrm{~m} / \mathrm{s}\right)$. Alguns pontos não apresentaram variação ao longo do perfil, enquanto outros apresentaram variações significativas dos valores da $\mathrm{K}_{\mathrm{sat}}$ e das demais propriedades dos solos. Observou-se, em um dos pontos, que houve um forte aumento da $\mathrm{K}_{\mathrm{sat}}$ entre 0,6 e $0,9 \mathrm{~m}$ de 
profundidade (de $3,27 \times 10^{-7}$ para $1,90 \times 10^{-5} \mathrm{~m} / \mathrm{s}$ ) (Figura 2.13). Tal comportamento foi acompanhado por um acréscimo de macroporos neste mesmo intervalo (de 6,28 para $11,11 \%)$.
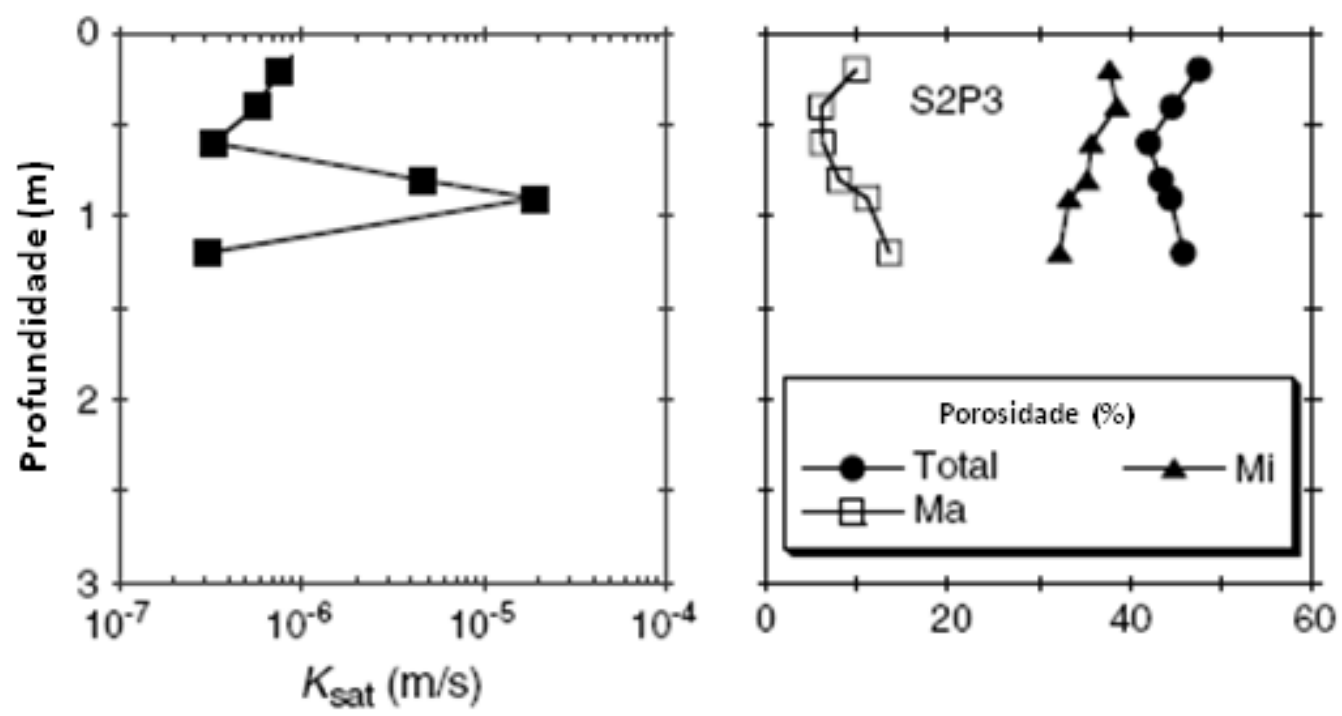

Figura 2.13. Variação da $\mathrm{K}_{\text {sat }}$ em profundidade. A macroporosidade (Ma) apresenta a mesma tendência da $\mathrm{K}_{\text {sat }}$ entre as profundidades de 60 e $90 \mathrm{~cm}$. No entanto, entre os 90 e $120 \mathrm{~cm}$, não há uma correlação positiva entre a $\mathrm{K}_{\text {sat }}$ ea macroporosidade. Fonte: modificada de Vieira e Fernandes(2004).

Seguindo esta mesma linha, Shoaeie Sidle (2009), desenvolveram seu trabalho buscando compreender os possíveis condicionantes pedológicos e hidrológicos na deflagração de inúmeros deslizamentos e corridas de detritos em uma região de topografia suave e de intensidade baixa de chuvasnas proximidades da cidade de Ogaya, no Japão. Trata-se de uma região que foi ocupada há mais de 14.000 a.C. por uma comunidade mesolítica, que praticava extensivamente a 
queimada das florestas, cujo produto se acumulou nos hollows existentes na região. A caracterização pedológica e da $\mathrm{K}_{\mathrm{sat}}$, ambas em laboratório, mostrou a existência de algumas camadas deste material, ricas em matéria orgânica, onde os valores de $\mathrm{K}_{\mathrm{sat}}$ são os mais baixos encontrados nos perfis. Além disso, observou-se que nos perfis analisados, a primeira camada negra estavaimediatamente abaixo de uma camada com a maior concentração de argila dos perfis (próximo a 1,2 m de profundidade). Os autores afirmaram que esta configuração pedológica/hidrológica deve ter provocado, quando de um acumulado de chuva muito maior que o registrado nos anos anteriores, a geração de um nível freático elevado temporário, e consequentemente, de poro-pressões positivas, levando às rupturas.

Com o objetivo de compreender os efeitos do tamanho dos grãos de minerais do embasamento na estrutura das camadas de solos e o período de retorno de rupturas rasas nos solos próximo de Seul, na Coreia do Sul, Wakatsukiet al. (2005) realizaram uma caracterização das propriedades físicas, mecânicas, mineralógicas,químicas e da $\mathrm{K}_{\text {sat }} \mathrm{em}$ amostras de solos e rochas do topo de uma cicatriz e do plano de ruptura. O trabalho mostrou que as taxas de intemperismo foram maiores no granito e que a profundidade das superfícies potenciais de ruptura se encontram entre 80 e $90 \mathrm{~cm}$ nos granitos e 120 a $180 \mathrm{~cm}$ nos gnaisses. Analisando os valores de $\mathrm{K}_{\mathrm{sat}}$ em cada um dos materiais, observou-se que, em ambas as profundidades consideradas como críticas para ruptura,apresentaram-se tendências de diminuição seguidas por um aumento brusco. Além disso, os autores sugerem que o período de retorno de ocorrência de rupturas rasas nos solos deveria ser menor nas encostas constituídas de granitosdo que nas de gnaisses.Neste sentido, AhrendteZuquette (2003), também procuraram entender a influência da precipitação como um fator deflagratório dos escorregamentos rasos em Campos do Jordão/SP. 
Por meio da identificação e análise dos mecanismos e fatores naturais que os controlam, caracterizaramos materiais inconsolidados e a $\mathrm{K}_{\mathrm{sat}}$ em laboratório e esta última também em campo, tendo sido utilizado o método do duplo cilindro. Estas investigações permitiram aos autores afirmar que a superfície de ruptura ocorreu frequentemente entre camadas silto-arenosas e argilo-arenosas, cujas permeabilidades, em média, apresentam de 1 a 2 ordens de grandeza de diferença $\left(10^{-4}\right.$ a $10^{-6} \mathrm{~m} / \mathrm{s}$, embora os ensaios não tenham sido realizados em profundidade nos perfis).

Os trabalhos aqui citados demonstram que as variações nas propriedades dos solos têm importantes implicações na estabilidade das encostas, sobretudo as propriedades hidrológicas.Benessiutie Bernardes (2011) apresentaram uma investigação dos mecanismos de escorregamentos rasos que ocorreram na bacia do Ribeirão Guaratinguetá, Vale do Paraíba/SP. O estudo compreendeu as propriedades físicas, hidráulicas e mecânicas dos escorregamentos, neste caso, em encostas constituídas de migmatitos homogêneos e gnaisses bandados. Os ensaios realizados em cinco profundidades na lateral de um dos taludes mostraram que a $\mathrm{K}_{\mathrm{sat}}$ é mais baixa na camada superficial do solo, aumentando ao longo do perfil. $\mathrm{Na}$ profundidade referente ao plano de ruptura existente $(1,5 \mathrm{~m})$, há uma diminuição no seu valor.

Estes trabalhos mostram a relação da variação da condutividade hidráulica saturadas dos solos com a ocorrência ou com os planos potenciais de ruptura de escorregamentos translacionais rasos. Além disso, o grande número de trabalhos sobre esta tipologia de movimento de massaindica que estes ocorrem preferencialmentena profundidade média de $1,5 \mathrm{~m}$, conforme apontado nos manuais teóricos sobre movimentos de massa. 


\section{3 ÁREA DE ESTUDO}

A área selecionada para o desenvolvimento desta pesquisa, como mencionado anteriormente, pertence ao município de Caraguatatuba, Litoral Norte do Estado de São Paulo. A bacia do rio Guaxinduba abrange uma área de aproximadamente $24 \mathrm{~km}^{2}$, sendo que a maior parte se localiza nas escarpas da Serra do Mar, com a drenagem em direção ao oceano.

A referida bacia, assim como todo o município de Caraguatatuba, em março de 1967, foi atingida por chuvas intensas, que deflagraram inúmeros escorregamentos rasos e corridas de detritos, que alcançaram um raio de $3 \mathrm{~km}$ (CRUZ, 1974). Alguns dos condicionantes biofísicos que levaram à ocorrência destes fenômenos serão apresentados neste capítulo, assim como uma caracterização geral do meio biofísico da Serra do Mar (SP) e da área em questão, tratando dos aspectos geológicos, geomorfológicos, pedológicos, hidrológicos, climatológicos e fitogeográficos, informações relevantes para o desenvolvimento deste trabalho.

\subsection{Serra do Mar}

O Cinturão Orogênico do Atlântico compõe a costa sul e sudeste do Brasil, e possui um papel preponderante na evolução geomorfológica regional. Trata-se de um rebordo de planalto, que segue sob a forma de escarpas íngremes em direção ao mar (TITARELLI, 1986). É resultado de sistemas de falhamentos transcorrentes, normais e inversos, dispostos preferencialmente na direção ENE, os quais definem um sistema de riftes continentais (AB'SÁBER, 1956; ALMEIDA, 1974; TITARELLI, 1986; ALMEIDA eCARNEIRO, 1998). Segundo a maioria dos autores, são escarpas dissecadas dos blocos falhados, que já recuaram das posições 
originais, pela ação erosiva diferencial. A presença de milonitos evidencia a importância dos falhamentos na configuração da Serra do Mar (TITARELLI, 1986).

Além dos falhamentos, feições estruturais menores, como fraturas e foliações bem delimitadas, preferencialmente no sentido NE-SW, também desempenham papel fundamental no desenvolvimento das feições (ALMEIDA e CARNEIRO, 1998).

A ampla variedade de tipos litológicos do embasamento também registra a complexa origem e evolução da Serra. Associações migmatíticas e metamórficas, bem como inúmeros complexos ígneos coexistem ao longo de toda a Serra do Mar. De acordo com Titarelli (1986), as maiores saliências coincidem com corpos graníticos ou intrusões básicas (andesito, diabásio), seguindo-se os quartzitos e até calcários como sustentadores dos relevos enérgicos.

Nesse contexto geológico e estrutural, sob a ação de clima ora mais seco, ora mais úmido, se desenvolveram as feições geomorfológicas características da Serra do Mar (ALMEIDA e CARNEIRO, 1998; IPT, 1986). O registro da coluna geológica quaternária costeira permite assegurar que, durante períodos mais secos e frios, a cobertura vegetal estava restrita a pequenos refúgios e o manto de alteração espesso (formado em períodos mais úmidos e quentes) ficava desprotegido e exposto a chuvas torrenciais concentradas e à ocorrência de movimentos de massa generalizados (IPT, 1986).

As feições geomorfológicas resultantes desse conjunto de fatores naturais na Serra do Mar paulista, de acordo com IPT (1986), são quatro: (I) Escarpa da borda do planalto, estabelecida a partir da ruptura de declive positiva contínua, interrompida pela drenagem; (II) espigões, caracterizados por topos angulosos e vertentes abruptas, dos quais podem partir espigões menores, cuja ocorrência está 
condicionada à rede de drenagem;(III) morros maiores no seu sopé,apresentando topos subarredondados a arredondados. Encontram-se nivelados aos níveis de aplainamento dos espigões da escarpa, com declividades médias a altas; e (IV) morros e morrotes isolados na planície costeira, que ocorrem no interior da mesma, apresentando, geralmente, formas convexas amplas, com encostas de baixa e média declividade.

A rede de drenagem nas escarpas apresenta tendência ao padrão dendrítico, embora muitas vezes sejam observadas drenagens que podem ser classificadas como padrão paralelo, refletindo as características lito-estruturais da área. Outra característica intrínseca à rede de drenagem da Serra é sua pequena extensão e seu regime torrencial (TITARELLI, 1986).

No que diz respeito à curvatura das encostas, IPT (1986) destacou que as encostas retilíneas são as mais freqüentes, e associam-se, majoritariamente, a declividades muito altas, quase verticais, próximas à borda do planalto. Encostas de perfil convexo são menos freqüentes, tendo seus limites superiores sempre definidos por uma ruptura de declive negativa. Nessas curvaturas freqüentemente são observados solos coluvionares e clastos grossos, configurando formas mais estáveis aos movimentos de massa e aos processos erosivos (Tabela 3.1). No entanto, elas contribuem com maior quantidade de material para possíveis instabilizações (SANTOS, 2004). Quanto à curvatura côncava, ressalta-se sua pequena freqüência em relação às demais, mas de grande importância para o entendimento dos processos hidrogeomorfológicos. 
Tabela 3.1. Resultados provenientes de avaliações de cicatrizes de escorregamentos.

\section{SITUAÇÕES DE MAIOR INSTABILIDADE}

\section{FEIÇÕES MORFOLÓGICAS E GEOLÓGICAS}

\section{FENÔMENOS MAIS COMUNS}

\begin{tabular}{|c|c|}
\hline $\begin{array}{l}\text { Encostas retilíneas (predominantemente) } \\
\text { ou convexas associadas a rupturas } \\
\text { positivas de declive, com inclinações } \\
\text { superiores a } 30^{\circ} \text { e desenvolvidas sobre } \\
\text { migmatitos e granitóidesembrechíticos }\end{array}$ & $\begin{array}{l}\text { Nessa situação, ocorrem principalmente } \\
\text { escorregamentos superficiais translacionais, que } \\
\text { constituem a grande maioria dos movimentos de } \\
\text { massa nas encostas dos morros. Ocorrem } \\
\text { naturalmente e induzidamente. }\end{array}$ \\
\hline $\begin{array}{l}\text { Encostas retilíneas ou convexas com } \\
\text { inclinações superiores a } 30^{\circ} \\
\text { desenvolvidas sobre o Granito Santos }\end{array}$ & $\begin{array}{l}\text { Ocorrem principalmente fenômenos de queda de } \\
\text { blocos, por condicionamento estrutural ou por } \\
\text { descalçamento de base em matacões superficiais. } \\
\text { Ocorrem induzidamente como conseqüência de } \\
\text { desmatamento e de descalçamento por erosão } \\
\text { superficial. }\end{array}$ \\
\hline $\begin{array}{l}\text { Encostas retilíneas com inclinações } \\
\text { superiores a } 30^{\circ} \text { e desenvolvidas sobre os } \\
\text { gnaisses estromatíticos }\end{array}$ & $\begin{array}{l}\text { Ocorrem principalmente os escorregamentos } \\
\text { profundos rotacionais; menos freqüentes nos morros, } \\
\text { mas de conseqüências sempre graves pelos volumes } \\
\text { de material envolvidos. Ocorrem induzidamente por } \\
\text { desmatamento e mutilações. }\end{array}$ \\
\hline $\begin{array}{l}\text { Encostas convexas cor } \\
\text { detríticos localizadas a } \\
\text { parte basal, com espes } \\
\text { granulométrica e incli }\end{array}$ & $\begin{array}{l}\text { Ocorrem movimentações lentas e contínuas, porém } \\
\text { constituindo regiões altamente sensíveis a mutilações } \\
\text { e a alterações na drenagem superficial, quando então } \\
\text { podem ser mobilizados grandes volumes. }\end{array}$ \\
\hline
\end{tabular}
Fonte: Santos(2004).

Segundo Santos (2004), nas encostas, as maiores espessuras de solos se encontram nas cristas dos espigões (perfil convexos) e nas "saias" das encostas já próximas ao talvegue (perfis côncavos). As menores espessuras estão no trecho da vertente, normalmente retilíneo. Ainda de acordo com o referido autor, nas condições apresentadas na Serra do Mar, a constituição e espessuras médias dos diferentes horizontes de solo variam muito, respondendo, além do posicionamento na encosta, à inclinação da vertente, ao histórico de movimentos de massa no local, à pluviosidade, ao tipo, textura e estrutura da rocha matriz. 
Wolle e Carvalho (1989), analisando os deslizamentos translacionais ocorrentes na Serra do Mar paulista, por meio de ensaios realizados in situ, elaboraram um esquema hipotético da configuração dos horizontes dos solos (Figura 3.1). Para os autores, a ruptura ocorreria no contato entre o solo coluvionar e o saprolítico.

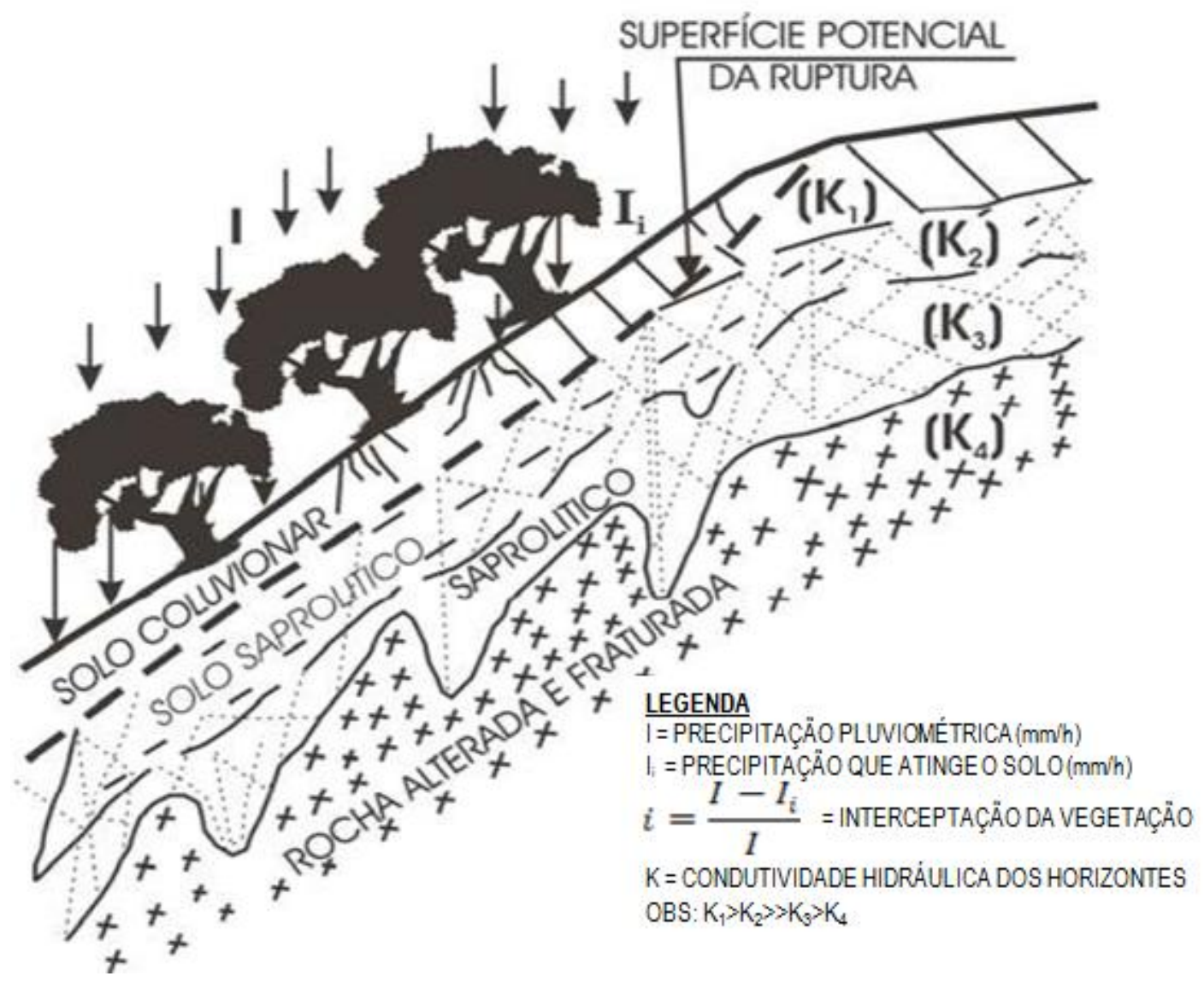

Figura 3.1. Esquema hipotético do perfil de uma das encostas que foram atingidas por escorregamentos translacionais rasos na Serra do Mar (SP). Fonte: Wolle e Carvalho (1989). 
Para Wolle e Carvalho (1989), os solos destas encostas, sobretudo na média e alta encostas, são porosos, intercalando entre argilo-arenoso ou arenoargiloso no horizonte superficial, com espessura média de $1 \mathrm{~m}$ e matriz arenosa ou siltosa no horizonte saprolítico, com espessuras variáveis ao longo do perfil. Essa disposição de materiais no perfil pode favorecer a percolação de água superficial ou subsuperficial, o que pode levar à ocorrência de processos erosivos e, em condições pré-estabelecidas de saturação, à deflagração dos escorregamentos.

Os índices pluviométricos, muitas vezes responsáveis pela deflagração dos escorregamentos na Serra do Mar paulista, estão diretamente associados à complexa interação entre circulação atmosférica e características topográficas, destacando-se a hipsometria e orientação da escarpa e demais encostas.

No que se refere às condições climáticas, Tatizanaet al. (1987) apontam para o predomínio do clima tropical chuvoso de selva, o qual não apresenta estações secas bem definidas. Segundo Monteiro (1973) e Conti (1975), este clima está condicionado às Massas Tropical Atlântica, quente e úmida, sobretudo no verão; Polar Atlântica, fria e úmida, ocorrendo no inverno; Equatorial Continental, quente e úmida, com maior atuação durante o verão; e Tropical Continental, quente e seca.

Observando as principais características de tais sistemas meteorológicos, nota-se que três das quatro massas que atuam na Serra são úmidas, responsáveis pela alta média anual pluviométrica, em torno de $3.300 \mathrm{~mm}$. Contudo, a distribuição espacial da precipitação não se dá de forma homogênea, uma vez que a topografia interfere na circulação atmosférica (MONTEIRO, 1973; CONTI, 1975; PELLEGATTI, 2008). 
Conforme a configuração da Serra do Mar, a precipitação aumenta na direção costa-interior, registrando, portanto, maiores índices nas partes mais altas da Serra (CONTI, 1975). Este comportamento confere um caráter predominantemente orográfico à precipitação da região (PELLEGATTI, 2008).

Tatizanaet al. (1987) definiram o número de dias anteriores que apresenta influência efetiva nos escorregamentos e a relação numérica entre o acumulado de chuva e intensidade horária para os casos de escorregamentos. Observaram-se que os escorregamentos estavam ligados a chuvas intensas associadas à alta pluviometria acumulada em 4 dias (Figura 3.2).

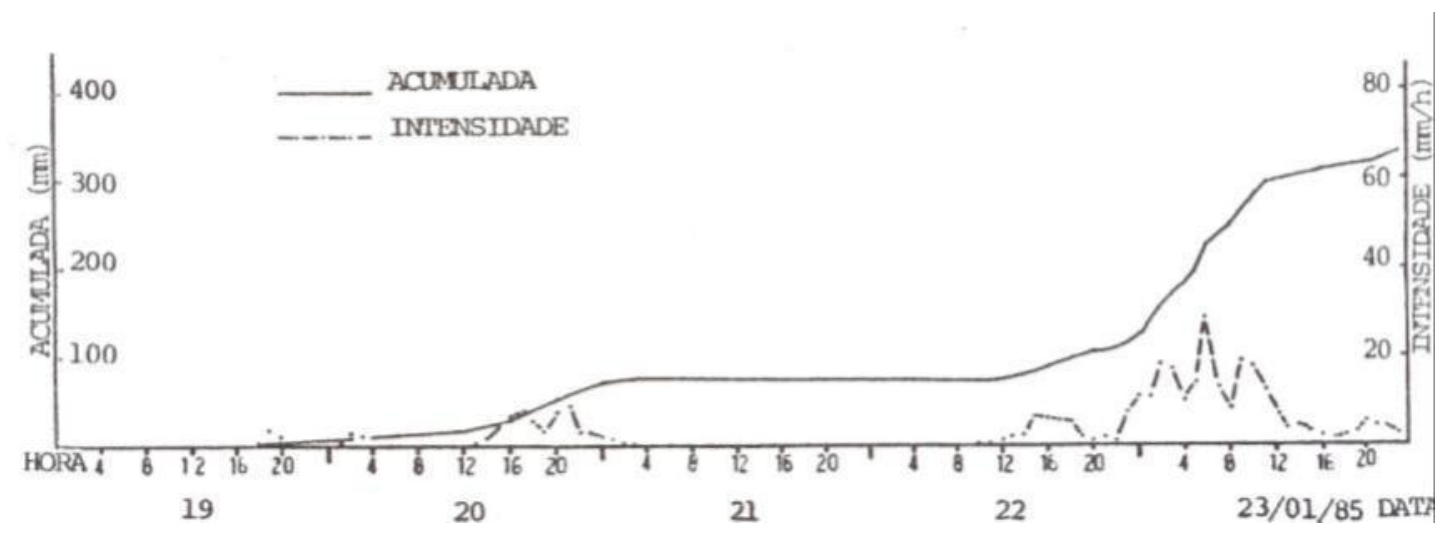

Figura 3.2. Gráfico do evento chuvoso de 23 de janeiro de 1985, em Cubatão-SP, relacionando acumulada pluviométrica e intensidade horária. Fonte:Tatizanaet al.(1987).

O recorte temporal apresentado no gráfico corresponde ao evento que deflagrou uma grande quantidade de escorregamentos translacionais rasos no vale do rio Moji, Cubatão-SP, nos dias 22 e 23 de janeiro de 1985. Nesse evento, postos pluviográficos na região registraram totais diários acima de 100mm. 
Embora os totais pluviométricos registrados tenham sido elevados, eventos semelhantes e até acumulados maiores não foram capazes de deflagrar escorregamentos coletivos, permitindo considerar que outro condicionante foi responsável pela ocorrência desses escorregamentos. De acordo com alguns autores como Prandiniet al. 1976; IPT, 1986; Wolle, 1986,a degradação da cobertura vegetal, ocasionada por sua exposição aos gases e particulados emitidos pelo pólo industrial de Cubatão, favoreceu a instabilização das encostas atingidas pelo evento pluviométrico em questão.

A cobertura vegetal na Serra é constituída por mata tropical atlântica ou floresta latifoliada úmida de encosta(Figura 3.3), se caracterizando por uma vegetação densa, predominando espécies de lenhosas de 20 a 30m de altura (IPT, 1986).

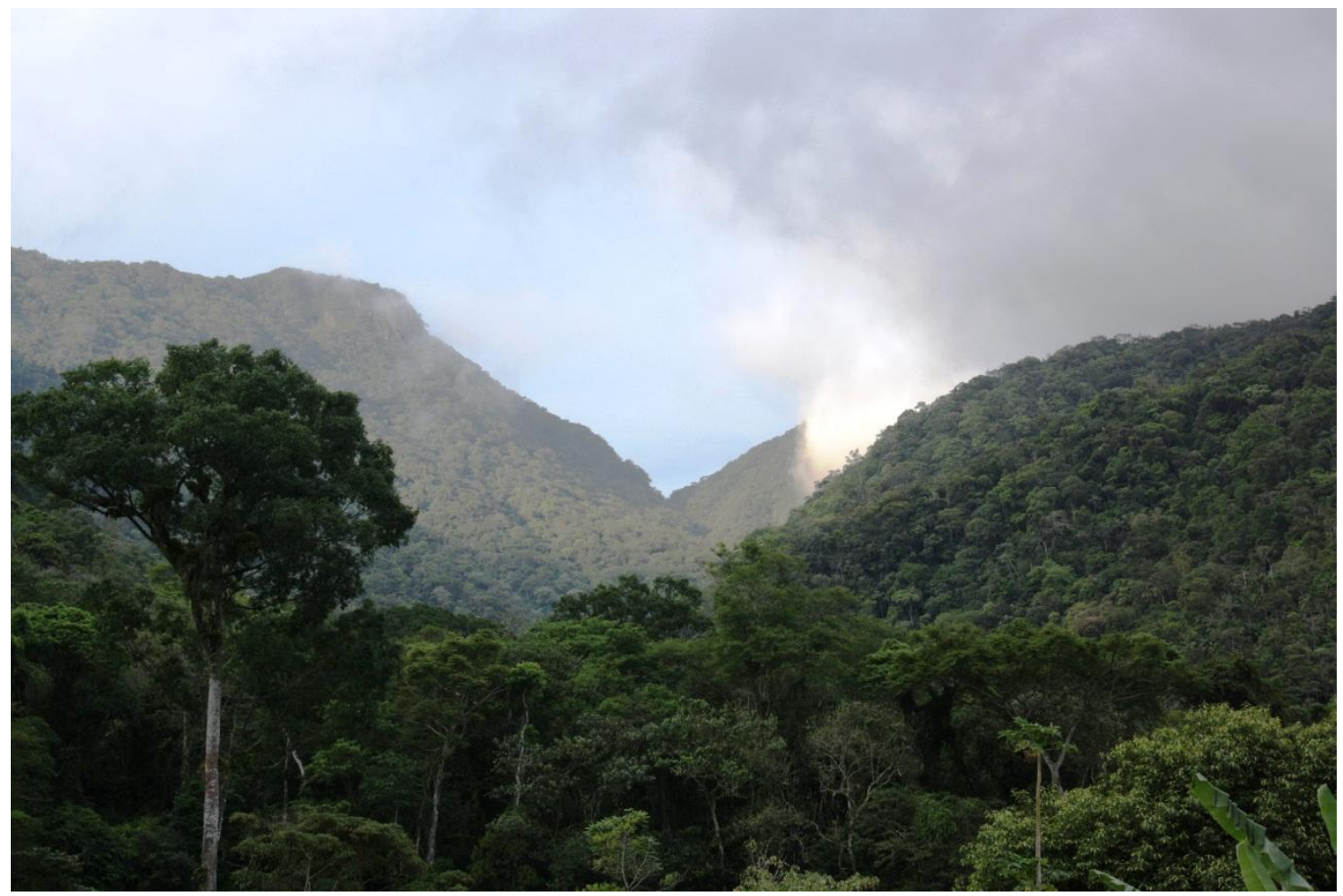

Figura 3.3. Encostas florestadas com vegetação densa e de grande porte. 


\subsection{Caraguatatuba/SP - Bacia do Rio Guaxinduba}

As adjacências do município de Caraguatatuba foram objeto de investigação geomorfológica minuciosa, sobretudo após os movimentos de massa catastróficos de março de 1967. Cruz (1974) desenvolveu sua pesquisa em Caraguatatuba, tendo por objetivo compreender a geomorfogênese do litoral na área em questão. Para tanto, era indispensável entender a evolução das escarpas da Serra do Mar. O resultado deste trabalho foi uma caracterização detalhada do meio físico, bem como dos processos atuantes em ambiente tropical.

Há de se destacar, primeiramente, a diferente configuração da Serra do Mar no município de Caraguatatuba, onde a escarpa recua para o interior e como conseqüência disso, o preenchimento desse anfiteatro serrano por uma vasta planície sedimentar, como mostra a Figura 3.4 (CRUZ, 1974). Para a autora, as maiores reentrâncias das escarpas da Serra de Caraguatatuba, que formam grandes alvéolos e recôncavos, podem ser atribuídas ao encontro e cruzamento das direções estruturais ou contatos de áreas de metamorfismo regional.

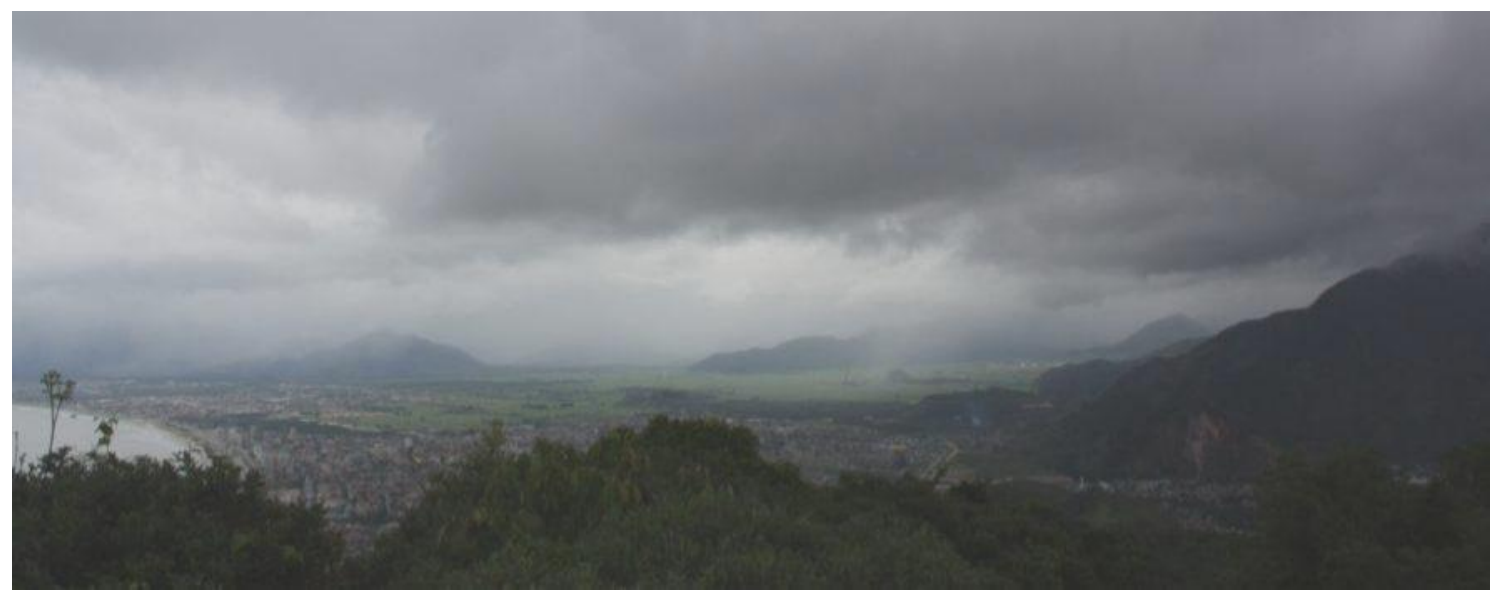

Figura 3.4. Recuo da Serra do Mar e planície sedimentar em Caraguatatuba-SP. 
No que se refere à litologia, são inúmeras as variedades petrográficas, muitas vezes originadas nas zonas de falhamentos e flexuras. As bordas do planalto são sustentadas por faixas de biotita-gnaisses e de gnaisses graníticos, intensamente dobrados e falhados (CRUZ, 1974). Foi elaborado um perfil geológico a partir da Paraibuna-Caraguatatuba (Rodovia dos Tamoios SP-99), cujas variedades litológicas presentes são as mais freqüentes nesse trecho da Serra. As sondagens e coletas de amostras revelam os litotipos Biotita gnaisse com intercalações de gnaisse micáceo, Gnaisse leptito, Gnaisse facoidal, diques de quartzo-diorito, de diabásio e e de diabásiomilonitizados, Migmatitos, Granitos gnaissificados e Granitos.

As variações dos tipos de rochas são interrompidas por uma série de falhas normais, fissuras, e diques intrusivos, originados por alívio de tensão, de direção geral NE-SW (CRUZ, 1974).

Nos cortes da estrada afloram rochas e mantos de alteração, tendo como principal material parental os gnaisses facoidal e leptito. Durante as campanhas de campo realizadas pela referida autora, foram verificadas algumas propriedades do produto da alteração dessas rochas, sendo o gnaisse leptito menos suscetível ao intemperismo químico. Constituído de material mais grosseiro, sustenta os morros mais altos e pontudos da área. Já o gnaisse facoidal é muito sensível ao intemperismo químico, constituindo um material muito friável e alterado, mas, que mantém a estrutura. Há afloramentos da rocha sã apenas nos talvegues e nas cachoeiras. A granulometria do material é mais argilosa, removida com facilidade por fortes chuvas. Núcleos arredondados mais resistentes surgem em meio às formações argilosas (CRUZ, 1974). 
Quanto à hidrografia, as bacias fluviais não apresentam expressão na sua extensão espacial, nem chegam a recuar suas cabeceiras além dos altos da Serra, salvo raras exceções. Contudo, a energia do fluxo advinda dos fortes declives serranos, marca a paisagem, entalhando vales profundos em $\mathrm{V}$, controlados pelas direções estruturais (CRUZ, 1974).

Essa é a paisagem que foi atingida por eventos pluviométricos severos em março de 1967, que causaram graves conseqüências catastróficas em todo o município. O verão de 1966/67 foi muito chuvoso, culminando com o episódio de 17 e 18 de março. Cruz (1974) relata que chovia desde o dia 16, aumentando as chuvas a partir das $18 \mathrm{~h}$ do dia 17 . Nas primeiras horas da manhã do dia 18 , começaram os deslizamentos generalizados (Figuras 3.5, 3.6, 3.7 e 3.8) culminando em uma avalanche por volta das $13 \mathrm{~h}$, que alargou o rio Santo Antônio de 10-20 para 60-80 metros (Figura 3.9).

O posto pluviométrico de Caraguatatuba registrou 945,6mm no mês de março de 1967(Figura 3.10). No dia 17 de março, foram medidos $115 \mathrm{~mm}$, e no dia 18, o mais crítico, foram registrados $420 \mathrm{~mm}$, não acusando índice maior devido à saturação do pluviômetro(Figura 3.11). 


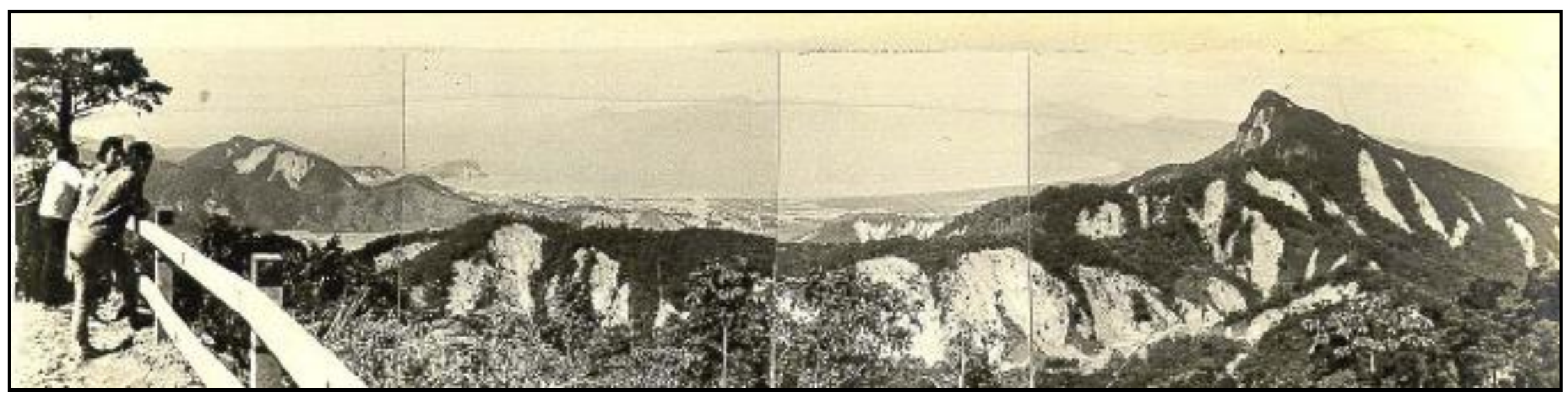

Figura 3.5. Vista da Rodovia dos Tamoios para a enseada de Caraguatatuba, de onde se observavam as cicatrizes dos escorregamentos ocorridos no ano de 1967. Fonte: O. Cruz e Prof. Nogamiapud Gramani (2001). 


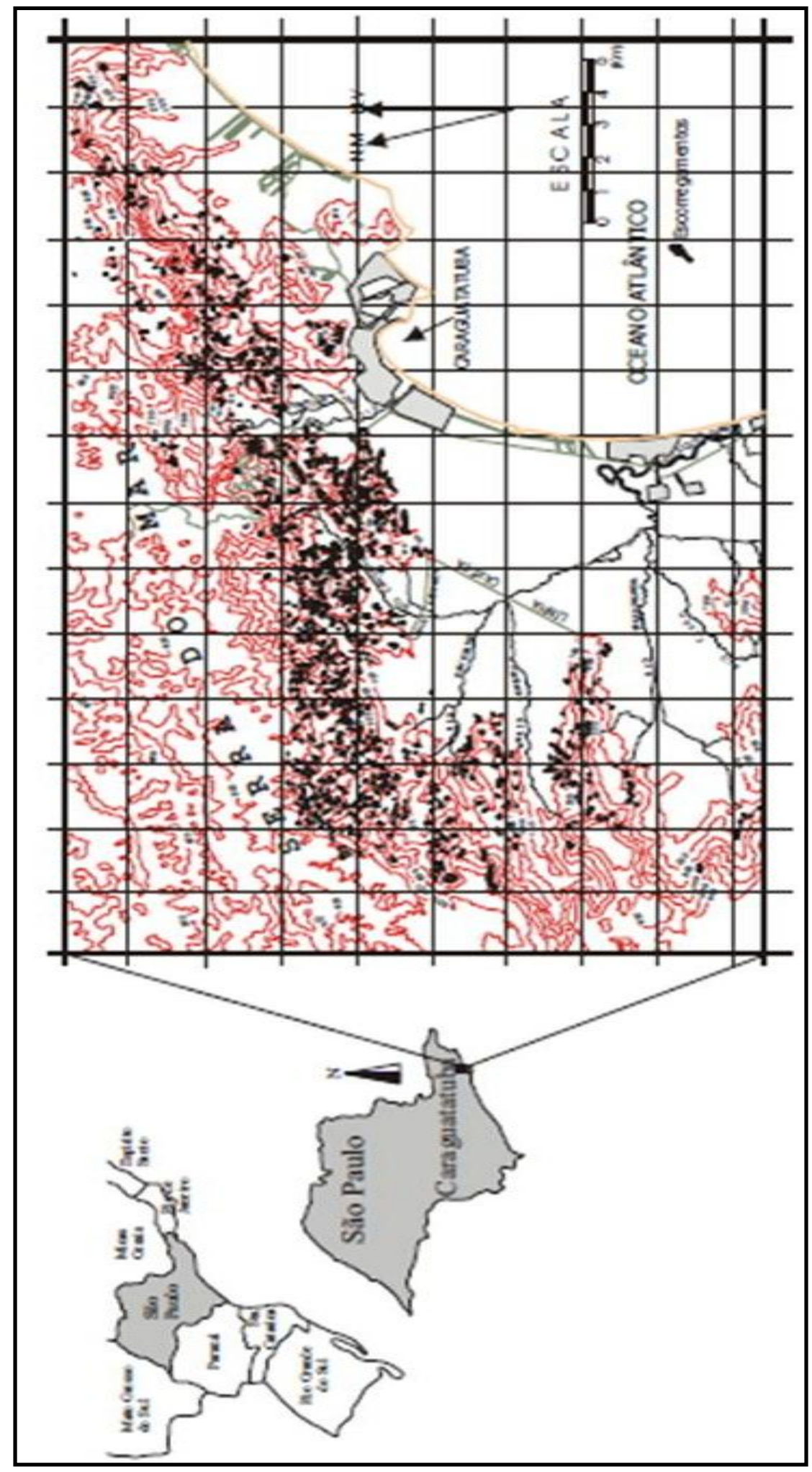

| 


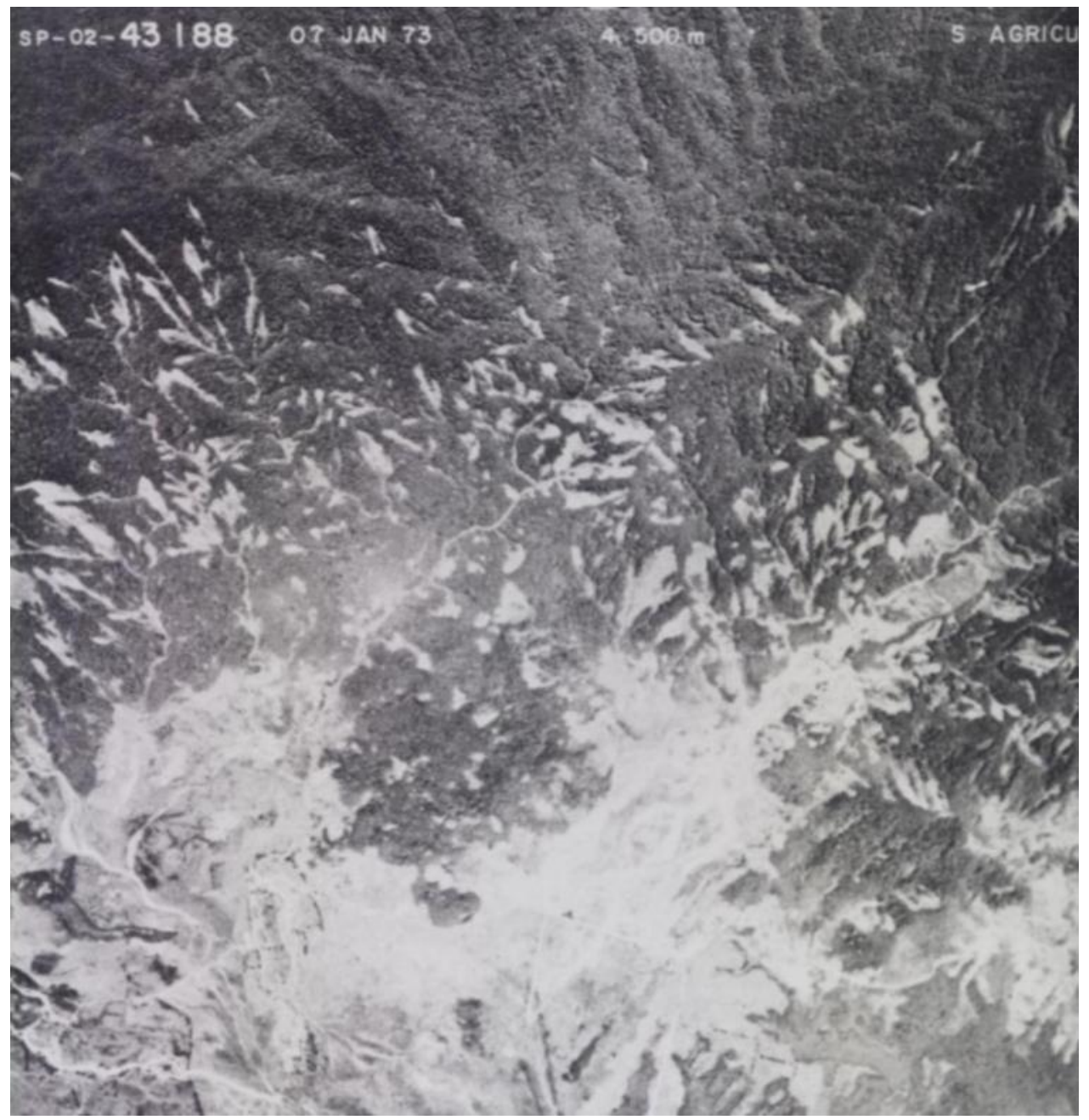

Figura 3.7. Fotografia aérea do ano de 1973, em que as cicatrizes dos escorregamentos generalizados e o material proveniente das encostas que atingiu a planície sedimentar aparecem em tons de cinza claro e branco (escala original 1:25.000). Foto: Secretaria de Agricultura do Estado de São Paulo (1973).

Considerada a dimensão catastrófica dos escorregamentos e corridas, Fúlfaroet al. (1976), com o objetivo de estimar o período de recorrência do evento de Caraguatatuba, analisaram a coluna sedimentar da planície costeira, baseado em técnicas de datação de C-14, concluindo que, nos últimos 3.300 anos teria ocorrido apenas uma grande fase de escorregamento deste tipo, pressupondo que todas as fases importantes de escorregamentos tenham deixado registro na coluna estratigráfica, e de que nenhum destes registros tenha sido destruído por erosão. 


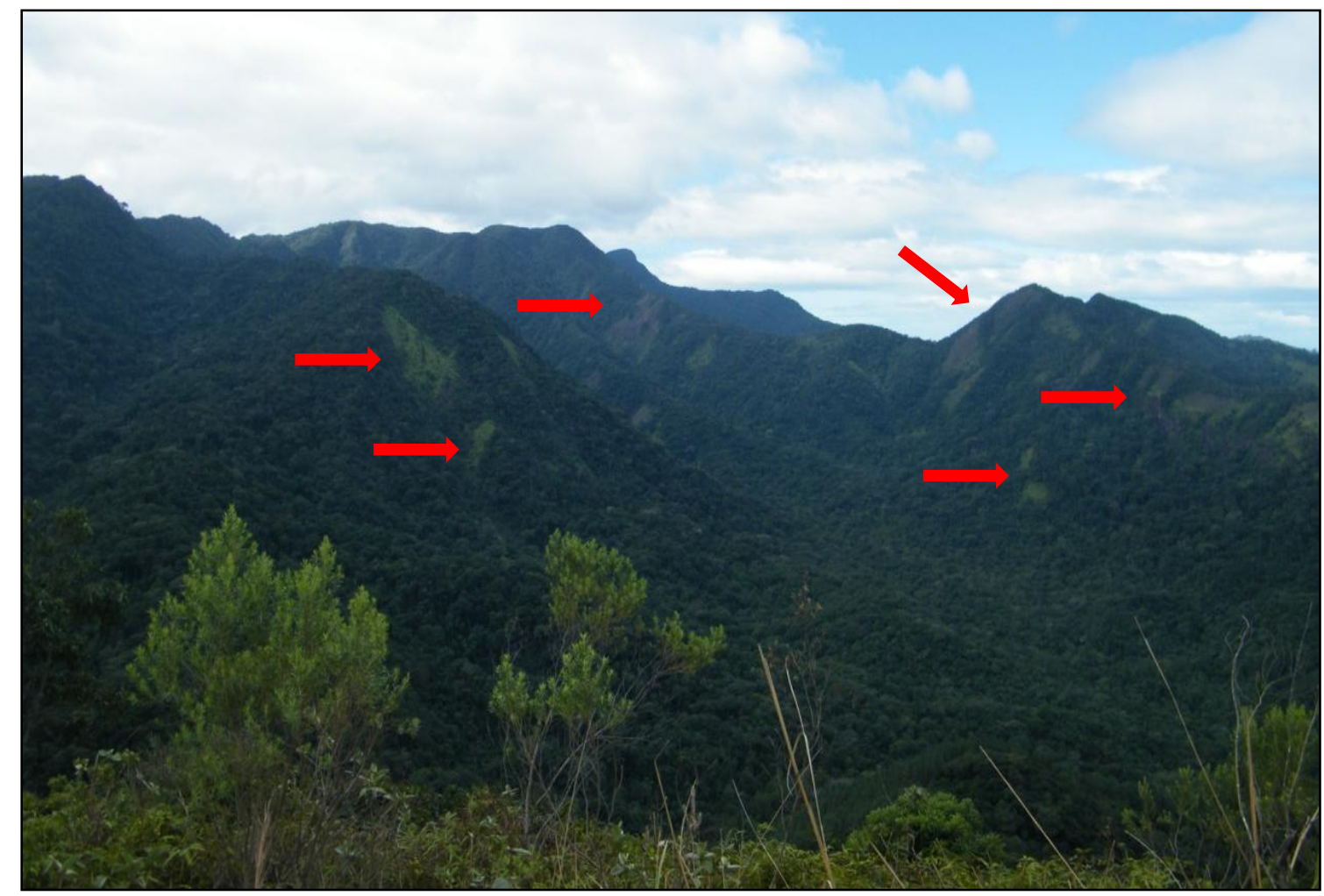

Figura 3.8. Observam-se indicadas pelas setas vermelhas as cicatrizes dos escorregamentos de 1967. Sua colonização pioneira pela espécie de pteridófitaGleycheniamanteve as cicatrizes preservadas por mais de 40 anos (Agosto/2010).

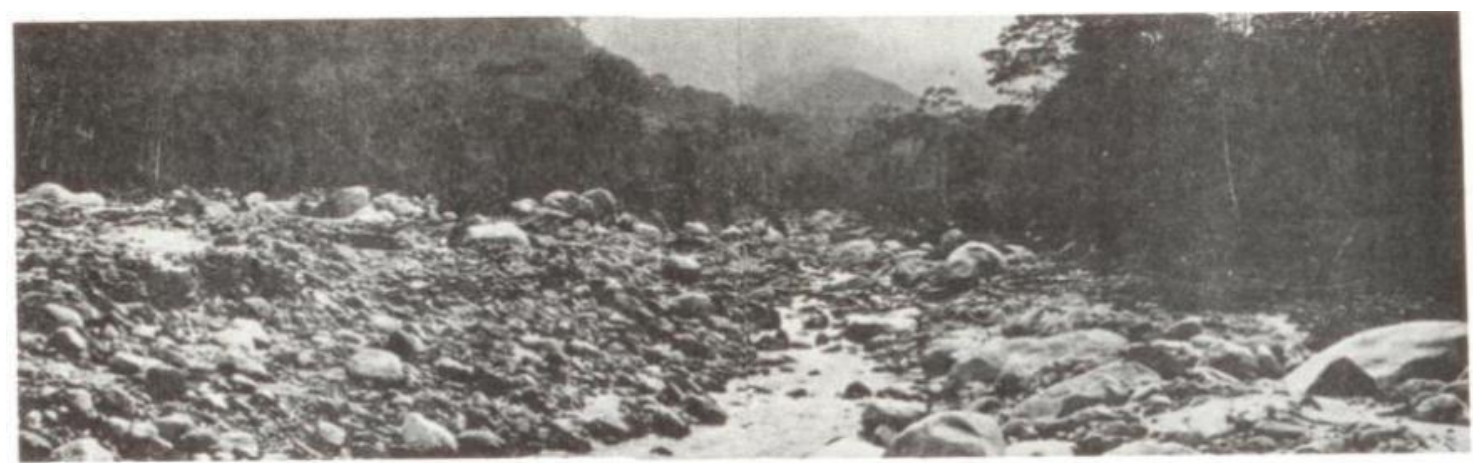

Figura 3.9. Baixo vale do rio Mantegueira, afluente do rio Santo Antônio, com os detritos provindos das vertentes. Fonte: $\operatorname{Cruz}(1974)$. 


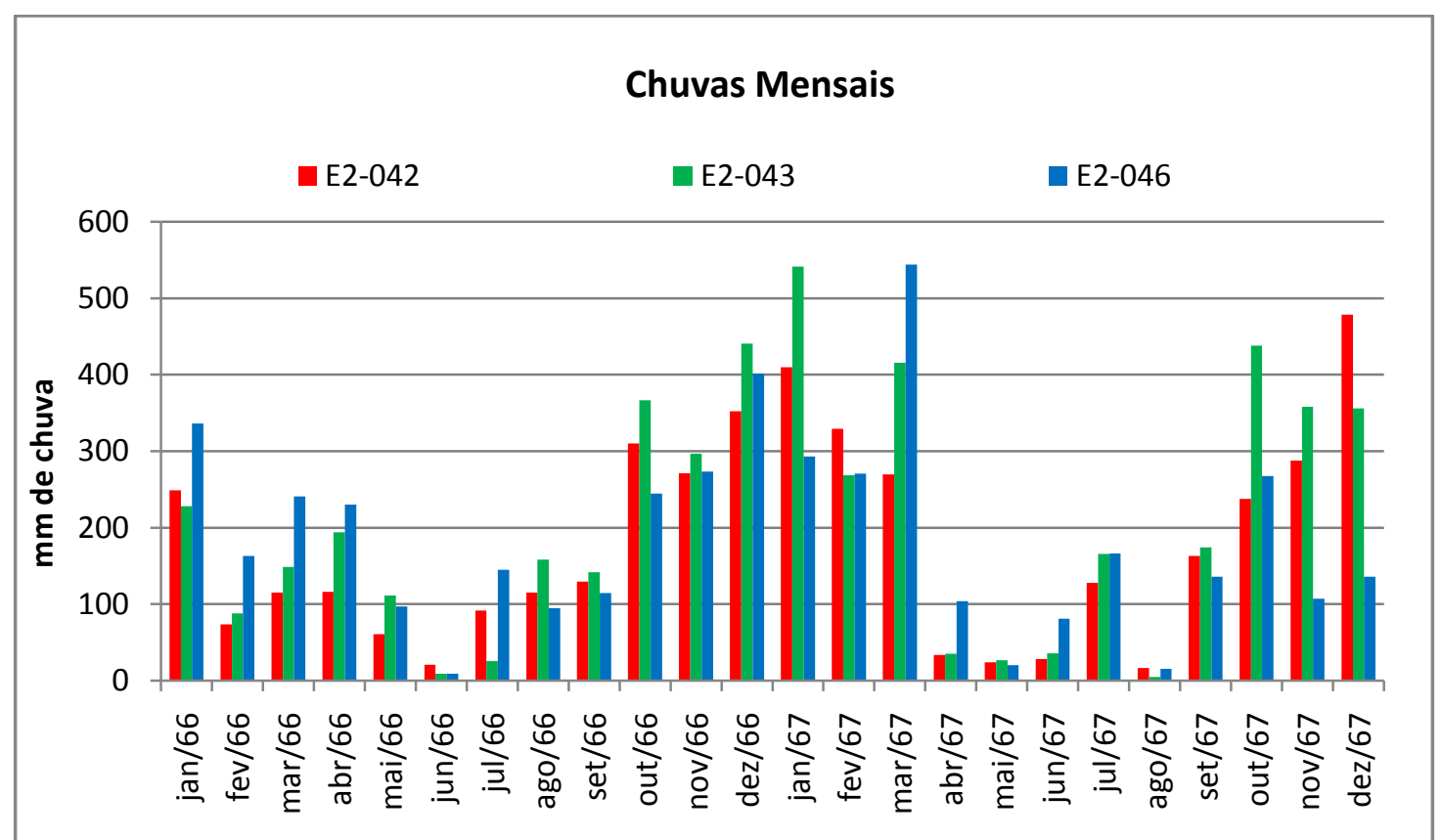

Figura 3.10.Chuvas mensais acumuladas (mm/mês) para o período entre 1966 e 1967, a partir de dados do DAEE. Vale ressaltar que,no mês de março de 1967, os postos E2-042, E2-043 e E2-046 registraram os volumes de chuva apenas até o dia 18. Fonte: Ramos (2012).

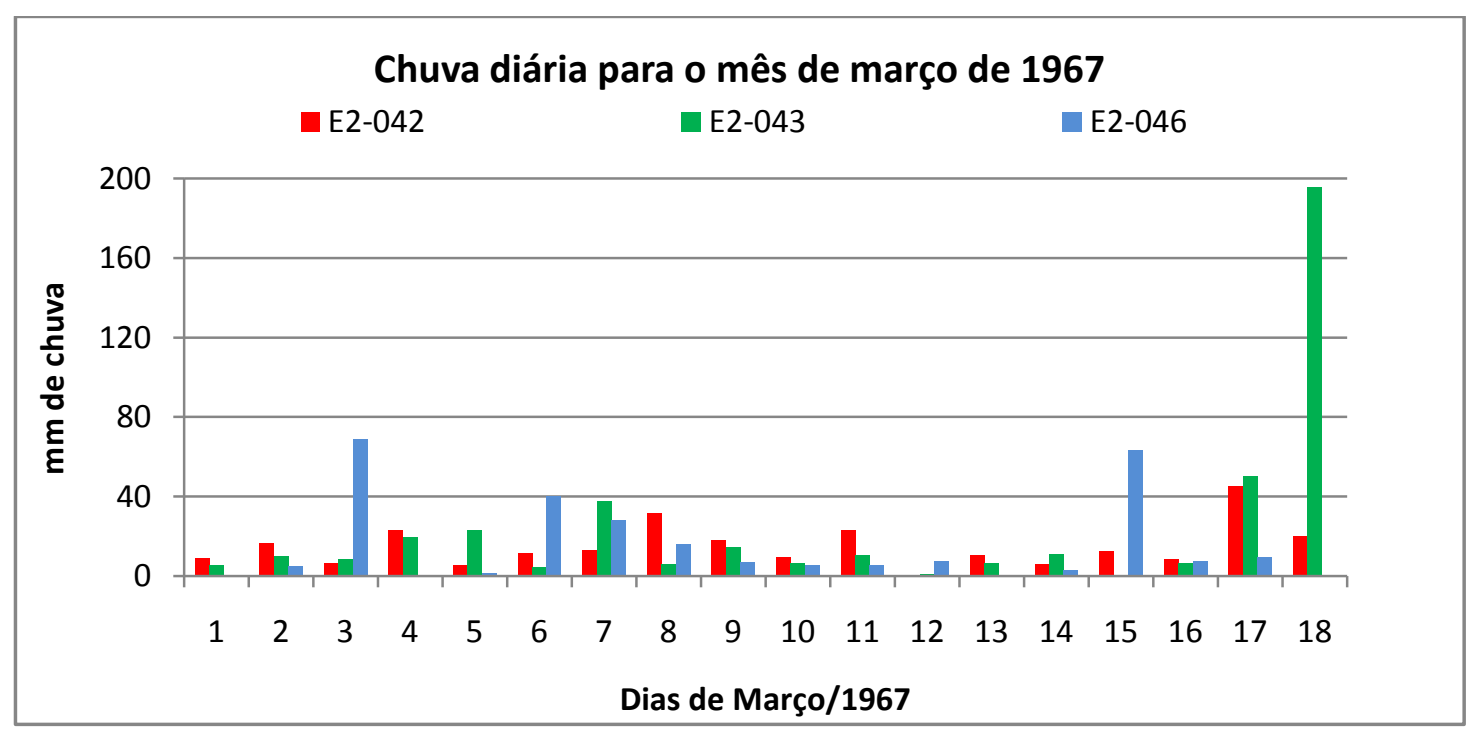

Figura 3.11. Chuvas diárias acumuladas (mm/dia) para o mês de março de 1967, a partir de dados do DAEE. Vale ressaltar que,no mês de março de 1967, os postos E2-042, E2-043 e E2046 registraram os volumes de chuva apenas até o dia 18. 
A bacia do rio Guaxinduba (Figura 3.12), embora não possua um levantamento de detalhe acerca das suas características geológicas, pedológicas e geomorfológicas, no mapa geomorfológico elaborado por Cruz (1974), o trecho mapeado da mesma bacia apresenta extensas rampas de colúvio, solos colúvioaluviais, contato côncavo entre baixas vertentes e baixada, entre algumas das feições observadas.

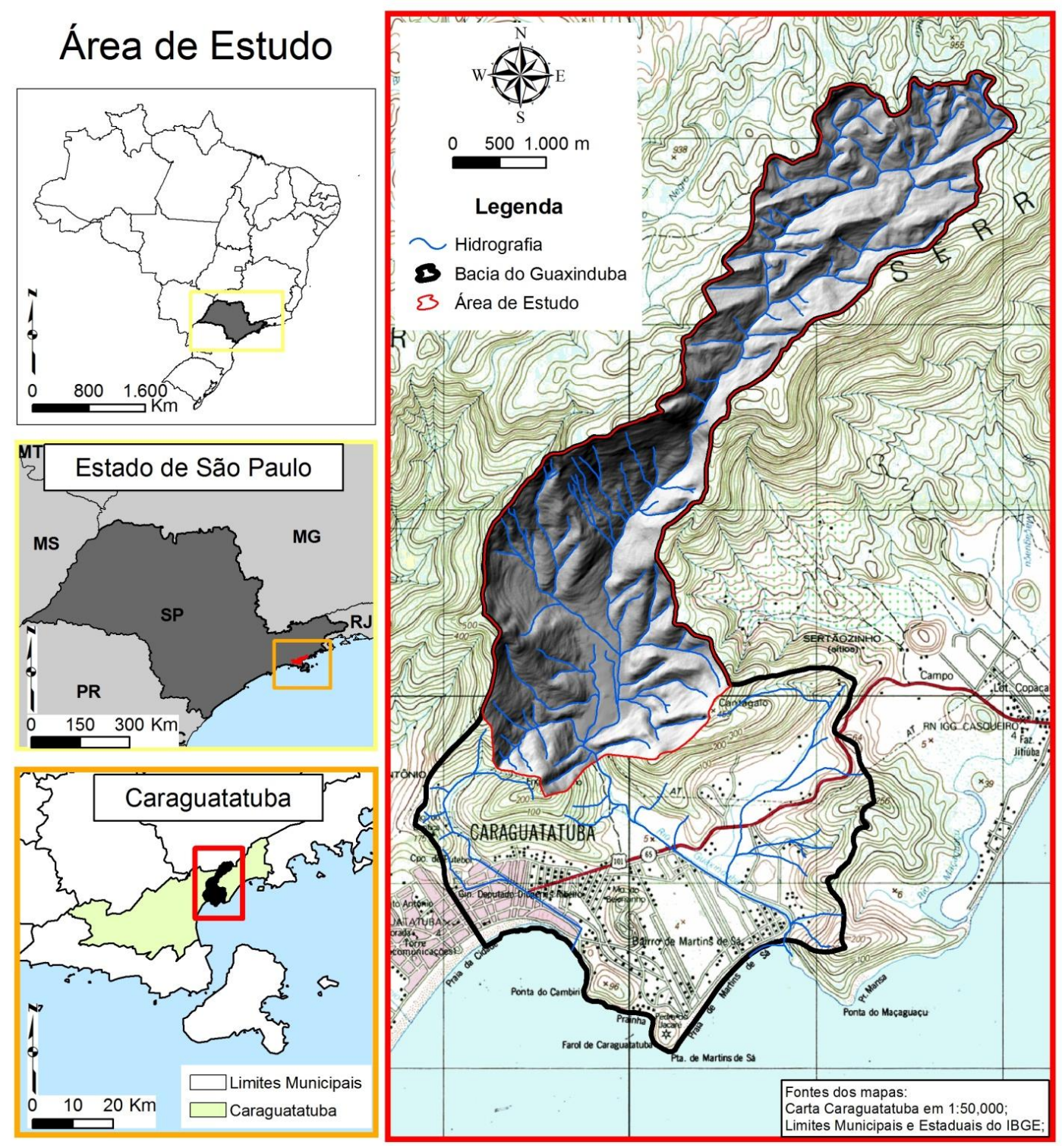

Figura 3.12. Localização da bacia do rio Guaxinduba. Fonte: Ramos (2012). 
Com $24,15 \mathrm{~km}^{2}$, a bacia possui um rio principal com 13,5 km de extensão, oriundo do planalto como resultado de uma suposta captura fluvial, possivelmente recente, se considerada a dissecação ainda insipiente das bordas das escarpas da Serra do Mar, de tal forma que a diferença altimétrica entre o planalto e o ponto onde o rio escoa abruptamente pela escarpa é pouco mais de 100 metros. Conforme Oliveira (2005), esse tipo de captura recebe a classificação "recuo de cabeceiras". Esta captura implica que o rio teve ampliada sua área de drenagem, aumentando, desta forma, a quantidade de água escoada pelo canal principal durante os eventos de precipitação.

Conforme destacado na Figura 3.13, o rio Guaxinduba apresenta uma evidente assimetria desde a área de nascente até próximo à sua foz. Com relação às declividades, é possível verificar que são relativamente suaves no perfil A-A' e muito mais acentuadas nos demais, sobretudo nos perfis B-B', C-C' e D-D'. Em todos os perfis, a margem direita mostrou-se mais extensa, sendo a porção que apresenta a maior densidade de drenagem quando comparada ao conjunto dos canais presentes na margem esquerda do rio (Ramos, 2012).

Para jusante destes morros situa-se a ocupação humana local, que tratou de estabelecer suas bases à planície costeira, sobretudo após a construção à beira da Rodovia Rio-Santos na década de 1970. Para a montante dos contrafortes existem apenas imóveis rurais, alguns com apenas a residência e outros com ocupação de uma porção de terra para cultivo de vegetais ou pecuária, ambos em escala familiar. 

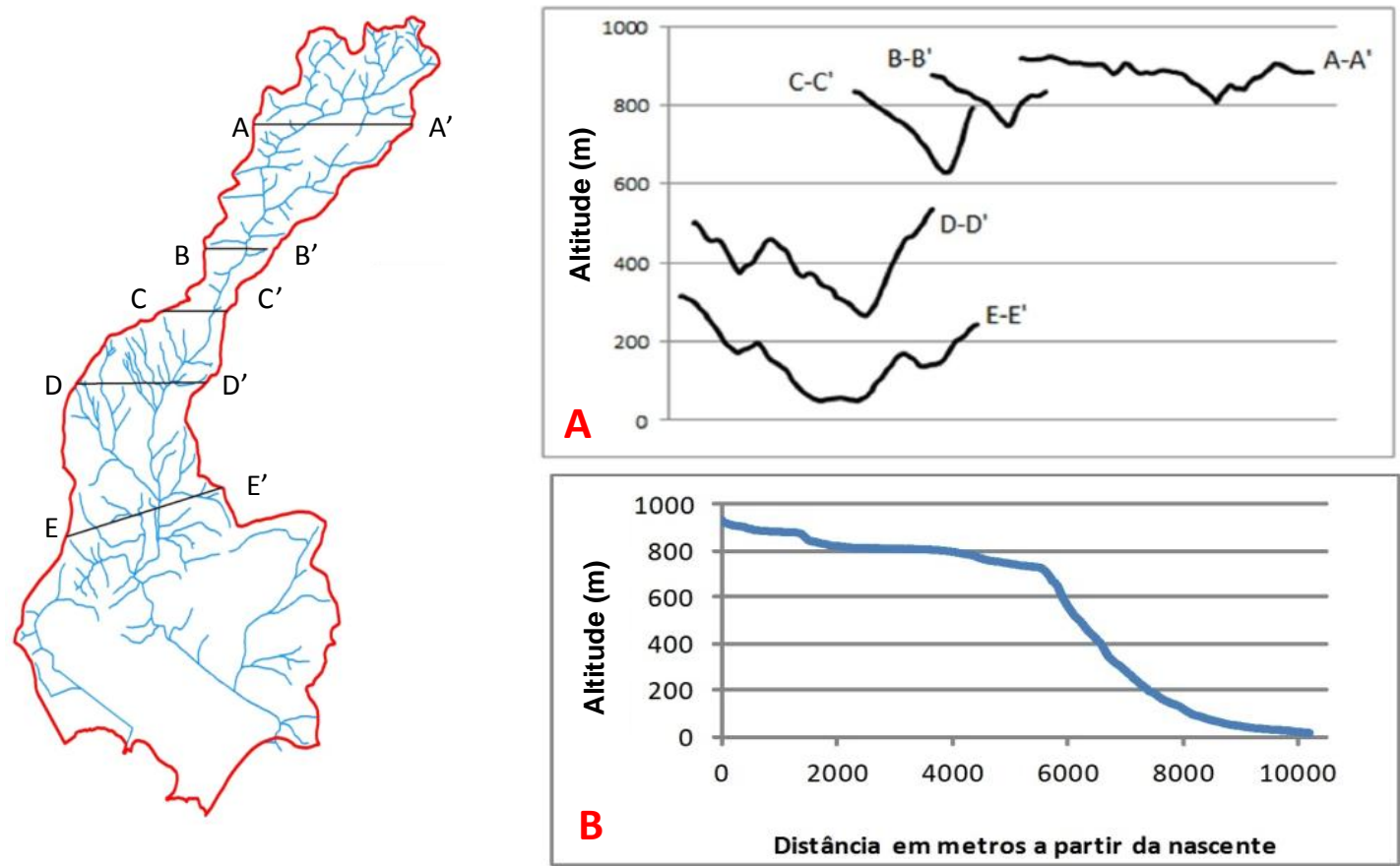

Figura 3.13. Perfis transversais (A) e longitudinal (B) realizados na bacia do Rio Guaxinduba e suas localizações. Fonte: modificado de Ramos (2012). 


\section{MATERIAIS E MÉTODOS}

Para que os objetivos propostos nesta pesquisa fossem alcançados, sobretudo a análise da influência da condutividade hidráulica saturada dos solos $\left(\mathrm{K}_{\mathrm{sat}}\right)$ nos escorregamentos rasos, alguns procedimentos e materiais foram adotados. Inicialmente, foi selecionada a área de estudo a partir de alguns critérios estabelecidos (4.1). Para a seleção das cicatrizes onde ocorreram os levantamentos in situ, foramconsiderados os mapeamentos das cicatrizes de escorregamentos e dos parâmetros topográficos e trabalho de campo (4.2).No capítulo 4.3 são apresentadosos procedimentos adotados para arealizaçãodos ensaios in situ e, por fim,a análise conjunta da variação espacial da $\mathrm{K}_{\mathrm{sat}}$, das propriedades físicas dos solos ensaiados e dos parâmetros topográficos, de forma a compreender seu comportamento hidrológico (4.4) e reflexos nos processos de encostas (Figura 4.1).

\subsection{Seleção da bacia hidrográfica}

A pré-seleção da bacia teve como base uma revisão bibliográfica dos trabalhos produzidos sobre movimentos de massa, especialmente os escorregamentos rasos, na Serra do Mar paulista.

Os registros dos escorregamentos na literatura referentes ao tema datam do início da década de 1960, período no qual houve no Brasil um significativo avanço técnico em mecânica dos solos (GUIDICINI e NIEBLE, 1983). Desta forma, a préseleção deu-se por meio de consultas a essas obras, como Cruz (1974); Wolle (1980); IPT (1987), Tatizanaet al. (1987), Wolle e Carvalho (1989), Carvalho (1989), Gramani (2001), Marcelino (2003), Sestini e Florenzano (2004), Lopes (2006), Vieira (2007), Passarela et al. (2008), entre outros. Foram indicadas bacias com 
registros de um grande número de escorregamentos, principalmente aquelas com estudos aprofundados, possibilitando a melhor análise dos resultados.

Durante a consulta bibliográfica, foram encontrados inúmeros trabalhos desenvolvidos na região da Baixada Santista, sobretudo em Cubatão, onde os escorregamentos são recorrentes.

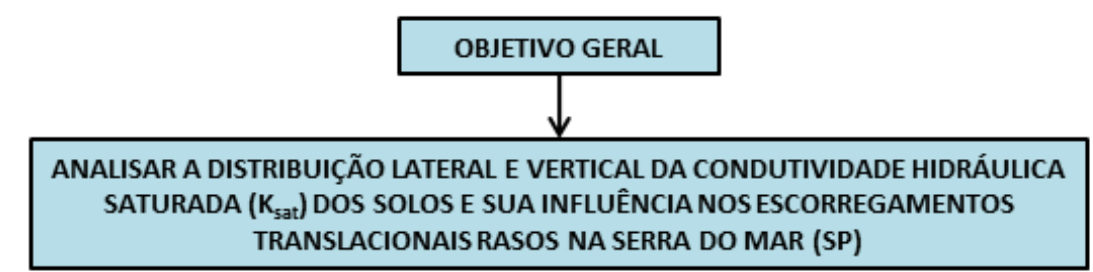

(4.1)

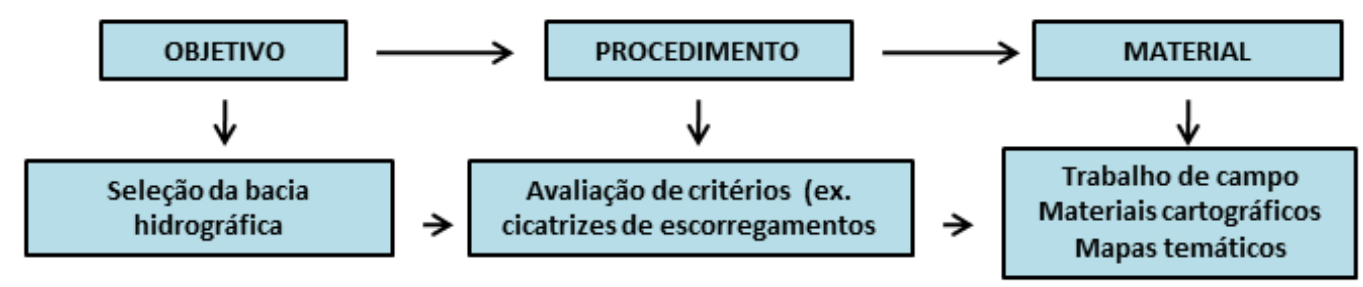

(4.2)
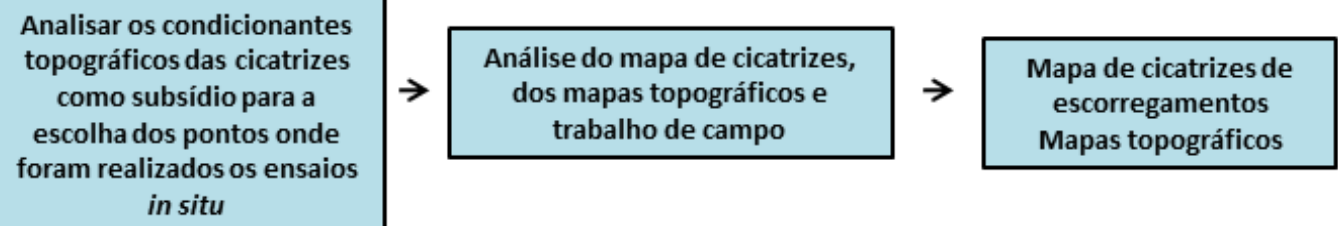

(4.3)
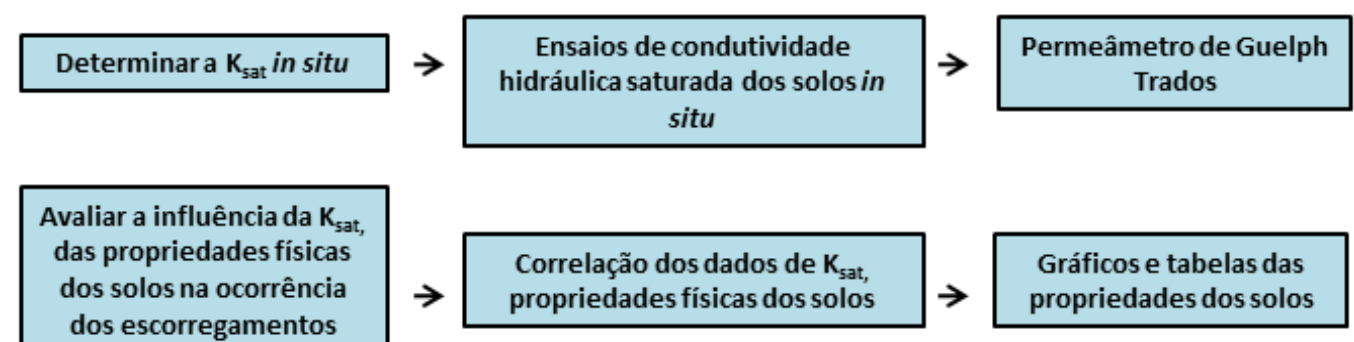

Figura 4.1. Fluxogramas das etapas metodológicas e dos materiais da pesquisa. 
Outro grupo de trabalho refere-se à Caraguatatuba, no litoral norte de São Paulo, devido aos escorregamentos rasos e corridas de detritos deflagrados em 1967 (CRUZ, 1974; MARCELINO, 2003; SESTINI e FLORENZANO, 2004). Portanto, admitiu-se que Cubatão e Caraguatatuba seriam localidades nas quais possivelmente uma bacia se enquadraria nos critérios estabelecidos, que foram:(a) a existência de vias e caminhos que permitissem o acesso às encostas, viabilizando a execução dos ensaios; (b) sua representatividade das condições naturais da Serra do Mar paulista e dos processos associados, para que seja possível confrontar os resultados obtidos e; (c) a existência de cicatrizes de escorregamentos rasos observadas em campo ou em fotografias aéreas, pois estas representam condições de instabilidade nas encostas(GOMES e VIEIRA, 2010).

Para a definição do roteiro do trabalho de campo, considerando os critérios acima mencionados, foram utilizados: cartas topográficas do Instituto Brasileiro de Geografia e Estatística (IBGE) na escala de 1:50.000 (folhas de Santos (SG-23-V-B-I-1), Bertioga (2F-23-Y-D-VI-4), São Sebastião (SF-23-Y-D-VI-3), Caraguatatuba (SF-23-Y-D-VI-1) e Picinguaba (SF-23-V-B-I-1)); fotografias aéreas do ano de 1973 (1:25.000), cedidas pelo Instituto de Pesquisas Tecnológicas do Estado de São Paulo (IPT) e; imagens de satélite do Google Earth. A utilização desta última teve como objetivo verificar se as bacias mais adequadas à proposta possuíam vias de acesso.

Foram selecionadas bacias desde a Baixada Santista até o município de Ubatuba. Em todas as bacias foram registradas as coordenadas geográficas com Global Position System (GPS), no total de 23 pontos (Figura 4.2). O número de pontos em cada bacia variou em virtude dos diferentes elementos que foram assinalados (ex. vias de acesso, cicatrizes e cursos d'água). 
Em Cubatão, a existência do pólo industrial no sopé das encostas da Serra restringiu muito a seleção de bacias devido à restrição ao terreno estabelecida pelas indústrias. Dessa forma, apenas a bacia do Rio Perequê foi pré-selecionada, pois é um dos poucos acessos à escarpa da Serra que não é propriedade particular, e leva ao Parque Ecológico do Perequê.

Em Caraguatatuba, este tipo de entrave não foi encontrado, uma vez que a atividade industrial é incipiente, predominando o uso urbano (residencial). Assim, algumas bacias foram selecionadas, sobretudo, por apresentarem inúmeras cicatrizes e acessos, atendendo às exigências deste trabalho. São elas: Bacia do Ribeirão Poiares, do Rio Guaxinduba e do Córrego Bacuí.

Após a revisão bibliográfica optou-se por realizar o trabalho de campo prioritariamente nos dois municípios mencionados. No entanto, em Ubatuba, mesmo sem registros bibliográficos de eventos de dimensões catastróficas, como os referidos anteriormente, foram identificadas muitas cicatrizes de escorregamentos rasos, as quais possivelmente não correspondem a um mesmo evento pluviométrico intenso. Foi verificado nas imagens do Google Earth, se havia acesso a essas bacias onde as cicatrizes estavam preservadas. Fundamentado nos critérios estabelecidos, duas bacias se mostraram adequadas: as Bacias do Rio Perequê-Mirim e do Rio Iriri.

Nas bacias com ocupação, alguns moradores foram entrevistados informalmente, com o objetivo de levantar algumas informações sobre a ocorrência de movimentos de massa recentes e sua freqüência, e sobre as trilhas e os caminhos para o acesso às encostas, principalmente para as áreas com presença de cicatrizes. 
Após a investigação das bacias pré-selecionadas em campo, foi possível classificá-las de acordo com o grau de adequabilidade de cada uma à proposta do trabalho. O critério que teve peso fundamental foi existência de cicatrizes, especialmente aquelas observadas in situ.

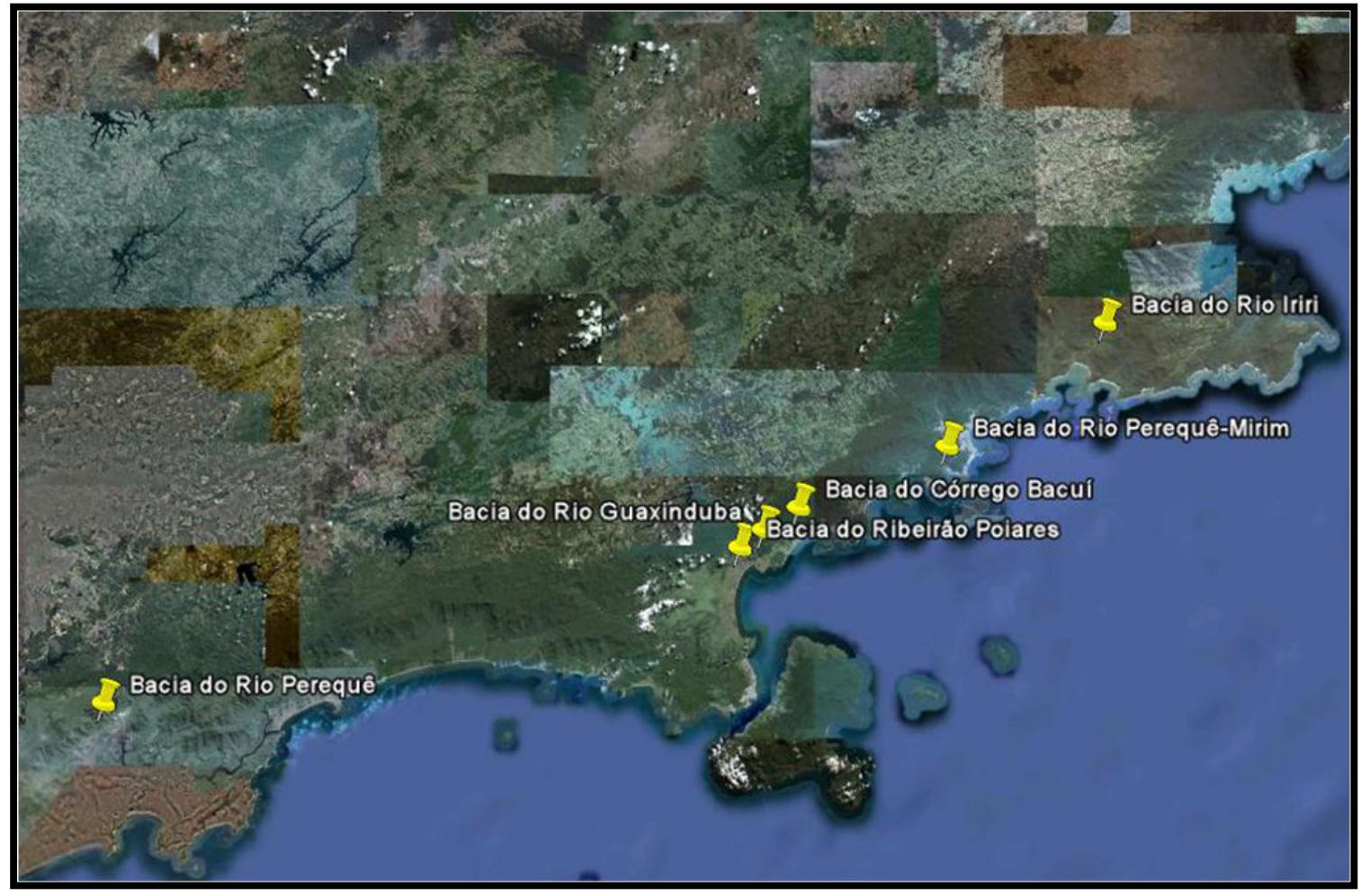

Figura 4.2. Imagem compreendendo a Baixada Santista e o litoral norte do estado de São Paulo. Em amarelo, alguns pontos registrados pelo GPS e visitados em campo. (Foto: GOOGLE EARTH, acesso em 07.08.2010). 
Algumas bacias, embora dentro dos critérios de representatividade das condições naturais da Serra e dos registros de escorregamentos, apresentaram difícil acesso, o que poderia comprometer a execução dos levantamentos de campo. São elas: Bacias do Rio Perequê (Cubatão), e do Ribeirão Poiares e do Córrego Bacuí, (Caraguatatuba).

Na Bacia do Perequê, o acesso foi impossibilitado pela inexistência de trilhas nos setores das encostas apropriados para a execução dos ensaios, além da densa cobertura vegetal. As bacias do Poiares e do Bacuítornaram-se inviáveis, por apresentarem restrição de acesso às propriedades particulares, como fazendas e condomínios fechados. Além disso, a bacia do Poiares não apresenta morfometria apropriada para sua utilização em métodos de previsão baseados na modelagem matemática.

Na bacia do Rio Perequê-Mirim (Ubatuba) foram verificados alguns acessos, sendo uma via principal que acompanha a drenagem principal, e as secundárias que seguem do sopé em direção ao topo das encostas. Há registro de escorregamentos rasos em fotografias aéreas e cicatrizes no campo. Desta forma, constatou-se que esta bacia satisfaz todos os critérios estabelecidos, apresentando apenas um inconveniente: a ocorrência de furtos de equipamentos em trabalhos já desenvolvidos na área, tornando-a insegura (MENDES, informação verbal) ${ }^{1}$.

As bacias que melhor atenderam aos critérios aqui considerados foram as Bacias do Rio Guaxinduba (Caraguatatuba) e do Rio Iriri (Ubatuba). A Bacia do Guaxinduba possui ocupação humana, sobretudo nos níveis de terraço fluvial e baixa encosta. Setores de média e alta encosta, em sua maioria, não possuem ocupação, apenas a retirada da cobertura vegetal para a construção das linhas de transmissão de

\footnotetext{
1 Rodolfo Moreda MENDES desenvolveu sua tese de doutorado na bacia em questão. Aparelhos
} utilizados no monitoramento das propriedades geotécnicas dos solos foram furtados algumas vezes. 
energia. A existência de manchas de vegetação de menor porte foi uma característica que facilitou o acesso, bem como a realização dos ensaios. Cicatrizes do ano de 1967 são nítidas, se comparadas às fotografias aéreas de 1973, sendo possível identificálas pela diferença de textura e pela cor das espécies de pteridófitas que colonizaram as cicatrizes (Figura 4.3).

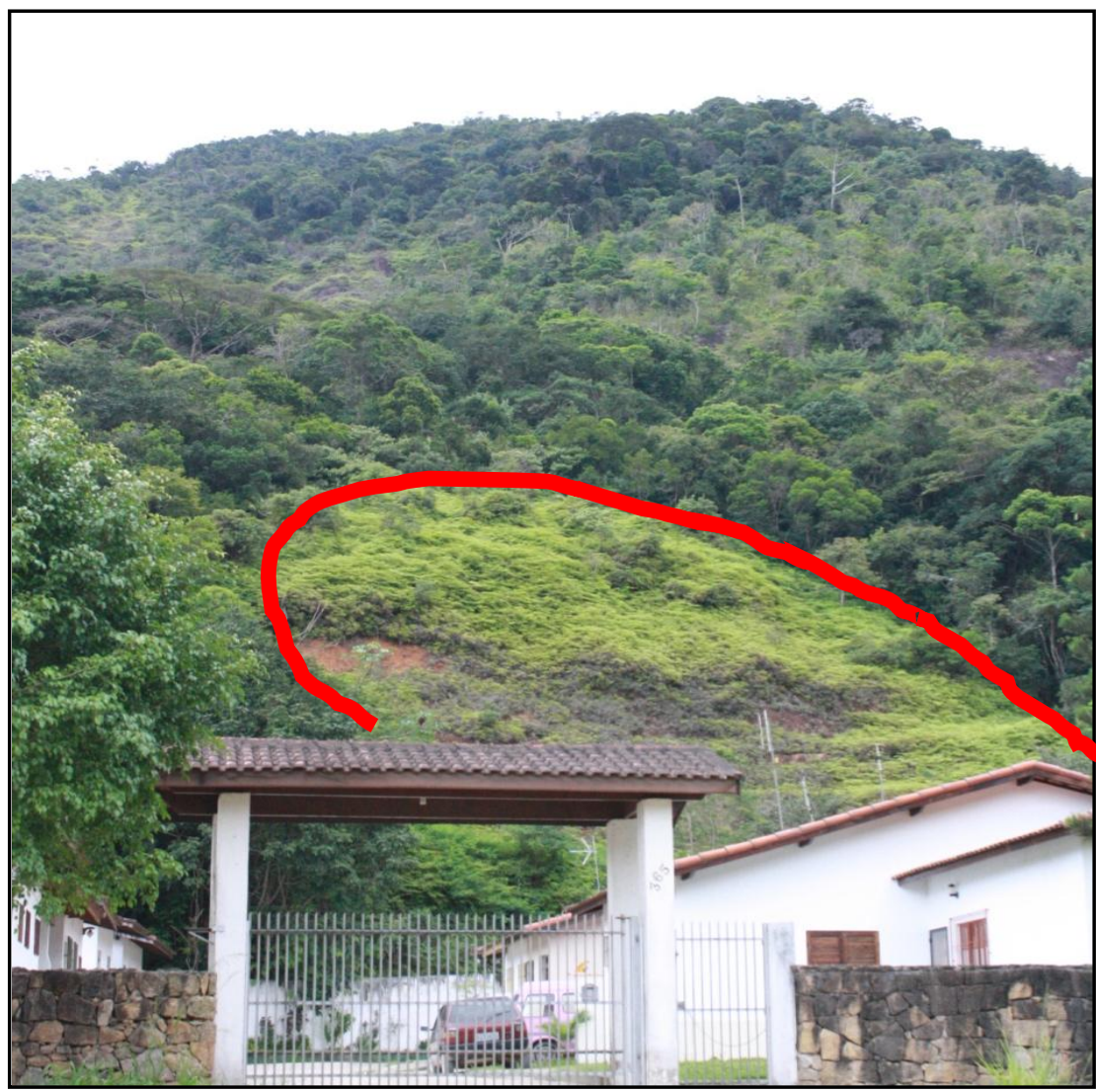

Figura 4.3. Cicatriz (em vermelho) recolonizada por espécie pioneira de pteridófita. 
Optou-se pela bacia do Rio Guaxinduba (Figura 4.4) devido ao estado de conservação das cicatrizes de escorregamentos e à existência de cobertura vegetal de menor porte, o que colabora muito para o acesso às encostas onde serão realizados os ensaios. Por se adequar bem aos critérios propostos, poderá servir de área piloto para outros trabalhos, nos quais se faz necessário a realização de atividades em campo ou de aplicação de modelagem matemática utilizando tais dados.

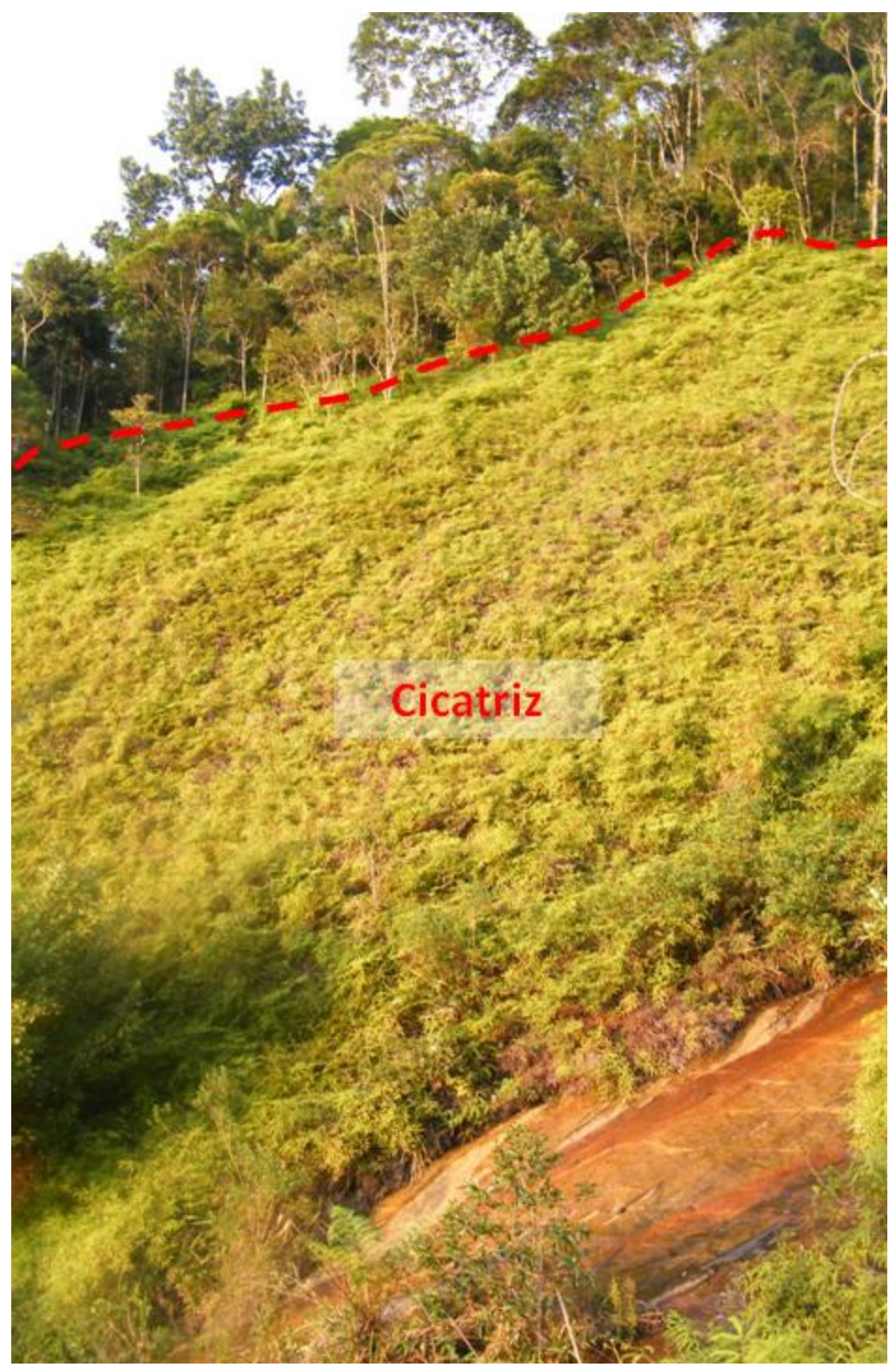

Figura 4.4. Bacia do Guaxinduba. Nota-se, no centro da figura, uma cicatriz recoberta pela samambaia Gleychenia, adequado para a realização de levantamentos in situ. 


\subsection{Seleção dos pontos para os ensaios in situ}

A seleção dos pontos onde foram realizados os ensaios, embora incialmente tenha sido proposto que a caracterização topográfica das cicatrizes a direcionasse, foi inviabilizada pelas dificuldades de correção geométrica das fotografias aéreas do ano de 1972, o levantamento aerofotogramétrico mais próximo do evento. Desta forma, a partir do trabalho de Ramos (2012), no qual foram mapeadas as cicatrizes dos escorregamentos de 1967 e caracterizada a topografia da bacia do Guaxinduba, foram selecionadas as cicatrizes.

Os critérios adotados para a definição dos pontos, não menos importantes que a caracterização topográfica, foram a identificação em campo de cicatrizes com as principais características dos escorregamentos rasos, como seu formato alongado e plano de ruptura paralelo ao ângulo da encosta, a existência de limites bem preservados nas cicatrizes (para a definição dos pontos próximo às bordas) e o acesso a elas.

Foram utilizadas em campo as fotografias aéreas de 1972, para que fossem verificadas apenas cicatrizes de escorregamentos deflagrados em 1967, e o mapa de ângulo das encostas da bacia. Além disso, foi imprescindível o conhecimento minucioso da área pelo morador que acompanhou os trabalhos de campo (tanto do acesso quanto das cicatrizes).

Foram selecionadas três cicatrizes, que se localizam próximas ao baixo curso do rio Guaxinduba (Figura 4.5), devido à existência de trilhas turísticas, de manutenção das linhas de transmissão e daquelas utilizadas pelos moradores (único setor da bacia onde há ocupação humana). Outra característica comum às três cicatrizes é a existência da samambaia Gleychenia recobrindo toda a extensão das cicatrizes. 
De forma geral, a bacia do Guaxinduba apresenta predominantemente encostas convexas nas escarpas, seguidas pelas retilíneas e com menor frequência das côncavas. Quanto ao ângulo das encostas, destacam-se aqueles acima dos $20^{\circ}$, orientados, sobretudo, para os Quadrantes Sul (20\%) e Sudeste (19\%), enquanto os menos frequentes são voltados para Norte (8\%) e Nordeste (6\%). Mais informações sobre as características topográficas da bacia estão disponíveis em Gomes et al. (2011).Embora as cicatrizes não tenham sido definidas com base na representatividade das suas características topográficas, a aplicação do modelo matemático Shalstab por Ramos (2012) mostrou que as referidas cicatrizes se enquadram em classes de instabilidade (Figura 4.6). Este método de previsão de escorregamentos rasos, que combina em sua formulação um modelo de estabilidade com um modelo hidrológico, estabelece as seguintes classes de suscetibilidade: incondicionalmente estável e saturado, incondicionalmente estável e não saturado, estável e não saturado, instável e não saturado, instável e saturado, incondicionalmente instável e não saturado e incondicionalmente instável e saturado.

As Cicatriz 1,2 e 3 estão localizadas, segundo o mapa de suscetibilidade a escorregamentos de Ramos (2012), predominantemente em uma área classificada como instável e não saturada.

Ainda que esta não seja a classe que apresentou o maior Potencial de Escorregamento, ou seja, a maior razão entre o número de células desta classe afetada pelas cicatrizes e o total de células desta mesma classe, as classes de maior suscetibilidade estão restritas principalmente à escarpa e a declividades muito acentuadas. Desta forma, a seleção em campo das cicatrizes pode ser considerada satisfatória, pois estas são representativas da classe de maior instabilidade com viabilidade para realização dos ensaios. 

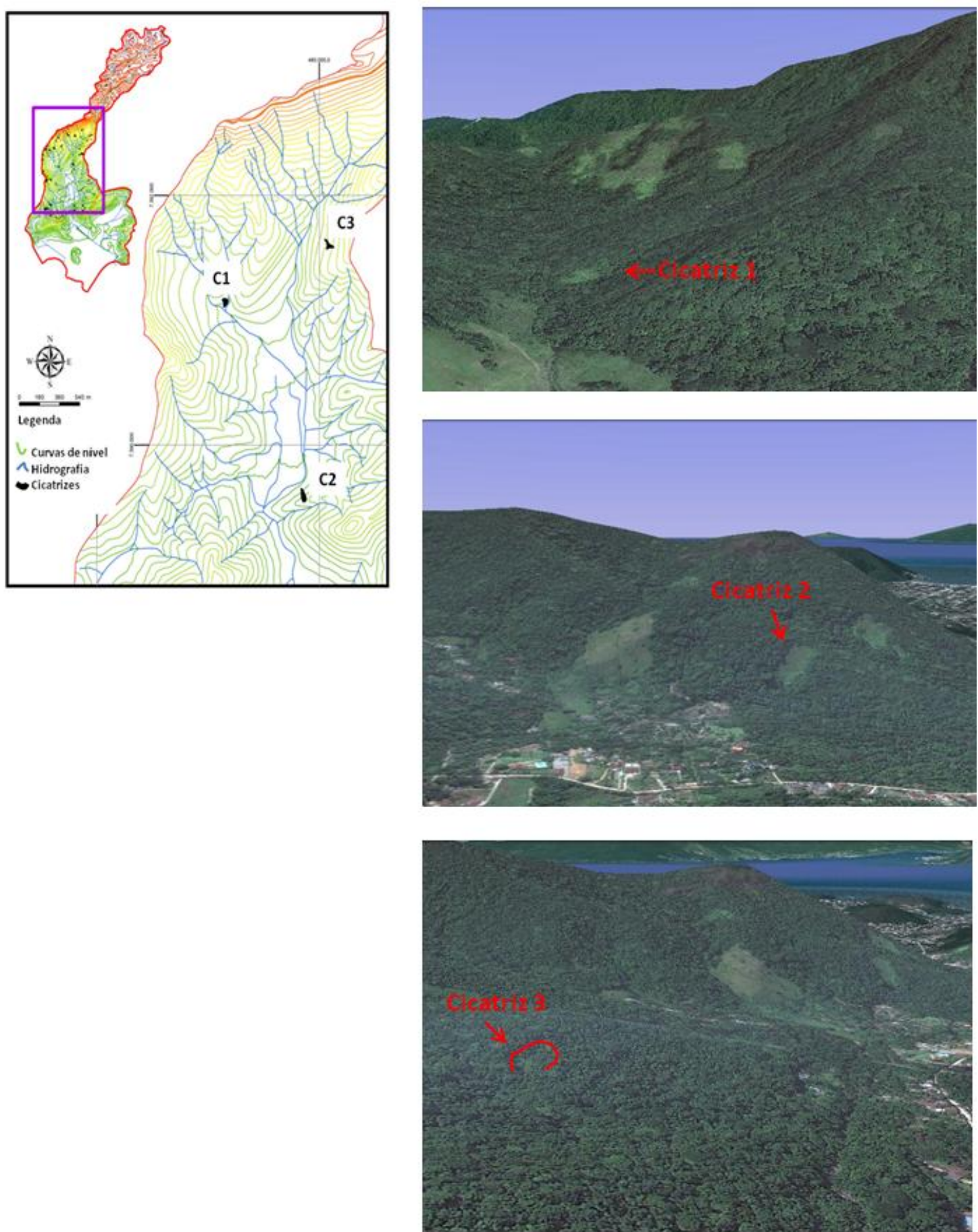

Figura 4.5. Localização das três cicatrizes $(\mathrm{C} 1, \mathrm{C} 2$ e $\mathrm{C} 3)$ na bacia do Guaxinduba. 


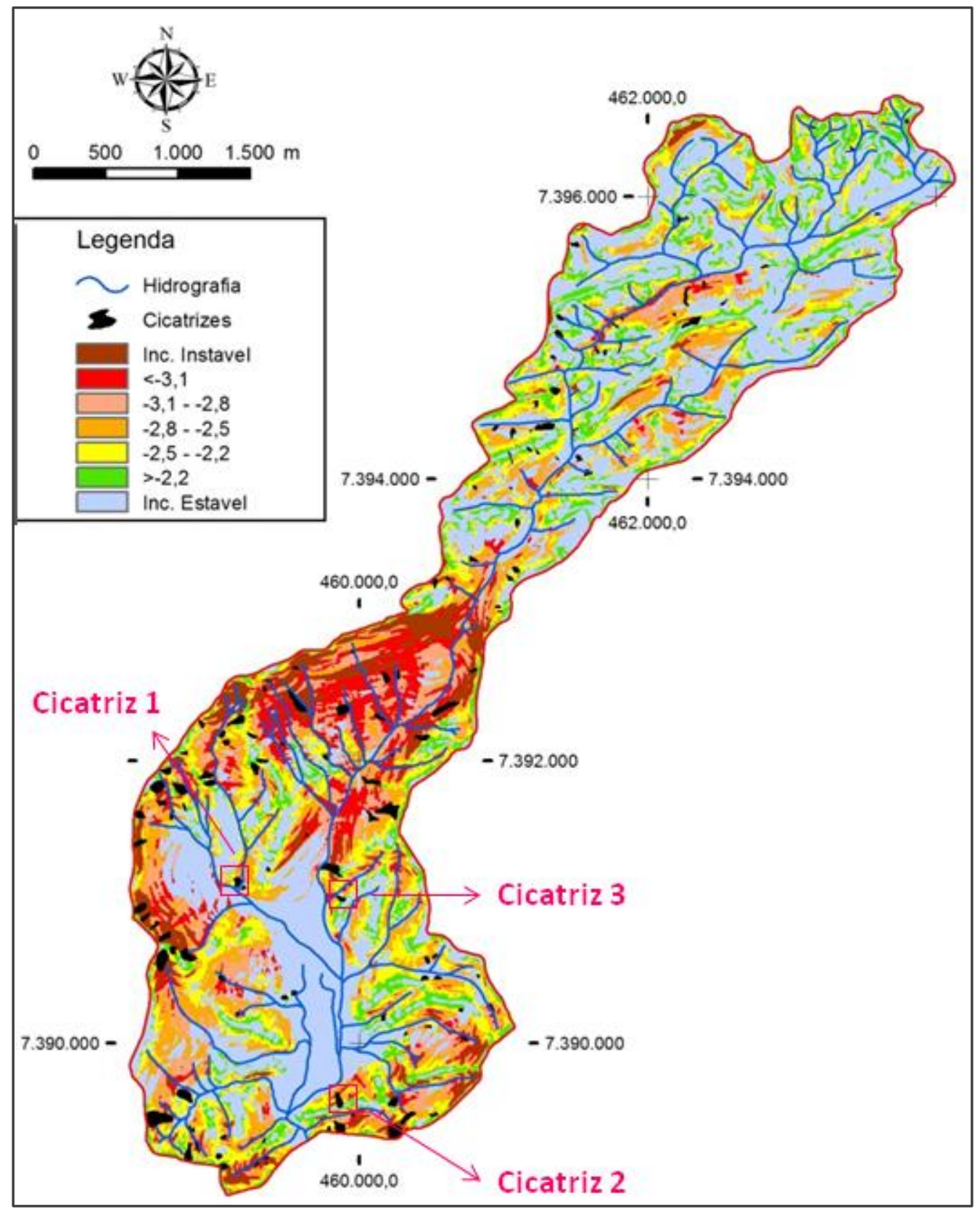

Figura 4.6.Mapa de suscetibilidade gerado a partir do modelo matemático Shalstab. Observa-se a concentração das classes de áreas instáveis na escarpa da Serra do Mar. As cicatrizes selecionadas se encontram à jusante da escarpa, nos espigões. Fonte: Ramos (2012). 
As cicatrizes apresentaram parâmetros topográficos distintos (Figura 4.7), sendo que as cicatrizes C2 e C3 maior semelhança, como o topo em segmentos convexos nas encostas e ângulos mais acentuados longitudinalmente. De forma geral, as três cicatrizes se encontram em encostas convexas/retilíneas, com ângulos acentuados (entre 20 e $40^{\circ}$ ), área de contribuição considerada grande para as condições da Serra do Mar (3,9 a 4,9 $\left.\log _{10} \mathrm{~m}^{2}\right)$ e quadrantes de Oeste (Noroeste e Sudoeste).

A Cicatriz 1 se encontra majoritariamente em uma encosta orientada para Sudeste, com ângulos entre 20 e $30^{\circ}$, tendo seu topo entre 30 e $40^{\circ}$. Já em relação à curvatura, o topo é retilíneo, enquanto o corpo da cicatriz é predominantemente convexo, importante condicionante da pequena área de contribuição.

Diferentemente da Cicatriz 1, o topo da Cicatriz 2 apresenta ângulos menores (menores que $20^{\circ}$ ), estando sua principal extensão entre os 30 e $40^{\circ}$ (Figura 4.8), terminando na baixa encosta acima dos $40^{\circ}$. Assim como o ângulo variou ao longo da cicatriz, a curvatura se comportou da mesma maneira - longitudinalmente é convexa no topo, retilínea e côncava ao longo do trecho que apresenta ângulos entre 30 e $40^{\circ}$, convexa e finalmente côncava onde os ângulos são os mais acentuados.

A Cicatriz 2 está totalmente voltada para Noroeste e o tamanho da área de contribuição segue as variações de curvatura - no topo convexo é pequena, enquanto que no setor retilíneo-côncavo do centro da cicatriz já exibe maior contribuição, aumentando na concavidade do sopé da encosta, onde se encontra a zona terminal da cicatriz. 


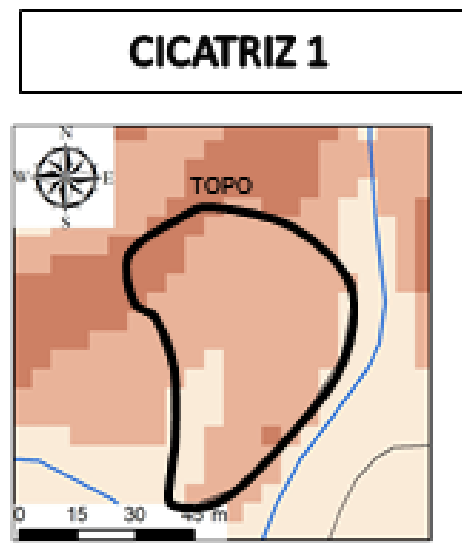

\section{CICATRIZ 2}

CICATRIZ 3
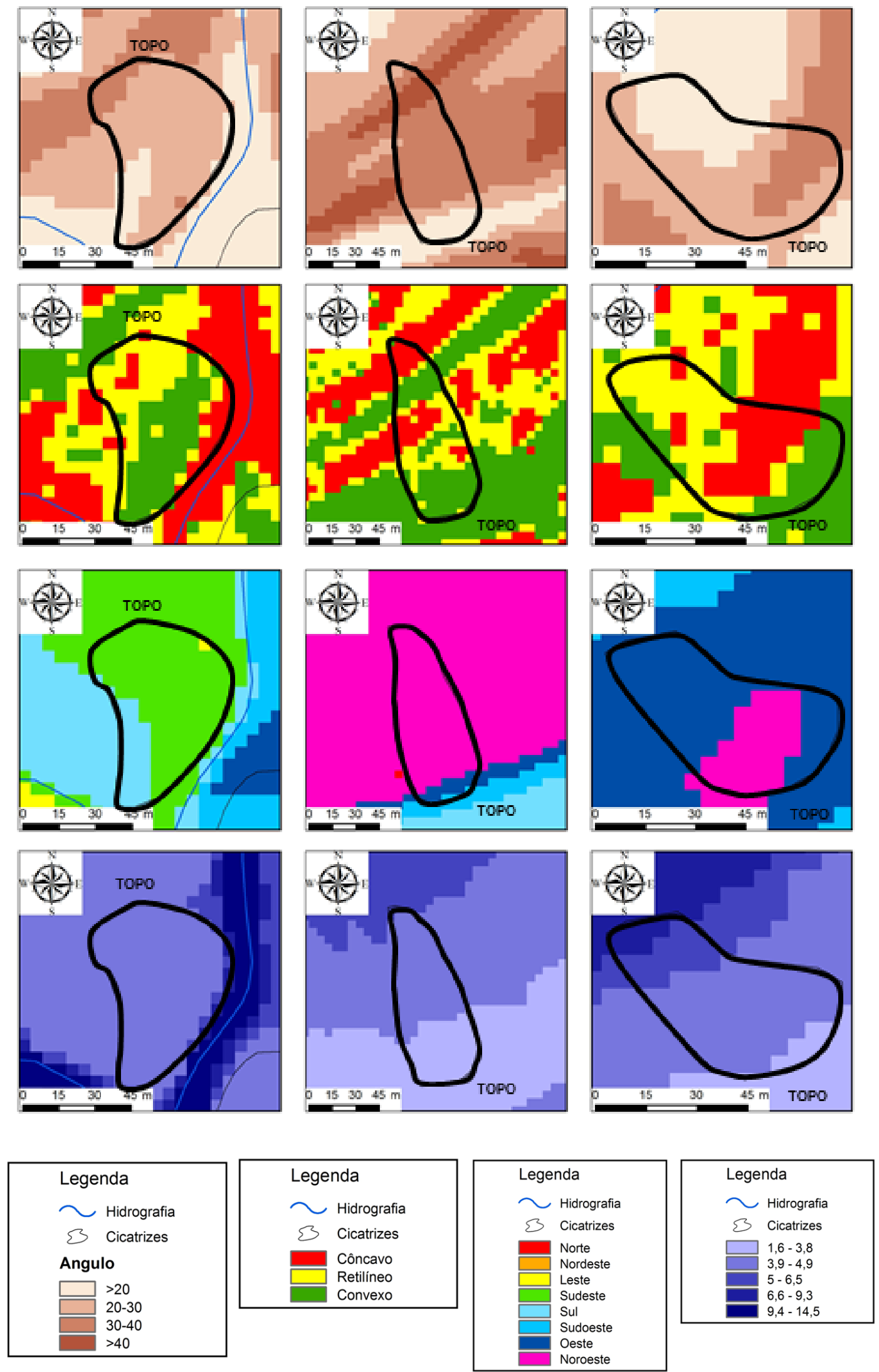

Figura 4.7. Caracterização espacial da topografia (ângulo, curvatura e orientação da encosta e área de contribuição) das três cicatrizes. 


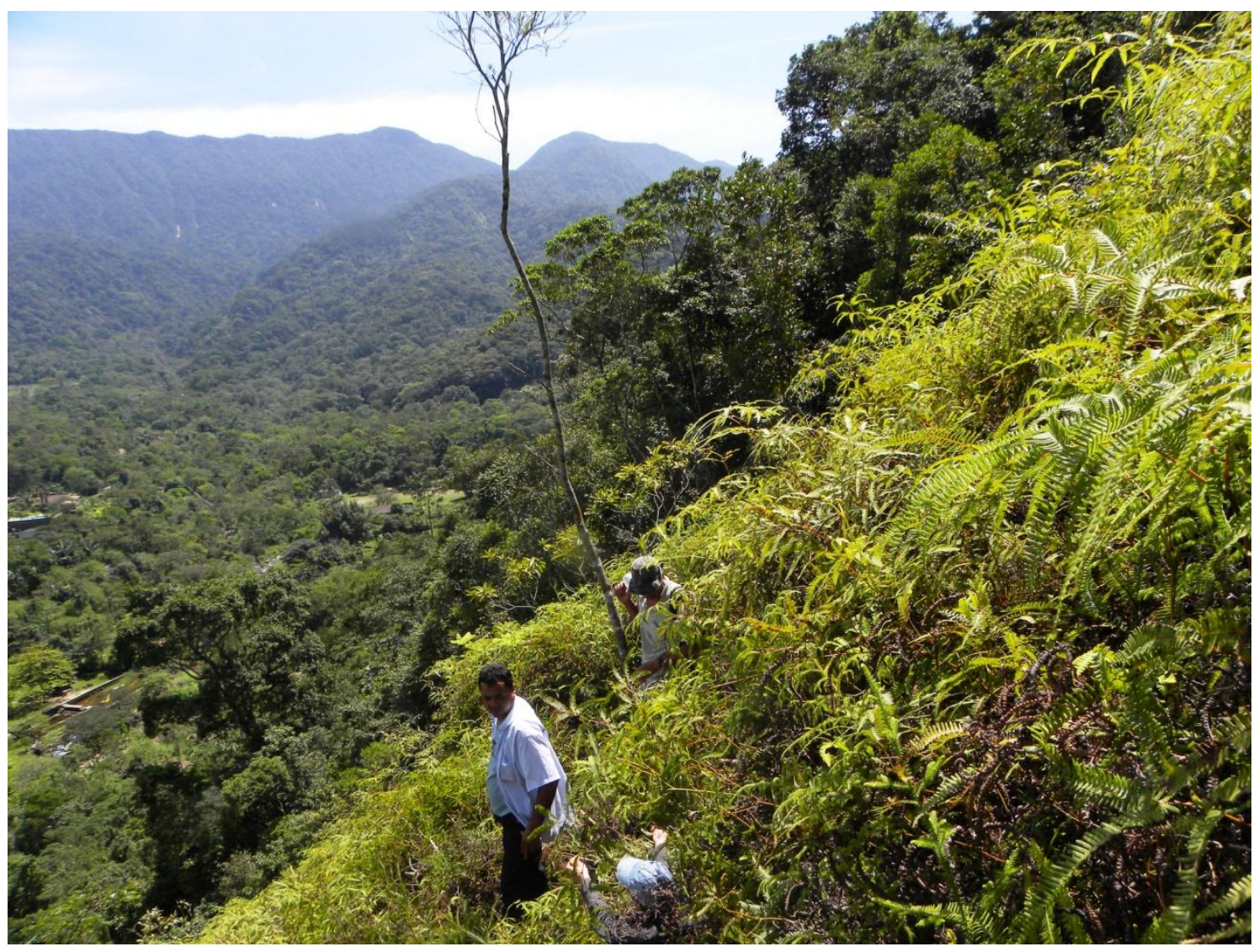

Figura 4.8. Vista da lateral da Cicatriz 2, onde também se observa a Gleycheniae uma cobertura vegetal bem preservada no seu entorno.

Com um perfil retilíneo orientado para Oeste, a Cicatriz 3 tem seu topo entre os 30 e $40^{\circ}$, apresentando ângulos mais suaves (20 a $30^{\circ}$ ) ao longo de sua extensão (Figura 4.9). Por se localizar próxima à base da encosta e apresentar algumas concavidades mais pontuais, sua área de contribuição é maior do que nas demais cicatrizes. 


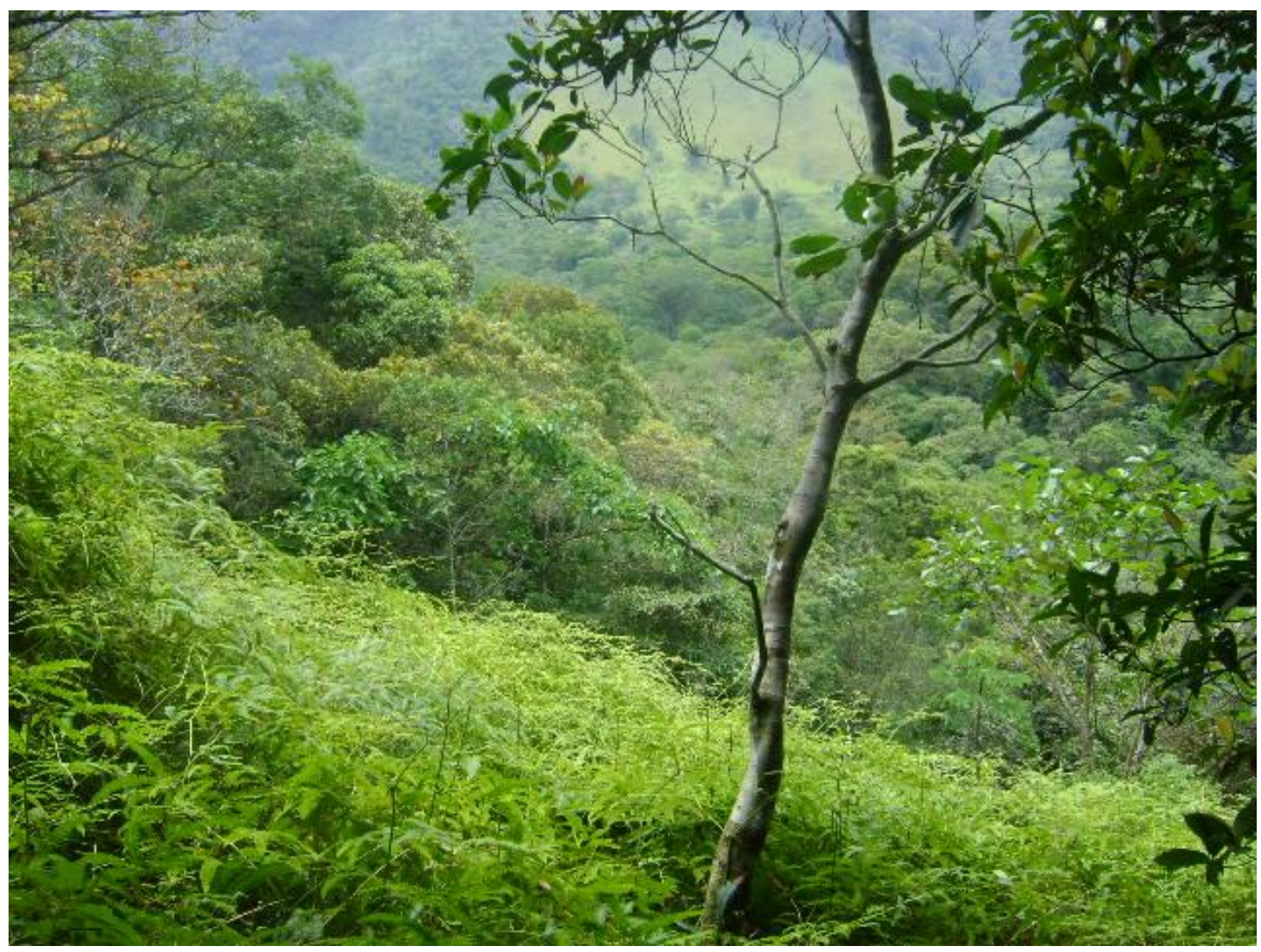

Figura 4.9. Vista do ponto do centro da Cicatriz 3, na qual indivíduos de árvores isoladas estão em meio à Gleychenia.

Após a definição das cicatrizes, foram realizados trabalhos de campo, para que fosse realizada uma caracterização morfológica preliminar dos solos, como ferramenta para a definição dos pontos onde seriam realizados as mensurações de condutividade hidráulica saturada.

Foram abertas trincheiras de aproximadamente um metro de profundidade nos locais onde seriam realizados os ensaios, e, por meio de análise tátil-visual, foram identificados os diferentes materiais. Mais detalhes sobre esta caracterização podem ser obtidos em Gomes et al. (2012).

As propriedades analisadas foram principalmente a textura e a estrutura dos perfis de alteração, assim como outras características que influenciam nos 
comportamentos geotécnico e hidrológico dos materiais, como, por exemplo, a descrição do sistema radicular em relação à profundidade e a existência de pipings, que podem contribuir no processo de infiltração durante eventos pluviométricos.

De forma geral, os 8 perfis apresentaram um padrão de variação com mudanças significativas da morfologia nas profundidades de 0,10-0,25 m (matriz mais grossa), 0,50-0,80 m (aumento das frações finas) e, sobretudo, aos 2,25-2,65 m, sendo nesta última a transição solo maduro/saprolito. Também foram encontrados minerais primários mais preservados a partir de 1,50 $\mathrm{m}$ de profundidade.

No perfil C1P1 (Cicatriz 01, topo), foi identificado, até a profundidade de 2,00 m, um corpo de tálus com matriz mais fina, cujos blocos decimétricos se concentraram mais próximos à superfície. Já no C1P2 predominou o saprolito com baixos teores de finos, com boa preservação da estrutura do material parental.

Nos perfis $\mathrm{C} 2 \mathrm{P} 1$ e $\mathrm{C} 2 \mathrm{P} 3$ os materiais encontrados possuem matriz fina, com um sistema radicular denso até $1,00 \mathrm{~m}$ de profundidade. No perfil $\mathrm{C} 2 \mathrm{P} 2$, observou-se novamente um material cuja origem não foi identificada, mas de matriz fina, sobre saprolito/rocha alterada dura.

Os perfis C3P1, C3P2 e C3P3 apresentaram material fino ao longo de todo o perfil, sendo que no $\mathrm{C} 3 \mathrm{P} 2$ houve um aumento da granulometria com a profundidade.

A partir desta caracterização, foram definidas as profundidades onde seriam realizados os ensaios de condutividade hidráulica saturada, sendo eles: 0.25 , $0.50,1.00,1.50,2.00$ e $2.50 \mathrm{~m}$. 


\subsection{Ensaios da $K_{\mathrm{sat}}$ in situ}

Considerando os procedimentos anteriores, os ensaios foram realizados em pontos com diferentes características topográficas e pedológicas, executados em diferentes pontos em superfície e em profundidade, para que fosse possível compreender tanto a distribuição lateral quanto a vertical da $\mathrm{K}_{\mathrm{sat}}$.

Com base em Vieira e Fernandes (2004), querealizaram medições de $\mathrm{K}_{\mathrm{sat}}$ em 4 cicatrizes de deslizamentos, tendo sido demarcados 4 pontos para as medições: no topo da cicatriz, dois pontos nas laterais e um ponto localizado no centro da cicatriz(Figura 4.10), foram definidos que os ensaios seriam realizados no topo (P1), na lateral (P2) e no centro $(\mathrm{P} 3)$ da cicatriz. Na cicatriz $\mathrm{C} 1$ não foi possível executar os ensaios em nenhuma das laterais, visto que a declividade era tão acentuada que não houve como apoiar o aparelho.

As profundidades foram definidas a partir da caracterização morfológica dos perfis de alteração, cuja avaliação permitiu identificar um padrão de variação com mudanças significativas da morfologia nas profundidades de $0,10-0,25 \mathrm{~m}$ (matriz mais grossa), 0,50-0,80 m (predomínio das frações finas) e, sobretudo, aos 2,25-2,65 m, sendo nesta última a transição solo maduro/saprolito. Desta forma, foram definidas as profundidades de $0,25 \mathrm{~m}, 0,50 \mathrm{~m}, 1,00 \mathrm{~m}, 1,50 \mathrm{~m}, 2,00 \mathrm{~m}$ e 2,50 m. 


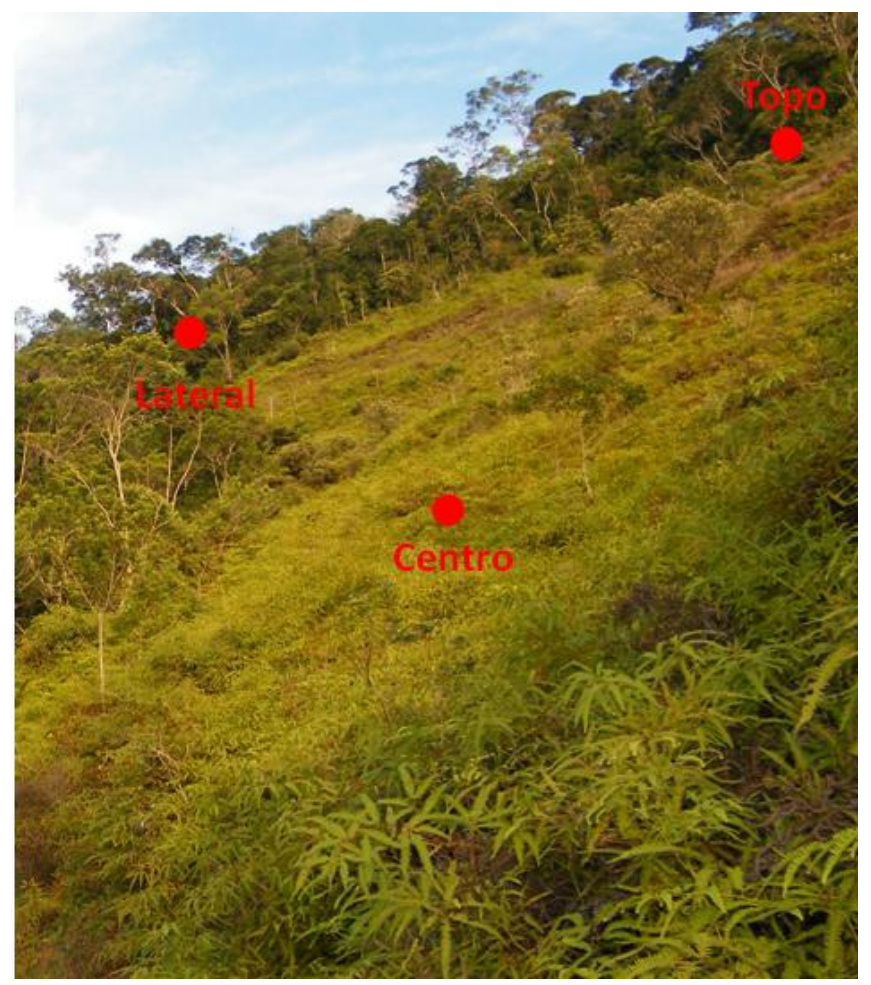

Figura 4.10.Exemplo dalocalização dos perfis abertos em uma cicatriz de escorregamento.

Para a abertura das trincheiras, foi observado se havia raízes de grande porte, que dificultariam o aprofundamento das mesmas, assim como a possibilidade derealizaçãodos ensaios com o permeâmetro na superfície do solo (medidas aos 0,25 e $0,50 \mathrm{~m}$ de profundidade) nas proximidades da trincheira.

Para que fosse possível posicionar adequadamente o PGM, as tricheiras foram abertas com aproximadamente $1,50 \mathrm{~m}$ de comprimento, $0,80 \mathrm{~m}$ de largura e 2,00 m de profundidade, dimensão que comportou o aparelho e uma pessoa para que o operasse em seu interior. 
Após o preparo da trincheira, faz-sea limpezadas roscas dos tubos de ar e de saída de águapara que os tubos fiquem bem vedados e, no caso de ocorrerem vazamentos, sugere-se que seja utilizado veda-rosca(Figura 4.11).A seguir, abastecêlo de água sem permitir a saída de água (deixar a ponteira de saída de água fechada).

O procedimento para a mensuração da $\mathrm{K}_{\text {sat }}$ com o Permeâmetro de Guelph Modificado seguiu as mesmas etapas utilizadas com o instrumento original (REYNOLDS et al., 1983; REYNOLDS e ELRICK, 1985)(Figura 4.12), ou seja:

- Abertura de um furo, neste caso, de 0,07 $\mathrm{m}$ de diâmetro, até a profundidade desejada;

- Verificação do furo para conferir se,durante a tradagem, não houve a compactação nas suas paredes e no fundo;

- Posicionamentodo PGMpreferencialmente já cheio de água, sobretudo quando o ensaio é realizado em locais de difícil apoio do aparelho, como encostas muito íngremes ou com afloramentos rochosos. Evitar que a ponteira de saída de água pressione o fundo ou as paredes do furo e compacte o mesmo e atentar para a posição da escala graduada do reservatório de água (para não dificultar a leitura);

- Estabelecer uma carga $\mathrm{H}$ por meio do levantamento da ponteira até a altura desejada (Figura 4.13). Este procedimento deve ser executado com atenção, de forma que a carga hidráulica aplicada não seja turbulenta; 
- Leitura do registro de queda d'água no reservatório em intervalo de tempo constante, geralmente na ordem de cm/s (Figura 4.14). Quando esta queda for constante em 3 leituras seguidas (no mesmo intervalo de tempo), tem-se o fluxo constante (steadystate)(Figura 4.15). No caso de utilização de apenas um par de dados $\mathrm{H}-\mathrm{Q}$ (utilizando as análises de Laplace e/ouElricket al.(1989)), o ensaio é finalizado. Caso sejam utilizados dois ou mais pares de H- Q (análise de Richards), deve-se estabelecer outro(s) valor(es) de carga, iniciando o ensaio imediatamente após o término do primeiro.
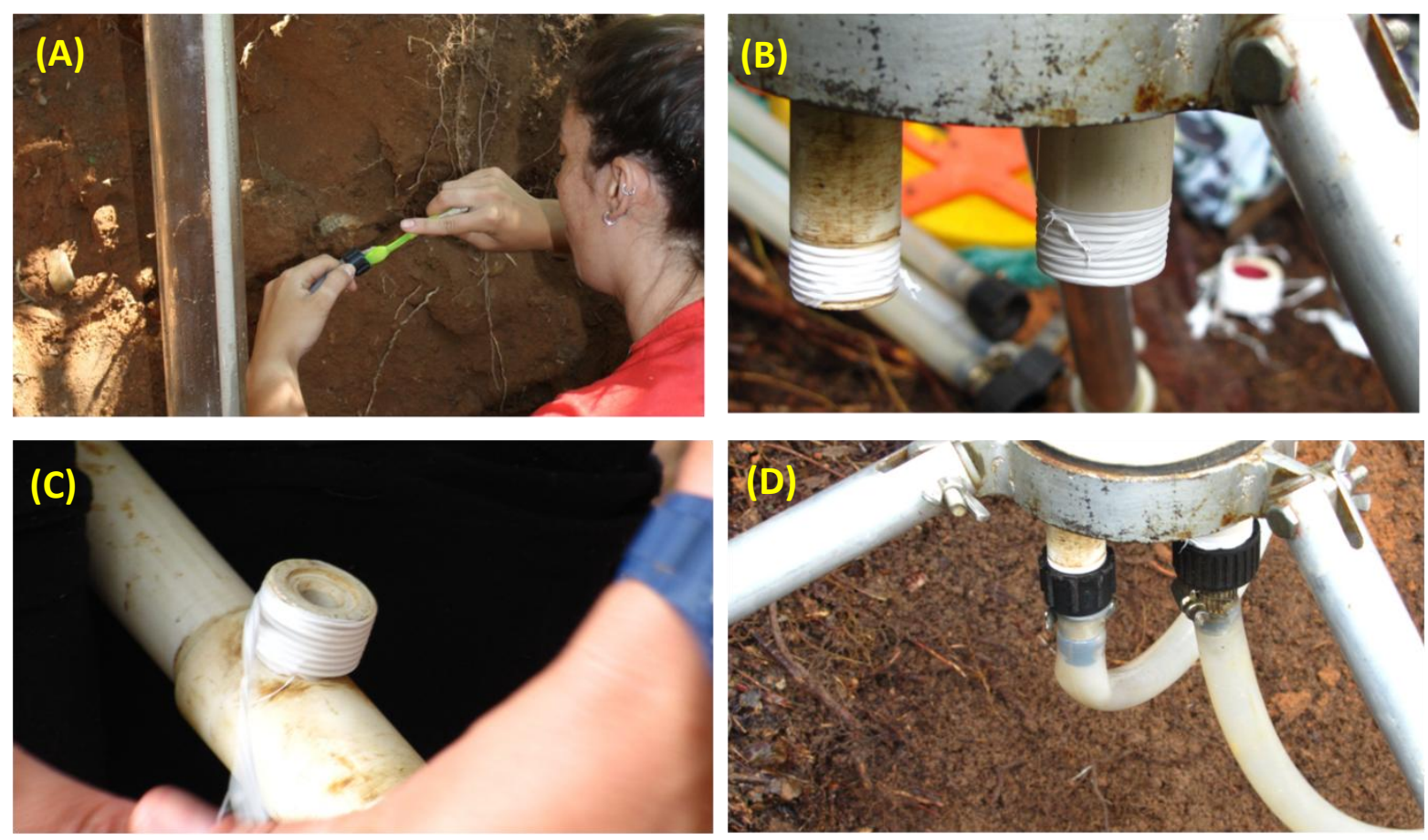

Figura 4.11.Procedimentos de montagem do PGM. Limpeza das roscas (A), utilização de veda-rosca nos tubos de ar e de água e na ponteira (B e C) e acoplamento das mangueiras nos tubos de ar e água (D). 

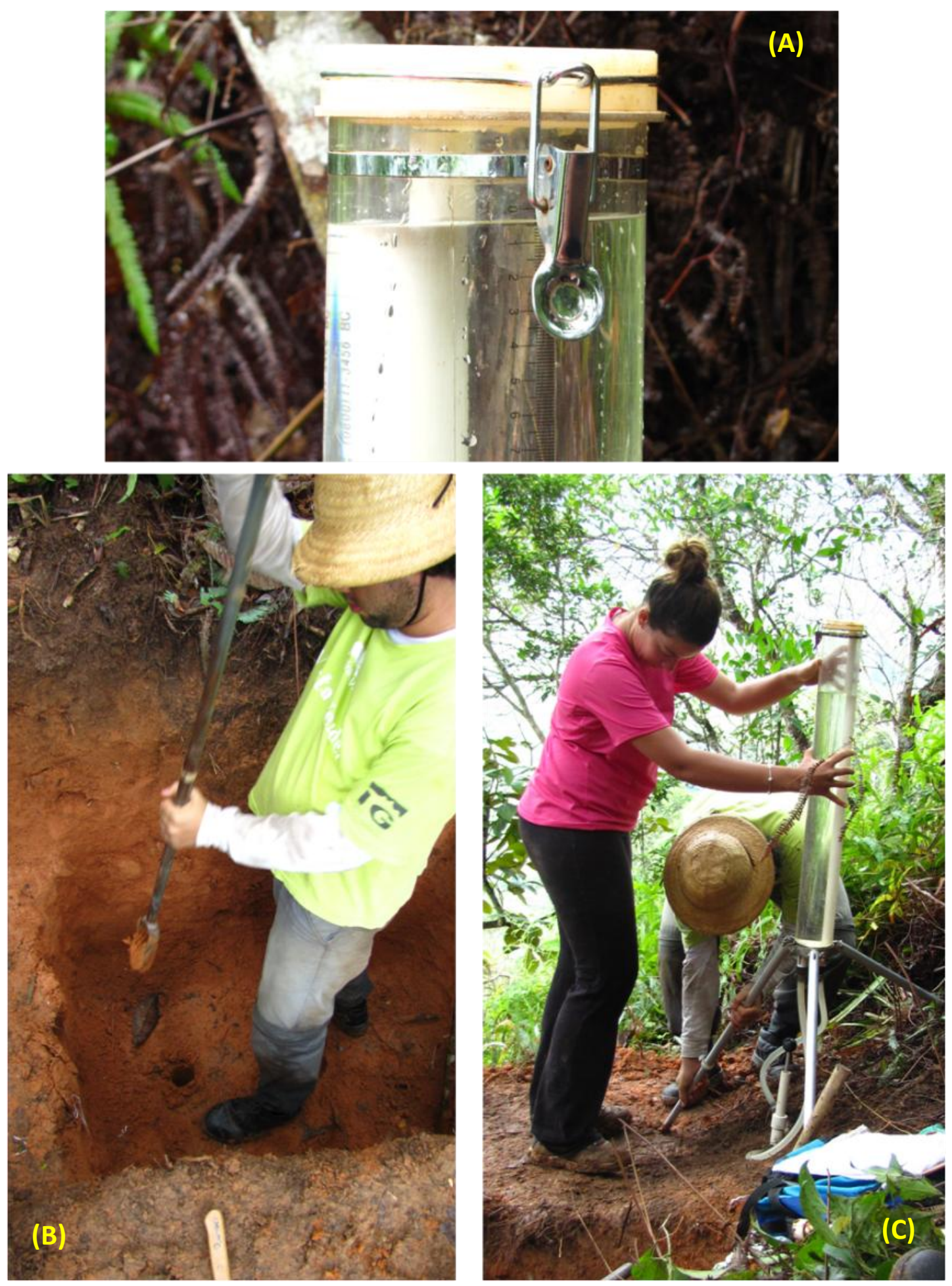

Figura 4.12. PGM com seu reservatório de água já abastecido (A); abertura do furo para posicionamento da ponteira no seu interior (B); e ajuste do tripé para o posicionamento do PGM para se realizar a leituraadequadamente $(\mathrm{C})$. 

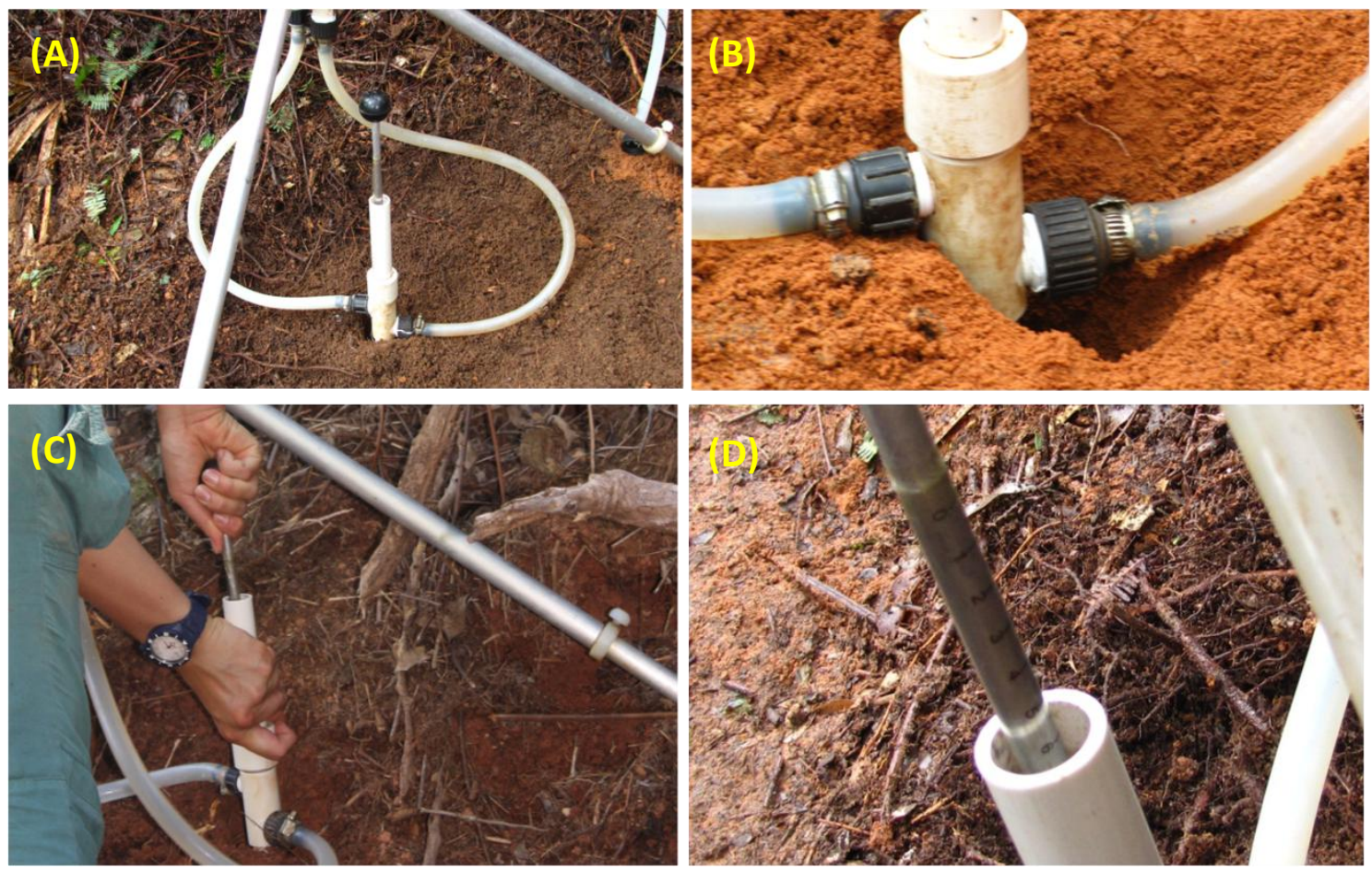

Figura 4.13.Ponteira posicionada no furo (A); detalhe do posicionamento no furo (B); aplicação da carga $\mathrm{H}$ (C); e marcação da carga $\mathrm{H}$ estabelecida (D).

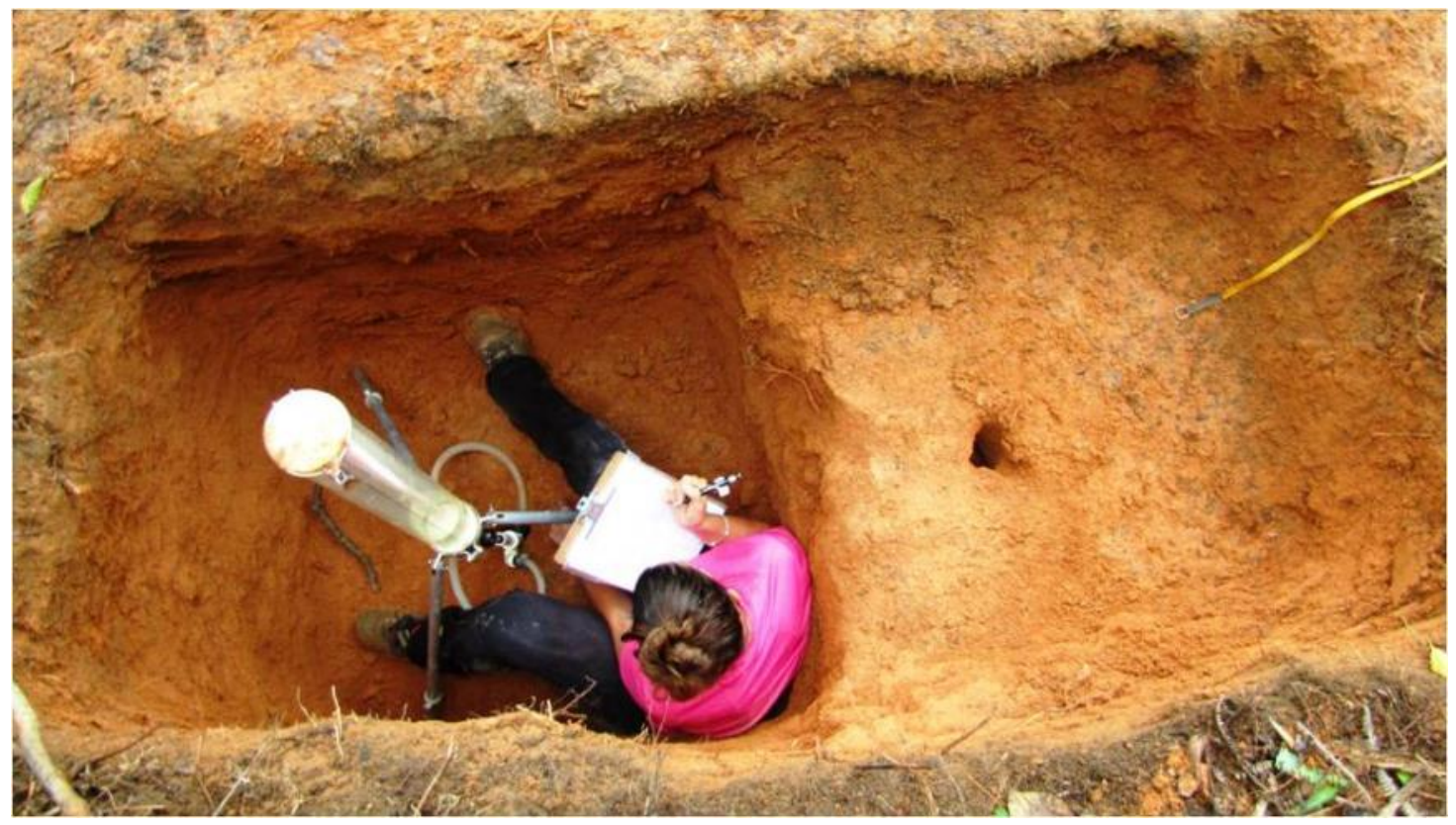

Figura 4.14. Leitura da queda d'água no PGM para se obter o valor Da vazão Q. 
ENSAIO DE PERMEABILIDADE

Data:_06/12/11

OBS:

Cicatriz:_do Bode

Ponto:_Superior

Profundidade:_2,00

Diâmetro do furo:

Uso:_Mata

CARGA $\mathrm{H}_{1}:{ }_{3}{ }_{3} \mathrm{~cm}$

\begin{tabular}{|c|c|c|c|}
\hline $\begin{array}{l}\text { № da } \\
\text { leitura }\end{array}$ & Tempo & $\begin{array}{c}\text { Nível da } \\
\text { água } \\
\text { (cm) }\end{array}$ & $\begin{array}{c}\text { Variação } \\
\text { da água } \\
\text { (cm) }\end{array}$ \\
\hline 1 & 0 & 19,1 & - \\
\hline 2 & $20 "$ & 26,3 & 7,2 \\
\hline 3 & $20 "$ & 27,6 & 1,3 \\
\hline 4 & $20 "$ & 28,8 & 1,2 \\
\hline 5 & 20" & 28,8 & 0 \\
\hline 6 & $1^{\prime}$ & 28,8 & 0 \\
\hline 7 & $2^{\prime}$ & 30,3 & 1,5 \\
\hline 8 & $2^{\prime}$ & 31,2 & 0,9 \\
\hline 9 & 2' & 33,1 & 1,9 \\
\hline 10 & $2^{\prime}$ & 34,4 & 1,3 \\
\hline 11 & $2^{\prime}$ & 35,5 & 1,1 \\
\hline 12 & $2^{\prime}$ & 36,9 & 1,4 \\
\hline 13 & $2^{\prime}$ & 38,0 & 1,1 \\
\hline 14 & $2^{\prime}$ & 39,3 & 1,3 \\
\hline 15 & $2^{\prime}$ & 40,4 & 1,1 \\
\hline 16 & $2^{\prime}$ & 41,6 & 1,2 \\
\hline 17 & 2' & 42,5 & 0,9 \\
\hline 18 & $2^{\prime}$ & 43,7 & 1,2 \\
\hline 19 & $2^{\prime}$ & 44,9 & 1,2 \\
\hline 20 & $2^{\prime}$ & 46,1 & 1,2 \\
\hline \multicolumn{4}{|l|}{21} \\
\hline \multicolumn{4}{|l|}{22} \\
\hline \multicolumn{4}{|l|}{23} \\
\hline \multicolumn{4}{|l|}{24} \\
\hline \multicolumn{4}{|l|}{25} \\
\hline \multicolumn{4}{|l|}{26} \\
\hline \multicolumn{4}{|l|}{27} \\
\hline \multicolumn{4}{|l|}{27} \\
\hline \multicolumn{4}{|l|}{29} \\
\hline 30 & & & \\
\hline
\end{tabular}

CARGA $\mathrm{H}_{2}:\left[6,4 \_\mathrm{cm}\right.$

\begin{tabular}{|c|c|c|c|}
\hline $\begin{array}{l}\text { № da } \\
\text { leitura }\end{array}$ & Tempo & $\begin{array}{c}\text { Nível da } \\
\text { água } \\
\text { (cm) }\end{array}$ & $\begin{array}{c}\text { Variação } \\
\text { da água } \\
\text { (cm) }\end{array}$ \\
\hline 1 & 0 & 48,5 & - \\
\hline 2 & $2^{\prime}$ & 49,2 & 0,7 \\
\hline 3 & $2^{\prime}$ & 51,0 & 1,8 \\
\hline 4 & $2^{\prime}$ & 52,8 & 1,8 \\
\hline 5 & $2^{\prime}$ & 53,9 & 1,1 \\
\hline 6 & $2^{\prime}$ & 55,6 & 1,7 \\
\hline 7 & $2^{\prime}$ & 46,8 & 1,2 \\
\hline 8 & $2^{\prime}$ & 57,5 & 0,7 \\
\hline 9 & $2^{\prime}$ & 58,9 & 1,7 \\
\hline 10 & $2^{\prime}$ & 60,1 & 1,2 \\
\hline 11 & 2' & 61,3 & 1,2 \\
\hline 12 & $2^{\prime}$ & 62,5 & 1,2 \\
\hline 13 & $2^{\prime}$ & 63,7 & 1,2 \\
\hline 14 & & & \\
\hline 15 & & & \\
\hline 16 & & & \\
\hline 17 & & & \\
\hline 18 & & & \\
\hline 19 & & & \\
\hline 20 & & & \\
\hline 21 & & & \\
\hline 22 & & & \\
\hline 23 & & & \\
\hline 24 & & & \\
\hline 25 & & & \\
\hline 26 & & & \\
\hline 27 & & & \\
\hline 27 & & & \\
\hline 29 & & & \\
\hline 30 & & & \\
\hline
\end{tabular}

Figura 4.15. Ficha utilizada em campo para registro dos ensaios. Em vermelho estão as leituras realizadas quando o fluxo d'água já estava constante (steadystate). 
4.4 Análise das propriedades físicas dos solos na variabilidade espacial da $K_{\text {sat }}$

Conformemencionado anteriormente, a condutividade hidráulica é uma propriedade hidrológica cuja variação depende diretamente das propriedades dos solos. A caracterização destas propriedades permite que seja avaliada a influência destas na variação de $\mathrm{K}_{\text {sat }}$ e, se possível, identificar padrões de variação da $\mathrm{K}_{\text {sat }}$ em relação às variações nas propriedades físicas.

Estas propriedades dos solosforam analisadas a partirdos dados disponíveis em Ferreira (em fase de elaboração) ${ }^{2}$, que realizou ensaios granulométricos, de porosimetria, de resistência ao cisalhamento (coesão e ângulo de atrito) e Limites de Atterberg nos mesmos pontos e profundidades desta pesquisa.

\footnotetext{
${ }^{2}$ Análise das propriedades físicas dos solos na deflagração dos escorregamentos translacionais rasos na Serra do Mar (SP), de autoria de Fabiana Souza Ferreira, dissertação a ser defendida no Departamento de Geografia da Fac. De Fil. Letras e Cien Humanas da Universidade de São Paulo em 2012.
} 


\section{RESULTADOS E DISCUSSÕES}

Neste capítulo, inicialmente, serão apresentados e discutidos os resultados da $\mathrm{K}_{\text {sat }}$ obtidos in situ com o Permeâmetro de Guelph Modificado em três cicatrizes a partir das análises de Laplace, Richards e a análise proposta por Elricket al. (1989) (5.1). Posteriormente, será analisada a variabilidade espacial da $\mathrm{K}_{\mathrm{sat}}$ levando-se em conta os dados das propriedades físicas dos solos (5.2) e, por fim, será discutida a variabilidade da $\mathrm{K}_{\text {sat }}$ associada aos parâmetros topográficos e de resistência ao cisalhamento em relação aos escorregamentos rasos deflagrados em 1967 (5.3), buscando compreender melhor os fatores controlados destes processos.

\subsection{Valores da $\mathbf{K}_{\mathrm{sa}}$ in situ}

Foram obtidos 41 valores de Q em campo, sendo que em apenas 2 ensaios não houve fluxo constante, o que inviabilizou o levantamento $\mathrm{K}_{\text {sat }}$ naquelas profundidades.

Por terem sido aplicadas 2 cargas $\mathrm{H}$ em cada profundidade, utilizou-se primeiramente para o cálculo da $\mathrm{K}_{\mathrm{sat}}$ a análise $\mathrm{K}_{\mathrm{sat}} \mathrm{R}$. Contudo, uma significativa parcela dos valores obtidos (40\%) foinegativa, corroborando com as porcentagens de valores negativos obtidos em outros trabalhos que utilizaram esta análise. Reynolds e Elrick (1985) obtiveram entre 27 e $45 \%$ de valores negativos em solo franco heterogêneo, Vieira (2001) encontrou $43 \%$ e Soto et al. (2009) apenas $25 \%$, justificado, segundo autores, pelo cuidado intensivo nos procedimentos experimentais. 
Assim como os referidos trabalhos, Salverda e Dane (1993), testando o PG em diferentes condições daquelas em que este método havia sido testado anteriormente,realizaram os ensaios em materiais siltosos, areno-siltosos e silto-arenosos, encontraram, em média, $41 \%$ de valores negativos. O material que apresentou maior porcentagem de valores negativos foi o silto-arenoso (55\%).

Reynolds e Elrick (1985) e Elricket al. (1989) afirmam que a superestimação da $\mathrm{K}_{\mathrm{sat}} \mathrm{R}$ é consequência de um aumento mais do que proporcional de $\mathrm{Q}$ com o aumento da carga $\mathrm{H}$. Isto quer dizer que a segunda carga aplicada forma um bulbo saturado em um material com diferentes características daquele onde foi formado o bulbo da aplicação da carga menor. Geralmente este material tem valores maiores de $\mathrm{K}_{\text {sat }}$, devido principalmente à macroporosidade (AMOOZEGAR, 1989; SALVERDA e DANE, 1993; SOTO et al., 2009). Quando os valores de Q são inseridos nas equações de fluxo, como o valor de $\mathrm{Q}_{1}$ é subtraído do valor de $\mathrm{Q}_{2}$ (como será esclarecido a seguir), se há um aumento mais do que proporcional na segunda carga, o valor final da $\mathrm{K}_{\text {sat }}$ será superestimado.

Ainda que os valores negativos sejam uma limitação importante da análise $\mathrm{K}_{\mathrm{sat}}{ }^{-}$ $\mathrm{R}$, deve-se atentar para a representatividade dos valores positivos (REYNOLDS e ELRICK, 1985). Tais autores afirmam que, se os valores positivos subestimarem aqueles obtidos por $\mathrm{K}_{\mathrm{sat}} \mathrm{L}$ e $\mathrm{K}_{\mathrm{sat}}-\mathrm{U}$ (devido às forças capilares), sugere-se que sejam desconsiderados os valores negativos e utilizem-se os resultados positivos encontrados.

A média dos valores obtidos em cada análise foi de $7,3 \times 10^{-5} \mathrm{~m} / \mathrm{s}\left(\mathrm{K}_{\mathrm{sat}} \mathrm{L}\right)$, $1,1 \times 10^{-4} \mathrm{~m} / \mathrm{s}\left(\mathrm{K}_{\mathrm{sat}}-\mathrm{R}\right)$ e $3,2 \times 10^{-5}\left(\mathrm{~K}_{\mathrm{sat}}-\mathrm{U}\right)$. Os resultados obtidos por meio de cada análise em cada cicatriz ( $\mathrm{C} 1, \mathrm{C} 2$ e $\mathrm{C} 3)$ e em cada um dos pontos (P1, P2 e P3) são descritos na Tabela 5.1. 
Tabela 5.1. Valores de $K_{\text {sat }}$ obtidos com as equações de Laplace $\left(K_{\text {sat }}-L\right)$, Richards $\left(K_{\text {sat }}-R\right)$ e Elricket al. (1989) $\left(\mathrm{K}_{\mathrm{sat}}-\mathrm{U}\right)$.

\section{Cicatriz da Cachoeira (C1)}

\begin{tabular}{c|l|c|c|}
\hline \multicolumn{4}{|c}{ Ponto Superior (C1P1) } \\
\hline $\begin{array}{c}\text { Prof. } \\
(\mathrm{m})\end{array}$ & $\begin{array}{l}\mathrm{K}_{\text {sat }}-\mathbf{R} \\
(\mathrm{m} / \mathbf{s})\end{array}$ & $\begin{array}{c}\mathrm{K}_{\text {sat-L }} \\
(\mathrm{m} / \mathbf{s})\end{array}$ & $\begin{array}{c}\mathrm{K}_{\text {sat-U }} \\
(\mathrm{m} / \mathbf{s})\end{array}$ \\
\hline 0,25 & $1,6 \times 10^{-5}$ & $1,2 \times 10^{-4}$ & $7,3 \times 10^{-5}$ \\
\hline 0,50 & Negativo & $2,5 \times 10^{-4}$ & $1,4 \times 10^{-4}$ \\
\hline 1,00 & Negativo & $1,2 \times 10^{-4}$ & $7,4 \times 10^{-5}$ \\
\hline 1,50 & $9,0 \times 10^{-5}$ & $1,9 \times 10^{-4}$ & $1,1 \times 10^{-4}$ \\
\hline 2,00 & $5,2 \times 10^{-6}$ & $2,1 \times 10^{-4}$ & $1,7 \times 10^{-4}$ \\
\hline 2,50 & $1,7 \times 10^{-6}$ & $1,4 \times 10^{-4}$ & $1,1 \times 10^{-4}$ \\
\hline
\end{tabular}

\begin{tabular}{|c|c|c|c}
\hline \multicolumn{4}{|c}{ Ponto Centro (C1P2) } \\
\hline $\begin{array}{c}\text { Prof. } \\
(\mathrm{m})\end{array}$ & $\begin{array}{c}\mathrm{K} \text { sat-R } \\
(\mathrm{m} / \mathrm{s})\end{array}$ & $\begin{array}{c}\mathrm{K} \text { sat-L } \\
(\mathrm{m} / \mathrm{s})\end{array}$ & $\begin{array}{c}\mathrm{K} \text { sat-U } \\
(\mathrm{m} / \mathrm{s})\end{array}$ \\
\hline 0,25 & - & $2,0 \times 10^{-6}$ & $1,2 \times 10^{-6}$ \\
\hline 0,50 & - & $5,9 \times 10^{-5}$ & $1,9 \times 10^{-5}$ \\
\hline 1,00 & - & - & - \\
\hline 1,50 & - & - & - \\
\hline 2,00 & - & - & - \\
\hline 2,50 & - & - & - \\
\hline
\end{tabular}

Cicatriz do Bode (C2)

\begin{tabular}{|c|c|c|c|c|c|c|c|c|c|c|c|}
\hline \multicolumn{4}{|c|}{ Ponto Superior (C2P1) } & \multicolumn{4}{|c|}{ Ponto Lateral (C2P3) } & \multicolumn{4}{|c|}{ Ponto Centro (C2P2) } \\
\hline $\begin{array}{l}\text { Prof. } \\
\text { (m) }\end{array}$ & $\begin{array}{l}\begin{array}{l}K_{\text {sat-R }} \\
(\mathrm{m} / \mathrm{s})\end{array} \\
\end{array}$ & $\begin{array}{l}K_{\text {sat-L }} \\
(\mathrm{m} / \mathrm{s})\end{array}$ & $\begin{array}{l}K_{\text {sat-U }} \\
(\mathrm{m} / \mathrm{s})\end{array}$ & $\begin{array}{c}\text { Prof. } \\
\text { (m) }\end{array}$ & $\begin{array}{l}K_{\text {sat }}-R \\
(\mathrm{~m} / \mathrm{s})\end{array}$ & $\begin{array}{l}\mathrm{K}_{\text {sat }}-\mathrm{L} \\
(\mathrm{m} / \mathrm{s})\end{array}$ & $\begin{array}{l}K_{\text {sat-U }} \\
(\mathrm{m} / \mathrm{s})\end{array}$ & $\begin{array}{l}\text { Prof. } \\
\text { (m) }\end{array}$ & $\begin{array}{l}K_{\text {sat }}-R \\
(\mathrm{~m} / \mathrm{s})\end{array}$ & $\begin{array}{l}K_{\text {sat }}-\mathrm{L} \\
(\mathrm{m} / \mathrm{s})\end{array}$ & $\begin{array}{l}K_{\text {sat-U }} \\
(\mathrm{m} / \mathrm{s}) \\
\end{array}$ \\
\hline 0,25 & - & $3,5 \times 10^{-6}$ & $2,7 \times 10^{-6}$ & 0,25 & Negativo & $1,3 \times 10^{-6}$ & $7,7 \times 10^{-7}$ & 0,25 & $3,6 \times 10^{-5}$ & $1,5 \times 10^{-5}$ & $9,2 \times 10^{-6}$ \\
\hline 0,50 & Negativo & $1,0 \times 10^{-5}$ & $7,7 \times 10^{-6}$ & 0,50 & $2,1 \times 10^{-5}$ & $1,2 \times 10^{-4}$ & $7,3 \times 10^{-5}$ & 0,50 & Negativo & $3,5 \times 10^{-5}$ & $2,0 \times 10^{-5}$ \\
\hline 1,00 & Negativo & $1,5 \times 10^{-5}$ & $9,2 \times 10^{-6}$ & 1,00 & $2,9 \times 10^{-5}$ & $3,5 \times 10^{-5}$ & $2,0 \times 10^{-5}$ & 1,00 & $2,2 \times 10^{-5}$ & $5,9 \times 10^{-6}$ & $3,4 \times 10^{-6}$ \\
\hline 1,50 & Negativo & $5,9 \times 10^{-5}$ & $3,4 \times 10^{-5}$ & 1,50 & - & $1,3 \times 10^{-5}$ & $8,1 \times 10^{-6}$ & 1,50 & - & - & - \\
\hline 2,00 & $3,2 \times 10^{-5}$ & $2,3 \times 10^{-5}$ & $1,3 \times 10^{-5}$ & 2,00 & $2,7 \times 10^{-6}$ & $8,9 \times 10^{-6}$ & $5,2 \times 10^{-6}$ & 2,00 & - & - & - \\
\hline 2,50 & $7,0 \times 10^{-6}$ & $5,9 \times 10^{-5}$ & $3,4 \times 10^{-5}$ & 2,50 & $9,02 \times 10^{-6}$ & $4,7 \times 10^{-5}$ & $2,7 \times 10^{-5}$ & 2,50 & - & - & - \\
\hline
\end{tabular}

Cicatriz do Toco Preto (C3)

\begin{tabular}{|c|c|c|c|c|c|c|c|c|c|c|c|}
\hline \multicolumn{4}{|c|}{ Ponto Superior (C3P1) } & \multicolumn{4}{|c|}{ Ponto Lateral (C3P3) } & \multicolumn{4}{|c|}{ Ponto Centro (C3P2) } \\
\hline $\begin{array}{c}\text { Prof. } \\
(\mathrm{m})\end{array}$ & $\begin{array}{c}K_{\text {sat }}-R \\
(\mathrm{~m} / \mathrm{s})\end{array}$ & $\begin{array}{l}K_{\text {sat }}-\mathrm{L} \\
(\mathrm{m} / \mathrm{s})\end{array}$ & $\begin{array}{l}K_{\text {sat }} U \\
(\mathrm{~m} / \mathrm{s})\end{array}$ & $\begin{array}{c}\text { Prof. } \\
(\mathrm{m})\end{array}$ & $\begin{array}{c}K_{\text {sat }}-R \\
(\mathrm{~m} / \mathrm{s})\end{array}$ & $\begin{array}{l}K_{\text {sat }}-L \\
(\mathrm{~m} / \mathrm{s})\end{array}$ & $\begin{array}{l}K_{\text {sat }} U \\
(\mathrm{~m} / \mathrm{s})\end{array}$ & $\begin{array}{c}\text { Prof. } \\
\text { (m) }\end{array}$ & $\begin{array}{c}K_{\text {sat }}-R \\
(\mathrm{~m} / \mathrm{s}) \\
\end{array}$ & $\begin{array}{l}K_{\text {sat }}-L \\
(\mathrm{~m} / \mathrm{s})\end{array}$ & $\begin{array}{l}K_{\text {sat }}-U \\
(\mathrm{~m} / \mathrm{s}) \\
\end{array}$ \\
\hline 0,25 & $3,1 \times 10^{-4}$ & $8,4 \times 10^{-5}$ & $4,9 \times 10^{-5}$ & 0,25 & - & $1,2 \times 10^{-5}$ & $1,0 \times 10^{-5}$ & 0,25 & $5,1 \times 10^{-5}$ & $1,5 \times 10^{-5}$ & $1,1 \times 10^{-5}$ \\
\hline 0,50 & Negativo & $9,5 \times 10^{-5}$ & $5,5 \times 10^{-5}$ & 0,50 & - & $1,1 \times 10^{-5}$ & $6,9 \times 10^{-6}$ & 0,50 & $8,7 \times 10^{-6}$ & $1,5 \times 10^{-5}$ & $9,2 \times 10^{-6}$ \\
\hline 1,50 & $8,7 \times 10^{-6}$ & $1,5 \times 10^{-5}$ & $9,2 \times 10^{-6}$ & 1,50 & $4,0 \times 10^{-6}$ & $1,3 \times 10^{-7}$ & $1,0 \times 10^{-6}$ & 1,50 & $1,6 \times 10^{-3}$ & $1,5 \times 10^{-5}$ & $9,2 \times 10^{-6}$ \\
\hline 2,00 & Negativo & $7,1 \times 10^{-5}$ & $4,1 \times 10^{-5}$ & 2,00 & Negativo & $6,5 \times 10^{-5}$ & $3,8 \times 10^{-5}$ & 2,00 & $2,9 \times 10^{-5}$ & $9,5 \times 10^{-5}$ & $5,5 \times 10^{-5}$ \\
\hline 2,50 & Negativo & $5,9 \times 10^{-6}$ & $3,4 \times 10^{-6}$ & 2,50 & Negativo & $7,1 \times 10^{-5}$ & $4,1 \times 10^{-5}$ & 2,50 & Negativo & $6,3 \times 10^{-4}$ & $3,7 \times 10^{-4}$ \\
\hline
\end{tabular}


Dos 21 valores obtidos pela $\mathrm{K}_{\text {sat }}-\mathrm{R}$, aproximadamente $71 \%$ subestimaram os valores de pelo menos uma das demais análises, ou seja, foram menores que aqueles obtidos por $\mathrm{K}_{\mathrm{sat}}-\mathrm{L}$ ou $\mathrm{K}_{\text {sat }}-\mathrm{U}$, enquanto $20 \%$ os superestimam. Nota-se que a maioria dos valores subestimados por $\mathrm{K}_{\mathrm{sat}}-\mathrm{R}$ ocorreram na profundidade de $1,00 \mathrm{~m}$, enquanto aqueles superestimados foram encontrados aos $0,25 \mathrm{~m}$.

Analisando estes resultados, observou-se que a distribuição dos valores superestimados por $\mathrm{K}_{\mathrm{sat}}-\mathrm{R}$ poderiam estar associados à distribuição granulométrica ao longo do perfil de solo. Aos $0,25 \mathrm{~m}$, onde há relativamente maior concentração de areia no solo residual, maior número de macroporos e maior teor de matéria orgânica, a $\mathrm{K}_{\mathrm{sat}}-\mathrm{R}$ foi superestimada.Já a 1,00 m de profundidade, com maior concentração de valores subestimados, tais valores podem estar associados a um material com maior capilaridade, ou seja, de menor granulometria, como as argilas. Esta tendência pode ser observada nos valores da $\mathrm{K}_{\text {sat }}-\mathrm{R}$ no ponto $\mathrm{C} 2 \mathrm{P} 3$, no qual todos os valores obtidos, na ordem de $10^{-6} \mathrm{~m} / \mathrm{s}$, considerados de baixa permeabilidade, subestimaram os demais valores. Da mesma maneira, o ponto C1P1, perfil composto por um corpo de tálus de matriz fina e blocos decimétricos, teve todos os valores a partir da $\mathrm{K}_{\text {sat }}-\mathrm{R}$ subestimados, apresentando uma diferença para $\mathrm{K}_{\mathrm{sat}}-\mathrm{L}$ e $\mathrm{K}_{\mathrm{sat}}-\mathrm{U}$ de até duas ordens de grandeza. Um exemplo disso são os valores a partir das três equações (Equações 3, 10 e 13), aos 2,50 m, onde $K_{\text {sat }}-R$ foi $1,7 \times 10^{-6}, \mathrm{~K}_{\mathrm{sat}}-\mathrm{L} 1,4 \times 10^{-4}$ e $\mathrm{K}_{\mathrm{sat}}-\mathrm{U} 1,1 \times 10^{-4} \mathrm{~m} / \mathrm{s}$. 
Considerando esta possível superestimação da $\mathrm{K}_{\text {sat }}-\mathrm{R}$ e, sobretudo, a necessidade de valores de todas as profundidades, optou-se por analisar a variabilidade espacial da $\mathrm{K}_{\mathrm{sat}}$ a partir dos valores obtidos pela equação de Laplace e aquela proposta por Elricket al. (1989). Além disso, não foi possível comparar as análises, visto que o número de valores positivos foi de aproximadamente $50 \%$ dos obtidos pelas equações de Laplace e Elricket al. (1989).

Os valores, pela análise de Elricket al. (1989), variaram entre $10^{-4}$ e $10^{-7} \mathrm{~m} / \mathrm{s}$, predominando entre as ordens de grandeza $10^{-5}$ e $10^{-6} \mathrm{~m} / \mathrm{s} \quad(47,5 \%$ e $35 \%$, respectivamente,e $82,5 \%$ no total). Estes valores monstram a baixa permeabilidade dos perfis de alteração investigados, e corroboram com os trabalhos desenvolvidos na Serra do Mar por Carvalho (1989), Campos et al. (1992), Vieira e Fernandes (2004) e Mendes (2008) (Tabela 5.2).

Tabela 5.2. Valores de $\mathrm{K}_{\mathrm{sat}} \mathrm{obtidos}$ por diversos autores na Serra do Mar.

\begin{tabular}{cccc}
\hline Trabalho & Local & $\begin{array}{c}\text { Valores de K } \\
\text { obtidos em campo } \\
(\mathbf{m} / \mathbf{s})\end{array}$ & Valor com maior \% \\
\hline Carvalho (1989) & Cubatão/SP & $10^{-5}$ a $10^{-8}$ & $10^{-6}$ \\
\hline $\begin{array}{c}\text { Campos } \text { et al. } \\
(1992)\end{array}$ & Rio de Janeiro/RJ & $10^{-5}$ a $10^{-7}$ & $10^{-5}$ \\
\hline $\begin{array}{c}\text { Vieira e } \\
\text { Fernandes (2004) }\end{array}$ & Rio de Janeiro/RJ & $10^{-4}$ a $10^{-7}$ & $10^{-5}$ \\
\hline $\begin{array}{c}\text { Mendes (2008) } \\
\text { Gomes e Vieira } \\
(2012)\end{array}$ & Ubatuba/SP & $10^{-5}$ a $10^{-7}$ & $10^{-7}$ \\
\hline
\end{tabular}




\subsection{Variação espacial da $K_{\mathrm{sat}} \mathrm{e}$ as propriedades físicas dos solos}

Conforme dito no capítulo anterior, os valores de $\mathrm{K}_{\text {sat }}$ que serão aqui apresentados são referentes à análise de Elricket al. (1989), devido à impossibilidade de se analisar a espacialidade do pequeno número de valores positivos obtidos a partir de $\mathrm{K}_{\mathrm{sat}}-\mathrm{R}$, mesmo esta sendo, teoricamente, a mais indicada em trabalhos com esta finalidade.

Destaca-se que os valores de $\mathrm{K}_{\text {sat }}-\mathrm{U}$ foram muito próximos daqueles obtidos por $\mathrm{K}_{\mathrm{sat}}-\mathrm{L}$, mas optou-se por utilizá-lo pois, conforme o exposto no capítulo 2, esta análise possui um termo que representa a textura e estrutura do solo ensaiado.

Os valores obtidos variaram entre as ordens de grandeza $10^{-4}$ e $10^{-7} \mathrm{~m} / \mathrm{s}$, sendo que aproximadamente $82 \%$ destes entre $10^{-5}$ e $10^{-6} \mathrm{~m} / \mathrm{s}$. A concentração dos valores em apenas duas ordens de grandeza não era esperada neste trabalho, devido à heterogeneidade dos materiais e a grande variabilidade espacial desta propriedade. A existência de vegetação em diferentes estágios sucessionais, espécies com diferentes sistemas radiculares, solos mais argilosos, solos predominantemente arenosos, saprolito, regolito, solos coluvionares, rochas fraturadas, dentre outras características dos meios físico e biótico, levaria a maior variabilidade espacial da $\mathrm{K}_{\text {sat }}$. Isto mostra que a variação da $\mathrm{K}_{\mathrm{sat}}$ depende do arranjo destas características, devendo-se analisá-las, se possível, em conjunto.

Considerando a distribuição dos valores nas 3 cicatrizes (C1, C2 e C3), observou-se que na $\mathrm{C} 1$ e na $\mathrm{C} 3$ os valores de $\mathrm{K}_{\text {sat }}$ variaram entre $10^{-4}$ e $10^{-6} \mathrm{~m} / \mathrm{s}$, sendo mais frequente a ordem de $10^{-4} \mathrm{~m} / \mathrm{s}$ na Cicatriz 1 e de $10^{-5} \mathrm{~m} / \mathrm{s}$ na Cicatriz 3. Já na Cicatriz 2 os valores variaram entre $10^{-5}$ e $10^{-7} \mathrm{~m} / \mathrm{s}$, predominando as ordens $10^{-5}$ e $10^{-6}$ $\mathrm{m} / \mathrm{s}$. 
Em relação às propriedades físicas dos solos, observou-se, por meio do levantamento realizado por Ferreira (em fase de elaboração) ${ }^{3}$ nos mesmos perfis de solo onde foram realizados os ensaios de $\mathrm{K}_{\text {sat }}$, solos em sua maioria silto-arenosos e arenosiltosos, havendo apenas um perfil de matriz argilosa e um solo franco-siltoso.

Quanto à distribuição em relação à localização dos perfis nas cicatrizes, os valores obtidos nospontos do topo predominaram na ordem de $10^{-5} \mathrm{~m} / \mathrm{s}$, assim como nos pontos laterais, enquanto nos pontos do centro os valores mais frequentes foram na ordem $\operatorname{de} 10^{-6} \mathrm{~m} / \mathrm{s}$.

\subsubsection{Cicatriz 1}

No primeiro ponto da Cicatriz 1 (C1P1), localizado a 3 metros do seu topo, a variação da $\mathrm{K}_{\text {sat }}$ Ocorreu entre as ordens de grandeza $10^{-4}$ e $10^{-5} \mathrm{~m} / \mathrm{s}$, com uma tendência de aumento a partir de 1,00 m de profundidade (Figura 5.1). Trata-se de um depósito de tálus, cujos blocos centimétricos a decimétricos estão imersos em uma matriz fina (Figura 5.2) sobrejacente aum material arenoso com características de in situ, que guarda algumas feições do regolito imediatamente abaixo. A variação da $\mathrm{K}_{\mathrm{sat}}$ apresentou uma boa correlação com a granulometria do material, principalmente a fração areia. A partir desta profundidade $(1,00 \mathrm{~m})$, nota-se que há uma redução significativa no teor de argila $(32 \%$ aos $0,6 \mathrm{~m}$ e $12 \%$ aos $1,7 \mathrm{~m})$.

Em relação à $\mathrm{K}_{\text {sat }}$ observada neste ponto, nota-se que, mesmo com uma porcentagem considerável de finos no solo, $60 \%(0,25 \mathrm{~m}), 42 \%(0,40 \mathrm{~m})$ e $56 \%(0,6 \mathrm{~m})$, a existência de blocos decimétricos na matriz fina, do sistema radicular denso e da

\footnotetext{
${ }^{3}$ Análise das propriedades físicas dos solos na deflagração dos escorregamentos translacionais rasos na Serra do Mar (SP), de autoria de Fabiana Souza Ferreira, dissertação a ser defendida no Departamento de Geografia da Fac. De Fil. Letras e Ciências Humanas da Universidade de São Paulo em 2012.
} 
matéria orgânica podem ter favorecido caminhos preferenciais para a água. A partir do $1,00 \mathrm{~m}$, o teor de areia do material, chegando a $70 \%$ em 2,30 m de profundidade, pode ter sido responsável pelo valor alto de $\mathrm{K}_{\text {sat }}$.

A porosidade (Tabela 5.3) não apresentou uma correlação direta com a variação da $\mathrm{K}_{\mathrm{sat}}$ ao longo de todo o perfil. Apenas na camada mais superficial do solo, onde um aumento de $30 \%$ de areia possivelmente foi responsável por um aumento significativo na porosidade e, consequentementena $\mathrm{K}_{\text {sat }}$.

No ponto do centro da Cicatriz 1 (C1P2) só foi possível mensurar a $\mathrm{K}_{\text {sat }}$ em duas profundidades $(0,25 \mathrm{~m} \mathrm{e} 1,50 \mathrm{~m})^{4}$. Trata-se de um material in situ, que guarda algumas feições da rocha matriz e minerais primários (Figura 5.2). As tradagens realizadas até $2,70 \mathrm{~m}$ indicaram que o material permanece com características semelhantes até esta profundidade. Os valores obtidos foram $1,2 \times 10^{-6}(0,25 \mathrm{~m})$ e $1,9 \times 10^{-5}$ $\mathrm{m} / \mathrm{s}(1,5 \mathrm{~m})$ e a granulometria do material foi muito homogênea em todo o perfil, embora tenha havido um aumento de dez vezes na $\mathrm{K}_{\text {sat }}$ entre as duas profundidades (Figura 5.2).Desta forma, a granulometria não explica este comportamento, visto que as frações do material se mantém praticamente constantes ao longo de todo o perfil, no entanto, a porosidade total apresentou valores baixos (em torno de 50\%)

\footnotetext{
${ }^{4}$ Nas tentativas de mensurá-la aos 0,50 e 1,00 m não foi possível devido à não ocorrência de fluxo permanente. Houve a tentativa de se fazer outro furo nestas profundidades, mas, em razão da existência de sulcos no terreno sob a Gleychenia, o que deixa a superfície muito irregular, optou-se por não realizálos, pois demandaria muito tempo para a limpeza do terreno e remoção do material para duas medições.
} 

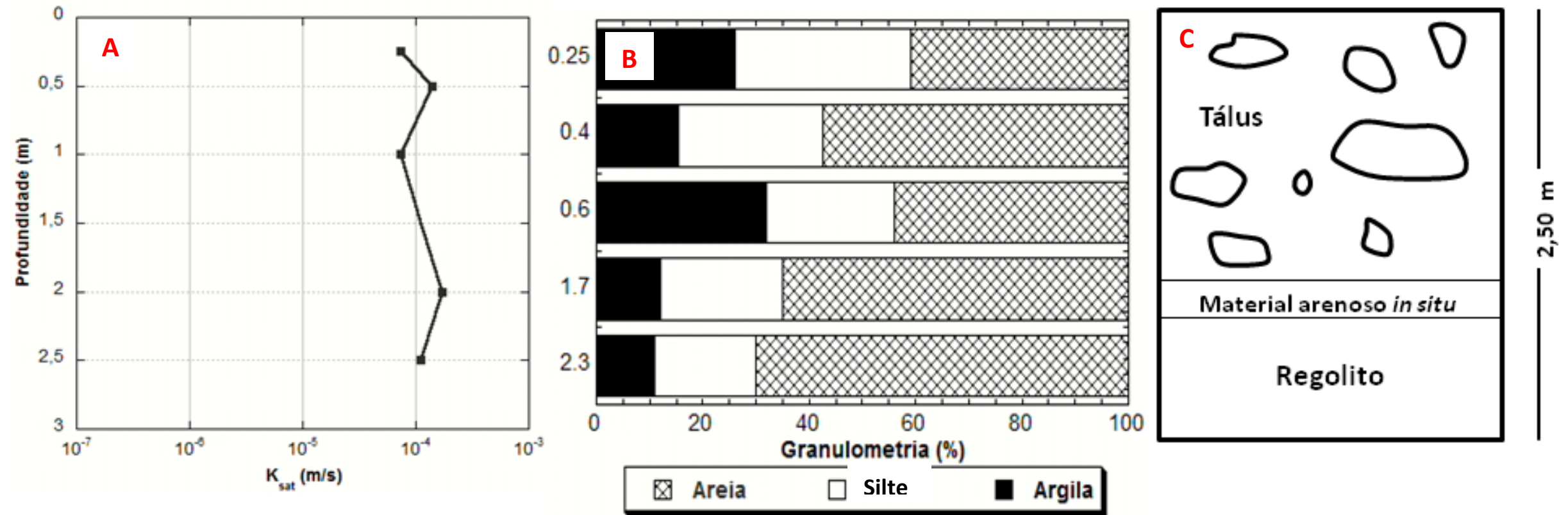

Figura 5.1. Variação da condutividade hidráulica saturada (A) em relação à granulometria do material (B) no perfil do topo da Cicatriz 1 (C1P1). Pode-se observar a correlação entre a $\mathrm{K}_{\text {sat }}$ e as oscilações dos teores de areia e argila. Destaca-se a matriz franco-arenosa mais próxima à superfície, na qual estão os blocos centimétricos $(\mathrm{C})$, enquanto em profundidade (aproximadamente 2,00 m) está o regolito com aproximadamente $70 \%$ de areia. Dados de granulometria: Ferreira (no prelo). 
Tabela 5.3.Valores de macroporosidade, microporosidade e porosidade total dos pontos onde foram realizados os ensaios de $\mathrm{K}_{\text {sat }}$.

\begin{tabular}{|c|c|c|c|c|c|}
\hline Cicatriz & Ponto & Profundidade(m) & $\begin{array}{c}\text { Macroporosidade } \\
\text { (\%) }\end{array}$ & $\begin{array}{c}\text { Microporosidade } \\
\text { (\%) }\end{array}$ & $\begin{array}{c}\text { Porosidade } \\
\text { total }\end{array}$ \\
\hline \multirow{6}{*}{ C1 } & & 0,25 & 20,34 & 54,25 & 74,59 \\
\hline & & 0,40 & 40,23 & 39,85 & 80,08 \\
\hline & & 0,60 & 25,18 & 40,25 & 65,43 \\
\hline & & 1,60 & 19,31 & 45,36 & 64,67 \\
\hline & & 0,25 & 22,09 & 27,84 & 49,93 \\
\hline & & 0,85 & 24,51 & 25,38 & 49,89 \\
\hline \multirow{7}{*}{ C2 } & & 0,20 & 18,80 & 44,24 & 63,04 \\
\hline & $\operatorname{cor} 1$ & 0,55 & 25,51 & 45,42 & 70,93 \\
\hline & & 0,12 & 21,22 & 43,63 & 64,85 \\
\hline & C2P2 & 0,25 & 24,24 & 39,55 & 63,79 \\
\hline & & 0,10 & 29,49 & 37,85 & 67,34 \\
\hline & C2P3 & 0,34 & 18,77 & 46,52 & 65,29 \\
\hline & & 0,60 & 15,38 & 50,11 & 65,49 \\
\hline \multirow{11}{*}{ C3 } & & 0,20 & 27,57 & 40,68 & 68,25 \\
\hline & C3P1 & 0,60 & 16,42 & 48,70 & 65,12 \\
\hline & & 2,00 & 20,22 & 43,84 & 64,06 \\
\hline & & 0,24 & 13,52 & 53,88 & 67,40 \\
\hline & C3P2 & 0,60 & 18,43 & 47,27 & 65,70 \\
\hline & & 1,30 & 13,31 & 56,72 & 70,03 \\
\hline & & 0,24 & 19,67 & 42,94 & 62,61 \\
\hline & & 0,41 & 16,88 & 47,35 & 64,23 \\
\hline & C3P3 & 0,67 & 16,86 & 49,38 & 66,24 \\
\hline & & 1,11 & 20,64 & 46,67 & 67,31 \\
\hline & & 1,27 & 21,02 & 49,69 & 70,71 \\
\hline
\end{tabular}

Fonte dos dados: Ferreira (no prelo). 

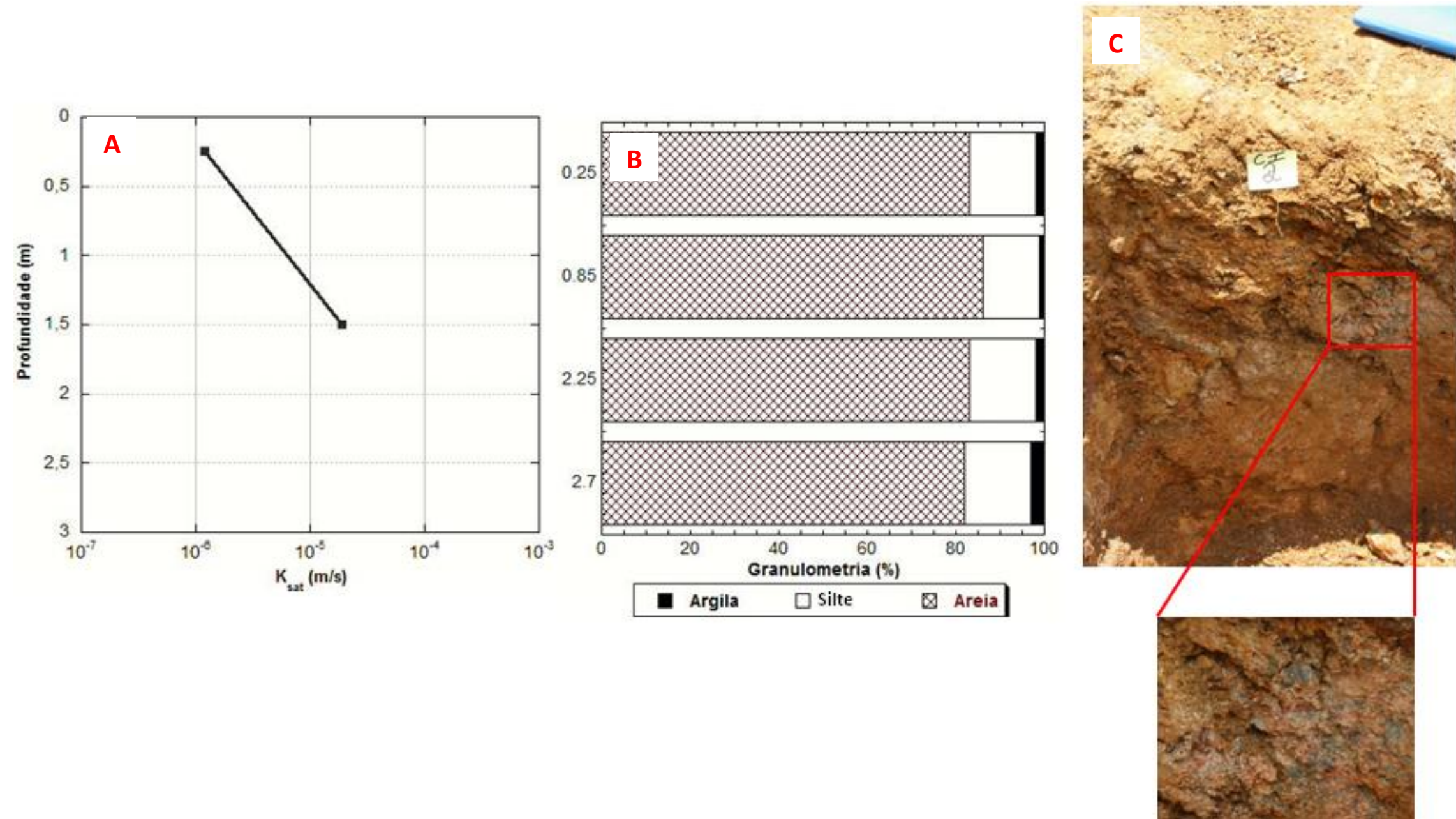

Figura 5.2. Variação da $K_{\mathrm{sat}}(A)$ no ponto C1P2. Neste ponto apenas dois ensaios foram realizados, apontando uma tendência de aumento da $K_{\mathrm{sat}} \mathrm{Na}$ figura $B$ observa-se a homogeneidade das frações argila, silte e areia com a profundidade, destacando-se a grande porcentagem de areia (aproximadamente 83\%). A figura $\mathrm{C}$ mostra o saprolito que compõe este setor da encosta até os 2,70 m de profundidade,em que se observam em diversos pontos minerais primários (em destaque).Fonte dos dados de granulometria: Ferreira (no prelo). 


\subsubsection{Cicatriz 2}

$\mathrm{Na}$ Cicatriz 2 foram observados padrões distintos de comportamento da $\mathrm{K}_{\mathrm{sat}}$ ao longo dos perfis $\mathrm{C} 2 \mathrm{P} 1, \mathrm{C} 2 \mathrm{P} 2$ e $\mathrm{C} 2 \mathrm{P} 3$. No ponto $\mathrm{C} 2 \mathrm{P} 1$ (Figura 5.5) foi observada a tendência de aumento da $\mathrm{K}_{\mathrm{sat}}$ com a profundidade. Até $1,00 \mathrm{~m}$ foram observados os valores $2,7 \times 10^{-6}(0,25 \mathrm{~m}), 7,7 \times 10^{-6}(0,50 \mathrm{~m})$ e $9,2 \times 10^{-6} \mathrm{~m} / \mathrm{s}(1,00 \mathrm{~m})$. A partir desta profundidade, os valores foram reduzidos para a ordem de magnitude $10^{-5} \mathrm{~m} / \mathrm{s}\left(3,4 \times 10^{-5}\right.$, $1,3 \times 10^{-5}$ e $3,4 \times 10^{-5} \mathrm{~m} / \mathrm{s}$ )(Figura 5.3). Este aumento com a profundidade pode ser explicado principalmente pelo acréscimo de $20 \%$ de areia e a redução de $15 \%$ da fração silte entre as profundidades de $0,20 \mathrm{~m}$ e $2,65 \mathrm{~m}$. A micro emacroporosidade e aporosidade total não explicaram da variação da $\mathrm{K}_{\mathrm{sat}}$ ao longo do perfil.

No ponto C2P2 o perfil é composto por um saprolito subjacente a uma camada fina (aproximadamente $0,10 \mathrm{~m}$ ) de material transportado (Figuras $5.4 \mathrm{C}$ ). Neste ponto o saprolito guarda muitas feições relíquias do material parental, como os minerais primários e o bandamento, que acompanha o mergulho da encosta (Figura 5.5). Os valores obtidos nos levantamentos in situ foram de $9,2 \times 10^{-6} \mathrm{~m} / \mathrm{saos} 0,25 \mathrm{~m}, 2,0 \times 10^{-5}$ $\mathrm{m} / \mathrm{saos} 0,50 \mathrm{~m}$ e $3,4 \times 10^{-6} \mathrm{~m} / \mathrm{saos} 1,00 \mathrm{~m}$ (Figura $5.4 \mathrm{~A}$ ). Na profundidade de $0,25 \mathrm{~m}$, houve o predomínio da fração areia, com $64 \%$, enquanto silte e argila perfizeram os $36 \%$ (material coluvial) (Figura 5.4B). A $1,00 \mathrm{~m}$ houve um aumento significativo na quantidade de areia, alcançando 90\%, embora tenha havido um aumento na macroporosidade em relação àquela observada a $0,25 \mathrm{~m}$. Esta mesma tendência de variação de $K_{\text {sat }}$ com a profundidade foi encontrada por Vieira e Fernandes (2004), observada na figura 2.13 , em que os referidos autores identificaram umaumento na $\mathrm{K}_{\text {sat }}$ entre os 0,60 e 0,90 m de 100 vezes, seguido por uma redução de 100 vezes entre 0,90 e 1,20 m de profundidade. 

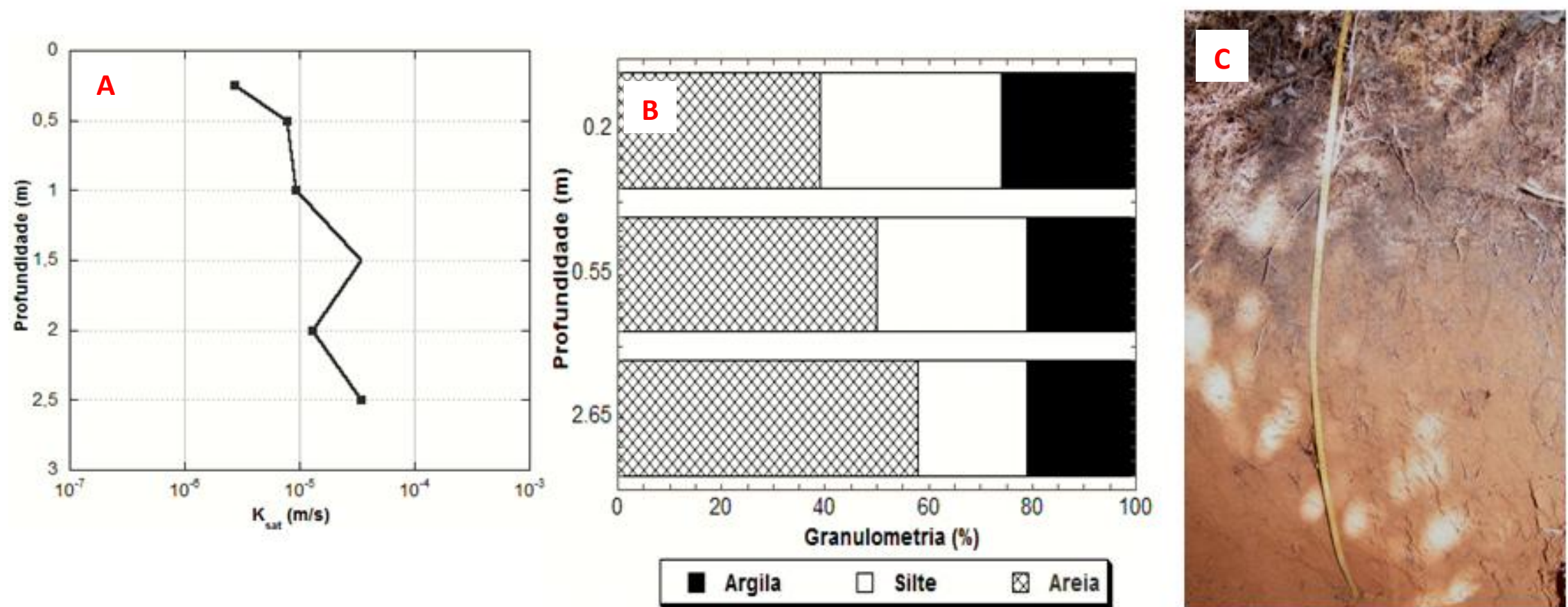

Figura 5.3. Variação da $\mathrm{K}_{\mathrm{sat}}$ no ponto $\mathrm{C} 2 \mathrm{P} 1(\mathrm{~A})$. É observada a tendência de aumento da $\mathrm{K}_{\mathrm{sat}}$ ao longo do perfil, que parece corresponder ao aumento do teor de areia e redução do silte (B). A figura C ilustra o perfil de solo observado neste ponto, com características de solo residual maduro, com raízes pequenas até $0,70 \mathrm{~m}$ de profundidade.Fonte dos dados de granulometria: Ferreira (no prelo). 

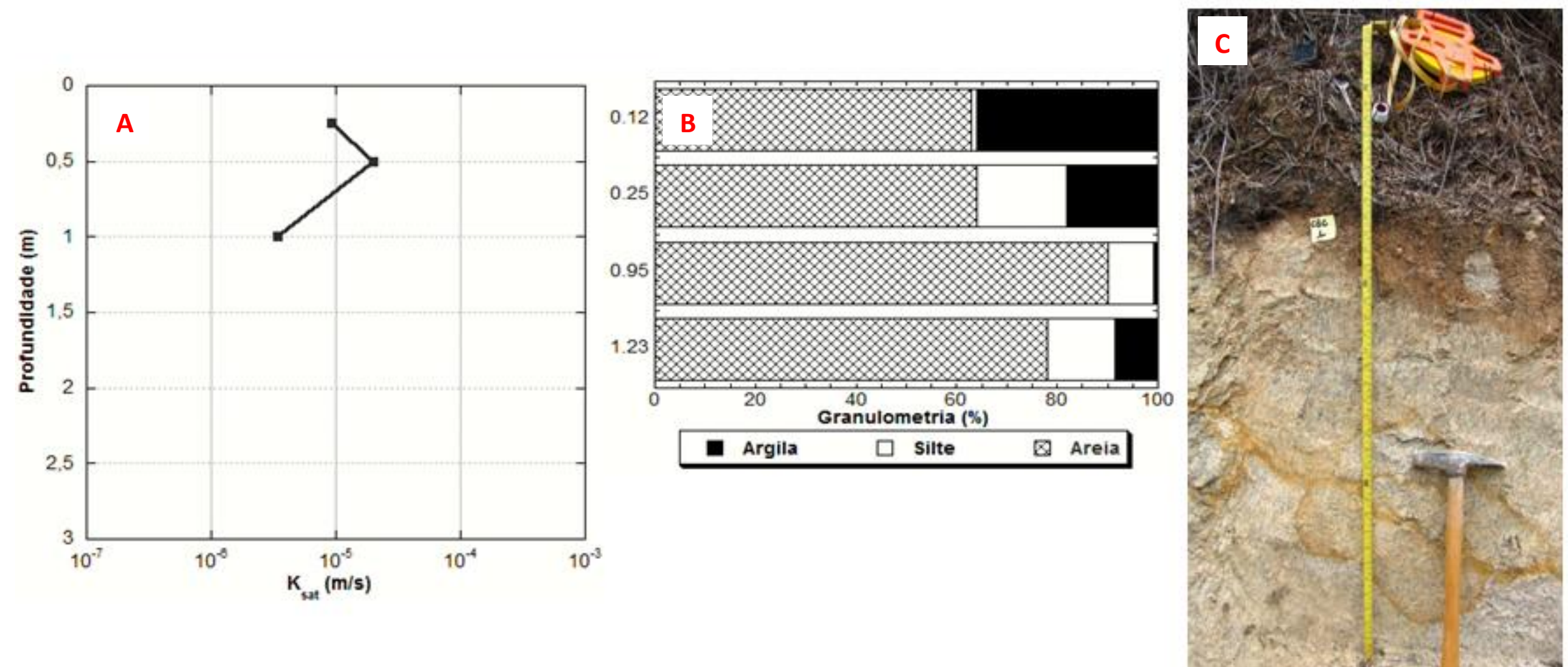

Figura 5.4.Variação da $K_{\text {sat }}$ no ponto $C 2 P 2$ (A), que, aparentemente, não apresenta uma correlação com a granulometria do material (B). Na figura C nota-se o material coluvial sobre o saprolito. Dados de granulometria: Ferreira (no prelo). 


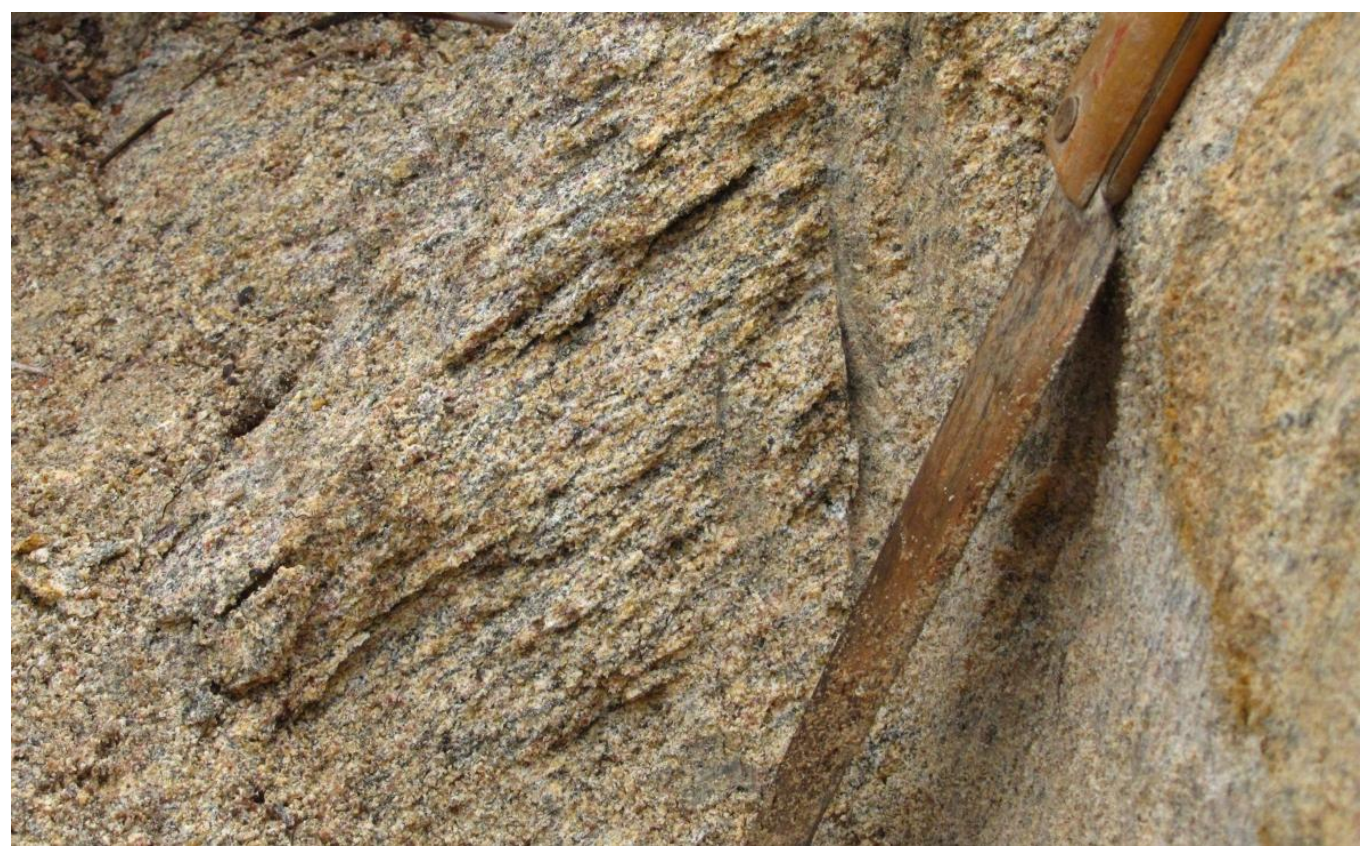

Figura 5.5. Feições relíquias da rocha no saprolito, com mergulho na direção do ângulo da encosta.

$\mathrm{O}$ ponto da lateral desta cicatriz $(\mathrm{C} 2 \mathrm{P} 3)$ apresentou valores semelhantes àqueles da $\mathrm{C} 2 \mathrm{P} 1$, com exceção do valor obtido em $0,25 \mathrm{~m}\left(7,7 \times 10^{-7} \mathrm{~m} / \mathrm{s}\right)$. Este valor não era esperado para esta profundidade, uma vez que existe um sistema radicular denso (Figura 5.6C) e uma camada orgânica espessa, importantes condicionantes para a formação de macroporos. Uma possibilidade para a ocorrência deste valor está relacionada à umidade do solo, pois a abertura de furos em solos de matriz mais fina quando muito úmidos pode causar a compactação da parede do furo, o que dificulta a infiltração da água, subestimando a $\mathrm{K}_{\text {sat }}$. Há também a possibilidade de influência da mineralogia das argilas, visto que o índice de atividade das argilas nesta profundidade foi sensivelmente mais alto que os valores observados nas outras profundidades e pontos mensurados, embora esteja, assim como os demais valores, na classe das argilas de baixa atividade, segundo Pinto (2002). 
Levando-se em conta que este valor não pôde ser considerado representativo devido à interferência dos procedimentos na mensuração, os demais valores oscilaram entre as ordens de grandeza $10^{-5}$ e $10^{-6} \mathrm{~m} / \mathrm{s}$ (Figura 5.6A). Até $1,00 \mathrm{~m}$ de profundidade, os valores foram $7,3 \times 10^{-5} \mathrm{~m} / \mathrm{s}(0,50 \mathrm{~m})$ e $2,0 \times 10^{-5} \mathrm{~m} / \mathrm{s}(1,00 \mathrm{~m})$. Abaixo de $1,00 \mathrm{~m}$, os valores de $\mathrm{K}_{\mathrm{sat}}$ obtidos foram mais baixos que aqueles observados mais próximos à superfície, predominando na ordem de $10^{-6} \mathrm{~m} / \mathrm{s}$. Esta redução na $\mathrm{K}_{\mathrm{sat}}$ com a profundidade pode ser explicada pelo aumento de $14 \%$ (entre $1,00 \mathrm{~m}$ e $2,30 \mathrm{~m}$ ) da fração argila, e diminuição de $12 \%$ da quantidade de areia (Figura 5.6B). 

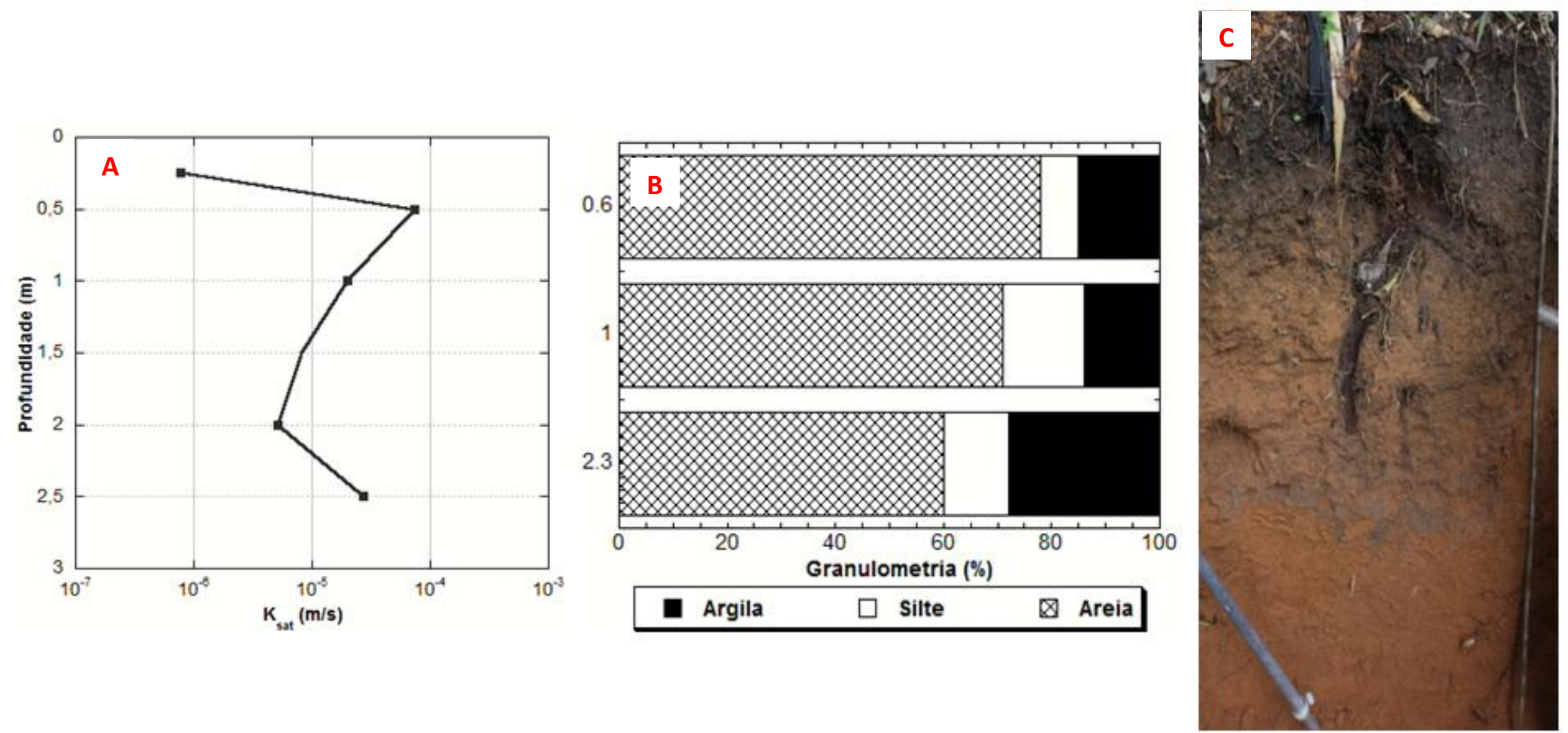

Figura 5.6.Variação da $\mathrm{K}_{\text {sat }}$ no ponto $\mathrm{C} 2 \mathrm{P} 3$ (A). Observa-se que a diminuição da $\mathrm{K}_{\text {sat }}$ está associada à redução dos teores de areia e aumento da argila (B), enquanto a granulometria não explica o aumento entre 2,00 e 2,50 m de profundidade.Perfil do ponto C2P3. Destaca-se a camada orgânica mais espessa neste ponto, além de raízes de diversos tamanhos e pipes(C). Fonte dos dados de granulometria: Ferreira (no prelo). 


\subsubsection{Cicatriz 3}

Na Cicatriz 3, em seu ponto superior (C3P1), pôde ser observado, assim como na Cicatriz 2, o predomínio de valores de $\mathrm{K}_{\mathrm{sat}}$ entre as ordens de $10^{-5}$ e $10^{-6} \mathrm{~m} / \mathrm{s}$ (Figura 5.7). À profundidade de $0,25 \mathrm{~m}$, a porcentagem de argila embora significativa (37\%), não explicou os valores de $\mathrm{K}_{\text {sat }}$, fato que pode ser justificado pelos caminhos preferenciais da água nas raízes e pelo alto teor de matéria orgânica. No entanto, o aumento da microporosidade (aproximadamente $48 \%$ ) entre $0,50 \mathrm{~m}$ e $1,00 \mathrm{~m}$ pode justificar a diminuição da $\mathrm{K}_{\mathrm{sat}}$ a $1,00 \mathrm{~m}$ de profundidade $\left(4,8 \times 10^{-6} \mathrm{~m} / \mathrm{s}\right)$ e a maior macroporosidade aos 2,00 $\mathrm{m}(20 \%)$ explica o aumento da $\mathrm{K}_{\mathrm{sat}}$ nesta profundidade $\left(4,1 \times 10^{-5} \mathrm{~m} / \mathrm{s}\right)$. A partir desta profundidade $(0,25 \mathrm{~m})$, os valores de $\mathrm{K}_{\text {sat }}$ tendem a diminuir $-5,5 \times 10^{-5} \mathrm{~m} / \mathrm{s}(0,50$ $\mathrm{m}), 4,8 \times 10^{-6} \mathrm{~m} / \mathrm{s}(1,00 \mathrm{~m}), 9,2 \times 10^{-6} \mathrm{~m} / \mathrm{s}(1,50 \mathrm{~m}), 4,1 \times 10^{-5} \mathrm{~m} / \mathrm{s}(2,00 \mathrm{~m})$ e $3,4 \times 10^{-6}(2,50$ m).

O ponto do centro da Cicatriz 3 (C3P2) apresentou uma variabilidade da $\mathrm{K}_{\text {sat }}$ maior (Figura 5.8A), embora no campo tenham sido identificados com clareza apenas três camadas distintas (Figuras 5.8C), além dos veios de quartzo intemperizados existentes à profundidade de 1,50 m (Figura 5.9). Observou-se que o padrão de variação da $\mathrm{K}_{\mathrm{sat}}$ ao longo deste perfilapresenta uma tendência de aumento, justificado pela redução da fração argila e aumento de $30 \%$ de areia.

Em apenas 1,00 m de profundidade houve uma aumento de duas ordens de grandeza na $\mathrm{K}_{\mathrm{sat}}\left(9,2 \times 10^{-6}\right.$ aos $0,50 \mathrm{~m}$ para $1,3 \times 10^{-4} \mathrm{~m} / \mathrm{s}$ a $\left.1,00 \mathrm{~m}\right)$ e a redução na $\mathrm{K}_{\mathrm{sat}}$ de duas ordens de grandeza $\left(1,3 \times 10^{-4}\right.$ a $1,00 \mathrm{~m}$ para $9,2 \times 10^{-6} \mathrm{~m} / \mathrm{s}$ aos $\left.1,50 \mathrm{~m}\right)$. O valor de $\mathrm{K}_{\text {sat }}$ na profundidade de $1,00 \mathrm{~m}$ pode estar relacionado ao aumento da macroporosidade $(18,43 \%)$ e diminuição da microporosidade $(48,70 \%)$, uma vez que a distribuição granulométrica não sofreu alterações sensíveis entre os $0,60 \mathrm{~m} \mathrm{e} \mathrm{1,30} \mathrm{m.}$ 
A descontinuidade hidráulica entre 1,00 m e 1,50 m não pôde ser explicada pelas variações espaciais da granulometria do solo, mas pelo aumento de aproximadamente $10 \%$ na quantidade de microporos e redução no número de macroporos. $\mathrm{O}$ aumento da $\mathrm{K}_{\mathrm{sat}}$ entre os 2,00 m e 2,50 $\mathrm{m}$ de profundidade pode estar associado ao aumento expressivo de areia (de 53\% para 70\%) e redução das frações finas do solo. 

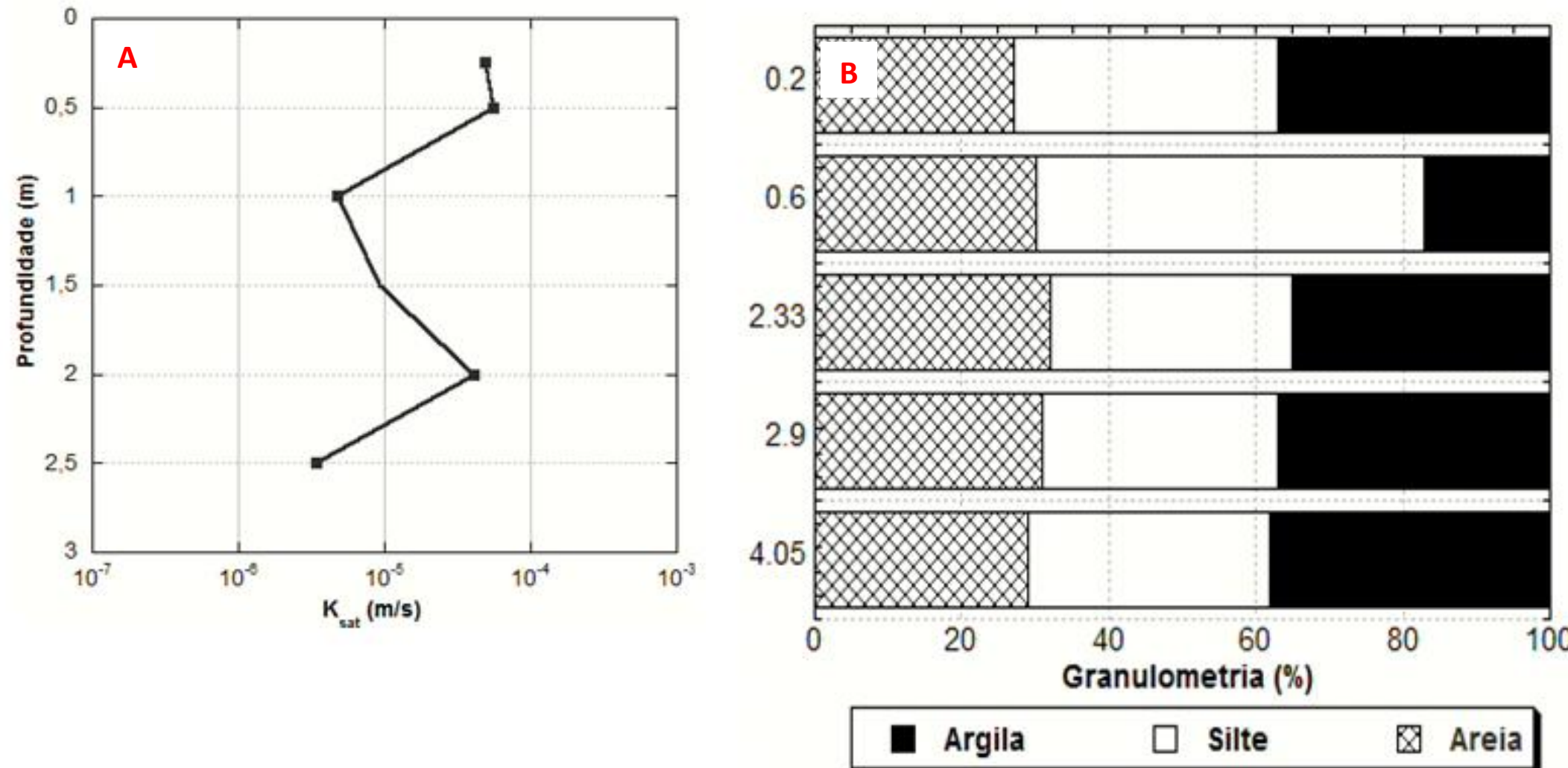

Figura 5.7. Variação no ponto $C 3 P 1$ da $K_{\text {sat }}(A)$. Nota-se uma redução da $K_{\text {sat }}$ de 10 vezes entre 0,50 e $1,00 \mathrm{~m}$ e um aumento até os $2,00 \mathrm{~m}$. A partir daí, há a diminuição novamente da $\mathrm{K}_{\text {sat }}$, que não pôde ser explicada pela distribuição granulométrica (B). Dados de granulometria: Ferreira (no prelo). 

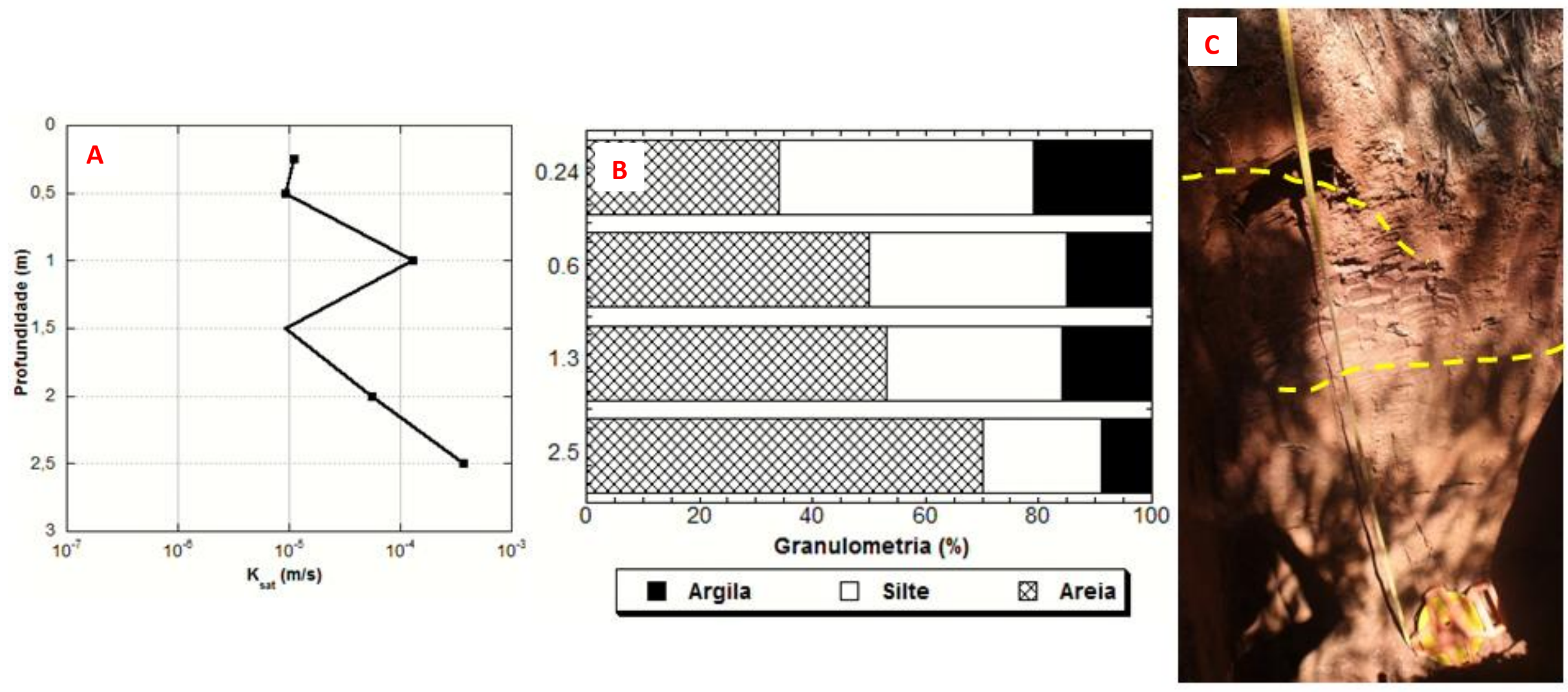

Figura 5.8. Variação da $\mathrm{K}_{\text {sat }}$ no ponto C3P2 (A). Observam-se descontinuidades hidráulicas ao longo do perfil, associadas ao aumento da microporosidade (entre 1,00 e $1,50 \mathrm{~m}$ ) e da fração areia (entre 2,00 e 2,50 m) (B). O perfil do ponto(C) mostra três camadas com granulometria distintas, delimitadas pelas linhas amarelas. A primeira camada, com matriz fina e areia grossa, ocorre sobre um material areno-siltoso, que também ocorre na terceira camada, com microporosidade sensivelmente maior.Fonte dos dados de granulometria: Ferreira (no prelo). 


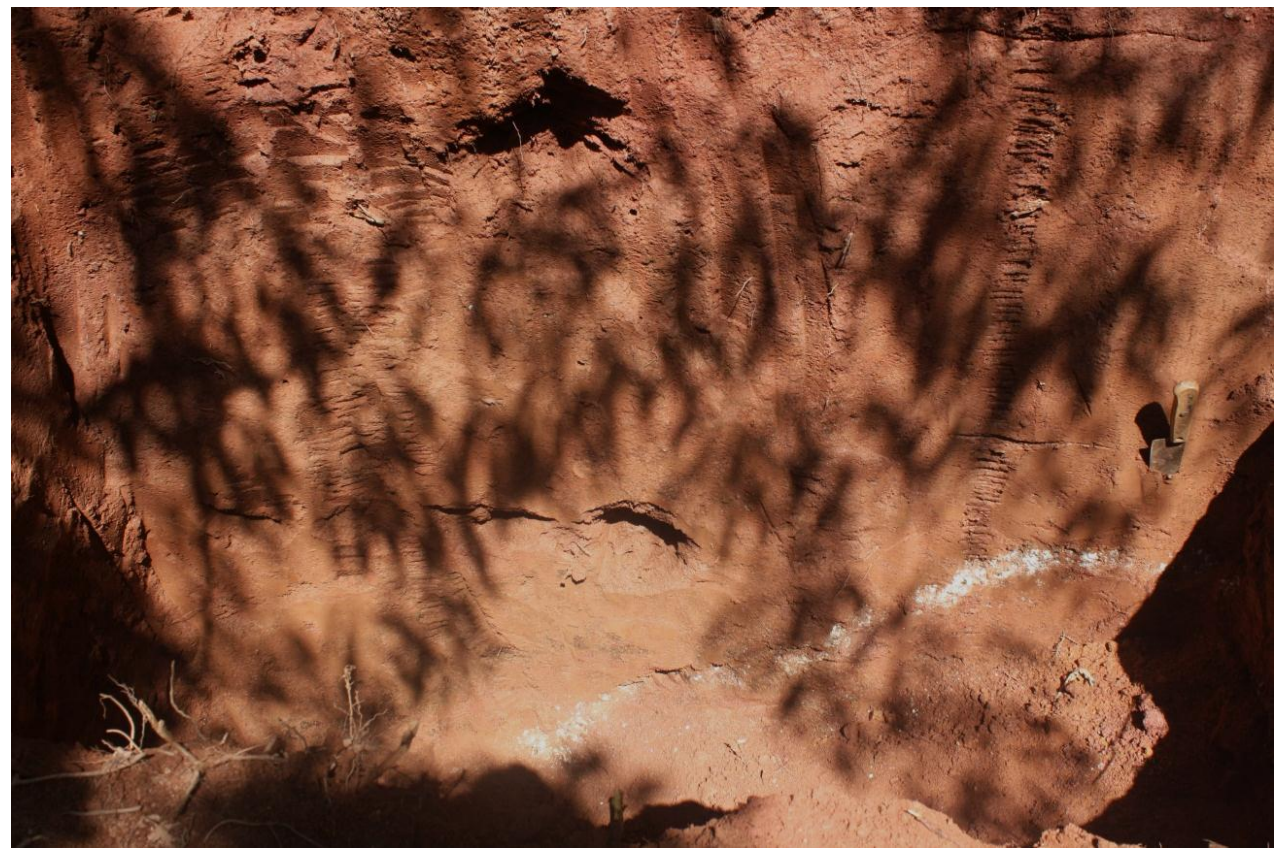

Figura 5.9. Ponto do centro da Cicatriz 3 (C3P2) com veio de quartzo intemperizado à profundidade de $1,50 \mathrm{~m}$.

No ponto lateral da Cicatriz 3 (C3P3) o comportamento da $\mathrm{K}_{\text {sat }}$ apresentou grandes variações ao longo do perfil (Figura 5.10A). Os valores obtidos variaram entre as ordens $10^{-5}$ e $10^{-6} \mathrm{~m} / \mathrm{s}$. Próximo à superfície os valores de $\mathrm{K}_{\text {sat }}$ apresentados foram $1,0 \times 10^{-}$ ${ }^{5} \mathrm{~m} / \mathrm{s}(0,25 \mathrm{~m})$ e $6,9 \times 10^{-6} \mathrm{~m} / \mathrm{s}(0,50 \mathrm{~m})$. Esta diminuição da $\mathrm{K}_{\text {sat }}$ pode ser atribuída ao aumento de $18 \%$ do teor de argila (Figura 5.10B) e a menor macroporosidade (16,88\%), que pode estar relacionada ao menor teor de matéria orgânica e número de raízes (Figura 5.10C). À 1,00 m de profundidade, a $\mathrm{K}_{\text {sat }}$ volta a sofrer um aumento, certamente em razão do aumento da macroporosidade (20,22\%) (Figura 5.11), visto que a distribuição granulométrica permaneceu nas mesmas proporções. A partir de $1,00 \mathrm{~m}$, a $\mathrm{K}_{\text {sat }}$ diminuiu com a profundidade, tendência que não pode ser explicada pela distribuição granulométrica e porosidade. À 1,50 m, a $\mathrm{K}_{\mathrm{sat}}$ aumenta, devido a um acréscimo na fração areia (31\% aos $0,96 \mathrm{~m}$ e $42 \%$ aos $2,57 \mathrm{~m})$ e redução da argila (53\% aos $0,96 \mathrm{~m}$ e $38 \%$ aos $2,57 \mathrm{~m})$. 

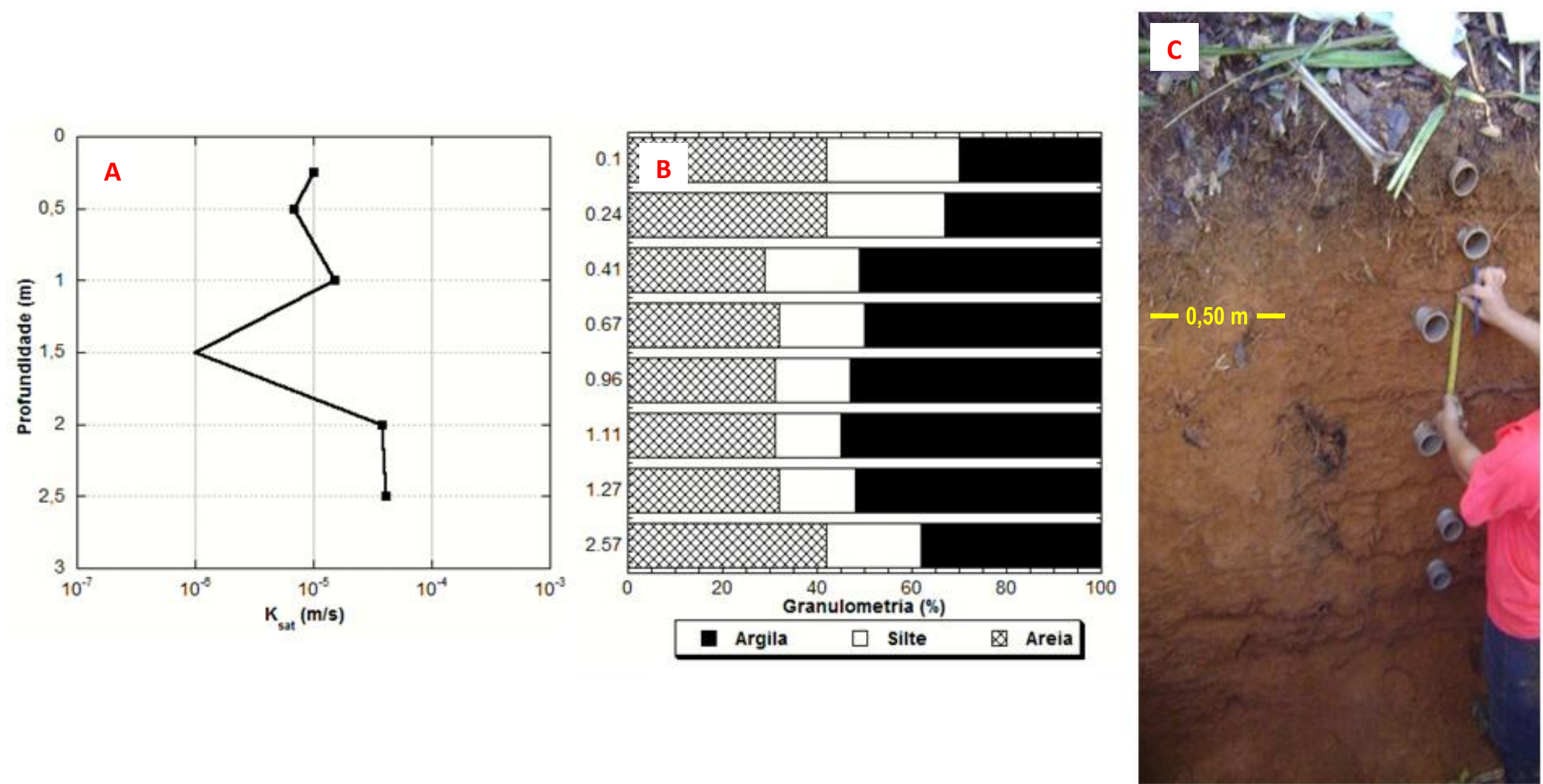

Figura 5.10. Variação da $K_{\text {sat }}$ ao longo do perfil C3P3 (5A). Observa-se a redução entre as profundidades 1,00 e 1,50 m que pôde ser explicada pelo aumento no teor de argila entre 0,41 e 1,27 m e pela redução de aproximadamente $10 \%$ na fração areia. O perfil do ponto C3P3 mostra a profundidade a partir de onde a quantidade de raízes é significativamente menor. Fonte dos dados de granulometria: Ferreira (no prelo). 


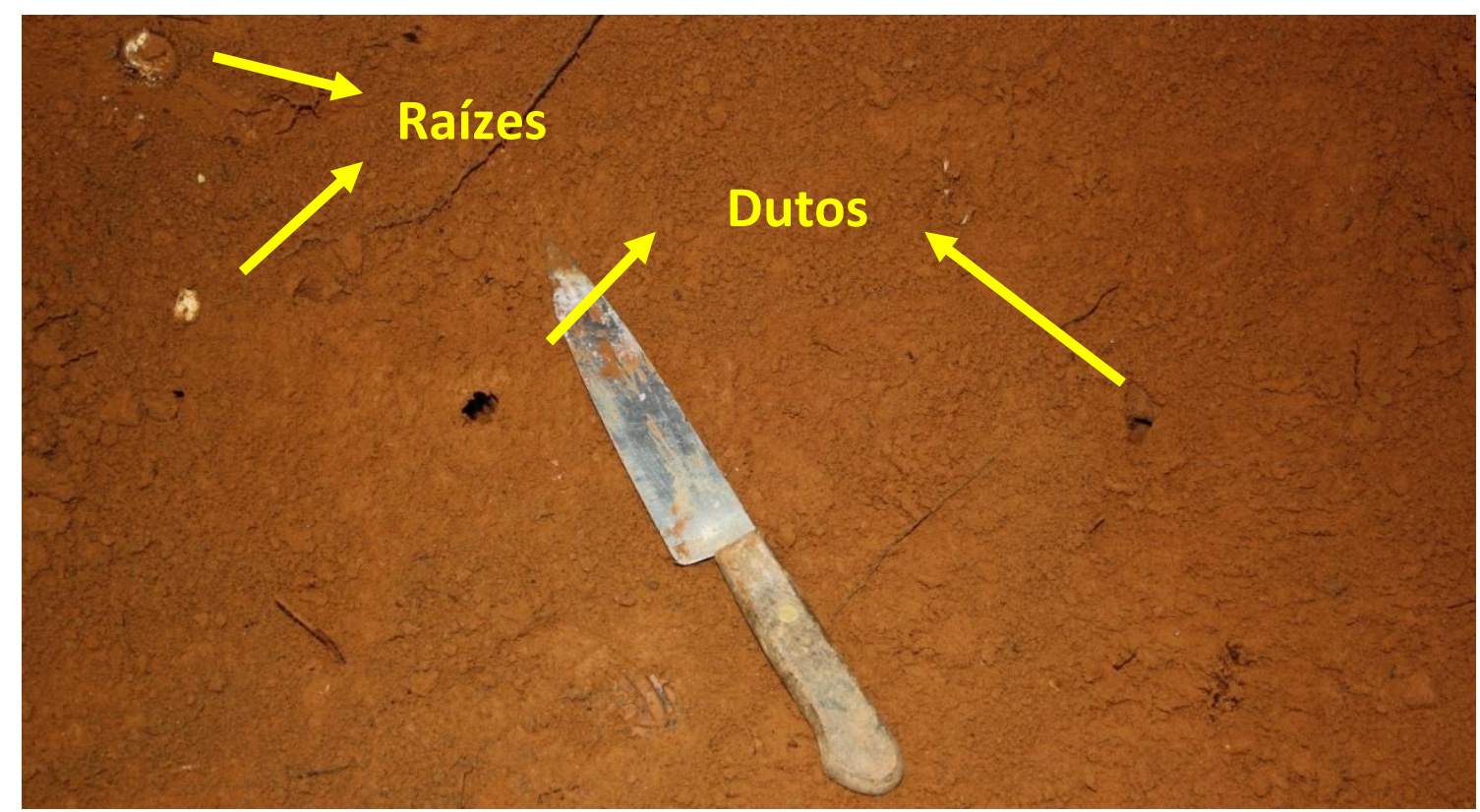

Figura 5.11.Base da trincheira a $1,00 \mathrm{~m}$ de profundidade. Observam-se dutos e raízes, possivelmente responsáveis pelo aumento da macroporosidade nesta profundidade. 


\subsection{Padrões de variação da $K_{\text {sat }}$ com a profundidade}

De forma geral, a $\mathrm{K}_{\mathrm{sat}}$ apresentou uma tendência de aumento ao longo dos perfis, sobretudo entre $1,00 \mathrm{~m}$ e $1,50 \mathrm{~m}$, com exceção dos pontos C2P2 e C2P3 (Cicatriz 2).Benessiuti e Bernardes (2011) encontraram um padrão de variação semelhante em solo oriundo do mesmo litologia, embora o aumento da $\mathrm{K}_{\text {sat }}$ tenha ocorrido a partir de 2,00 m. Esta diferença na profundidade onde ocorre o aumento pode ser decorrente do solo mais espesso investigado pelos referidos autores. Campos et al. (1992) também identificaram um aumento nos valores de $\mathrm{K}_{\text {sat }}$ com a profundidade, mas, como Benessiuti e Bernardes (2011), a profundidade a partir de onde houve o aumento foi maior que $1,82 \mathrm{~m}$.

Nos pontos do topo de cada cicatriz (C1P1, C2P1 e C3P1)notou-se que na Cicatriz 1 (C1P1) a $\mathrm{K}_{\text {sat }}$ apresentou um perfil homogêneo com variações que não ultrapassaram uma ordem de grandeza. Já no ponto C2P1 é nítida a tendência de aumento da $\mathrm{K}_{\text {sat }}$ com a profundidade, ainda que este aumento tenha alcançado pouco mais que 10 vezes desde o primeiro ponto de mensuração $\left(2,7 \times 10^{-6} \mathrm{~m} / \mathrm{s}\right.$ aos $\left.0.25 \mathrm{~m}\right)$ até o ponto mais profundo $\left(3,4 \times 10^{-5} \mathrm{~m} / \mathrm{s}\right.$ aos $\left.2,50 \mathrm{~m}\right)$. No ponto C3P1 não foi observada uma tendência ao longo do perfil, mas a existência de descontinuidades hidráulicas de até uma ordem de grandeza, sendo a primeira entre 0,5 e 1,00 $\mathrm{m}$ e a segunda entre 2,00 e 2,50 m.

Em relação aos pontos do centro das cicatrizes (C1P2, C2P2 e C3P2), dois deles apresentaram tendência de aumento com a profundidade (C1P2 e C3P2), embora nos C1P2 e C2P2 não tenha sido possível realizar abaixo dos $1,50 \mathrm{~m}$. No ponto $\mathrm{C} 1 \mathrm{P} 2$, a $\mathrm{K}_{\text {sat }}$ aumentou em mais de 10 vezes entre as profundidades 0,25 e $1,50 \mathrm{~m}\left(1,2 \times 10^{-6}\right.$ e $1,9 \times 10^{-5}$ $\mathrm{m} / \mathrm{s}$, respectivamente), enquanto no ponto $\mathrm{C} 3 \mathrm{P} 2$ a tendência de aumento ao longo perfil variou entre as ordens $10^{-4}$ e $10^{-6} \mathrm{~m} / \mathrm{s}$. Além deste aumento, foi observada uma descontinuidade hidráulica significativa entre 1,00 e $1,50 \mathrm{~m}$, com redução de $1,3 \times 10^{-4}$ para $9,2 \times 10^{-6} \mathrm{~m} / \mathrm{s}$. Isto mostra que, embora haja um aumento progressivo da $\mathrm{K}_{\text {sat }}$ ao longo do 
perfil, a existência de uma camada onde há uma redução brusca em apenas 0,50 m, permite que ocorra o desenvolvimento de poro-pressões neste local.

$\mathrm{O}$ ponto $\mathrm{C} 2 \mathrm{P} 2$ não apresentou este comportamento, mas se assemelhou aos resultados obtidos por Vieira e Fernandes (2004), que também identificaram um perfil com um aumento da $\mathrm{K}_{\mathrm{sat}}$ seguido por uma redução significativa entre 0,50 e 1,20 m.

Quanto aos pontos da lateral das cicatrizes (C2P3 e C3P3), ambos apresentam valores de $\mathrm{K}_{\mathrm{sat}}$ menores próximos à superfície e valores maiores em profundidade. No caso da C3P3 mesmo com o aumento da $\mathrm{K}_{\text {sat }}$ observou-se uma redução de 13 vezes: $1,3 \times 10^{-}$ ${ }^{5}(1,00 \mathrm{~m})$ e $1,0 \times 10^{-6}(1,50 \mathrm{~m})$

Quandoos perfis do topo e centro são sobrepostos, ou seja, presumindo que o material observado no topo já esteve sobre o material do centro da cicatriz, a variação em profundidade da $\mathrm{K}_{\text {sat }}$ apresentou, nas Cicatrizes 2 e 3 um aumento com a profundidade(Figura 5.12).

O aumento da $\mathrm{K}_{\text {sat }}$ com a profundidade foi observado por Campos et al. (1992) em encostas no estado do Rio de Janeiro e por Benessiuti e Bernardes (2011) em Guaratinguetá-SP, próximo a uma cicatriz de escorregamento raso. Wolle e Hachich (1989) apontaram, a partir da constatação de que os trechos de média e alta encosta da Serra do Mar em São Paulo são capeados por mantos pouco espessos de solos coluvionares e saprolíticos sobre rochas intensamente fraturadas, altamente drenantes, levariam ao aumento da $\mathrm{K}_{\mathrm{sat}}$ com a profundidade. Esta tendência deacréscimo da $\mathrm{K}_{\text {sat }}$ com a profundidade pode ter provocado a ruptura no contato entre o solo maduro e o solo saprolítico/saprolito (Figura 5.13), visto quea maior permeabilidadenos materiais com menor resistência (ângulo de atrito e coesão)pode levar à criação de condições de instabilização. 


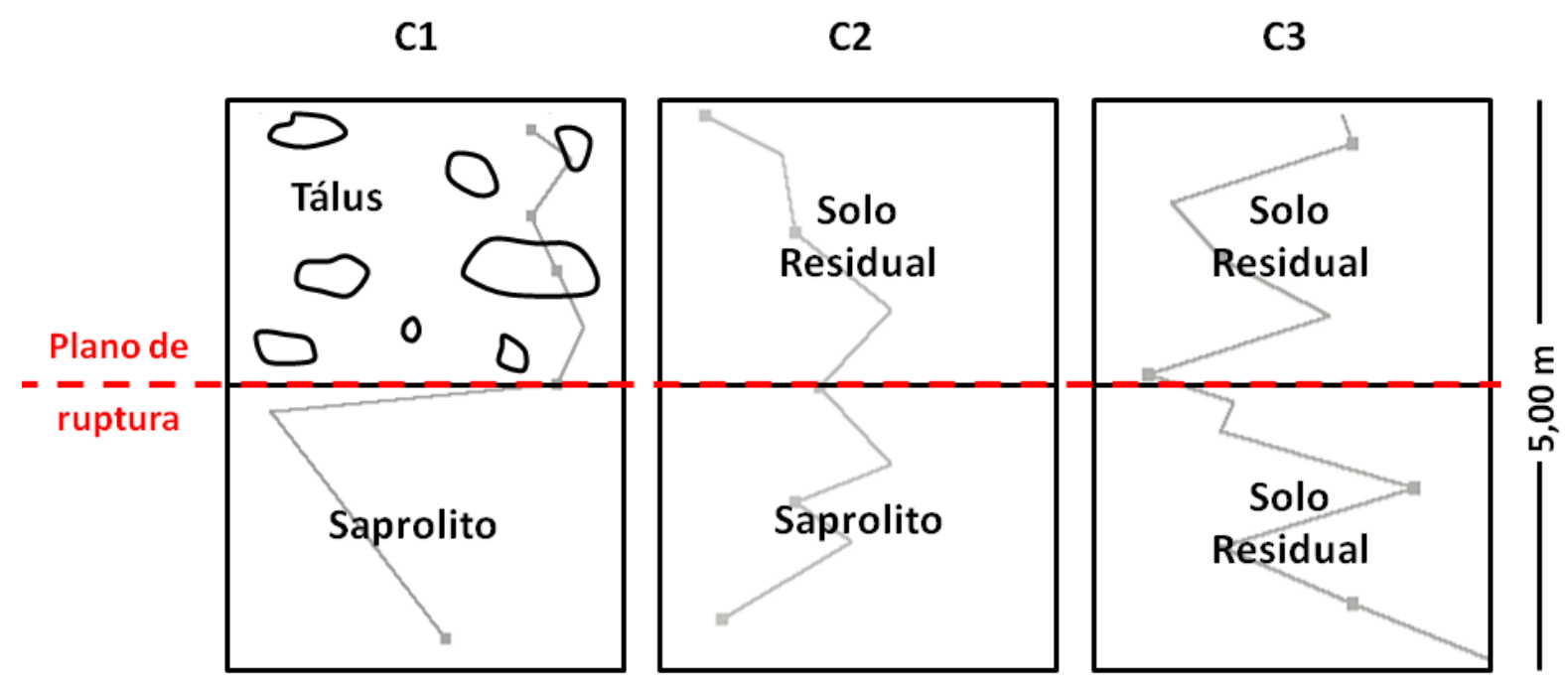

Figura 5.12. Diagrama dos perfis formados a partir da sobreposição dos perfis do topo e do cento das cicatrizes, mostrando a variação do material e da $\mathrm{K}_{\mathrm{sat}}$ e o possívelplano de ruptura. 
C1
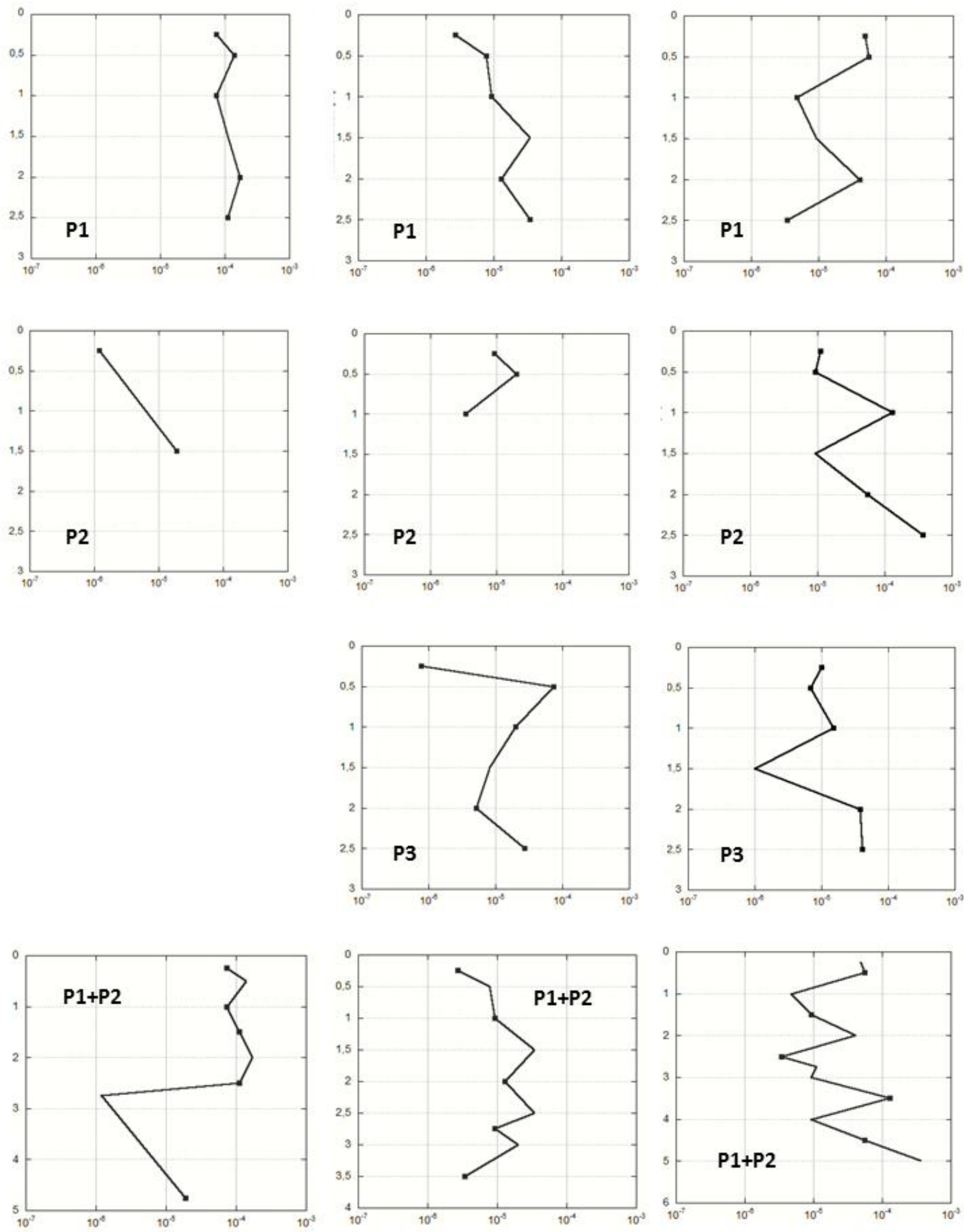

C2
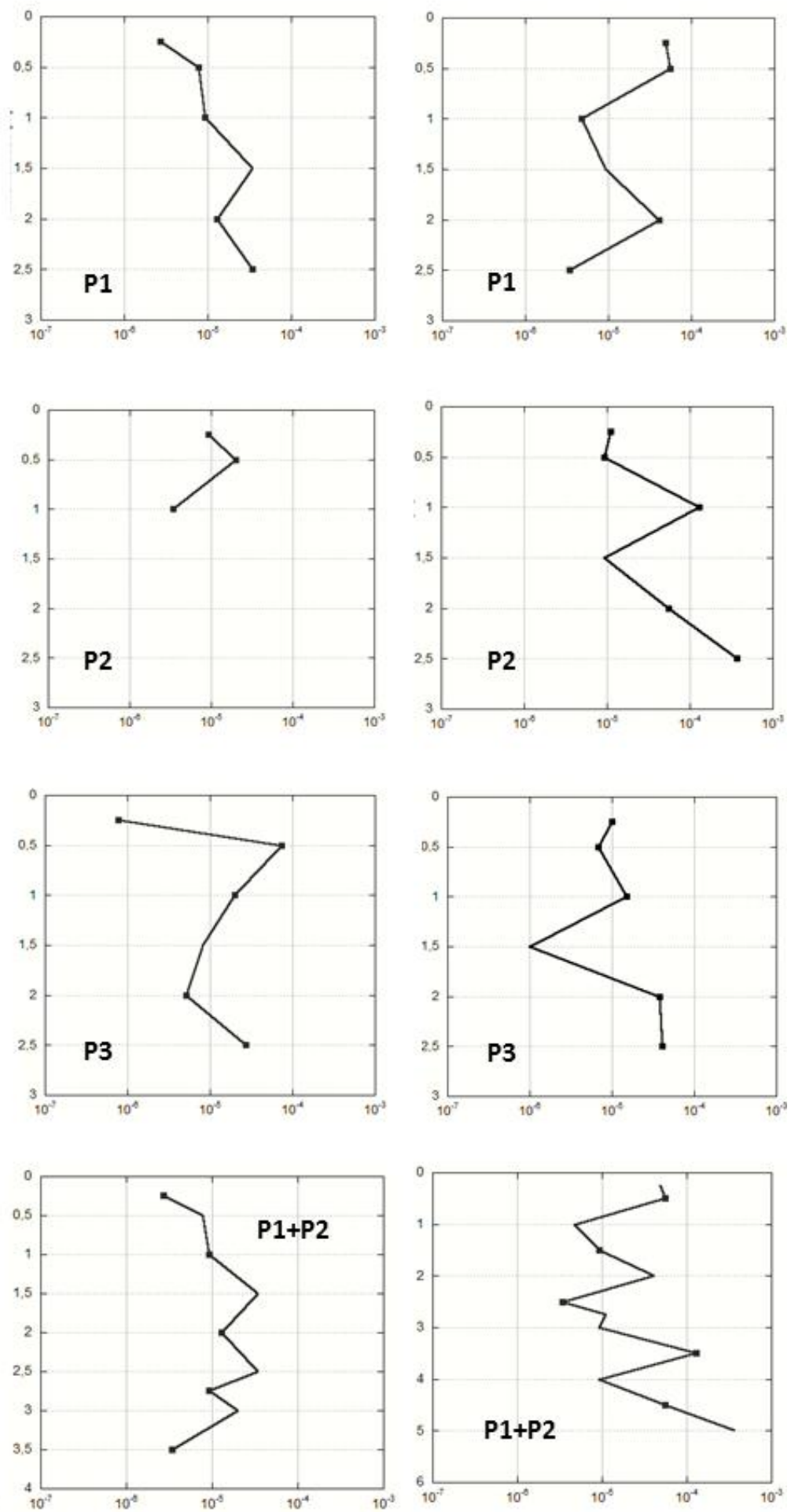

Figura 5.13. Gráficos de variação da $K_{\text {sat }}($ eixox) com a profundidade (eixo y) nas cicatrizes $C 1, C 2$ e $\mathrm{C} 3$ nos pontos do topo (P1), do centro (P2) e da lateral (P3). 


\subsection{Variação espacial da $K_{\text {sat }}$ e os escorregamentos rasos de 1967}

As variações no comportamento da água nos solos dos perfis investigados, somadas às propriedades físicas dos solos e às características topográficas do terreno podem explicar ou, ao menos, sugerir a influência destes fatores condicionantes na ocorrência dos escorregamentos ocorridos em 1967.

Destaca-se que nas três cicatrizes estudadas o plano de ruptura se localizou entre 1,50 e 2,00 m de profundidade, o que corrobora com os trabalhos sobre escorregamentos rasos e principalmente com aqueles desenvolvidos na Serra do Mar, como WOLLE (1988); CAMPOS et al. (1992); VIEIRA e FERNANDES (2004) e MENDES (2008). Observa-se também que em outros trabalhos sobre escorregamentos rasos, em solos de alteração de gnaisses, o plano de ruptura está localizado entre as mesmas profundidades (WAKATSUKI et al., 2005; BENESSIUTI e BERNARDES, 2011).

No que diz respeito à distribuição da $\mathrm{K}_{\text {sat }}$ ao longo dos perfis, foram observadas poucas descontinuidades hidráulicas significativas, destacando-se duas variações, com duas ordens de grandeza cada. No ponto $\mathrm{C} 3 \mathrm{P} 2$, na profundidade de $1,00 \mathrm{~m}$, a $\mathrm{K}_{\text {sat }}$ foi estimada em $1,3 \times 10^{-4} \mathrm{~m} / \mathrm{s}$, enquanto que aos $1,50 \mathrm{~m}$ o valor foi de $9,2 \times 10^{-6} \mathrm{~m} / \mathrm{s}$. Já no ponto $\mathrm{C} 2 \mathrm{P} 2$, na profundidade de $0,25 \mathrm{~m}$ o valor foi $7,7 \times 10^{-7} \mathrm{~m} / \mathrm{s}$, enquanto que aos $0,50 \mathrm{~m}$ a $\mathrm{K}_{\text {sat }}$ foi estimada em $7,3 \times 10^{-5} \mathrm{~m} / \mathrm{s}$, ou seja, um aumento de 100 vezes a partir dos 0,25 m.

Sobrepondo-se os perfis do topo (C1P1) e do centro (C1P2) da Cicatriz 1, observa-se uma tendência de média permeabilidade até $2,50 \mathrm{~m}$ de profundidade $\left(10^{-5} \mathrm{~m} / \mathrm{s}\right)$, moderadamente reduzida a partir dos $2,50 \mathrm{~m}\left(10^{-6} \mathrm{~m} / \mathrm{s}\right)$. O ponto do topo (C1P1) apresentou um comportamento muito homogêneo até os 2,50 m (Figura 5.14). Os parâmetros de resistência ao cisalhamento foram $28,6^{\circ}$ (ângulo de atrito) e $0 \mathrm{kPa}$ (coesão) aos 0,60 m e ângulo de atrito sensivelmente maior $\left(36,8^{\circ}\right)$ e coesão maior $(11,05 \mathrm{kPa})$ aos 
2,00 m. Embora tenham sido mensurados valores altos dos parâmetros de resistência na profundidade de $2,00 \mathrm{~m}$, a média permeabilidade ao longo de todo o perfil pôde favorecer uma situação de instabilidade quando ocorrem eventos pluviométricos intensos.

Considerando que até $2,50 \mathrm{~m} \mathrm{a}_{\mathrm{sat}}$ apresentou um valor médio, no que diz respeito aos escorregamentos rasos, a encosta pode ter rompido por duas razões: perda de sucção do solo devido ao avanço da frente de saturação e ruptura em uma profundidade crítica ou devido ao desenvolvimento de poro-pressões positivas entre a zona mais permeável $\left(10^{-4} \mathrm{~m} / \mathrm{s}\right)$ e a menos permeável $\left(10^{-6} \mathrm{~m} / \mathrm{s}\right)$, entre as profundidades de 2,5 e 2,75 m. Este mecanismo foi observado por D’Amato Avanziet al. (2004) na região da Toscana, onde $84,5 \%$ dos 647 escorregamentos ocorreram em embasamentos impermeáveis e semiimpermeáveis, os quais constituíam 48,4\% da área. Já Campos et al. (1992) identificaram um comportamento oposto, identificando uma zona mais permeável nas proximidades do contato solo maduro/solosaprolítico.

Devido à profundidade da superfície de ruptura estar acima dos 2,00 m, é possível que o mecanismo responsável pela instabilização na encosta tenha sido a perda da sucção e, consequentemente, da coesão aparente do solo. 

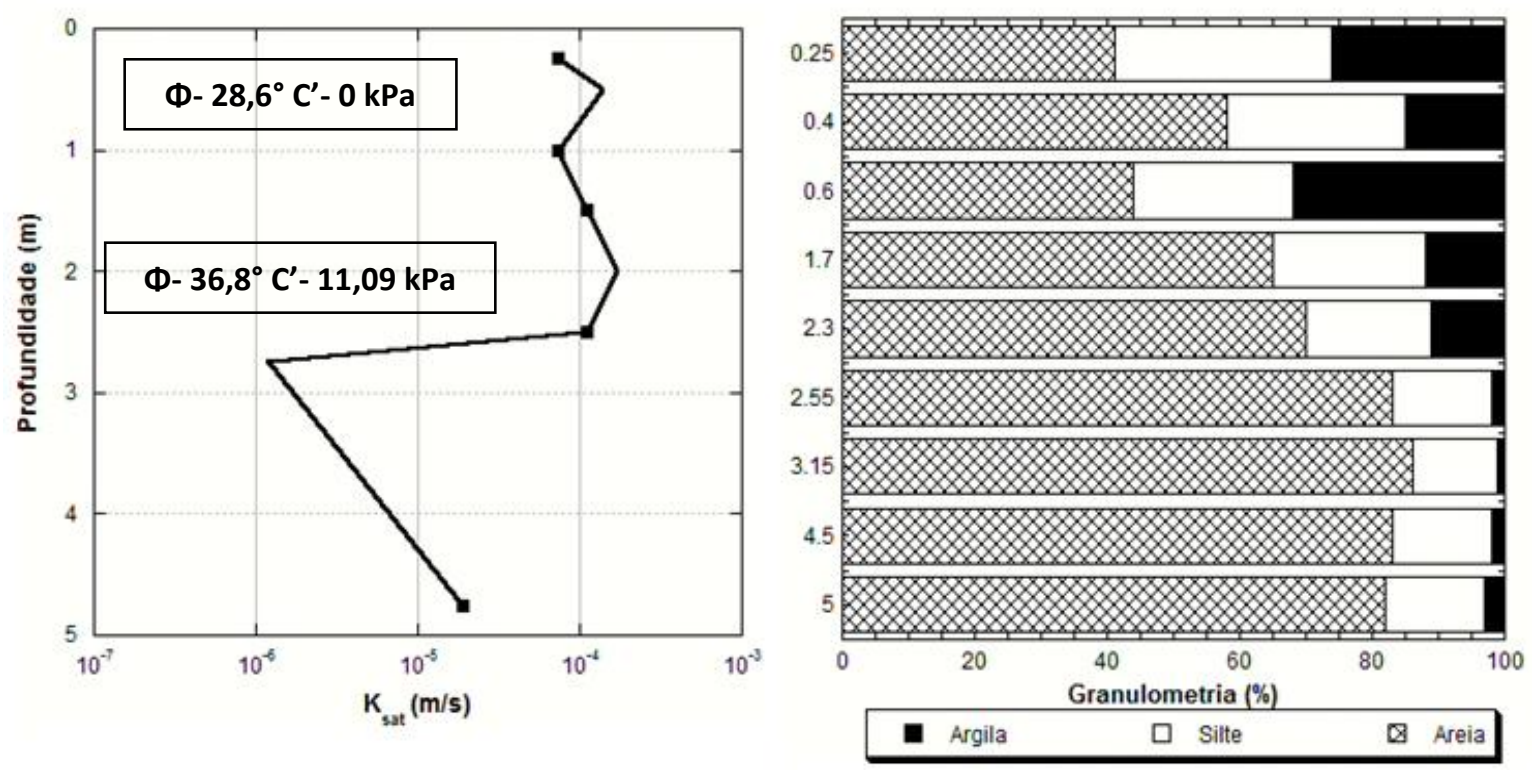

Figura 5.14. Sobreposição dos perfis do topo (C1P1) e centro (C1P2) da Cicatriz 1. Observa-se uma importante descontinuidade hidráulica entre os 2,50 e 3,00 m, onde há uma diminuição brusca da $\mathrm{K}_{\text {sat. }}$ Fonte dos dados de granulometria: Ferreira (no prelo).

$\mathrm{Na}$ Cicatriz 2, ao unir os perfis do topo (C2P1) e do centro (C2P2) (Figura 5.15), o perfil formado apresenta até $1,00 \mathrm{~m}$ uma baixa permeabilidade $\left(10^{-6} \mathrm{~m} / \mathrm{s}\right)$, a partir de onde a $\mathrm{K}_{\text {sat }}$ é reduzida para a ordem de $10^{-5} \mathrm{~m} / \mathrm{s}$ até os $2,50 \mathrm{~m}$. Esta variação mostrou a tendência de aumento com a profundidade desde a superfície. Os parâmetros de resistência ângulo de atrito e coesão são $24,5^{\circ}$ e $4,16 \mathrm{kPa}$, respectivamente, na profundidade de 0,40 m. Já aos 0,55 m, onde já há mudanças nas características morfológicas no solo, o ângulo de atrito aumenta para $31,9^{\circ}$ enquanto a coesão sofre uma redução significativa, $1,19 \mathrm{kPa}$.

Ao longo de todo o perfil não há descontinuidades hidráulicas significativas nem valores muito baixos de permeabilidade, o que pode influenciar muito pouco no desenvolvimento de poro-pressões positivas. Embora o ângulo de atrito do material seja alto próximo à superfície $\left(31,9^{\circ}\right.$ aos $\left.0,55 \mathrm{~m}\right)$, o baixo valor de coesão $(1,19 \mathrm{kPa})$, em um perfil de média permeabilidade pode ser reduzido devido à redução da sucção quando do avanço da frente de saturação. 
Merece atenção também o fato de na base desta cicatriz os condicionantes topográficos, como a curvatura côncava e o ângulo acima dos $40^{\circ}$, podem ter contribuído com o aumento da instabilidade desta encosta. Considerando suas características topográficas, pode-se pensar em uma ruptura na parte terminal da cicatriz, o que pode ser favorecido pelas caraterísticas mecânicas/ hidráulicas do material e pela maior proximidade do nível freático à superfície.
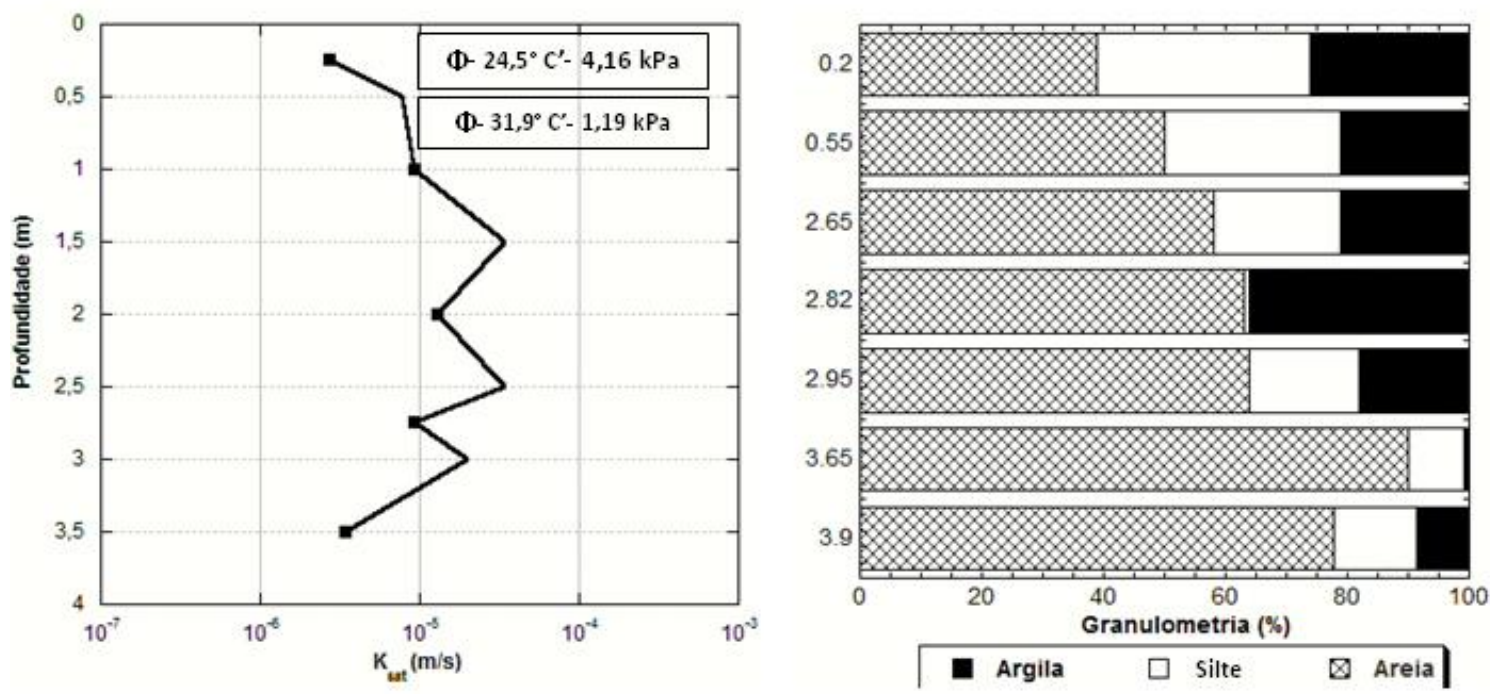

Figura 5.15. Sobreposição dos perfis do topo $(\mathrm{C} 2 \mathrm{P} 1)$ e centro $(\mathrm{C} 2 \mathrm{P} 2)$ da Cicatriz 2. É observado neste ponto uma menor permeabilidade no topo do perfil, que aumenta entre $0,5 \mathrm{e}$ $1,5 \mathrm{~m}$, se mantém até $2,5 \mathrm{~m}$ e volta a diminuir a partir desta profundidade. Dados de granulometria: Ferreira (no prelo). 
$\mathrm{Na}$ Cicatriz 3 (Figura 5.16), quando sobrepostos os perfis C3P1 e C3P2, observa-se que este perfil apresenta $\mathrm{K}_{\mathrm{sat}}$ com tendência de aumento com a profundidade. Neste perfilocorrem várias descontinuidades de, pelo menos, uma ordem de grandeza em $0,50 \mathrm{~m}$ do solo, sendo elas entre os $0,50 \mathrm{~m}$ e $1,00 \mathrm{~m}\left(5,5 \times 10^{-5}\right.$ para $\left.4,8 \times 10^{-6} \mathrm{~m} / \mathrm{s}\right)$, os $2,00 \mathrm{e}$ $2,50 \mathrm{~m}\left(4,1 \times 10^{-5}\right.$ para $\left.3,4 \times 10^{-6} \mathrm{~m} / \mathrm{s}\right)$, os 3,00 e $3,50\left(9,2 \times 10^{-6}\right.$ para $\left.1,3 \times 10^{-4} \mathrm{~m} / \mathrm{s}\right)$ e entre os 4,00 e 5,00 m $\left(5,5 \times 10^{-5}\right.$ para $\left.3,7 \times 10^{-4} \mathrm{~m} / \mathrm{s}\right) . \mathrm{O}$ ângulo de atrito aos $0,60 \mathrm{~m}$ é $42,0^{\circ}$ e a coesão $0,003 \mathrm{kPa}$, enquanto que aos 2,00 m de profundidade estes valores são $33,5^{\circ}$ e $0,003 \mathrm{kPa}$. Tais valores mais altos do ângulo de atrito, tanto próximo à superfície $(0,60 \mathrm{~m})$ quanto em profundidade $(2,00 \mathrm{~m})$, se contrapõem àqueles valores mais baixos de coesão. A existência de baixa coesão do material na parte do perfil onde a $K_{\text {sat }}$ tem valores médios $\left(10^{-4}-10^{-5}\right.$ $\mathrm{m} / \mathrm{s}$ ) pode levar a redução total da coesão do material devido à redução da sucção, ocasionando a ruptura.
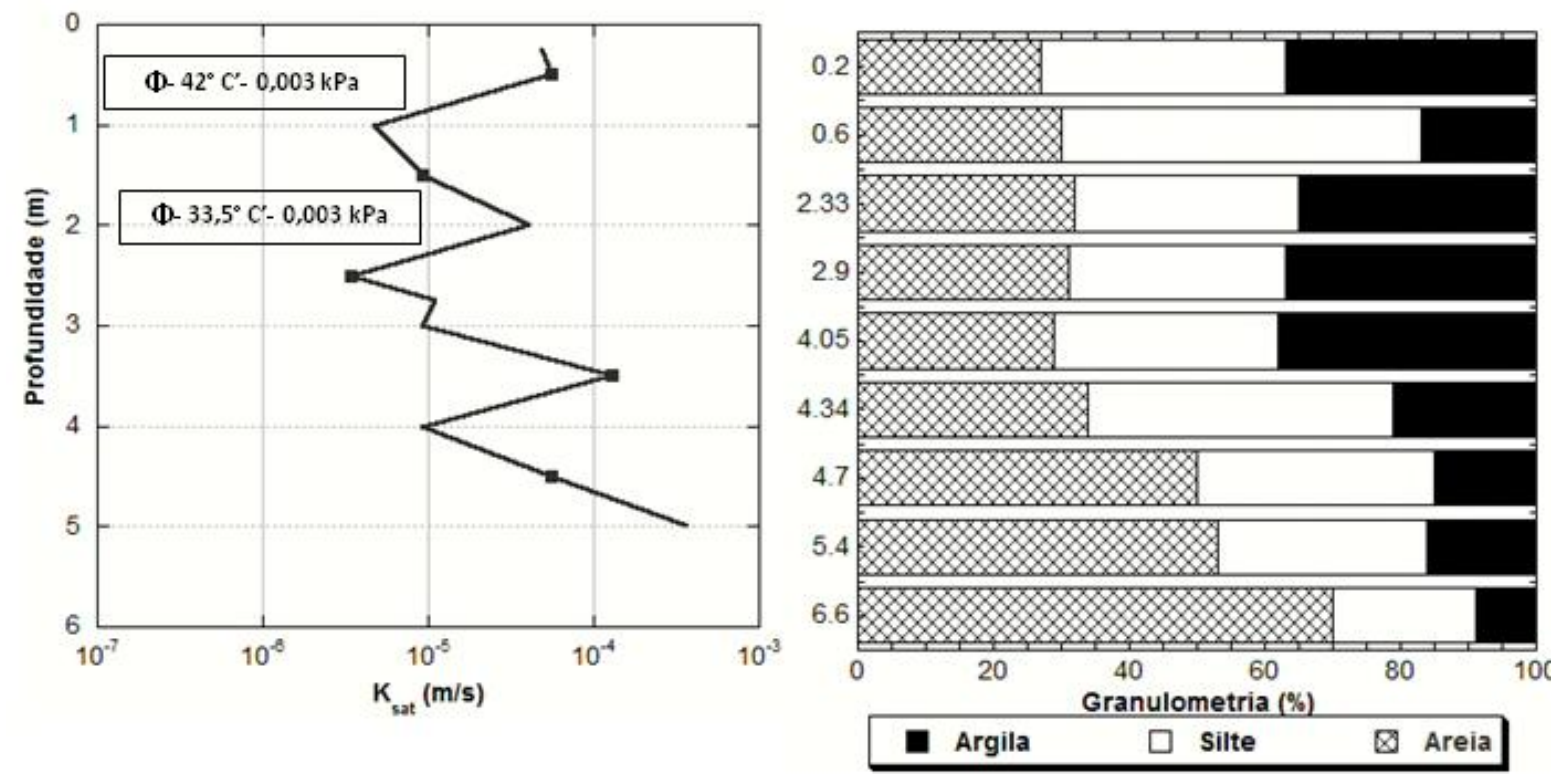

Figura 5.16. Sobreposição dos perfis do topo (C3P1) e centro (C3P2) da Cicatriz 3. Neste perfil ocorrem algumas descontinuidades hidráulicas de, pelo menos, uma ordem de grandeza. Dados de granulometria: Ferreira (no prelo). 
Comparando-se os resultados obtidos nesta pesquisa com outros trabalhos desenvolvidos na Serra do Mar como CAMPOS et al. (1992) e VIEIRA e FERNANDES (2004), assim como Benessiuti e Bernardes (2011), que trabalharam no reverso da escarpa da Serra, observou-se que em todos há uma redução da $\mathrm{K}_{\mathrm{sat}}$ entre 1,00 e 2,00 m, seguida por um aumento com a profundidade (Figura 5.17). Tal comportamento na maioria dos perfis corrobora com os trabalhos de Wolle e Carvalho (1989) e Wolle e Hachich (1989), em que os referidos autores afirmam que o mecanismo de ruptura responsável pela deflagração dos escorregamentos rasos na Serra do Mar paulista apresenta tendência de aumento da $\mathrm{K}_{\mathrm{sat}}$ com a profundidade (Figura 3.1), embora não seja possível afirmar devido à inexistência de dados sobre o comportamento da sucção nestes materiais durante eventos pluviométricos.

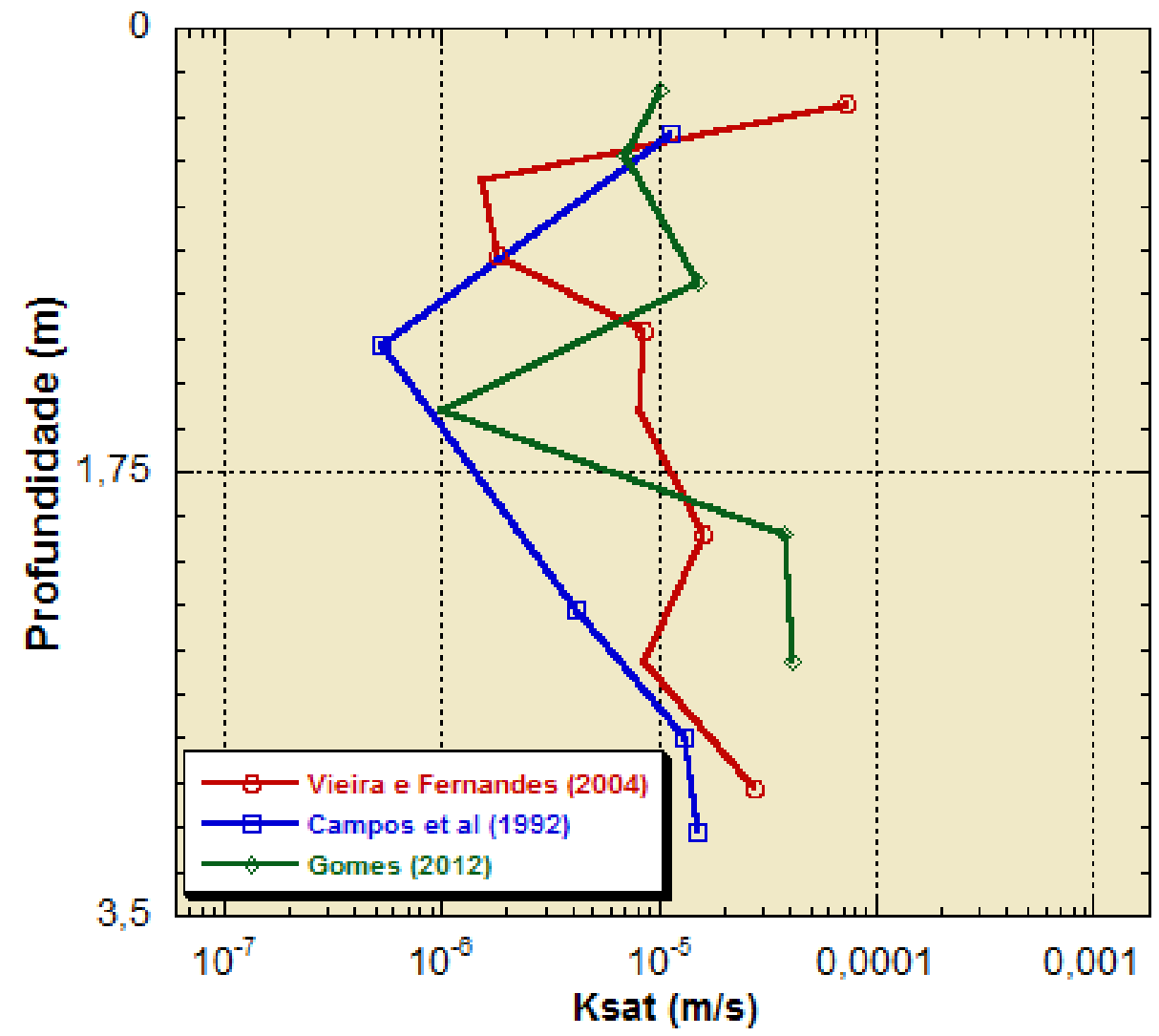

Figura 5.17.Variação da $K_{\text {sat }}$ em profundidade encontradas por Campos et al. (1992a), Vieira e Fernandes (2004) e Gomes (2012). Observa-se a diminuição da $\mathrm{K}_{\text {sat }}$ entre 1,00 e 2,00 m, seguida por um aumento progressivo com a profundidade. 


\section{CONSIDERAÇÕES FINAIS}

O objetivo geral desta pesquisa, analisar a distribuição lateral e vertical da condutividade hidráulica saturada $\left(\mathrm{K}_{\mathrm{sat}}\right)$ dos solos e sua influência nos escorregamentos translacionais rasos, foi alcançado. A condutividade hidráulica saturada dos solos não apresentou uma grande variabilidade espacial, uma vez que a maioria dos valores variou entre duas ordens de grandeza.

$\mathrm{Na}$ Cicatriz 1 foi observada uma descontinuidade hidráulica significativa aos 2,5 m, que pode ser responsável pelo desenvolvimento de poro-pressões positivas no contato entre o corpo de tálus e o saprolito. Nas Cicatrizes 2 e 3 foi identificada a tendência de aumento da $\mathrm{K}_{\text {sat }}$ com a profundidade (até os 5,0 m).Este padrão pode explicar a ocorrência de escorregamentos devido à redução da sucção (coesão aparente).

Ainda que somente os dados de $\mathrm{K}_{\mathrm{sat}}$ não forneçam informações suficientes para a identificação do mecanismo de ruptura que predomina na Serra, seu comportamento vertical, principalmente o aumento com a profundidade,confirma os modelos hipotéticos da variação dessa propriedade em encostas da Serra do Mar paulista.

Referente aos objetivos específicos, a bacia selecionada se mostrou representativa do meio físico da Serra do Mar, em função dos parâmetros morfométricos das suas encostas, da tipologia dos escorregamentos e das propriedades físicas e hidrológicas dos solos, incluindo a condutividade hidráulica.

Foi possível determinar a variação da condutividade hidráulica in situ eavaliar a influência de algumas das propriedades físicasna sua variação, sobretudo a granulometria. A variação da $\mathrm{K}_{\text {sat }}$ apresentou uma boa correlação com os dados de granulometria do material, especialmente a fração areia, embora ainda seja necessário um tratamento estatístico destes dados para uma análise mais precisa. 
A literatura referente ao papel das propriedades físicas dos solos na variação da $\mathrm{K}_{\text {sat }}$ indica, muitas vezes, a inferência desta a partir de outros dados, como granulometria e porosidade. Neste trabalho, como a granulometria não pôde explicar a $\mathrm{K}_{\text {sat }}$,pode-se afirmar que inferir a $\mathrm{K}_{\mathrm{sat}}$ apenas por esta propriedade não é adequado para paisagens como estas. Um exemplo disso foi a média permeabilidade $\left(10^{-4} \mathrm{~m} / \mathrm{s}\right)$ mensurada no corpo de tálus de matriz fina na C1P1. Neste sentido, a porosidade fornece uma resposta melhor, embora não substitua os ensaios realizados in situ.

O Permeâmetro de Guelph Modificado foiprático durante os trabalhos de campos, tanto para seu transporte e montagem assim como a operação. A preparação cautelosa do PG favoreceu a realização de ensaios sem interrupções. A proximidade das cicatrizes a fontes de água também facilitou o andamento dos ensaios, especialmente nos perfis com material mais permeável, que necessitam de um volume maior de água para sua execução.

Merece destaque também o desempenho do PGM em relação ao tempo utilizado na realização dos ensaios. Desconsiderando a montagem, abertura do furo e posicionamento do equipamento, o tempo utilizado foi significativamente menor do que aquele gasto por outros equipamentos. Aproximadamente $62 \%$ dos ensaios foram realizados em até 19 minutos, enquanto os demais métodos levam até alguns dias para mensurar a $\mathrm{K}_{\text {sat. }}$.

A análise dos condicionantes topográficos (ângulo, curvatura, orientação das encostas e área de contribuição) dos escorregamentos rasos ocorridos em 1967, como subsídio para a seleção dos pontos ensaiados (objetivo específico), não foi realizada. Entretanto, o mapa de suscetibilidade gerado pelo Shalstab (Ramos, 2012) mostrou que as três cicatrizes selecionadas se encontravam em áreas previstas como instáveis. Desta 
forma, as cicatrizes selecionadas foram representativas quanto aos pontos mais instáveis na bacia do Guaxinduba.

A mensuração das propriedades dos solos utilizadas para previsão de escorregamentos rasos por meio dos modelos matemáticos é fundamental para que seja incorporada sua variabilidade espacial, sem a qual os graus de suscetibilidade variam apenas em função dos parâmetros topográficos. Espera-se que os resultados apresentados neste trabalho sejam utilizados para tal finalidade.Neste sentido, trabalhos futuros devem buscar compreender o comportamento da sucção dos solos ao longo do perfil, a partir do qual, juntamente com o perfil de condutividade saturada dos solos, poder-se-á interpretar com maior precisão o modelo hipotético de ruptura que melhor representa os escorregamentos translacionais rasos na Serra do Mar paulista. 


\section{REFERÊNCIAS}

1. AB' SABER, A. N. (1956) A terra paulista, Separata do Boletim Paulista de Geografia: São Paulo, n 23: 5-38.

2. AGUIAR, A. B. (2001) O emprego do Permeâmetro de Guelph na determinação da permeabilidade do solo, de camadas de lixo e sua cobertura. Dissertação (Mestrado em Ciências) COPPE/UFRJ, 90p.

3. ALMEIDA, F. F. M. (1974) Fundamentos geológicos do relevo paulista. In: Geologia do Estado de São Paulo, São Paulo - IG/USP: 56-62.

4. ALMEIDA, F. F. M. \& CARNEIRO, C. D. R. (1998) Origem e Evolução da Serra do Mar. Revista Brasileira de Geociências: 135-150.

5. AMOOZEGAR, A. (1989) Comparison of the Glover solution with the simultaneous-equations approach for measuring hydraulic conductivity.Soil Sci. Soc. Am. J., 53:1362-1367.

6. ANDERSON, M. G.; BURT, T. P. (1978) The role of topography in controlling throughflow generation. Earth Surface Processes and Landforms, 3: 331-344.

7. AUGUSTO FILHO, O.; VIRGILI, J. C. (1998) Estabilidade de Taludes. In OLIVEIRA, A. M. D. S.; BRITO, S. N. A. D. (org) Geologia de Engenharia. ABGE, São Paulo: 243-269.

8. BENESSIUTI, M. F.; BERNARDES, G. P. (2011) Retro-análise de dois taludes de solo residual de biotita-gnaisse considerando a variação do grau de saturação do solo.VII Simpósio Brasileiro de Solos Não Saturados. Anais.....Pirenópolis: 403-410.

9. BRADY, N. C. (1989) Natureza e propriedade dos solos. Freitas Bastos, Rio de Janeiro: 878p.

10. CAMPOS, J. L. E.; VARGAS Jr., E. A.; CAMPOS, T. M. P. (1992a) Avaliação de campo da permeabilidade saturada e não-saturada de solos em encostas. In: $1^{\text {a }}$ Conferência Brasileira sobre Estabilidade de Encostas, Rio de Janeiro. $1^{\text {a }}$ Conferência Brasileira sobre Estabilidade de Encostas, Rio de Janeiro: 371-381.

11. CAMPOS, T. M. P.; VARGAS Jr., E. A.; EISENSTEIN, Z. (1992b) Considerações sobre o processo de instabilização de encostas em solos nãosaturados no Rio de Janeiro. In: $1^{\text {a }}$ Conferência Brasileira sobre Estabilidade de Encostas, Rio de Janeiro. $1^{\text {a }}$ Conferência Brasileira sobre Estabilidade de Encostas, Rio de Janeiro: 741-755.

12. COATES, D. R. (1990) The relation of subsurface water to downslope movement and failure.In Higgins, C. G.; Coates, D. R. (org.) Groundwater geomorphology: the role of subsurface processes and landform. Geological Society of America Special Paper, Boulder: 252p. 
13. CONTI, J. B. (1975) Circulação secundária e efeito orográfico na gênese das chuvas na região lesnordeste paulista. IGEOG-USP. Tese de Doutorado, São Paulo: (Série Teses e Monografias nº18): 82p.

14. CRUZ. O. A Serra do Mar e planície na área de Caraguatatuba- contribuição à geomorfologia litorânea tropical. (1974) Série Teses e Monografias, 11, IGEOG/USP: 181p.

15. D'AMATO AVANZI, G.; GIANNECCHINI, R.; PUCCINELLI, A. (2004) The influence of the geological and geomorphological settings on shallow landslides. An example in a temperature climate environment: the june 19, 1996 event in northwestern Tuscany (Italy). Engeneering Geology 73: 215-228.

16. DANIEL, D. E. (1989) In situ hydraulic conductivity tests for compacted clay. Journal of Geotechnical Engineering - ASCE, 115(9): 1205-1226.

17. DUNNE, T.; ZHANG, W.; AUBRY, B. F. (1991) Effects of rainfall, vegetation and microtopography on infiltration and runoff. Water Res. Research, v.27(9): 2271-2285.

18. ELRICK, D. E.; REYNOLDS, W. D.; TAN, K. A. (1989) Hydraulic conductivity measurements in the unsaturated zone using improved well analyses. Ground Water Monitoring Review 185:184-193.

19. ESPINHA MARQUES, J.; DUARTE, J. M.; CONSTANTINO, A. T.; AGUIAR, C.; ROCHA, F. T.; MARQUES, J. M.; SAMPER, J.; BORGES, F. S.; CARVALHO, J. M.; CHAMINÉ, H. I. (2009) Avaliação in situ da condutividade hidráulica dos solos de montanha: um caso de estudo na Serra da Estrela (Centro de Portugal). Cadernos Lab. Xeológico de Laxe, 34: 143-164.

20. FERNANDES, N. F.; COELHO NETTO, A. L.; LACERDA, W. A. (1994) Subsurface hydrology of layered colluvium mantles in unchannelled valleys Southeastern Brazil. Earth Surface Processes and Landforms, 19: 609-626.

21. FERNANDES, N. F.; AMARAL, C. P. (1996) Movimentos de massa: uma abordagem geológico-geomorfológica. In GUERRA, A.J.T. and S.B. CUNHA (Ed) Geomorfologia e Meio Ambiente. Bertrand Brasil, Rio de Janeiro: 123-194.

22. FERNANDES, N.F., R.F. GUIMARÃES, R.A.T. GOMES, B.C. VIEIRA, D.R. MONTGOMERY, and H. GREENBERG. (2001) Condicionantes geomorfológicos dos deslizamentos nas encostas: Avaliação de metodologias e aplicação de modelo de previsão de áreas susceptíveis. Revista Brasileira de Geomorfologia 1: 51-71.

23. FERNANDES, N. F.; GUIMARÃES, R. F.; GOMES, R. A. T.; VIEIRA, B. C.; MONTGOMERY, D. R.; GREENBERG, H. (2004)Topographiccontrols in Rio de Janeiro: Field evidence and modeling.CATENA, 55: 163-181.

24. FERREIRA, F. S. (no prelo) Análise da influência das propriedades físicas no solo na deflagração dos escorregamentos translacionais rasos na Serra do Mar. Dissertação em andamento. 
25. FREEZE, R.A; CHERRY,J. A. (1979) Groundwater. Englewood Cliffs, Prentice Hall: 604p.

26. FÚlfARO, V. J.; PONÇANO, W. L.; BISTRICHI, C. A.; STEIN, D. P. (1976) Escorregamentos de Caraguatatuba: expressão atual, e registro na coluna sedimentar da planície costeira adjacente. In: CBGE, 3, Rio de Janeiro: 341-350.

27. GERSCOVICH, D. M. S.; VARGAS Jr., E. A.; CAMPOS, T. M. P. (1992) Avaliação dos fatores que influenciam a modelagem numérica do regime de fluxo em uma encosta no Rio de Janeiro. In: $1^{\text {a }}$ Conferência Brasileira sobre Estabilidade de Encostas, Rio de Janeiro. $1^{\text {a }}$ Conferência Brasileira sobre Estabilidade de Encostas, Rio de Janeiro: 657-673.

28. GOMES, M. C. V.; FERREIRA, F.S.; VIEIRA, B.C. (2012) Caracterização morfológica dos solos nas áreas afetadas por escorregamentos translacionais rasos em 1967 em Caraguatatuba (SP)

29. GOMES, M. C. V.; FERREIRA, F.S.; BIGANZOLLI, R. F.; RAMOS, H. A. A.; VIEIRA, B.C. (2011)Geomorphological Characterization of Guaxinduba Basin, Serra do Mar (São Paulo), Brazil. In: Conferencia Geográfica Regional UGI 2011, Santiago. Regional Geographic Conference.

30. GOMES, M. C. V. ; VIEIRA, B.C. (2010) Análise preliminar da bacia do rio Guaxinbuda, Caraguatatuba (SP). IV Encontro de Pós-Graduandos da FFLCH. Anais do IV Encontro de Pós-Graduandos da FFLCH.

31. GRAMANI, M. F. (2001) Caracterização Geológico-Geotécnica das Corridas de Detritos ("Debris Flows") no Brasil e Comparação com Alguns Casos Internacionais. Dissertação (Mestrado em Engenharia) - Escola Politécnica, Universidade de São Paulo, São Paulo:372p.

32. GREENWAY, D.R. (1987) Vegetation and slope stability. In: ANDERSON, M.G.; RICHARDS, K.S. Slope Stability. John Wiley \& Sons 1td, 187-229.

33. GUEDES, L. P. C.; URIBE-OPAZO, M. A.; JOHANN, J. A.; SOUZA, E. G. (2008) Anisotropia no estudo da variabilidade espacial de algumas variáveis químicas do solo. Revista Brasileira de Ciências do Solo 32:2217-2226.

34. GUIDICINI, G.; NIEBLE, C.M. (1983) Estabilidade de Taludes Naturais e de Escavação. Edgard Blücher Ltda., São Paulo: 194p.

35. HAVENITH, H.B.; STROM, A; CACERES, F. \& PIRARD, E. (2006) Analysis of landslide susceptibility in the Suusamyr region, Tien Shan: statistical and geotechnical approach. Landslides. 3: 39-50.

36. HARP, E.L.; WELLS II, W.G.; SARMIENTO, J.G. (1990) Pore pressures responses during failures soils. Geological Society of America Bulletin, 102: 428438. 
37. INSTITUTO DE PESQUISA TECNOLÓGICAS DO ESTADO DE SÃO PAULO (1986) Indicação preliminar de áreas prioritárias para recomposição da cobertura vegetal na Serra do Mar afetadas por poluição na área de Cubatão.São Paulo, Relatório no 24.293.

38. INSTITUTO DE PESQUISAS TECNOLÓGICAS DO ESTADO DE SÃO PAULO (1987) Programa Serra do Mar: estudo geotécnico dos principais mecanismos de instabilização na Serra do Mar. IPT, São Paulo.

39. KEIM, R.F.; SKAUGET, A.E. (2003) Modelling effects of Forest canopies on slope stability. Hydrological Processes (17): 1457-1467.

40. KLAR, A.E. (1984) A água do sistema solo-planta-atmosfera. Nobel, São Paulo: 408p.

41. KURIAKOSE, S.L. (2006) Effect of vegetation on debris flow initiation: conceptualisation and parameterisation of a dynamic model for debris flow initiation in Tikovil River Basin, Kerala, India, using PCRaster. MSc Thesis, International Institute for Geo-information Science and Earth Observation, Enschede, The Netherlands, and Indian Institute of Remote Sensing, Dehradun, India: $133 p$.

42. KURIAKOSE, S.L.; Van BEEK, L.P.H.; Van WESTEN, C.J. (2009) Parameterizing a physically based shallow landslide model in a data poor region. Earth Surfaces Processes and Landforms 34: 867-881.

43. LACERDA, W. A.; SANDRONI, S. (1985) Movimentos de massas coluviais. Mesa Redonda sobre Aspectos Geotécnicos de Encostas, Clube de Engenharia, Rio de Janeiro: 1-19.

44. LIBARDI, P. L. (2005) Dinâmica da água no solo. Editora da Universidade de São Paulo, São Paulo: 335p.

45. LITTLE, J. A.; SILVER, R. K.; JOSEPH, J. B. (1995) In situ permeability testing of partially saturated soils using a sealed double ring infiltrometer.UnsaturatedSoils/ Sols Non Saturés. A. Delage: 525-533.

46. LOPES, E. S. S. (2006) Modelagem Espacial Dinâmica Aplicada ao Estudo de Movimentos de Massa em uma Região da Serra do Mar Paulista, na escala de 1:10.000. Tese de doutorado. Universidade Estadual Paulista, Rio Claro, 302p.

47. MARCELINO, E.V. (2003) Mapeamento de áreas suscetíveis a escorregamentos no município de Caraguatatuba (SP) usando técnicas de sensoriamento remoto. Dissertação (Mestrado em Sensoriamento Remoto) INSTITUTO NACIONAL DE PESQUISAS ESPACIAIS, São José dos Campos, 228p.

48. MEIS, M.R.M. de \& XAVIER DA SILVA, J. (1968) Considerações geomorfológicas a propósito dos movimentos de massa ocorridos no Rio de Janeiro. Revista Brasileira de Geografia 30 (1): 55-73. 
49. MENEZES, S. M.; SAMPAIO, F. M. T.; RIBEIRO, K. D. (2006a) Estudo da condutividade hidráulica relacionada com alguns parâmetros físicos do solo. In: XIII Congresso Brasileiro de Mecânica dos Solos e Engenharia Geotécnica/ IV Simpósio Brasileiro de Mecânica das Rochas/ III Congresso Luso-Brasileiro de Geotecnia, Curitiba: 149-153.

50. MENEZES, S. M.; RIBEIRO, K. D.; SAMPAIO, F. M. T. (2006b) Influência da distribuição de vazios na condutividade hidráulica do solo saturado. In: XIII Congresso Brasileiro de Mecânica dos Solos e Engenharia Geotécnica/ IV Simpósio Brasileiro de Mecânica das Rochas/ III Congresso Luso-Brasileiro de Geotecnia, Curitiba: 143-147.

51. MIRANDA, E.E.; COUTINHO, A.C. (Coord.) Brasil visto do espaço. Campinas: EMBRAPA Monitoramento por Satélite, 2004. Disponível em: <http://www.cdbrasil.cnpm.embrapa.br/sp/htm3/sp05 05.htm $>$. Acesso em 24. abr. 2011.

52. MONTEIRO, C. A. F. (1973) A dinâmica climática e a as chuvas no estado de São Paulo: estudo em forma de Atlas. Instituto de Geografia da Universidade de São Paulo:130p.

53. OLIVEIRA, D. (2003) A captura do Alto Rio Guaratuba: uma proposta metodológica para o estudo da evolução do relevo na Serra do Mar ( BoracéiaSP).Tese (Doutorado em Geografia Física), Universidade de São Paulo.

54. PAIGE, G. B.; HILLEL, D. (1993) Comparison of three methods for assessing hydraulic properties. Soil Sci., 156: 175-189.

55. PELLEGATTI, C. H. G. (2007) Avaliação espaço-temporal da precipitação no perfil da Baixada Santista-Vertentes Oceânicas- Rebordo Interiorano da escarpa da Serra do Mar- SP. Dissertação (Mestrado em Geografia Física) Faculdade de Filosofia, Letras e Ciências Humanas - Universidade de São Paulo: $128 \mathrm{p}$.

56. PEREIRA, M. D. B., BRAGA, C. Z. F., D'AlGE, J. C. L., VALERIANO, D. M. (1986) Mapeamento das cicatrizes de escorregamento de terreno ocorridos no Vale do Rio Mogi, Cubatão, SP. Divisão de Sensoriamento Remoto (DSR) Instituto Nacional de Pesquisas Espaciais (INPE).

57. PINTO, C. S. (2002) Curso básico de Mecânica dos Solos. São Paulo, Oficina de Textos: $355 \mathrm{p}$.

58. PRANDINI, F.L.; GUIDICINI, G.; BOTTURA, J.A.; PONÇANO, W.L.; SANTOS, A.R. (1976) Resenha crítica da atuação da cobertura vegetal na estabilidade de encostas. $2^{\circ}$ Congresso Brasileiro de Florestas Tropicais. Mossoró. Separata.

59. PREFEITURA MUNICIPAL DA ESTÂNCIA BALNEÁRIA DE CARAGUATATUBA. A catástrofe de 1967. Disponível em: <http://www.caraguatatuba.sp.gov.br> Acesso em 24.abr. 2011. 
60. RAMOS, H.A. (2012) Avaliação da Suscetibilidade aos Escorregamentos Translacionais Rasos a partir do Modelo Shalstab na Bacia do Rio Guaxinduba em Caraguatatuba (SP). Trabalho de Conclusão de Curso (Graduação em Geografia) - Universidade de São Paulo.

61. RENEAU, S. L.; DIETRICH, W. E. (1987) Size and location of colluvial landslides in the steep forested landscape.Int. Assoc. Hydrol. Sci. Pub., 165: 3548.

62. RENEAU, S.L.; DIETRICH, W.E.; DORN, R.I.; BERGER, C.R. and Robin, M. (1986) Geomorphic and paleoclimatic implications of latest Pleistocene radiocarbon dates from colluvium-mantled hollows, California: Geology, v. 14, p. 655-658.

63. REYNOLDS, W.D.; ELRICK, D.E. (1985) Measurement of field-saturated hydraulic conductivity, sorptivity and the conductivity-pressure head relationship using the "Guelph Permeameter". Proceedings, National Water Association Conference on Characterization and Monitoring of Vadose (Unsaturated) Zone, Denver, Colorado- EUA, 25p.

64. REYNOLDS, W. D.; ELRICK, D. E. (1987) A laboratory and numerical assessment of the Guelph Permeameter Method.Soil Sci., 144: 282-299.

65. REYNOLDS, W.D.; ELRICK, D.E.; TOPP, G. C. (1983) A reexamination of the constant-head well permeameter method for measuring saturated hydraulic conductivity above the water table. Soil Sci, 136(4):250-268.

66. REYNOLDS, W. D.; VIEIRA, S. R. E TOPP G.C. (1992).An assessment of the single-head analysis for the constant head well permeameter. Canadian Journal Soil Science, Ottawa, 72: pp 489-501.

67. SALVERDA, A. P.; DANE, J. H. (1993) An examination of the Guelph Permeameter for measuring the soil's hydraulic properties. Geoderma 57:405421.

68. SANTOS, A.R. 2004. A grande barreira da Serra do Mar: da trilha dos Tupiniquins à Rodovia dos Imigrantes. São Paulo: Ed. O Nome da Rosa, 2004, $122 p$.

69. SELBY, M.J. (1993) Hillslope: materials \& processes. Oxford: Oxford University Press, 446p.

70. SESTINI, M.F. \& FLORENZANO, T.G. (2004) Caracterização de cicatrizes de deslizamentos por processamento de dados TM LANDSAT em Caraguatatuba -SP. Revista Geologia USP: Série Científica, v.4, n.2, p. 57-69.

71. SHOAEI, G.; SIDLE, R. C. (2009) Variation in soil characteristics and hydrologic properties associated with historic land use near a recent landslide, Nagano Prefecture, Japan. Geoderma, 153: 37-51. 
72. SOBIERAJ, J. A.; ELSENBEER, H.; COELHO, R. M.; NEWTON, B. (2002) Spatial variability of hydraulic conductivity along a tropical rainforest catena. Geoderma, 108: 79-90.

73. SOTO, M. A.; CHANG, K. H.; VILAR, O. M. (2009). Análise do método do Permeâmetro de Guelph na determinação da condutividade hidráulica saturada. Águas Subterrâneas (23)01: 137-152.

74. STEPHENS, D. B. (1996) Vadose zone hydrology.Lewis Publishers: 347p.

75. TABALIPA, N. L.; FIORI, A. P. (2008) Influência do vento na estabilidade dos taludes da bacia do rio Ligeiro, município de Pato Branco. Caminhos de Geografia (27)9: 82-98.

76. TATIZANA, C.; OGURA, A. T.; ROCHA, M. C. M. da (1987) Análise de correlação entre chuvas e escorregamentos - Serra do Mar, Município de Cubatão. $5^{\circ}$ Congresso Brasileiro de Geologia de Engenharia, São Paulo: 225-236.

77. TERLIEN, M. T. J. (1997) Hydrological landslide triggering in ash-covered slopes of Manizales (Colombia). Geomorphology, 20: 165-175.

78. TERZAGHI, K. (1952) Mecânica teórica de los suelos.Acme, Buenos Aires, $571 \mathrm{p}$.

79. TERZAGHI, K. (1967) Mecanismos dos escorregamentos de terra. São Paulo: Escola Politécnica - Universidade de São Paulo: 44p.

80. TITARELli, A.H.V. (1986) A Serra do Mar. Orientação, IGEOG, São Paulo, 7: 86-93.

81. TU, X.B., A.K.L. Kwong, F.C. Dai, L.G. Tham\& H. Min (2009) Field monitoring of rainfall infiltration in a loess slope and analysis of failure mechanism of rainfall-induced landslides. Engineering Geology. 105: 134-150.

82. VAN ASCH, T.; BUMA, J.; VAN BEEK, L.P.H. (1999) A view on some hydrological triggering systems in landslides. Geomorphology, 30: 25-32.

83. VIEIRA, B.C. (2001) Caracterização in situ da condutividade hidráulica saturada dos solos e sua influência nos escorregamentos da bacia do rio Papagaio. Dissertação (Mestrado em Geografia). Universidade Federal do Rio de Janeiro.

84. VIEIRA, B. C. (2007) Previsão de escorregamentos translacionais rasos na Serra do Mar (SP) a partir de modelos matemáticos em bases físicas. Tese (Doutorado em Geografia). Universidade Federal do Rio de Janeiro: 193p.

85. VIEIRA, B.C.; FERNANDES,N. F. (2004) Landslides in Rio de Janeiro: The role played by variations in soil hydraulic conductivity. Hydrological processes, 18: 791-805. 
86. WAKATSUKI, T.; TANAKA, Y.; MATSUKURA, Y. (2005) Soil slips on weathearing-limited slopes underain by coarse- grained granite or finegrained gneiss near Seoul, Republic of Korea. Catena, 60: 181-203.

87. WANG, G.; SASSA, K. (2003) Pore-pressure generation and movement of rainfall-induced landslides: effects of grain size and fine particles. Engineering Geology (69): 109-125.

88. WOLLE, C. M. (1980). Taludes naturais- mecanismos de instabilização e critérios de segurança. Dissertação de mestrado apresentado a Escola Politécnica da USP, São Paulo: 345p.

89. WOLle, C. M. (1986) Poluição e escorregamentos - causa e efeito na Serra do Mar, em Cubatão - SP. In: VIII Congresso Brasileiro de Mecânica dos Solos e Engenharia de Fundações, Porto Alegre. VIII Congresso Brasileiro de Mecânica dos Solos e Engenharia de Fundações, Porto Alegre: 178-190.

90. WOLLE, C. M. (1988). Análise dos escorregamentos translacionais numa região da Serra do Mar no contexto de uma classificação de mecanismos de instabilização de encosta. Tese de Doutorado apresentado a Escola Politécnica da USP, São Paulo: 406p.

91. WOlLE, C. M. \& CARVAlHO, C. S. (1989) Deslizamentos em encostas na Serra do Mar - Brasil. Solos e Rochas, v. 12: 27-36.

92. Wolle, C.M.; Carvalho, C.S. (1994). Taludes Naturais. In Solos do litoral de São Paulo. IN FALCONI, F..F.; A. NEGRO Jr. (Ed) Associação Brasileira de Mecânica dos Solos- Núcleo Regional de São Paulo- ABMS, São Paulo: 180-203. 